\title{
THE EFFECT OF HIGH TEMPERATURE DEFORMATION ON THE HOT DUCTILITY OF Nb-MICROALLOYED STEEL
}

By

\section{Faramarz MH Zarandi}

Department of Mining, Metals, and Materials Engineering McGill University

Montreal, Canada

\begin{abstract}
A Thesis Submitted to the Faculty of Graduate Studies and Research in partial fulfillment of the requirements for the degree of

Doctor of Philosophy
\end{abstract}




$\begin{array}{ll}\begin{array}{l}\text { Library and } \\ \text { Archives Canada }\end{array} & \begin{array}{l}\text { Bibliothèque et } \\ \text { Archives Canada }\end{array} \\ \begin{array}{l}\text { Published Heritage } \\ \text { Branch }\end{array} & \begin{array}{l}\text { Direction du } \\ \text { Patrimoine de l'édition }\end{array} \\ \begin{array}{l}\text { 395 Wellington Street } \\ \text { Ottawa ON K1A 0N4 } \\ \text { Canada }\end{array} & \begin{array}{l}\text { 395, rue Wellington } \\ \text { Ottawa ON K1A ON4 } \\ \text { Canada }\end{array}\end{array}$

Your file Votre référence ISBN: 0-494-06356-4 Our file Notre référence ISBN: 0-494-06356-4

NOTICE:

The author has granted a nonexclusive license allowing Library and Archives Canada to reproduce, publish, archive, preserve, conserve, communicate to the public by telecommunication or on the Internet, loan, distribute and sell theses worldwide, for commercial or noncommercial purposes, in microform, paper, electronic and/or any other formats.

The author retains copyright ownership and moral rights in this thesis. Neither the thesis nor substantial extracts from it may be printed or otherwise reproduced without the author's permission.
AVIS:

L'auteur a accordé une licence non exclusive permettant à la Bibliothèque et Archives Canada de reproduire, publier, archiver, sauvegarder, conserver, transmettre au public par télécommunication ou par l'Internet, prêter, distribuer et vendre des thèses partout dans le monde, à des fins commerciales ou autres, sur support microforme, papier, électronique et/ou autres formats.

L'auteur conserve la propriété du droit d'auteur et des droits moraux qui protège cette thèse. $\mathrm{Ni}$ la thèse ni des extraits substantiels de celle-ci ne doivent être imprimés ou autrement reproduits sans son autorisation.
In compliance with the Canadian

Privacy Act some supporting forms may have been removed from this thesis.

While these forms may be included in the document page count, their removal does not represent any loss of content from the thesis.
Conformément à la loi canadienne sur la protection de la vie privée, quelques formulaires secondaires ont été enlevés de cette thèse.

Bien que ces formulaires aient inclus dans la pagination, il n'y aura aucun contenu manquant. 


\begin{abstract}
Low hot ductility at the straightening stage of the steel continuous casting process, where the surface temperature ranges from 600 to $1200^{\circ} \mathrm{C}$, is associated with transverse cracking on the billet surface. This is attributed to various microalloying elements, which are essential for the mechanical characteristics of the final products. Thermomechanical processing is a new approach to alleviate this problem. In this work, two grades of $\mathrm{Nb}$ containing steel, one modified with B, were examined. In order to simulate the key parameters of continuous casting, specimens were melted in situ and subjected to thermal conditions similar to that occurring in a continuous casting mill. They were also deformed at different stages of the thermal schedule. Finally, the hot ductility was evaluated at the end of the thermal schedule, corresponding to the straightening stage in continuous casting at which the hot ductility problem occurs in the continuous casting process.

The results showed that the presence of $B$ is noticeably beneficial to the hot ductility. Failure mode analysis was performed and the mechanism of fracture was elaborated. As well, the potential mechanisms under which B can improve the hot ductility were proposed.

Deformation during solidification (i.e. in the liquid + solid two phase region) led to a significant loss of hot ductility in both steels. By contrast, deformation in the $\delta$-ferrite region, after solidification, was either detrimental or beneficial depending on the deformation start temperature.

The hot ductility was considerably improved in the steel without B when deformation was applied during the $\delta \rightarrow \gamma$ transformation. The effect of such deformation on the other steel grade was not significant. Examination of the microstructure revealed that such improvement is related to a grain refinement in austenite. Therefore, the effect of deformation parameters was studied in detail and the optimum condition leading to the greatest improvement in the hot ductility was determined.

Finally, some solutions to the industrial problem in the continuous casting process were proposed.
\end{abstract}




\section{RÉSUMÉ}

La mauvaise ductilité à chaud lors de l'étape de redressage pendant la coulée continue d'acier se caractérise par l'apparition de fissures à la surface de la billette. La température à la surface de la billette varie entre 600 à $1200^{\circ} \mathrm{C}$. La mauvaise ductilité est attribuée aux micro-additions qui sont essentielles pour les propriétés mécaniques du produit final. Le traitement thermomécanique est une nouvelle approche qui permet de résoudre le problème. Deux aciers qui contiennent $\mathrm{du} \mathrm{Nb}$, dont un est modifié avec du $\mathrm{B}$, ont été examinés. Afin de simuler les conditions en industrie, des échantillons ont été fondus in situ et ont été soumis à un traitement thermique qui reproduisaient les conditions réelles. Les échantillons ont également été déformés à différentes étapes du cycle thermique. A la fin de ce cycle, la ductilité à chaud a été mesurée. C'est en effet à cette étape que surviennent les problèmes de ductilité à chaud lors de la coulée continue.

Premièrement, on a montré que l'addition de B améliore la ductilité à chaud. L'analyse du mode de rupture a permis de mettre en lumière les mécanismes de rupture. Des mécanismes potentiels par lesquels le $\mathrm{B}$ améliore la ductilité à chaud ont été proposés.

La déformation pendant la solidification (c'est-à-dire en présence d'une phase solide et d'une phase liquide) entraîne une chute de la ductilité dans les deux nuances. On a montré que la déformation dans la région dans laquelle la ferrite $\delta$ est la phase stable, après solidification, peut avoir un effet positif ou négatif, selon la température de début de déformation.

La ductilité à chaud a été considérablement améliorée dans l'acier sans B quand la déformation a été appliquée pendant la transformation $\delta \rightarrow \gamma$. L'effet d'une telle déformation sur l'autre acier n'était pas significatif. L'examen de la microstructure a révélé que l'amélioration est liée à une diminution de la taille du grain austénitique. Par conséquent, l'effet des paramètres de déformation a été étudié en détail et les paramètres qui mènent à la plus grande amélioration de la ductilité à chaud ont été déterminés.

Finalement, on a proposé quelques solutions au problème de faible ductilité à chaud en cours de coulée continue. 


\section{ACKNOWLEDGEMENTS}

I would like to express my sincere gratitude, for his guidance, support, patience, and invariable encouragement, to my thesis supervisor professor Steve Yue. He has provided me with invaluable opportunities to investigate in physical and mechanical metallurgy and participate in scientific conferences that have enhanced and strengthened my knowledge of materials science. I am also grateful to professor John J. Jonas for both providing the opportunity to research in the CSIRA laboratory and his helpful discussions.

I am appreciative to professor Raynald Gauvin for his advice on electron microscopy and $\mathrm{x}$-ray analysis and Dr. Thomas Kelly for the LEAP analysis. As for the support staff, I am grateful to Edwin Fernandez for his assistance and instrumental ideas in resolving experimental difficulties. I am also thankful to Lorraine Mello for her administrative assistance in the CSIRA group. Certainly, all of these, which are essentials in a research environment, have contributed to provide a very enjoyable and friendly research group.

I would like to extend my appreciation to my fellow graduate students for their persistent and candid friendships. I am grateful to my officemates; Rocco Varano, Gregg Stewart, and Nadia Romani for their help and consideration in the office. As well, I am thankful to Dr. Mohammad Jahazi, Ahmad Rezaeian, Lan Jiang, Miguel Sanchez, and graduate students in the ceramic group; Farzad Jalilian, Fabian Edelmann, Ramona Vintila, Ozgur Ozdemir, Claudia Rodriguez, Mathieu Brochu and Juan Hernandez, from whom I have unforgettable memories.

I wish to deeply thank my parents for their unceasing love, support, and patience that have brought me to this point.

Last, but not least, the financial support received through the Natural Sciences and Engineering Research Council of Canada is gratefully appreciated. 


\section{TABALE OF CONTENTS}

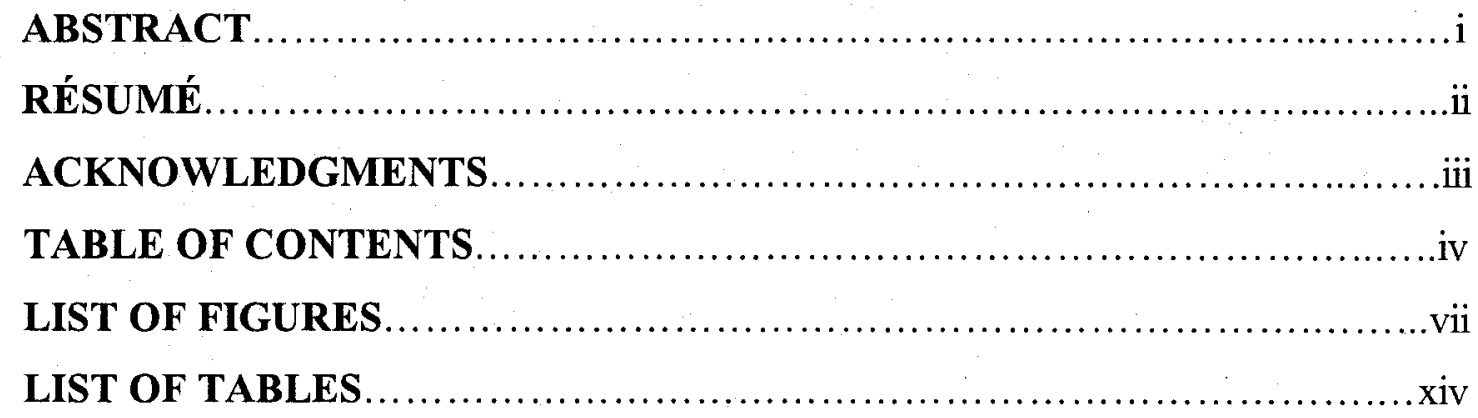

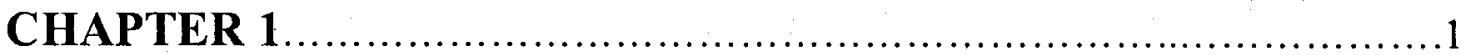

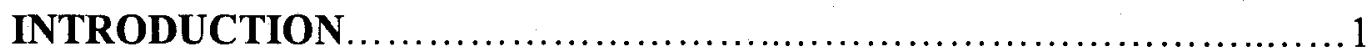

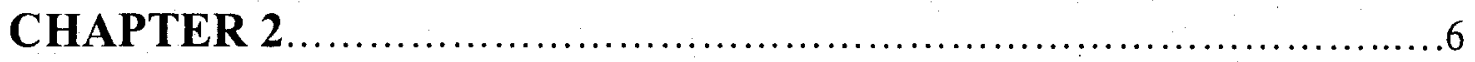

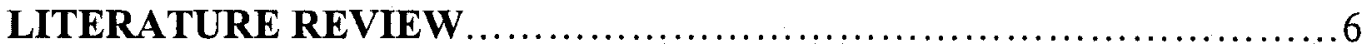

2.1. Stresses and Strains in Continuous Casting.........................9

2.2. Evaluation of Hot Ductility of Steel............................ 13

2.3. Description of Hot Ductility Loss.................................15

2.4. Embrittling Mechanisms..................................... 16

2.4.1. Ferrite at Grain Boundaries...............................16

2.4.2. Precipitate Free Zone....................................20

2.4.3. Grain Boundary Sliding..............................21

2.5. Influence of Microstructure on Hot Ductility........................24

2.5.1. Grain Size........................................24

2.5.2. Precipitates........................................ 26

2.6. Influence of Composition on Hot Ductility..........................30

2.6.1. Relevance of Experiment Method to Hot Ductility Evaluation............................................. 31

2.6.2. Influence of Residual and Alloying Elements................34

2.7. Influence of Deformation on Hot Ductility.........................46 


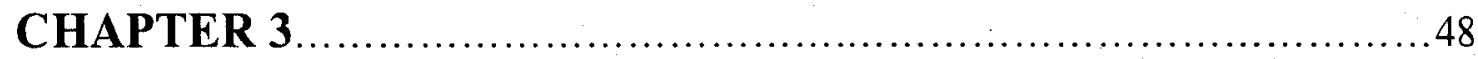

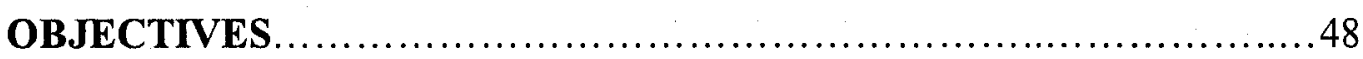

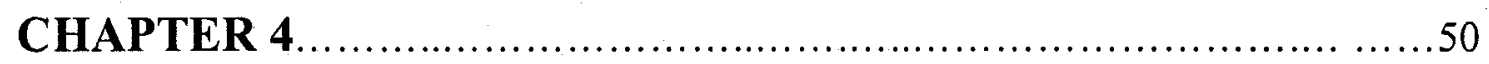

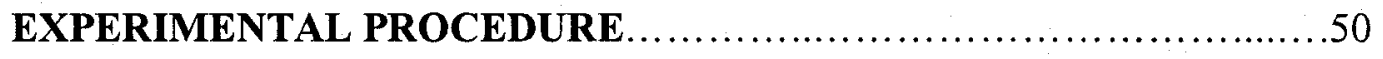

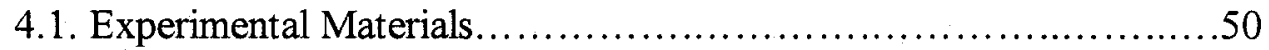

4.2. Hot Deformation Equipment......................................52

4.3. Continuous Heating Tension and Continuous Cooling Compression

Experiments................................................... 54

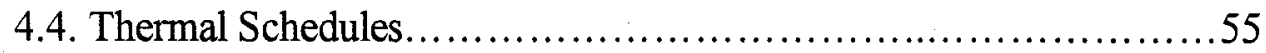

4.5. Thermomechanical Processes.....................................56

4.6. Characterization Techniques.....................................59

4.6.1. Optical Microscopy .......................................59

4.6.2. Electron Microscopy............................................59

4.6.3. Atomic Characterization...................................60

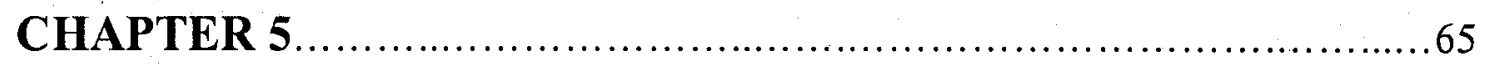

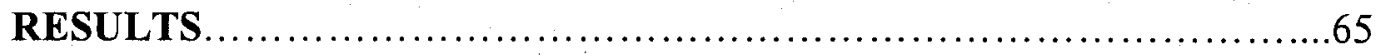

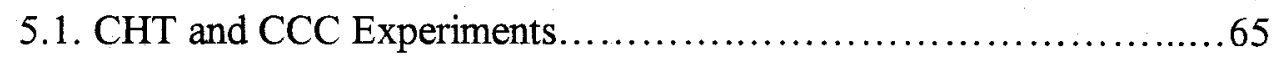

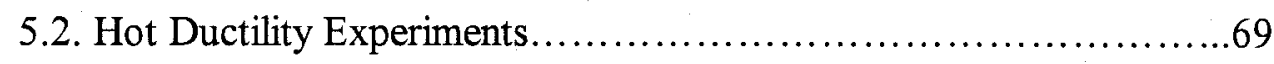

5.2.1. Effect of Thermal Schedule...................................69

5.2.2. Effect of Pre-Deformation Associated with Thermal Schedule ................................................. 71

5.2.3. Hot Ductility Evaluation..................................... 79

5.3. Fractography and Microstructure................................. 84

5.3.1. CHT Experiment...................................... 84

5.3.2. Effect of Thermal Schedule.............................. 85

5.3.3. Effect of Deformation Associated with Thermal Schedule...94

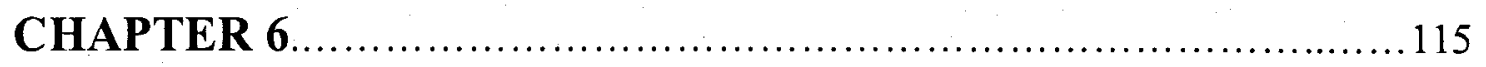

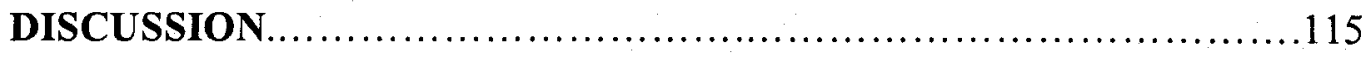


6.1. CHT and CCC Experiments................................ 115

6.2. Failure Mode Analysis...................................... 120

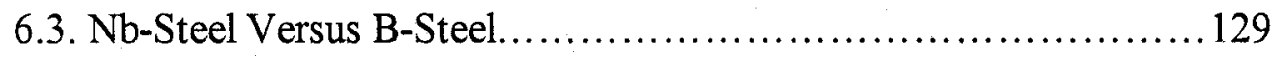

6.3.1. Hot Ductility Trough..................................129

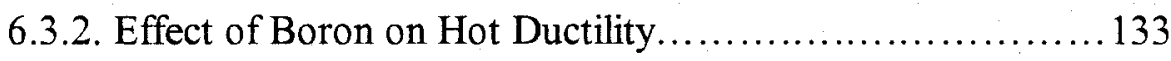

6.4. Effect of Deformation During Solidification.......................139

6.5. Effect of Deformation after Solidification...................... 147

6.5.1. Effect of Deformation in $\delta$-Ferrite Region............... 147

6.5.2. Effect of Deformation in $\delta \rightarrow \gamma$ Transformation Region...... 149

6.5.3. Effect of Cyclic Deformation after Pre-deformation in $\delta \rightarrow \gamma$

Transformation Region.................................170

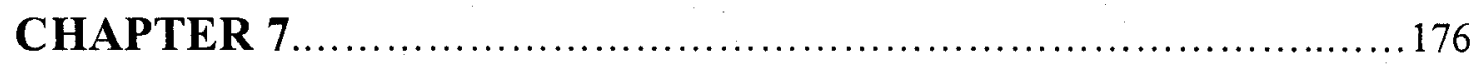

CONCLUSIONS................................................... 176

RECOMMENDATIONS FOR FUTURE WORK........................ 180

STATEMENT OF ORIGINALITY AND CONTRIBUTIONS TO

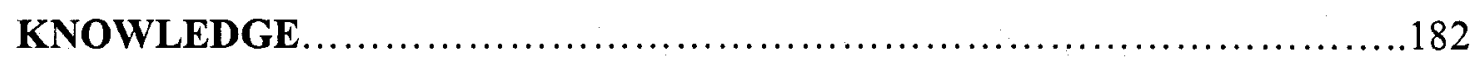

APPLICATION TO THE INDUSTRY TO RESOLVE THE PROBLEM....... 184

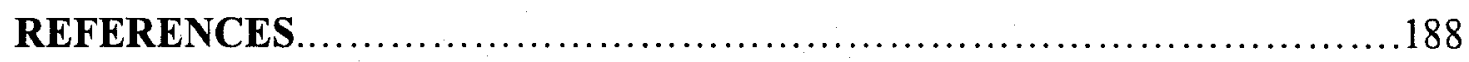




\section{LIST OF FIGURES}

\section{Chapter 2}

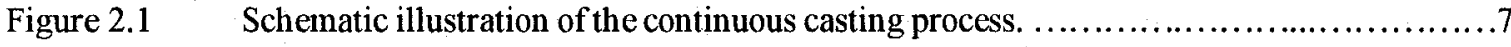

Figure 2.2 Appearance of oscillation marks on the narrow face of a slab..........................8

Figure 2.3. Schematic drawing of strand cast section showing different types of cracks. .............8

Figure 2.4 Schematic drawing of casting of steel into the mould in the continuous casting process.

Figure 2.5 Schematic drawing of axial and bending stresses in the solid shell resulting from friction in the mould.

Figure 2.6 Formation mechanism of segregation at the meniscus.

Figure 2.7 Effect of slight bulging of slab or offset rolls on stresses in solidifying skin. ............12

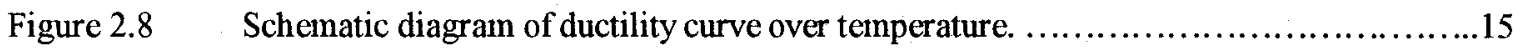

Figure 2.9 Schematic illustration showing microvoid formation and coalescence in ferrite film at austenite grain boundary.

Figure 2.10 Ferrite at austenite grain boundary in a high $\mathrm{Al}$ steel tested at $800^{\circ} \mathrm{C}$ (a) and grain

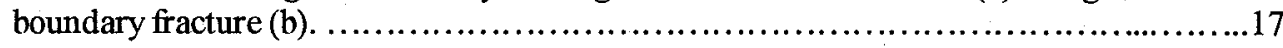

Figure 2.11 Effect of volume fraction of ferrite on strain concentration in ferrite .18

Figure 2.12 Effect of yield limit ratio (strain rate) on strain concentration in ferrite for 5\% ferrite.

Figure 2.13 Precipitate free zone adjacent to austenite grain boundaries in (a) $\mathrm{Nb}$ and (b) $\mathrm{Al}$ containing steel fractured at $950^{\circ} \mathrm{C}$ and $900^{\circ} \mathrm{C}$, respectively. Grain boundaries contain fine precipitates of $\mathrm{NbCN}$ and $\mathrm{AIN}$, and coarse $\mathrm{MnS}$ inclusions.

Figure 2.14 Schematic illustration of intergranular microvoid coalescence due to PFZ.

Figure 2.15 Grain boundary sliding (a) and fracture appearance (b) in austenitic alloy containing nickel. Pulled at $750^{\circ} \mathrm{C}$ and $\dot{\varepsilon}=5 \times 10^{-3} \mathrm{~s}^{-1}$.

Figure 2.16 Hot ductility curves for the $0.19 \mathrm{wt} \% \mathrm{C}$ steel at various grain size.

Figure 2.17 Volume fraction of ferrite as a function of temperature for $0.19 \mathrm{wt} \% \mathrm{C}$ steel at various grain size.

Figure 2.18 Influence of (a) particle size and (b) interparticle spacing on hot ductility of $\mathrm{Nb}$ containing steels, solution treated at $1330^{\circ} \mathrm{C}$, cooled to test temperature of $850^{\circ} \mathrm{C}$, and fractured at strain rate of $3 \times 10^{-3} \mathrm{~s}^{-1}$

Figure 2.19 Microstructures and corresponding $\mathrm{V}(\mathrm{C}, \mathrm{N})$ precipitate size distributions in C-Mn$\mathrm{V}$-Al steel, solution treated at $1330^{\circ} \mathrm{C}$, cooled to $850^{\circ} \mathrm{C}$, and held for (a) $1 \mathrm{~s}$ and (b) $6 \mathrm{~h}$ before testing.

Figure 2.20 TEM micrograph of extraction replica from a steel containing $0.78 w \mathrm{w} \% \mathrm{Nb}$ deformed at $850^{\circ} \mathrm{C}$ and at $10^{-3} \cdot \mathrm{s}^{-1}$ showing fine $\mathrm{Nb}(\mathrm{C}, \mathrm{N})$ precipitates within a 
grain.

Figure 2.21

Hot ductility of steels containing different amounts of $\mathrm{Nb}$.

Figure 2.22

Influence of soluble $\mathrm{Al}$ on the hot ductility of $\mathrm{Nb}$ containing steels $(0.03 \% \mathrm{Nb})$.

Figure 2.23 The effect of sulphur content on the hot ductility of (a) reheated and (b) as cast C$\mathrm{Mn}-\mathrm{Nb}-\mathrm{Al}$ steels.

Figure 2.24 Influence of temperature oscillation on the hot ductility of a C-Mn-Nb-Al steel. (CP1 refers to normal cooling to the test temperature at $60^{\circ} \mathrm{Cmin}^{-1}, \mathrm{CP} 2$ and $\mathrm{CP} 3$ incorporated a number of temperature oscillations of amplitude \pm 50 and $\pm 100^{\circ} \mathrm{C}$, respectively).

Figure 2.25 Hot ductility curves for (a) as cast $\mathrm{C}-\mathrm{Mn}-\mathrm{Al}$ and (b) as cast $\mathrm{C}-\mathrm{Mn}-\mathrm{Al}$ with a $\mathrm{Ti}$ addition.

Figure 2.26 Schematic illustration showing the effect of $\mathrm{C}$ on surface cracking susceptibility of continuously cast slab.

Figure 2.27 Effect of $\mathrm{C}$ content on the hot ductility. The specimens were deformed at 800 and $900^{\circ} \mathrm{C}$ after solution treatment at $1300^{\circ} \mathrm{C}$.

Figure 2.28 Relationship of shape and position of hot ductility curves to volume fraction of $\mathrm{NbC}$ precipitated, assuming equilibrium solubility, in steels with $0.025 \mathrm{wt} \% \mathrm{Nb}$, but with varying $C$ contents. The steels were solution treated, cooled to test temperature, and tested at strain rate of $3 \times 10^{-3} \mathrm{~s}^{-1}$.

Figure 2.29 Influence of small additions of $\mathrm{Ti}(0.02-0.03 \mathrm{wt} \%)$ on hot ductility behavior of C$\mathrm{Mn}-\mathrm{Al}$ steels heated to $1330^{\circ} \mathrm{C}$, cooled to test temperature, and fractured at strain rate of $3 \times 10^{-3} \mathrm{~s}^{-1}$.

Figure 2.30 Effects of (A) $\mathrm{N}$ content and (B) $\mathrm{Ti}$ addition on the hot ductility of $\mathrm{Nb}$-bearing steels.

Figure 2.31 Dynamic precipitation curves for $\mathrm{Nb}, \mathrm{V}$ and combination of $\mathrm{V}$ and $\mathrm{Nb}$ steels.

Figure 2.32 Influence of boron on hot ductility.

\section{Chapter 4}

Figure 4.1

Figure 4.2

Figure 4.3

Figure 4.4

Figure 4.5

Figure 4.6

Figure 4.7

Figure 4.8

Figure 4.9
Specimen configuration.

Experimental apparatus.

Schedule of CHT experiment.

Schedule of CCC experiment.

Thermal schedule applied to the B-steels.

Thermal schedule applied to the $\mathrm{Nb}$-steel. .56

Illustration of high temperature regions on the thermal schedule. .57

Schematic illustration of thermomechanical process and hot ductility evaluation. .58

The Oak Ridge National Laboratory three-dimensional atom probe (3DAP). 
Figure 4.10 2002 Imago Scientific Instrument Corp's LEAP microscope. .63

Figure 4.11 Specimens prepared for the LEAP microscopy. (B2-steel). .64

\section{Chapter 5}

Figure 5.1 CHT experiment. The tensile deformation was started at 1100 and $1200^{\circ} \mathrm{C}$ for the $\mathrm{Nb}$-steel and the B1-steel, respectively. $\left(\dot{\varepsilon}=3 \times 10^{-3} \mathrm{~s}^{-1}\right.$ and $\left.\dot{T}=2^{\circ} \mathrm{C} / \mathrm{s}\right)$.

Figure 5.2 CCC experiment. The deformation was incorporated with cooling after melting. $\left(\dot{\varepsilon}=3 \times 10^{-3} \mathrm{~s}^{-1}\right.$ and $\left.\dot{T}=10^{\circ} \mathrm{C} / \mathrm{s}\right)$

Figure 5.3 CCC experiment. $\dot{\varepsilon}=9 \times 10^{-3} \mathrm{~s}^{-1}$ and $\dot{T}=5^{\circ} \mathrm{C} / \mathrm{s}$. The arrow indicates the nonequilibrium solidus temperature on cooling. (B1-steel).

Figure 5.4 Some typical specimens used to determine the maximum temperature at which the melted steel can be held in situ.

Figure 5.5 Tensile tests at the straightening stage on the specimens subjected to the thermal schedules alone.

Figure 5.6 Tensile tests at the straightening stage on the $\mathrm{Nb}$-steel specimens undergone the thermal schedule alone and the thermal schedule with pre-deformation as specified......

Figure 5.7 Effect of straightening temperature on tensile bẹhavior of specimens subjected to the thermal schedules alone. (a): B2-steel. (b): Nb-steel.

Figure 5.8 Tensile tests at the straightening stage on specimens subjected to precompression and pre-tension in the 'liquid+solid' region. (B1-steel)

Figure 5.9 Tensile tests at the straightening stage on specimens subjected to precompression and pre-tension in $\delta$-ferrite and $\delta \rightarrow \gamma$ transition regions. (B1-steel)

Figure 5.10 Effect of pre-compression incorporated with the thermal schedule on tensile characteristics of the $\mathrm{Nb}$-steel. All specified pre-deformations initiated with the solidification stage.

Figure 5.11 (a) Schedules of pre-deformation started at different temperatures $\left(\mathrm{T}_{s}\right)$ over the thermal schedule. (b) Stress-strain curves at the straightening stage. I, II, and III correspond with their respective specimens in (a). TS: Thermal Schedule alone. (B1-steel)

Figure 5.12 (a) Pre-compression started before (I, II, III, IV) and after (V) the $\delta \rightarrow \gamma$ transformation. (b) Tensile tests, at the straightening stage, corresponding to the pre-deformation schedules in (a). TS: Thermal Schedule alone. (Nb-steel)

Figure 5.13 (a) Pre-compression during the $\delta \rightarrow \gamma$ transformation and, (b) corresponding tensile behavior at the straightening stage. Specimens I, II and III in (b) correspond with their respective specimens in (a). (Nb-steel)

Figure 5.14 (a) Schematic illustration of cyclic deformation, following the pre-compression during the $\delta \rightarrow \gamma$ transformation. (b) and (c): cyclic stress-strain curves of deformation schedules designated as $A$ and $B$, respectively, in (a). The deformation schedules A and B were separately applied to two different 
specimens. (d) Tensile tests, at the straightening stage, corresponding with the cyclic deformation schedules in (a). (Nb-steel)

Figure 5.15 Hot ductility troughs of the B2-steel and the Nb-steel corresponding with the specimens shown in Figure 5.7. The results of reference 112 are also presented for comparison.

Figure 5.16 A Nb-steel specimen experimented at the straightening stage at $700^{\circ} \mathrm{C}$. Necking has not occurred within the gauge length (re-melted region). 81

Figure 5.17 Effect of pre-compression start temperature on RA. All specimens were subjected to $\varepsilon=0.1$ pre-compression associated with the thermal schedule. (Nbsteel)

Figure 5.18 Dendritic structure of the B1-steel fractured at the incipient melting temperature in the CHT experiment.

Figure 5.19 Fracture surfaces of the B1-steel subjected to the thermal schedule alone and fractured at the straightening stage. (Corresponding with Figure 5.5)

(a): Overall observation. (b) and (c): Higher magnifications of (a). Circles in (b) specify grain surfaces. (d): Grain surface observed in FEGSEM.

Figure 5.20 Longitudinal microstructures of the B1-steel, which was subjected to the thermal schedule alone, quenched after fracture at the straightening stage (at $1000^{\circ} \mathrm{C}$ ). All etched with etchant \#4.

(a): Overall observation. (b): Higher magnification of (a). (c) and (d): Regions far from and near the fracture surface, respectively.

Figure 5.21 Fracture surfaces of the $\mathrm{Nb}$-steel subjected to the thermal schedule alone and fractured at the straightening stage. (Corresponding to Figure 5.5)

(a): Overall observation. (b): Higher magnification of (a).

Figure 5.22 Longitudinal microstructures of the $\mathrm{Nb}$-steel that underwent the thermal schedule alone and fractured at the straightening stage (at $1020^{\circ} \mathrm{C}$ ). The specimen was quenched immediately after fracture.

(a): Overall microstructure, etched with picral. (b): Higher magnification of (a). (c) and (d): Electro-polished microstructures. (e) and (f): EDS analyses of particles, inside the void and adjacent to the grain boundary, shown in (c) and (d), respectively.

Figure 5.23 Fracture surfaces of the B2-steel subjected to the thermal schedule alone and fractured at the straightening stage at $1100^{\circ} \mathrm{C}$. (Corresponding with Figure 5.15)

(b) is a typical grain surface shown in (a).

Figure 5.24 Longitudinal microstructures of the B2-steel specimens whose ductilities are presented in Figure 5.15. All quenched immediately after fracture at the straightening stage at (a) $700^{\circ} \mathrm{C}$, (b) $800^{\circ} \mathrm{C}$, (c) $900^{\circ} \mathrm{C}$, and (d) $1100^{\circ} \mathrm{C}$. (a) was etched with nital and the others with etchant $\# 4$.

Figure 5.25 Fracture surfaces of the $\mathrm{Nb}$-steel subjected to the thermal schedule alone and fractured at the straightening stage at $1200^{\circ} \mathrm{C}$. (Corresponding with Figure 5.15).

Figure 5.26 Longitudinal microstructures of the $\mathrm{Nb}$-steel specimens subjected to the thermal schedule alone and fractured at the straightening stage at (a) $700^{\circ} \mathrm{C}$ (gauge length region), (b) $700^{\circ} \mathrm{C}$ (necked region), (c) $800^{\circ} \mathrm{C}$, (d) $900^{\circ} \mathrm{C}$, (e) $1100^{\circ} \mathrm{C}$, and $(f) 1200^{\circ} \mathrm{C}$. All were quenched after fracture. (a) and (b) were etched with nital and the others with etchant $\# 4$. 
Figure 5.27 Fracture surfaces of the B1-steel at the straightening stage. The specimen had been pre-compressed in the 'liquid+solid' region. (Corresponding with Figure 5.8)

(a): Overall observation. (b): Higher magnification of (a). (c) and (d): Grain surfaces observed in FEGSEM.

Figure 5.28 Microstructure of the B1-steel quenched at the straightening stage just before the tensile experiment. The specimen was pre-compressed in the 'liquid+solid' region.

(a): Overall microstructure, etched with nital. (b), (c) and (d): Grain boundaries decorated with segregated elements and particles. Longitudinal electro-polished sections. (e) and (f): EDS analyses of grain boundary particles shown in (c) and (d), respectively. (g) and (h): Longitudinal sections of the gauge length. (i): EDS carbon map of $(\mathrm{h})$.

Figure 5.29 Fracture surfaces of the Bl-steel at the straightening stage. The specimen had been tolerated a pre-tension in the 'liquid+solid' region. (Corresponding with Figure 5.8)

(a): Overall observation. (b): Higher magnification of (a). (c): Grain surface in facet region observed in FEGSEM. (d), (e), and (f): Cracks at grain boundary and grain surfaces. Arrows indicate the cracks.

Figure 5.30 Longitudinal microstructure of the B1-steel deformed in tension in the 'liquid+solid' region and quenched at the straightening stage just before the tensile test.

(a) and (b): Overall microstructures, etched with nital. Optical and SEM, respectively. (c) and (d): Electro-polished structures in (a) and (b) observed in FEGSEM. (e) and (f): EDS analyses of particles in (c) and (d), respectively.

Figure 5.31 Fracture surface of the B1-steel at the straightening stage. The specimen had been pre-compressed in the $\delta$-ferrite region. (Corresponding with Figure 5.9 or specimen II in Figure 5.11).

Figure 5.32 Fracture surfaces of the B1-steel, which had been pre-deformed in tension in the $\delta$-ferrite region, at the straightening stage. (corresponding with Figure 5.9) (a) and (b): Observations at low and high magnifications, respectively. (c): Void nucleation and coalescence at grain boundaries.

Figure 5.33 Fracture surface of the B1-steel at the straightening stage. The specimen was pre-compressed in the $\delta \rightarrow \gamma$ transformation region. (Corresponding with Figure 5.9 or the specimen I in Figure 5.11)

Figure 5.34 Fracture surface of the specimen I in Figure 5.10.

(a): Overall observation. (b): Close look at grain surfaces in FEGSEM. (c) and

(d): Close look at regions $\mathbf{A}$ and $\mathbf{B}$, respectively, specified in (b) using

FEGSEM. The spectrum in (c) is EDS analysis of particles shown in the same picture.

Figure 5.35 Outer surface of the Nb-steel shown in Figure 5.34.

(a) and (b): At the straightening stage just before and after the tensile experiment, respectively. (a) is a horizontal image of the specimen. (c) and (d): Materials entrapped at grain boundaries, observed in FEGSEM. (e) and (f): EDS analyses of grain boundary materials shown in (c) and (d), respectively.

Figure 5.36 (a), (c), and (d): Fracture surfaces at the straightening stage of the specimens I, IV and V, respectively, presented in Figure 5.12. (b) is a magnified image of (a). 
Figure 5.37 (a), (b), (c), (d), and (e): Longitudinal microstructures of specimens I, II, III, IV, and $\mathrm{V}$ shown in Figure 5.12, respectively. All specimens were quenched immediately after fracture at the straightening stage. All etched with etchant \#4.

Figure 5.38 (a), (b), and (c): Longitudinal sections of specimens III, II and I, respectively, in

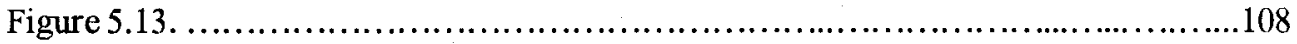

Figure 5.39 (a), (b), and (c): Fracture surfaces of the specimens III, II and I, respectively, in Figure 5.13. (d) is a magnified image of (b).

Figure 5.40 Detailed study of the grain surfaces in specimen III of Figure 5.13 in FEGSEM. (a): Overall observation. (b): Region A in (a). (c) and (d): Region B in (a). (d): EDS analysis of particles in (d).

Figure 5.41 (a), (b), and (c): Respectively, longitudinal sections, near the fracture regions, of specimens III, II and I in Figure 5.13. (a) was etched in picral and (b) and (c) in etchant \#4. Arrows point to voids formed inside grains.

Figure 5.42 Longitudinal microstructures of the B1-steel quenched after fracture at the straightening stage. Corresponding with specimen III in Figure 5.11. Etched with etchant \#4. (c), (d), and (e) FEGSEM images.

Figure 5.43 Longitudinal sections of the $\mathrm{Nb}$-steel specimens quenched at the straightening stage just before the tensile experiment. Etched with picral.

(a): After undergoing the thermal schedule alone. (b): After undergoing the thermal schedule together with pre-deformation schedule III in Figure 5.13(a).

\section{Chapter 6}

Figure 6.1 Effect of strain rate on the linear slope of the $\delta \rightarrow \gamma$ transformation region during the $\quad \mathrm{CCC} \quad$ experiments. $(\mathrm{Nb}-$

steel)

Figure 6.2 Grain boundary surface in the $\mathrm{Nb}$-steel at different magnifications. Lines in (b) indicate the steps of deformation.

Figure 6.3 Sequences of void propagation at grain boundaries through grain boundary sliding. Steps of sliding are obviously shown in (d).

Figure 6.4 Grain boundary sliding in the $\mathrm{Nb}$-steel subjected to the thermal schedule alone. Longitudinal sections. (b) and (c) are backscattered electron images in FEGSEM.

Figure 6.5 Typical images of atomic distributions in the B2-steel. (a) quenched just before the tensile test at the straightening stage, and (b) quenched immediately after the fracture at the straightening stage. Both quenched from $1000^{\circ} \mathrm{C}$.

Figure 6.6 Interdendritic solute enrichment in the $\mathrm{Nb}$-steel during solidification, if there is no reaction between elements during solidification.

Figure 6.7 Solid line; solubility limit of TiN versus interdendritically segregated $\mathrm{N}$ from 1500 to $1430^{\circ} \mathrm{C}$. Dashed line; interdendritically segregated Ti versus segregated N. (the Nb-steel)

Figure 6.8 Mechanism of crack formation and loss of grain boundary strength due to precompression during solidification. 
Figure 6.9 Microstructure near the fracture region in specimen III in Figure 5.13. Etched with picral.

Figure 6.10 Constant strain rate stress-strain curve typical of dynamic recrystallization.

Figure 6.11 Comparison of experimental stress-strain curves of the specimens in Figure $5.13(\mathrm{~b})$ with those obtained by their respective polynomials. (a), (b), and (c) correspond with specimens III, II, and I, respectively.

Figure 6.12 Strain hardening rate plots for the specimens introduced in Figure 5.13(b). I, II, and III correspond with the same specimens in Figure 5.13.

Figure 6.13 Determination of critical stress in the specimens of Figure 5.13. (I, II, and III correspond with the same specimens in Figure 5.13.)

Figure 6.14 Determination of critical strain in the specimens of Figure 5.13. (I, II, and III correspond with the same specimens in Figure 5.13.)........161

Figure 6.15 Strain hardening behavior of (I): the Nb-steel in Figure 5.5, (II): the Nb-steel fractured at $800^{\circ} \mathrm{C}$ in Figure $5.7(\mathrm{~b})$, and (III): the B-steel fractured at $700^{\circ} \mathrm{C}$ in Figure 5.7(a). (Absence of dynamic recrystallization)

Figure 6.16 Strain hardening behavior of the B-steel after pre-compression in the $\delta \rightarrow \gamma$ transformation region, corresponding with specimen III in Figure 5.11(b).

Figure 6.17 Dependence of $Z$ on initial grain size in a $0.16 \% \mathrm{C}$ steel.

Figure 6.18 Isothermal tensile test at $1200^{\circ} \mathrm{C}$, the beginning of the last step on the thermal schedule. (Nb-steel)

Figure 6.19 Determination of the critical strain in the specimen fractured at $1100^{\circ} \mathrm{C}$, Figure 5.7(b).

Figure 6.20 Z- $\quad Z$ s plot anticipated for the $\mathrm{Nb}$-steel.

\section{Application to the Industry to Resolve the Problem}

Figure I

Cross section of the billet in the mould.

Figure II Illustrations of compression schedules to be applied to the billet during continuous casting. 


\section{LIST OF TABLES}

\section{Chapter 4}

Table 4.1 Chemical compositions of experimental steels (wt\%). .51

\section{Chapter 5}

Table 5.1 Results of CHT and CCC experiments. . .68

Table 5.2 Hot ductility of specimens pre-deformed in the vicinity of the 'liquid+solid'

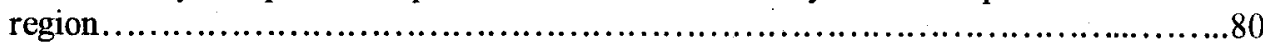

Table 5.3 Hot ductility of the specimens presented in Figure 5.6................................ 80

Table 5.4 Hot ductility of specimens deformed in the solid and the vicinity of the transformation regions.......................................................................83

\section{Chapter 6}

Table 6.1

Power law creep parameters .118

Table 6.2

$k$ values for some elements. .140

Table 6.3 Dynamic recrystallization parameters for the specimens in Figure 5.13(b). .165 


\section{INTRODUCTION}

Continuously cast steel, whether cast in a curved mould or straight mould, eventually has to be straightened when it has solidified throughout its cross section. This straightening or unbending operation generates tension on the top surface of a slab/billet. Investigations on carbon and microalloyed steels have indicated the temperature range of 600 to $1200^{\circ} \mathrm{C}$ as an embrittling thermal region. ${ }^{[1,2]}$ At the straightening stage of the continuous casting process, where the surface temperature ranges from 700 to $1000^{\circ} \mathrm{C}$, poor hot ductility has been a serious problem in carbon and low alloy steels since the advent of the process. ${ }^{[3-7]}$ Even though extensive work has been done to resolve this problem, material losses because of hot cracking still persist. The process of crack removal reduces productivity, and cracks can even lead to scrapping of a coil. In addition, a current trend in steel processing technology is to integrate the rolling process with the continuous casting process through 'direct rolling' or 'hot charging'. The development of a direct linkage between the continuous casting machine and hot working processes is supported by economic considerations. The charging of hot slabs into the reheating furnace makes possible an energy saving of $0.4 \mathrm{GJt}^{-1}$, whereas the direct rolling of hot slabs without reheating saves $1.2 \mathrm{GJt}^{-1} \cdot{ }^{[8]}$ This integration between casting and hot working processes does not allow any tolerance for surface cracks, since there is no interruption between casting and rolling to allow for inspection and scarfing. 
The major problem, which occurs during the slab/billet straightening, is edge and midface cracking occurring on the surface, as the stress is maximized on the surface during straightening. This so-called "transverse cracking" is associated with austenite intergranular fracture for which two mechanisms have been posited; a soft phase at austenite grain boundaries and austenite grain boundary sliding. The discovery of the ductility loss region, so-called "trough region", resulted in some changes in the continuous casting process; for instance straightening was implemented either above or below the trough region by changing the water-cooling or casting speed. Even though this strategy improved the situation to some extent, it must be noticed that stresses and thermal history developed during the continuous casting, from the mould down to the straightening stage, play the major role in controlling the ductility.

Stresses developed during continuous casting are generally classified into two categories; intrinsic and imposed stresses. The former is an 'inevitable' consequence of the process, including ferrostatic pressure of the unsolidified core metal on the solidified shell, friction as the steel slides on the mould surface, and temperature gradients due to surface cooling. Imposed stresses are deliberately applied to deform the cast steel, e.g. bending and straightening. These stresses may directly lead to cracking or indirectly lead to cracking by affecting the microstructure, and therefore the hot ductility, during continuous casting.

The hot ductility in steel is influenced by the thermomechanical history experienced by the solidified steel before being subjected to deformation at the straightening stage. In the laboratory, a hot tensile experiment is usually employed to assess the hot ductility. However, the steel microstructure at the test temperature controls the hot ductility. Thus, the experiment parameters must be as close to that of the continuous casting process as possible. In the past, a typical experiment involved pre-heating the specimen to around $1200^{\circ} \mathrm{C}$ to dissolve precipitates and to produce a coarse grain structure corresponding to that observed in cast steel before the straightening stage. Then, it was cooled to the hot ductility test temperature usually at a rate of $1^{\circ} \mathrm{C} / \mathrm{s}$. Eventually, the hot ductility test is executed at deformation rates similar to those commonly found in the continuous casting machines. However, other as cast microstructural features were found to be missing. For 
instance, regarding $\mathrm{Ti}$ and $\mathrm{S}$, the tensile specimens must be tested directly after casting to ensure dissolution of the TiN particles and $\mathrm{MnS}$ inclusions. ${ }^{[9]}$ As well, as cast austenite is dendritic, highly segregated of microalloying elements, ${ }^{[10]}$ and has a higher recrystallization temperature, amongst other characteristics. Because of this, many researchers have replaced the re-heating stage with re-melting.

Melting in situ was a significant improvement to the hot ductility tests but it is a difficult experimental setup. The situation was even more improved when the melting in situ was incorporated with the thermal condition similar to that of the billet surface in the continuous casting process. It was shown that, in addition to melting in situ, the thermal history undergone by the tensile specimens had also a significant effect on the hot ductility in steel. ${ }^{[11-13]}$ This is not surprising since the microstructure of steel is sensitive to the thermal history. Looking at the continuous casting process in more detail, it is apparent that the billet is under different modes of deformation throughout the continuous casting stage. The effect of deformation in the mould has been studied by some researchers to some extent. ${ }^{[14-16]}$ However, such work was done not with purpose of hot ductility assessment but mainly to study the effect of the mould movement on segregation patterns during solidification. The most comprehensive hot ductility evaluation procedure so far considerered the effect of all three parameters, i.e. melting in situ, thermal history undergone by the billet surface, and deformation. ${ }^{[12]}$ In that work, it was first shown that the ductility depended on the thermal history experienced by the specimen, a reconfirmation of the work in Ref. 11. Secondly, it was concluded that deformation, depending on the mode and temperature of execution, at specific stages prior to the execution of a strain to fracture can have significant influence on the hot ductility. There, even though beneficial effects of deformation were attributed to the carbonitride precipitates, the exact mechanisms according to which the deformation affected the hot ductility were not understood. Therefore, the theme of the current research work is to closely characterize the effect of deformation applied at very high temperatures on the subsequent hot ductility. For this, a Nb-Ti grade steel, similar to that studied in Ref. 12, is examined. As well, two Nb-Ti-B steels are studied since the effect of boron on the hot ductility has not yet clearly been understood. 
The uniqueness of this work is that it looks to the problem of hot ductility from a new perspective. Almost all investigators working on the hot ductility problem in steel have been studying the effect of steel chemistry and its relevance to the problem. From this body of work, causes of the cracking have been identified and, with some modifications in the chemistry, the problem has been alleviated somewhat. Nevertheless, the chemical composition cannot always be modified, especially in microalloyed steels. For instance, in $\mathrm{Nb}-\mathrm{Ti}$ microalloyed steel, $\mathrm{Nb}$ has been identified as the cause of the transverse cracking but its presence in steel is imperative because of mechanical properties. In this work, it is assumed that the chemistry, which also includes elements detrimental to the hot ductility, is already fixed. The desire is to alleviate the problem by deformation, especially very high temperature deformation. To this end, the thesis is concluded by suggesting a practical solution to industry in order to alleviate the problem of transverse cracking by very high temperature deformation.

Based on this overall objective, a literature review on the hot ductility deterioration, its mechanisms and causes and contributions of alloying elements, is given in chapter 2. Also in this chapter, different methodologies of hot ductility evaluation in laboratories, including advantages and disadvantages, and the evolution of evaluation method is explained. The objectives of the present research work are stated in chapter 3 . In chapter 4 , the experimental materials are introduced and the experimental configuration to apply the desired thermomechanical processes is described. Then, details of the deformation schedules are explained. Continuous heating tension and continuous cooling compression experiments, used to identify transformation temperatures, including solidification start temperature, during heating and cooling, are described as well. Characterization techniques encompassing optical and scanning electron microscopy, and high-resolution field emission gun scanning electron microscopy are also described in this chapter. Results of the hot ductility assessment, presented in chapter 5, reveal both improvement and deterioration of the hot ductility owing to high temperature deformations. The results of the failure mode analysis are also given. All the results presented in this chapter are discussed and rationalized in chapter 6. Conclusions and recommendations for future 
work are given in chapter 7. Eventually, the originality of this work and, then, the industrial application of the findings, are explained. 


\section{LITERATURE REVIEW}

High-Strength, Low Alloy (HSLA) steels constitute a classical metallurgical development in which alloying additions and thermomechanical processing have been combined to attain desirable mechanical properties through microstructural control. Such process and compositional variations can develop yield strengths typically in the range of 350 to $700 \mathrm{MPa}$ (50 to $100 \mathrm{ksi}$ ), thus doubling the corresponding yield strength of mild steels. This increased strength, coupled with good toughness and weldability, has resulted in applications in transportation, pipeline, construction, and pressure-vessel technologies.

HSLA steels are predominantly low in carbon ( 0.05 to $0.15 \mathrm{wt} \%)$ and are alloyed with small quantities of strong carbide-forming elements such as niobium, vanadium or titanium. This contributes to enhanced mechanical properties primarily through ferrite grain refinement, often supplemented by precipitation and/or substructural (dislocation) strengthening. ${ }^{[17]}$

The continuous casting of steel was introduced commercially around 1960, and it is presently the way in which the majority of high tonnage steels is produced, including HSLA steels. One of the problems specific to this process has been transverse cracking. The continuous casting operation is shown schematically in Figure 2.1. Molten steel is 


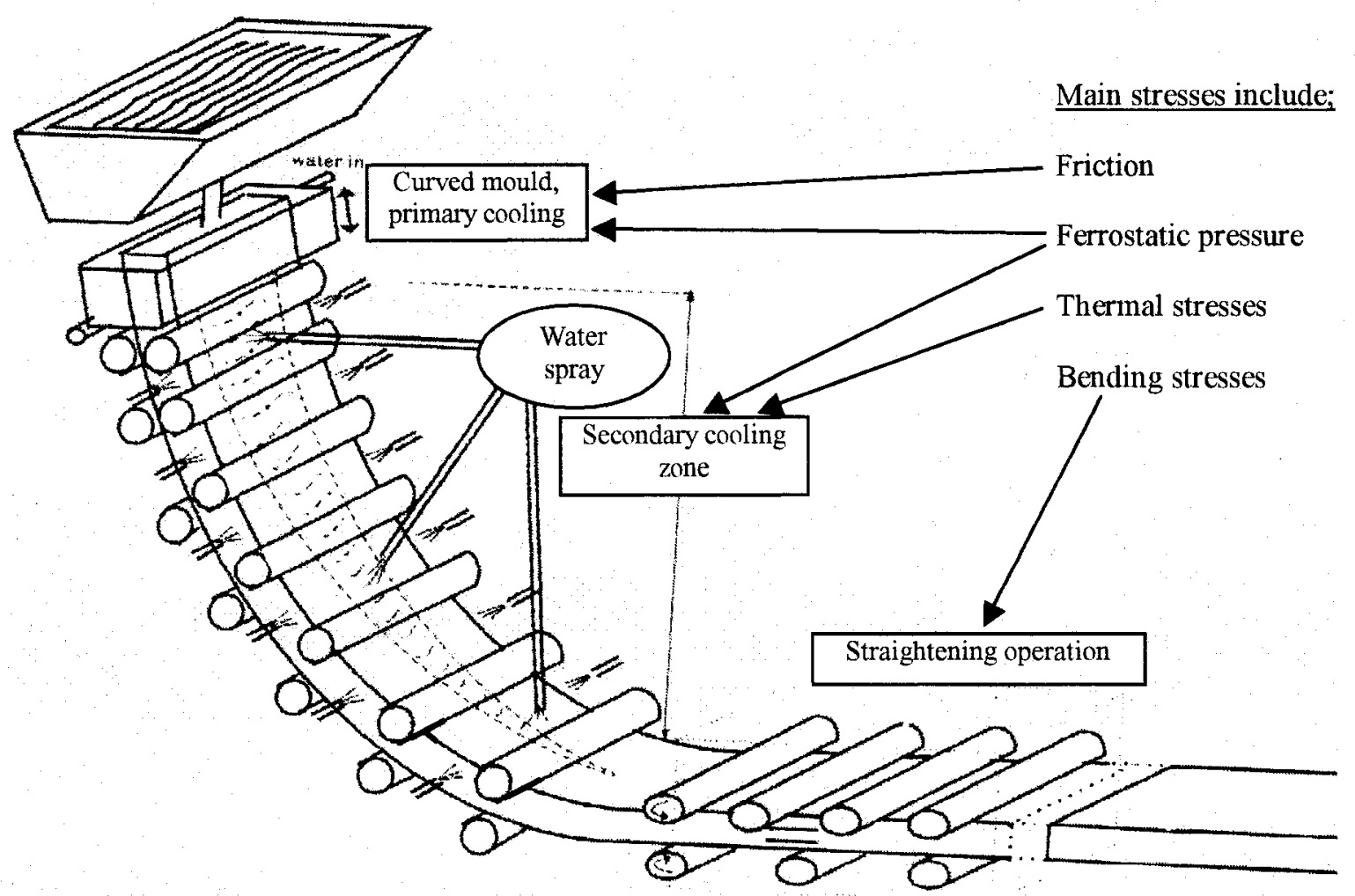

Figure 2.1. Schematic representation of typical continuous casting process. ${ }^{[3]}$

poured from a ladle via a tundish into an oscillating, water-cooled copper mould, which is often curved. The mould oscillates to prevent sticking, and this oscillation is responsible for transverse ripples (oscillation marks) on the surface of the strand. ${ }^{[18]}$ The oscillation marks have an important influence on the surface quality of slabs because they are often the site of transverse cracks, and therefore influence crack formation. ${ }^{[18]}$ Such cracks can be propagated while the movement of cast strand changes gradually from vertical to horizontal direction, during which the top surface and edges are put in tension, Figure $2.2 .^{[18]}$

The oscillation mark is not the only cause for cracking. Cracks have been observed at many other locations in cast steel strands. In the interior, cracks may be seen near the corners, at the centerline or diagonally between opposite corners. On the surface, transverse and longitudinal cracks may appear in both the midface and corner regions. Figure 2.3 shows schematically cracks on different locations of the cast strand. ${ }^{[19]}$ 


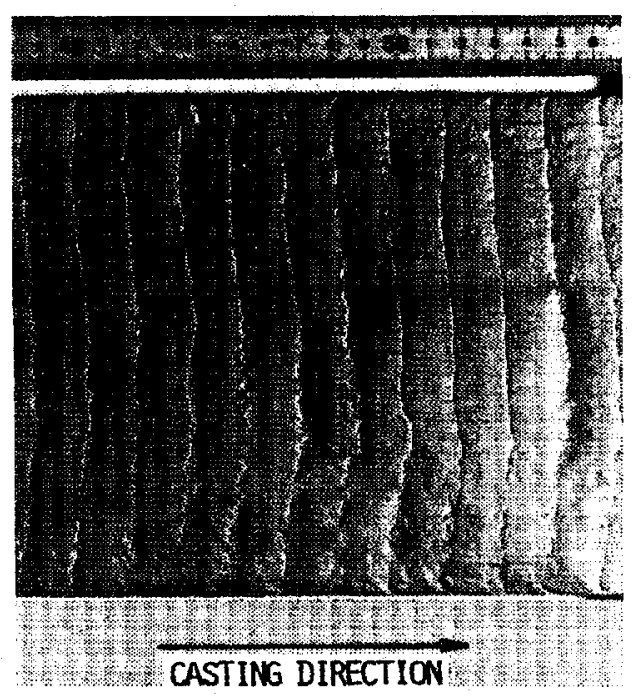

Figure 2.2. Appearance of oscillation marks on the narrow face of a slab. ${ }^{[18]}$

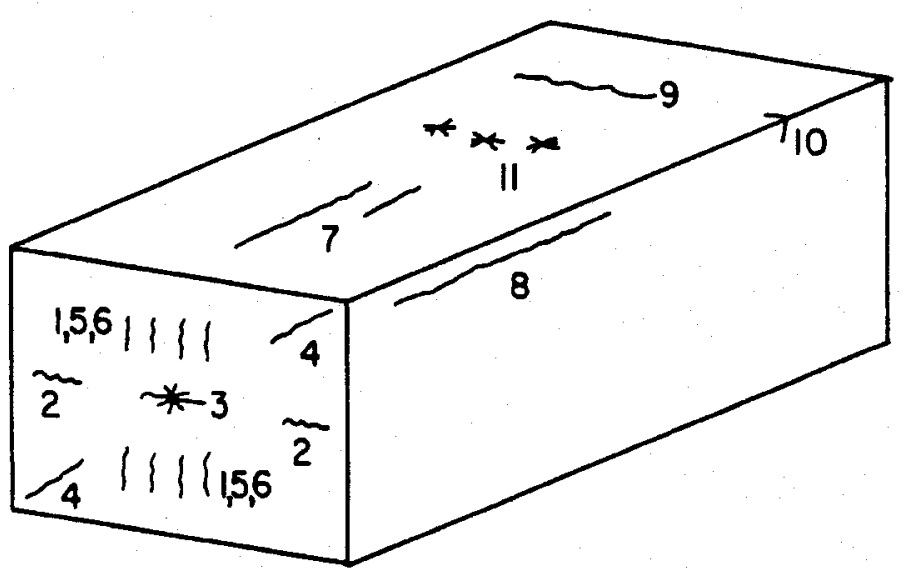

Internal cracks in continuously cast steel

1: Midway

2: Triple point

3: Centerline

4: Diagonal

5: Straightening / bending

6: Pinch roll surface cracks

7: Longitudinal, midface

8: Longitudinal, corner

9: Transverse, midface

10: Transverse, corner

11: Star

Figure 2.3. Schematic drawing of strand cast section showing different types of cracks. ${ }^{[18]}$

The process of continuous casting has gained popularity because of the high solidification rates due to the strand geometry combined with heat extraction at a striking rate with the combination of mould, water sprays and radiant cooling. Nonetheless, the rapid cooling causes steep temperature gradients in the solid shell and these can change rapidly and generate thermal strains as the shell expands and contracts. Furthermore, because the semisolid section is required to move through the machine, it is subjected to a diversity of 
mechanically induced stresses caused by friction in mould, roll pressure, ferrostatic pressure, machine misallignement, bending and straightening operations. All of these kinds of stress can result in crack formation. In the following sections, these stresses are studied briefly and then loss of hot ductility and transverse cracking is elaborated.

\subsection{Stresses and Strains in Continuous Casting}

The nature of stresses and strains that can cause cracks during continuous casting of steel, as it travels from the mould down to the cutting stage, has well been explained by Lankford ${ }^{[20]}$ and some other authors. After pouring liquid steel into the mould, the mould is oscillated in order to prevent welding or sticking of the cast metal to the mould, and consequent high apparent friction and tearing of the solidifying skin. However, some friction occurs at the interface of the mould and solidified skin, resulting in stresses in the skin, Figure 2.4. ${ }^{[21]}$ When the velocity of the casting relative to the mould wall is downward, an upward friction force acts on the surface, as illustrated in Figure 2.5. ${ }^{[20]}$ The magnitude of this friction force depends on the coefficient of friction and the ferrostatic force. Because of the friction, an axial tensile force and an axial tensile stress occur in the skin. Because the friction force is a surface force and eccentric to the resultant axial force, a bending moment occurs and causes additional stresses in the skin. As shown in Figure 2.5, the resultant stresses and strains are the sum of the bending and axial components and, in general, will be tensile across the entire solid layer. Provided these stresses are sufficiently high, tensile failure of the skin and a breakout can occur.

Surface segregation and inclusions are other outcomes of this movement of the mould. Harada et al. ${ }^{[22]}$ have shown that transverse surface cracks on continuously cast slabs have their origin in local segregation areas. They showed that a positive segregation of phosphorous can spread over an oscillation mark and, at the same time, a sharp negative segregation occurs adjacent to the positive segregation along the mark. This positive segregation penetrates deeply into austenite grain boundaries through which transverse cracks propagate. They also found $\mathrm{MnS}$ precipitates on fractured surfaces. It was 


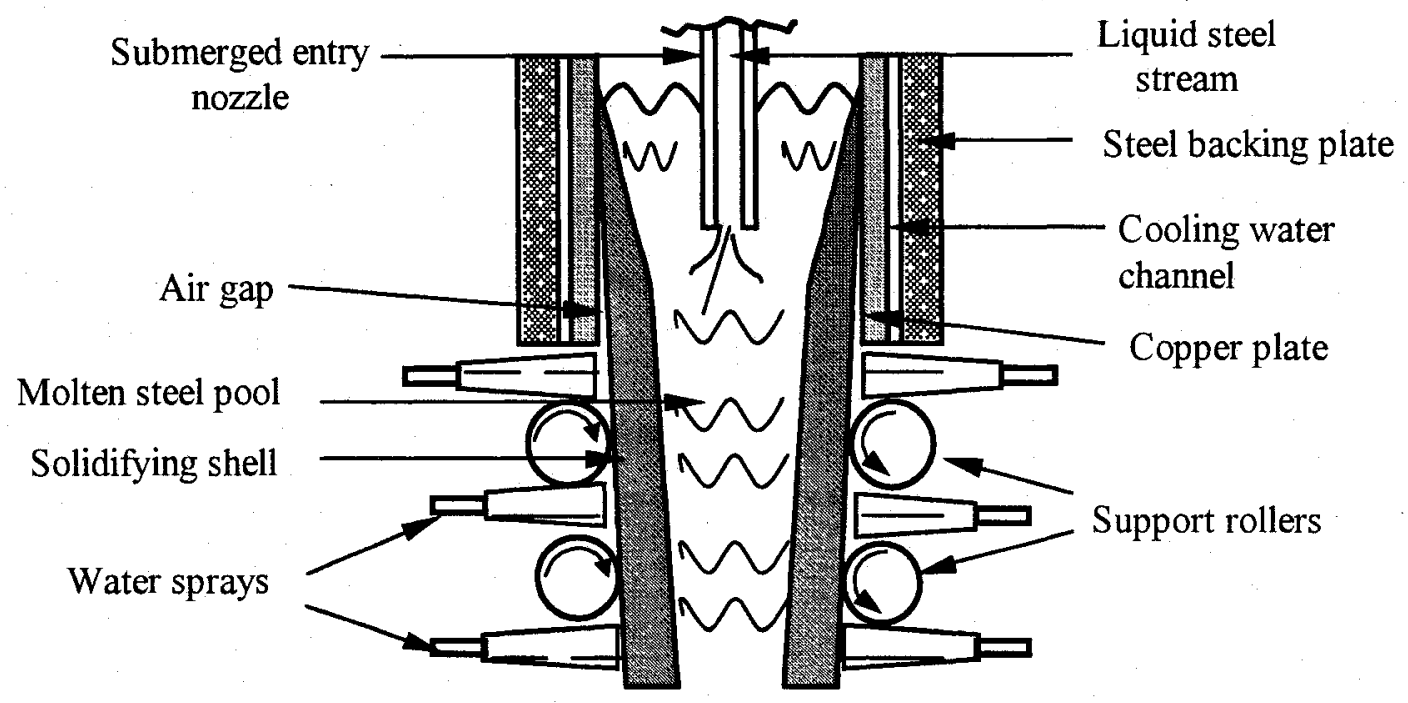

Figure 2.4. Schematic drawing of casting of steel into the mould in the continuous casting process. ${ }^{[21]}$

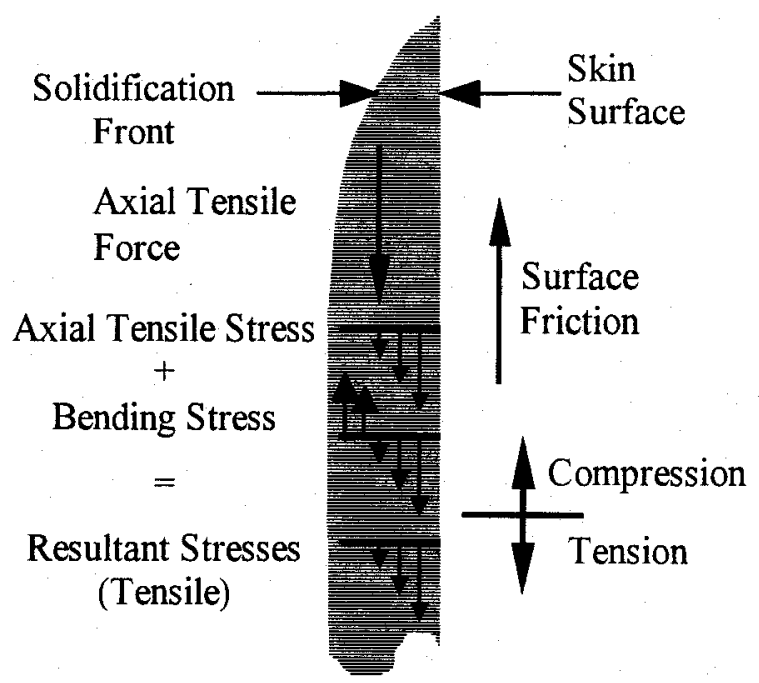

Figure 2.5. Schematic drawing of axial and bending stresses in the solid shell resulting from friction in the mould. ${ }^{[20]}$

suggested that, at the meniscus, when the tip of the partially solidified shell is bent down periodically during mould oscillation, interdendritic "dirty" liquid is squeezed out and accumulated at the valley of an oscillation mark, Figure 2.6(a). In another scenario, bulk liquid overflows on the tip of the shell and again interdendritic "dirty" liquid spreads out and accumulates there, Figure $2.6(\mathrm{~b})$. In any case, the local segregation forms at the 
valley of an oscillation mark. Since this segregated part of the shell is weak, cracks initiate there under any external stresses. Therefore, internal cracks form below the oscillation mark and propagate along austenite grain boundaries. Brimacombe and Takeuchi ${ }^{[14]}$ have also observed the positive segregation of phosphorous at the bottom of oscillation marks.

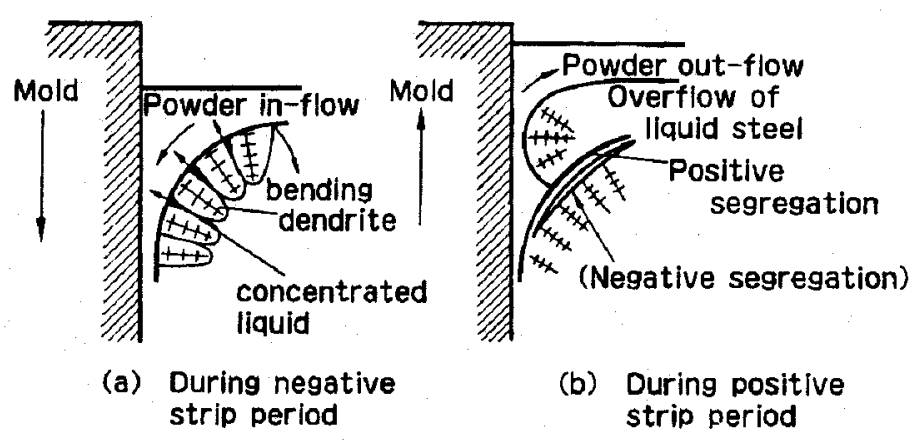

Figure 2.6. Formation mechanism of segregation at the meniscus. ${ }^{[22]}$

Trying to find a solution for the problem of oscillation marks, Itoyama et al. ${ }^{[15]}$ studied the solidification of steel in the mould with regard to the mould oscillations. They proposed a "horizontal oscillation" synchronized with the conventional vertical oscillation of the mould. This horizontal oscillation appeared successfully to reduce the depth of oscillation marks and surface segregation at oscillation marks, and was extremely effective when the wide face of the mould was expanded against the solidified shell during positive strip period

During the entire excursion through the caster, thermal gradients exist through the thickness of the solidifying skin and along the axis of the casting, resulting in thermal stresses in the skin. It can generally be concluded that tensile stresses occur in the cooler regions because of the contraction restraint provided by the adjacent hotter regions, and compressive stresses occur in the hotter regions. Thus, the strand surface is normally in tension and the solidification front is in compression. This profile can, however, be reversed should the surface temperature rebound owing to a sudden decrease in the rate of cooling. ${ }^{[19]}$ 
Below the mould, ferrostatic pressure can give rise to shell bulging, particularly of the wide face of slabs if support rolls are spaced too widely apart. As illustrated in Figure 2.7, the resultant stresses are tensile at the surface and compressive near the solidification front. However, this situation can change quickly if rolls, lower in the machine, are properly spaced since they will deform the bulged shell and set up tensile stresses at the solidification front. Similar stresses can arise if a set of rolls is too narrowly gapped. ${ }^{[19,20]}$

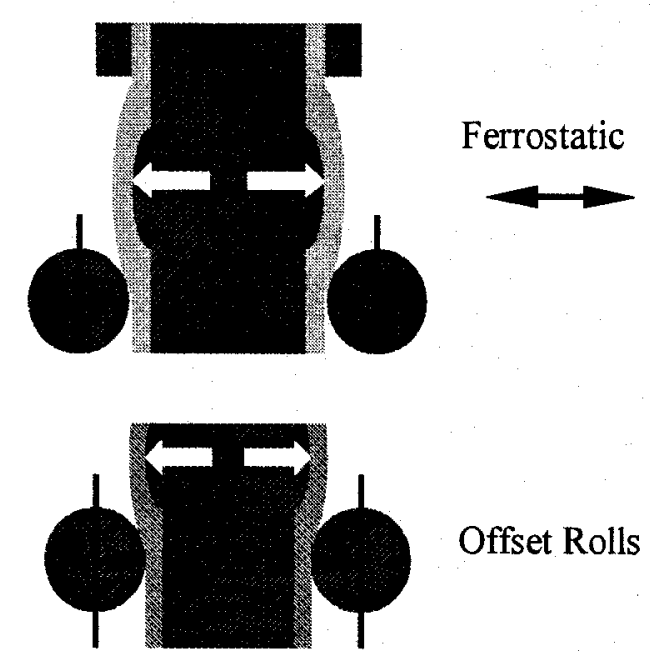

Figure 2.7. Effect of slight bulging of slab or offset rolls on stresses in solidifying skin. ${ }^{[20]}$

At the end of the casting and when the surface temperature is smoothly decreasing, the billet/strand is straightened at a temperature ranging from 700 to $1000^{\circ} \mathrm{C}^{[3,13,23,24]}$. At this point, the greatest strains may be imposed to the casting. These strains are tensile on the upper surface of the strand and compressive on the lower surface. However, the strains are reversed for bending. ${ }^{[19]}$ The surface strains due to overall bending of the slab in most situations are approximately given by the ratio of the slab thickness to twice the bending radius of the slab. ${ }^{[20]}$ The maximum surface strain on bending of slab was reported to be around $2 \% .^{[13]}$ The strain rate is less well-defined because of the uncertainty about the gauge length necessary to develop the full bending strain. For a casting machine constructed to bend a 10" thick bloom with $34 \mathrm{ft}$ radius at a maximum speed of $70 \mathrm{ipm}$, Lankford $^{[20]}$ reported a bending strain of about $1.2 \%$. For this situation, the bending strain 
rate was in the range of $0.5 \times 10^{-3}$ to $7 \times 10^{-3} \mathrm{sec}^{-1}$. A similar range of strain rate was also reported and used by other researchers, Refs. 13,23 , and 24, for instance.

There are some soft stresses applied deliberately during continuous casting in order to reduce segregation in the center of the solidified strand. ${ }^{[25]}$ Other sources of stresses can arise from mechanical inaccuracies or operating irregularities such as; nonconcentric roll cage, nonuniform cooling, and mould distortion. ${ }^{[19,20]}$.

Therefore, there are different sources of stresses being applied to the solidifying steel since it is poured in the mould down to the straightening point. These stresses can contribute to some detrimental effect, especially cracking. Among these, cracking in the mould and during the straightening of steel are of high importance. As for cracking in the mould, there have been numerous reports during last two decades about improvement in slab surface quality by technologies which do not depend on mould oscillation, such as molten steel flow control in the mould and electromagnetic force imposed on the meniscus. ${ }^{[15,26-29]}$ However, cracking during the straightening is still a severe problem, in spite of being investigated for four decades.

\subsection{Evaluation of Hot Ductility of Steel}

Much valuable work dealing with hot ductility was done in the 1960 s. $^{[30-35]}$ However, much of this primarily dealt with studies of hot ductility as related to hot working and deformation characteristics of materials at elevated temperatures. Even though some of these results can be relevant to the behavior in continuous casting, information on hot ductility under conditions more closely simulating those in continuous casting is needed. Specifically, information is required on the behavior of steels solidified from the melt but not cooled below the temperature range at which the mechanical behavior is of interest.

To study the hot ductility at the straightening stage of continuous casting, the test which best simulates the situation is the hot bending test. However, since surface cracking can 
not easily be quantified in this method, it is not popular. ${ }^{[3,20]}$ Compression and torsion tests have been also used. ${ }^{[3]}$ The problem concerning the torsion test is that the large strains associated with this method and difficulties in interpretation of the fracture appearance after failure make it unsuitable. The most popular technique to evaluate the hot ductility and the problem of transverse cracking is the hot tensile test. Normally, this test is carried out using a servohydraulic load frame equipped with either a furnace or an induction heater, in a protective atmosphere such as argon. The Gleeble machine has also proved to be a good method of hot ductility assessment, because of its ability to melt specimens and versatility in simulating thermal schedules. ${ }^{[20]}$

In both Tensile and Gleeble tests, specimens are usually heated to a temperature above the solution temperature of the microalloy precipitates to dissolve all these particles and produce a coarse grain size, charatceristic of the continuously cast microstructure before the straightening operation. The specimen is cooled at the rate experienced by the surface of the strand/billet, as transverse cracking is on the surface, during the continuous casting operation $\left(\sim 60 \mathrm{Kmin}^{-1}\right)$. Finally, it is strained at rates between $10^{-3}$ and $10^{-4} \mathrm{~s}^{-1}$, which is in the range of the straightening deformation rate. In more sophisticated simulations of the continuous casting operation, the specimen is actually melted, either by induction or electrical resistance, in a quartz tube placed over the mid span region to retain the liquid. This is mainly performed in Gleeble machine and is not popular in tension. However, a few hot ductility tests associated with melting have also been performed. Revaux et al. ${ }^{[13]}$ melted and cast steel in a crucible to form a tensile specimen on a tensile machine. Then, the crucible was broken and a tensile test was performed.

In order to evaluate the hot ductility, some researchers have used total elongation to fracture as a measure of the ductility and it can provide useful information regarding the role played by dynamic recrystallization in influencing the ductility. ${ }^{[36-38]}$ The majority of researchers, however, have used the reduction in area (RA) at fracture to provide quantitative information on the fracture strain. ${ }^{[3]}$ 


\subsection{Description of Hot Ductility Loss}

As mentioned before, poor hot ductility, associated with transverse cracking, in steel occurs within the temperature range of $700-1000^{\circ} \mathrm{C}$, where the straightening operation takes place. This region of hot ductility loss over temperature, the so-called trough, is shown in Figure 2.8. As the ductility curve suggests, there are three distinct regions to be specified as;

(i) the trough or embrittlement region

(ii) a high ductility, low temperature (HDL) region

(iii) a high ductility, high temperature (HDH) region.

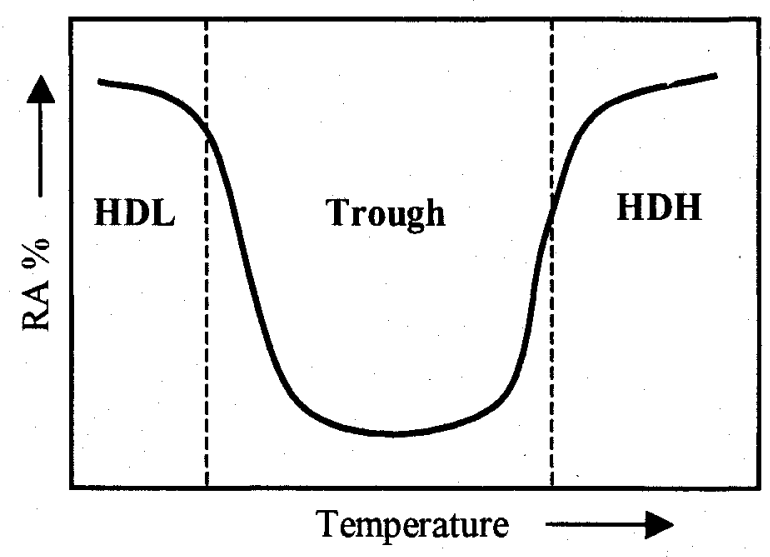

Figure 2.8. Schematic diagram of ductility curve over temperature.

It must be pointed out here that the transverse cracking associated with the ductility trough is different from that which occurs due to the mould oscillation. The latter is already on the surface of steel before it reaches the straightening stage, whereas the former occurs because of the straightening deformation. For the remainder of this thesis, whenever transverse cracking and hot ductility loss is referred to, it will concern the ductility trough as opposed to the oscillations. 


\subsection{Embrittling Mechanisms}

In the trough region, steel invariably fractures through austenite grain boundaries. ${ }^{[3]}$ The fracture facets are either covered with fine dimples or microvoids, or they are smooth. This implies that two distinct mechanisms of failure must be viable. In the former case, preferential deformation in regions close to the grain boundary initiates voids at grain boundary inclusions or precipitates, which leads to intergranular failure via microvoid coalescence. In the latter case, grain boundary sliding in the single phase of austenite region followed by wedge cracking appears to be a possible mechanism. These mechanisms can be considered in three categories.

\subsubsection{Ferrite at Grain Boundaries}

Intergranular failure can occur at a stage in the austenite to ferrite transformation when a thin film $\left(\sim 5-20 \mu \mathrm{m}\right.$ thick) of ferrite has formed around the austenite grains, Figure 2.9. ${ }^{[3]}$ The comparative ease of dynamic softening (recovery) in ferrite leads to lower flow stress compared with the austenite and, therefore, to strain concentration in the ferrite film. This results in ductile voiding, generally at $\mathrm{MnS}$ inclusions situated at the austenite grain

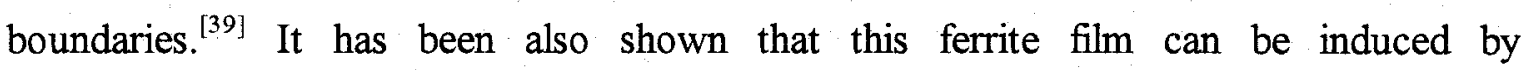
deformation. ${ }^{[40-45]}$
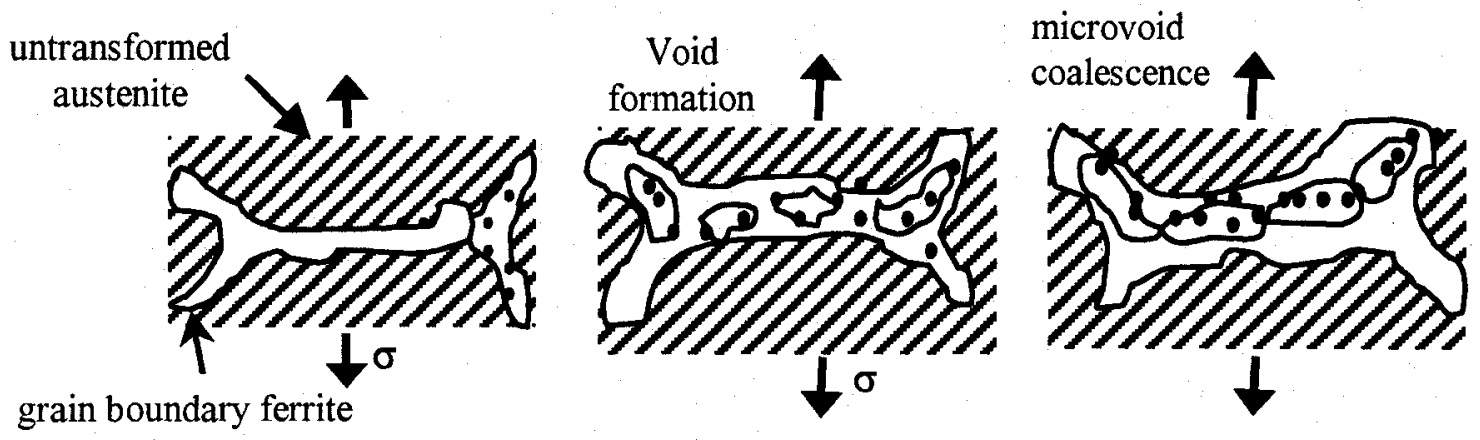

Figure 2.9. Schematic illustration showing microvoid formation and coalescence in ferrite film at austenite grain boundary. ${ }^{[3]}$ 
Strain induced ferrite can be formed at temperatures above the undeformed $\mathrm{Ar}_{3}$ temperature (the transformation start temperature at a constant cooling rate), an often as high as the $\mathrm{Ae}_{3}$ (the equilibrium austenite to ferrite transformation temperature). ${ }^{[45]}$ Figure 2.10 shows clearly austenite grain boundary fracture because of thin ferrite film.
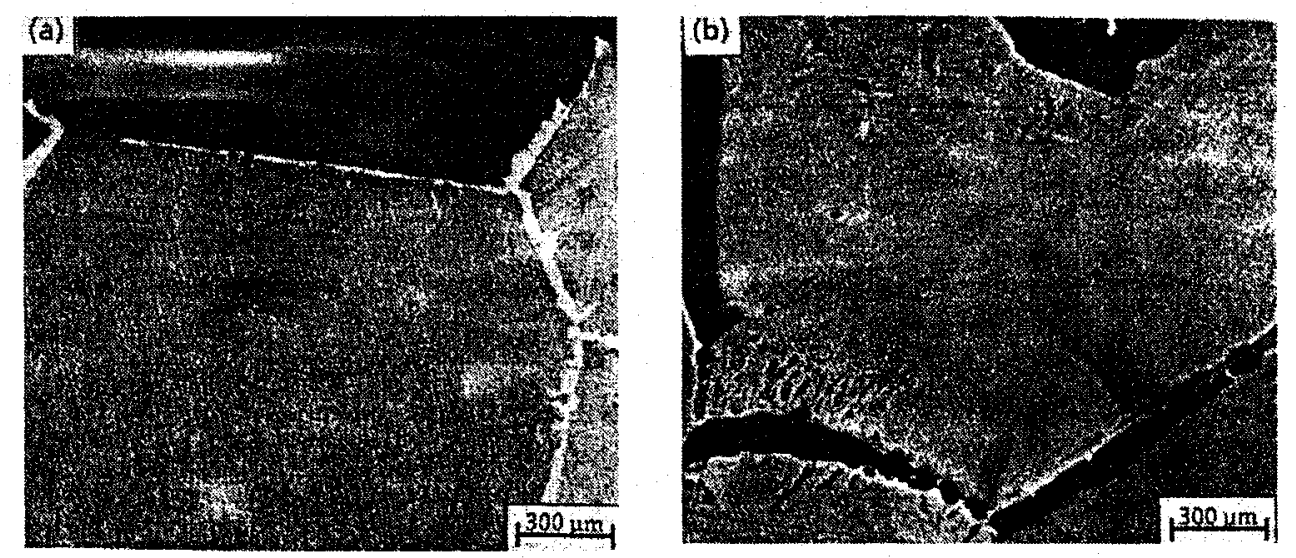

Figure 2.10. Ferrite at austenite grain boundary in a high $\mathrm{Al}$ steel tested at $800^{\circ} \mathrm{C}$ (a) and grain boundary fracture (b). ${ }^{[40]}$

There are various explanations proposed on how deformation encourages and accelerates ferrite nucleation: (a) bulged austenite boundary caused by local grain boundary migration which is assisted by deformation acts as ferrite nuclei, (b) subgrains are formed near the boundaries which raise the stored energy locally, and (c) the increased dislocation density in deformed austenite increases the strain energy, favouring ferrite nucleation in this way. ${ }^{[3,45]}$ This clearly implies the effect of grain size on volume fraction of deformation induced ferrite. The primary effect of grain size is the amount of grain boundary surface area, and the number of grain edges and corners, per unit volume as these influence the number of favourable nucleation sites. As well, the strain homogeneity and the overall dislocation density increase with decrease in grain size, so further accelerating the transformation. It was shown that ferrite can be induced by deformation in both coarse $(\sim 200 \mu \mathrm{m})$ and fine $(\sim 25 \mu \mathrm{m})$ austenite grain sizes. ${ }^{[45]}$ Nevertheless, it was only formed in narrow bands adjacent to grain boundaries in the coarse grained austenite whereas, in fine grained austenite, the deformation was far more homogeneous so that ferrite formation was not so severely limited or localized. 
Another point is the amount of deformation beyond which ferrite starts forming by deformation. It has been shown that strain induced ferrite can be produced in a fine grained $(\sim 25 \mu \mathrm{m})$ low $\mathrm{C}$, Mo steel, deformed to a true strain of 0.016 at a low strain rate of $7.4 \times 10^{-4} \mathrm{~s}^{-1}$. ${ }^{[46]}$. This result was obtained from hot compression tests in which specimens were cooled to test temperatures from a high temperature yet in solid state. Even though this shows that ferrite can form at low strain, it is not yet clear if it can form in steels with as cast coarse grains $(\sim 500 \mu \mathrm{m})$ at low strains $(\sim 2 \%)$ applied during the straightening.

In addition to the interaction between ferrite and precipitates at grain boundaries, which leads to grain boundary voiding, as discussed above, ferrite alone can have a detrimental effect on ductility as well. Assuming that there is a thin layer of ferrite between two adjacent austenite grains, as long as both materials behave elastically, a homogeneous stress-strain field has to be expected. After the stress state exceeds the yield limit of the ferrite phase, plasticity starts within the boundary layer and the stress distribution develops mostly in the ferrite. Due to the significant difference between the strengths of ferrite and austenite, all the plastic deformation is concentrated within the ferritic films leading to localized strains. It has been shown that, for a thin ferritic film, after the initiation of plastic flow, the strain concentration increases rapidly to reach a local strain, which exceeds several times the global strain, Figure $2.11 .^{[47]}$ As can be seen, it is only after the formation of $40 \%$ ferrite that the strain concentration is eliminated.

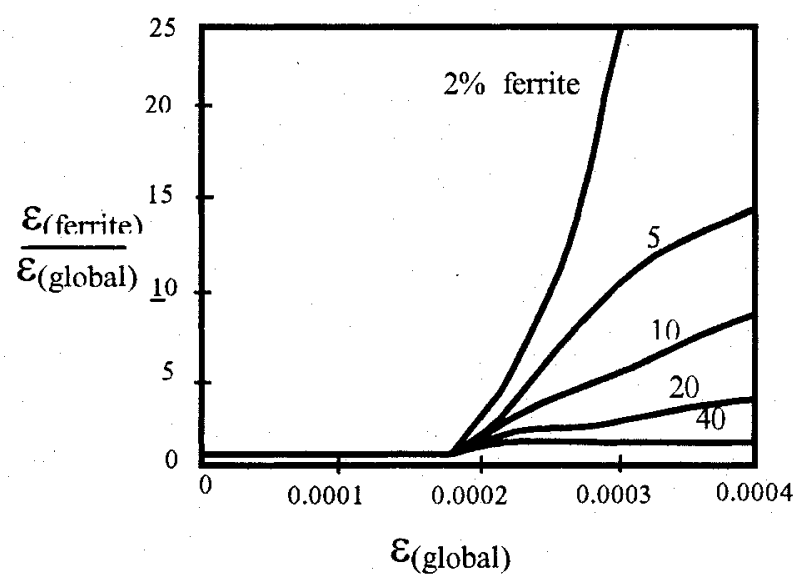

Figure 2.11. Effect of volume fraction of ferrite on strain concentration in ferrite. ${ }^{[47]}$ 
The study of strain rate effects in this respect has shown that higher strain rates correspond with reduced stress concentrations in the ferrite. This is simply because of the lower yield limit ratio between ferrite and austenite $\left(\sigma_{\mathrm{y}}(\right.$ Austenite $) / \sigma_{\mathrm{y}}($ Ferrite) $)$, Figure $2.12 \cdot{ }^{[47]}$ Using this concept, the impact of strain rate on the hot ductility of steel can be explained in an easy way; the higher the strain rate, the higher the ductility.

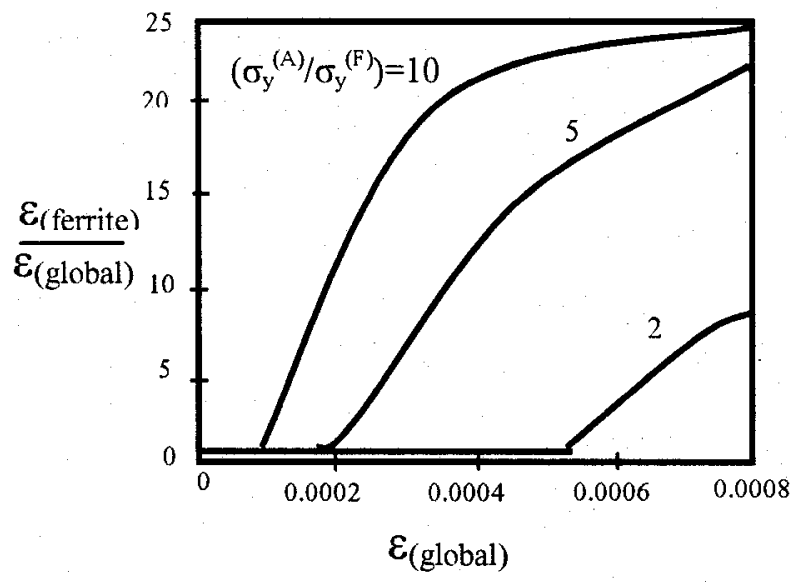

Figure 2.12. Effect of yield limit ratio (strain rate) on strain concentration in ferrite for $5 \%$ ferrite. $^{[47]}$

The left hand side of the hot ductility trough, adjacent to HDL region in Figure 2.8 is attributed to this mechanism of embrittlement. As can be understood, one of the essentials in avoiding embrittlement under this mechanism is to reduce the strain concentration at grain boundaries. This concept readily applies to the case of HDL region, which coincides with a relatively high volume fraction of ferrite. Here, the strain is no longer concentrated in a thin ferrite film at the austenite grain boundaries. Furthermore, the strength differential between austenite and ferrite decreases with decreasing temperature, thus increasing plastic strain in the austenite and, more importantly decreasing the strain in the ferrite. ${ }^{[48]}$ The concentration of strain at grain boundaries is thus minimized, and high ductilities are observed. Ferrite has a high stacking fault energy, and therefore dynamic recovery, which is a softening process and operates at all strains, readily takes place. ${ }^{[3]}$ Generally, the ductility is very good when high percentages of ferrite are present in the microstructure, in the vicinity of $700^{\circ} \mathrm{C} \cdot{ }^{[5,39,40]}$ At this temperature, recovery in the ferrite 
takes place with ease, the subgrain size is large, and the flow stress is low. Thus, ferrite flows readily at grain boundaries to relieve stress concentrations.

\subsubsection{Precipitate Free Zone}

The second embrittling mechanism liable to occur at high temperature region of the trough, the region adjacent to the HDH region in Figure 2.8, is formation of a soft region near grain boundaries. In $\mathrm{Nb}$-containing steels that have been solution treated before cooling to the test temperature, precipitation takes place during deformation in the austenite. The grain boundary precipitation, which usually occurs, is frequently accompanied by the formation of relatively weak precipitate free zones (PFZ) on both sides of the boundaries (500 nm wide) ${ }^{[49]}$ Fine precipitation can also take place in the matrix, leading to significant matrix strengthening. The situation is then similar to the soft films of ferrite, and microvoid coalescence fractures are frequently observed. In this case, however, void formation takes place at the microalloy precipitates $(\mathrm{Nb}(\mathrm{C}, \mathrm{N})$, and $\mathrm{AIN}$ when $\mathrm{Nb}$ and $\mathrm{Al}$ are present together), Figure 2.13. This fracture process is shown schematically in Figure 2.14. ${ }^{[3,50]}$

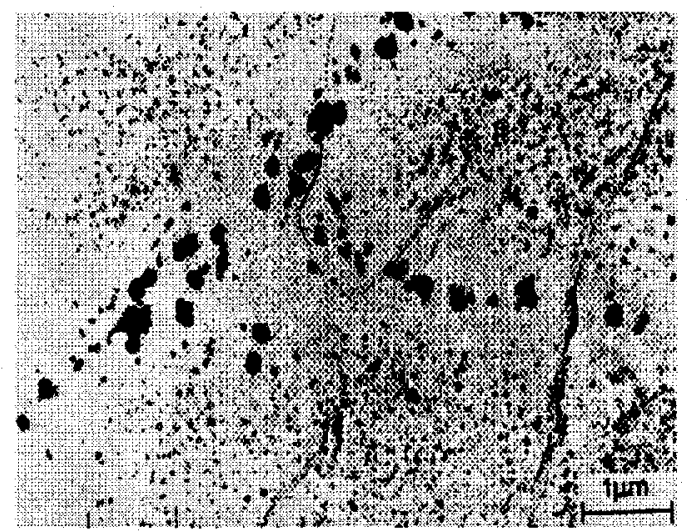

(a)

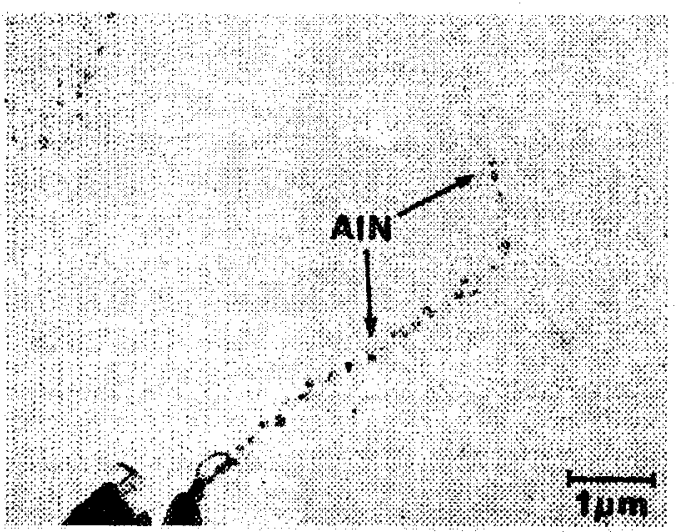

(b)

Figure 2.13. Precipitate free zone adjacent to austenite grain boundaries in (a) $\mathrm{Nb}^{[49]}$ and (b) $\mathrm{Al}^{[50]}$ containing steel fractured at $950^{\circ} \mathrm{C}$ and $900^{\circ} \mathrm{C}$, respectively. Grain boundaries contain fine precipitates of $\mathrm{NbCN}$ and $\mathrm{AlN}$, and coarse $\mathrm{MnS}$ inclusions. 

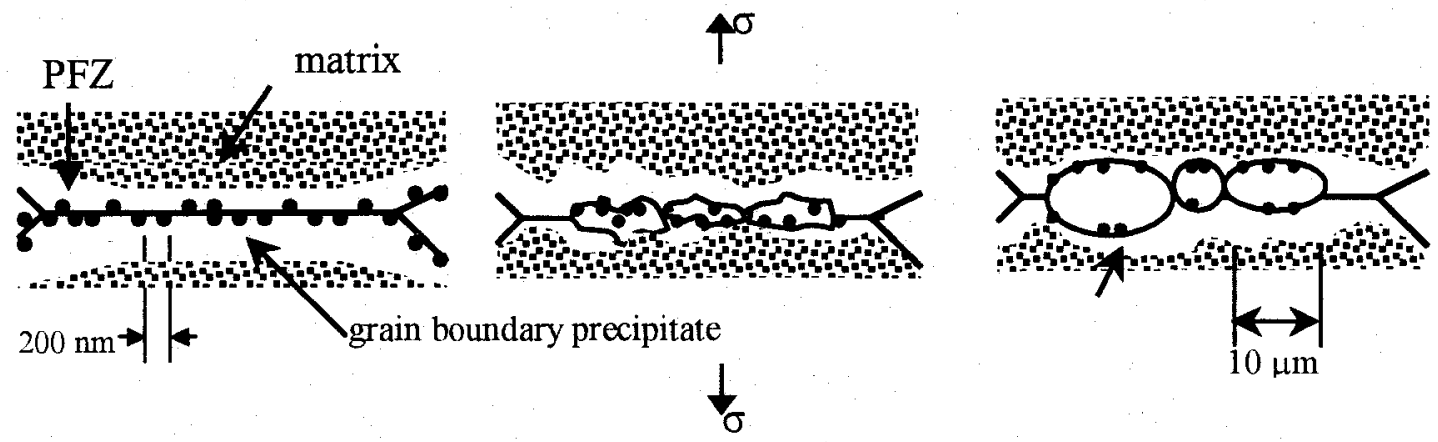

Figure 2.14. Schematic illustration of intergranular microvoid coalescence due to PFZ. ${ }^{[50]}$

It should be mentioned that, because the deformation is taking place in the single phase austenite region, grain boundary sliding (see section 2.4.3) is also likely to be instrumental in the embrittling process, most probably contributing to crack enlargement. ${ }^{[3]}$

On raising the temperature, the high ductility, high temperature (HDH) region is encountered. Continuing with the concept of a reduction in the strain concentration at grain boundaries, one obvious reason for this improvement in ductility is the eventual absence of the thin ferrite film. This, of course, is only effective in the austenite plus ferrite two-phase region, and does not affect the embrittlement due to PFZ regions in the single phase austenite. However, higher temperatures also lead to less precipitation in the matrix and at the grain boundaries, which offsets the PFZ embrittling mechanism. On the other hand, increased temperatures lead to lower flow stresses via increased dynamic recovery, which reduce the stress concentrations at the crack nucleation sites. ${ }^{[3]}$

\subsubsection{Grain Boundary Sliding}

Grain boundary sliding followed by cracking is seen in austenite rather than ferrite, because the former shows only limited dynamic recovery. This gives rise to high flow stresses and work hardening rates, preventing the accommodation, by lattice deformation, of the stresses built up at triple points or grain boundary particles, leading in this way to intergranular failure by the nucleation of grain boundary cracks. This rupture mechanism is usually associated with creep, the latter occurring at strain rates typically below $10^{-4} \mathrm{~s}^{-1}$. 
However, fractures characteristics of failure initiated by grain boundary sliding are frequently found at the strain rate generally used in hot ductility testing $\left(10^{-3} \mathrm{~s}^{-1}\right)^{[3,51]}$. Figure 2.15 shows a fracture surface occurred under the grain boundary sliding mechanism. ${ }^{[11]}$

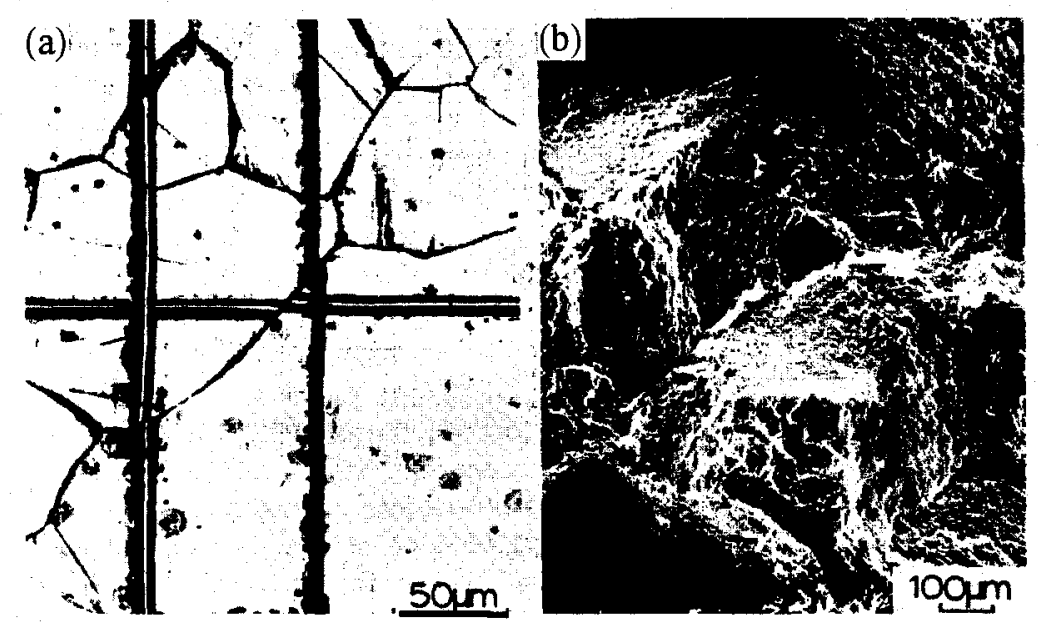

Figure 2.15. Grain boundary sliding (a) and fracture appearance (b) in austenitic alloy containing nickel. Pulled at $750^{\circ} \mathrm{C}$ and $\dot{\varepsilon}=5 \times 10^{-3} \mathrm{~s}^{-1}$. $\left.{ }^{[\mathrm{l}}\right]$

This mechanism of embrittlement is important substantially at high temperatures where other mechanisms, associated with precipitates and thin ferritic film, are not viable. Traditionally, grain boundary sliding, as correlated to creep, leads to nucleation of either 'grain edge' or $r$ type, or 'grain corner' or $w$ type cavities (cracks), both of which have been observed in specimens tested in tensile at strain rates in the range $10^{-3}-10^{-4} \mathrm{~s}^{-1}$, and both require grain boundary sliding for their nucleation. ${ }^{[3]}$

The $w$ type crack initiates at grain boundary triple point junction because the strain concentration can't be accommodated in the neighboring grains. In the case of $r$ type cracks, the ledges produced by the impingement of slip bands against the grain boundaries lead to the formation of cavities as grain boundary sliding proceeds. ${ }^{[4]}$

This model of ductility loss indicates that intergranular failure can take place without the presence of particles at the boundaries, even though particles expedite it. ${ }^{[3]}$ A mechanism to alleviate this problem which is not based on the concept of reducing the grain boundary 
strain concentration, requires the occurrence of grain boundary migration. ${ }^{[41,52]}$ In this case, cracks, which have already been initiated, are isolated from the prior grain boundaries, and high ductilities result because the growth and coalescence of these cracks is not readily achieved away from grain boundaries. This is evident from the large voids, characteristics of the fracture surfaces generated by testing in the high temperature-high ductility $(\mathrm{HDH})$ region, which apparently are not associated with second phase particles. ${ }^{[53,54]}$ These grow from the intergranular cracks which form during the early stages of deformation, and which become isolated within the grains as a result of grain boundary migration. The original cracks are then distorted into elongated voids, until final failure occurs by necking between these voids.

Nevertheless, although grain boundary migration can isolate cracks from grain boundaries, the cracks can also exert a grain boundary drag force and capture moving grain boundaries. Crack growth will then resume along the captured grain boundary by the applied tensile stress, until the boundary breaks away once more. If the capture frequency and/or the crack drag force are high, intergranular failure may ultimately occur, even if the prior grain boundaries had moved away from the initiated cracks at an earlier stage in the deformation. Thus, in order to offset embrittlement adequately, the driving force for grain boundary migration must be substantially higher than the drag force exerted by the cracks that are present. One way to achieve a high driving force for grain boundary migration is by dynamic recrystallization. ${ }^{[4,52]}$ The nucleation of dynamic recrystallization takes place at existing boundaries at low strain rates. ${ }^{[55]}$ Poorly developed subboundaries pin sections of the original boundaries, which bulge out and migrate relatively rapidly because of the strain energy difference across a given boundary. This is clearly a potent mechanism for bringing about grain boundary movement. ${ }^{[3]}$ It is not surprising, therefore, that the $\mathrm{HDH}$ region has been observed to coincide with the onset of dynamic recrystallization in many studies. ${ }^{[41,56,57]}$ However, there are numerous instances where dynamic recrystallization has been observed throughout all, or part of the region of embrittlement. ${ }^{[3,54,56]}$ Such results demonstrate that it is indeed grain boundary migration that is the important event, dynamic recrystallization being an effective means by which this can be achieved. 


\subsection{Influence of Microstructure on Hot Ductility}

\subsubsection{Grain Size}

Grain size is important with regard to its strong influence under creep conditions, which include the strain rate range used during straightening. However, it seems that it has not been paid as much attention as chemical composition. Some reports suggest that grain size refinement can be detrimental to the hot ductility. ${ }^{[3,58]}$ It was said that precipitation during prior processing of steel can refine the grain size which may favor intergranular fracture. However, extensive studies on both creep and ductility have generally shown that the high temperature ductility increases as the grain size is decreased. ${ }^{[33,59-64]}$. When the failure is intergranular, refining the grain size affects crack growth via;

1. the decrease in the crack aspect ratio, which controls stress concentration at the crack tip; this is lower in fine grained materials so that crack propagation is discouraged in this way. ${ }^{[62]}$

2. the difficulty in propagating the smaller cracks formed by sliding through triple points. $^{[62]}$

3. the increase in the specific grain boundary area (for a given volume fraction of precipitate), which reduces the precipitate density on the grain boundaries..$^{[5]}$

4. the reduction in the critical strain for dynamic recrystallization by increasing the number of grain boundary nucleation sites, thereby increasing the possibility of ductility improvement via grain boundary migration..$^{[3]}$

It has been shown that refining the grain size leads to reductions both in the depth and width of the trough, Figure 2.16, due in part to the form and distribution of the grain boundary ferrite, Figure 2.17. ${ }^{[65]}$ The ratio of surface area to volume of grain is high in fine grained austenite, so reducing local deformation at the boundaries. Therefore, the ferrite films are discontinuous and do not allow easy crack linkage, or nucleation sites are so numerous that deformation has little influence in providing extra sites. On the contrary, 


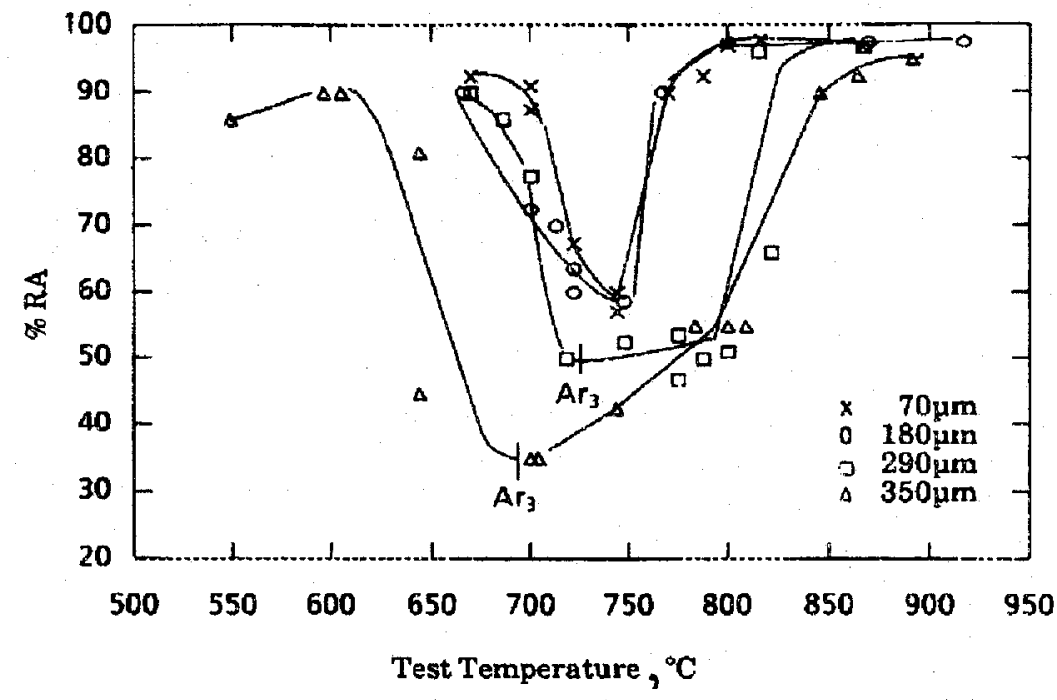

Figure 2.16. Hot ductility curves for the $0.19 \mathrm{wt} \% \mathrm{C}$ steel at various grain size. ${ }^{[65]}$

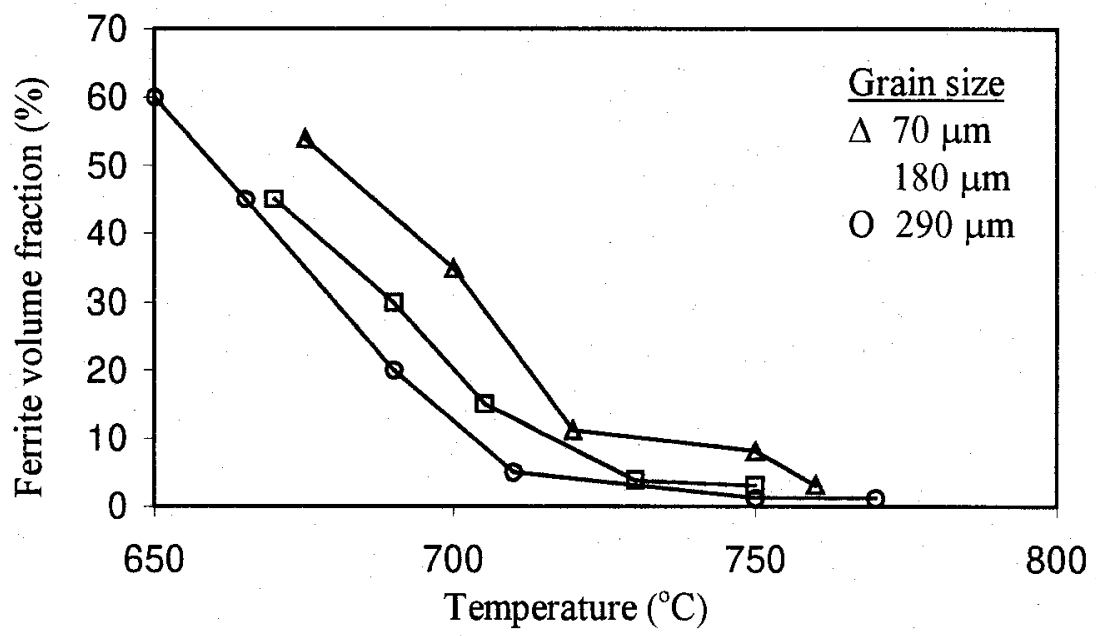

Figure 2.17. Volume fraction of ferrite as a function of temperature for $0.19 \mathrm{wt} \% \mathrm{C}$ steel at various grain size. ${ }^{[65]}$

the ferrite formed in coarse grained austenite tends to grow along austenite boundaries, and as a consequence, only a very small amount is required to produce a continuous network. Also, for fine grained steels, ferrite was observed to form, less detrimentally, as equiaxed, unconnected grains. ${ }^{[65]}$ Nevertheless, Cardoso and Yue ${ }^{[40]}$ have shown that, even in fine grained steels, deformation induced ferrite forms as thin, continuous films. It is possible that this had not been observed previously because of the much faster austenite 
to ferrite transformation rate resulting from the fine austenite grain size. In view of this, perhaps a more relevant factor controlling ductility in a finer grained structure is the increased volume fraction of the total ferrite that is produced at a given temperature. The narrow trough in a fine grained steel is then a consequence of the rapid increase in volume fraction of the ferrite which forms when the temperature is lowered to below the $\mathrm{Ae}_{3}{ }^{[3]}$

Microalloyed steels generally show little indication, from hot tensile tests, that grain size has a significant influence on their hot ductilities, because of the overriding effect of the precipitation of $\mathrm{AlN}$ or $\mathrm{Nb}(\mathrm{C}, \mathrm{N})$ at austenite boundaries. ${ }^{[3]}$ Where an attempt has been made to keep the precipitate distribution constant, the changes in hot ductility with grain size were similar to those observed in plain C-Mn steels. ${ }^{[66]}$

\subsubsection{Precipitates}

The role of precipitates has already been pointed out. Fine precipitates pin grain boundaries, allowing the cracks to join up. In addition, both precipitates and inclusions cause void formation. ${ }^{[50]}$ Microvoid coalescence failures are thus encouraged by an increase in the precipitate or inclusion density at the boundaries, these being preferential sites for void initiation.

It is generally accepted that it is the precipitation at the austenite grain boundaries that has the greatest influence in low ductility in microalloyed steels. ${ }^{[57]}$ This is seen more clearly in Figure 2.18, where the influence of the $\mathrm{Nb}(\mathrm{C}, \mathrm{N})$ precipitates at the austenite grain boundaries (particle size and interparticle spacing) on the hot ductility of C-Mn- $\mathrm{Nb}-\mathrm{Al}$ steels is shown, for the rare instance where all the other variables have been kept reasonably constant. ${ }^{[3]}$ Also included in this figure are the results from a commercial examination into the precipitate distributions at the austenite grain boundaries taken close to the surface of continuously cast slabs. Casts without cracks had mean particle sizes and interparticle spacings along the boundary of $\geq 40$ and $\geq 140 \mathrm{~nm}$, respectively. Rejected 


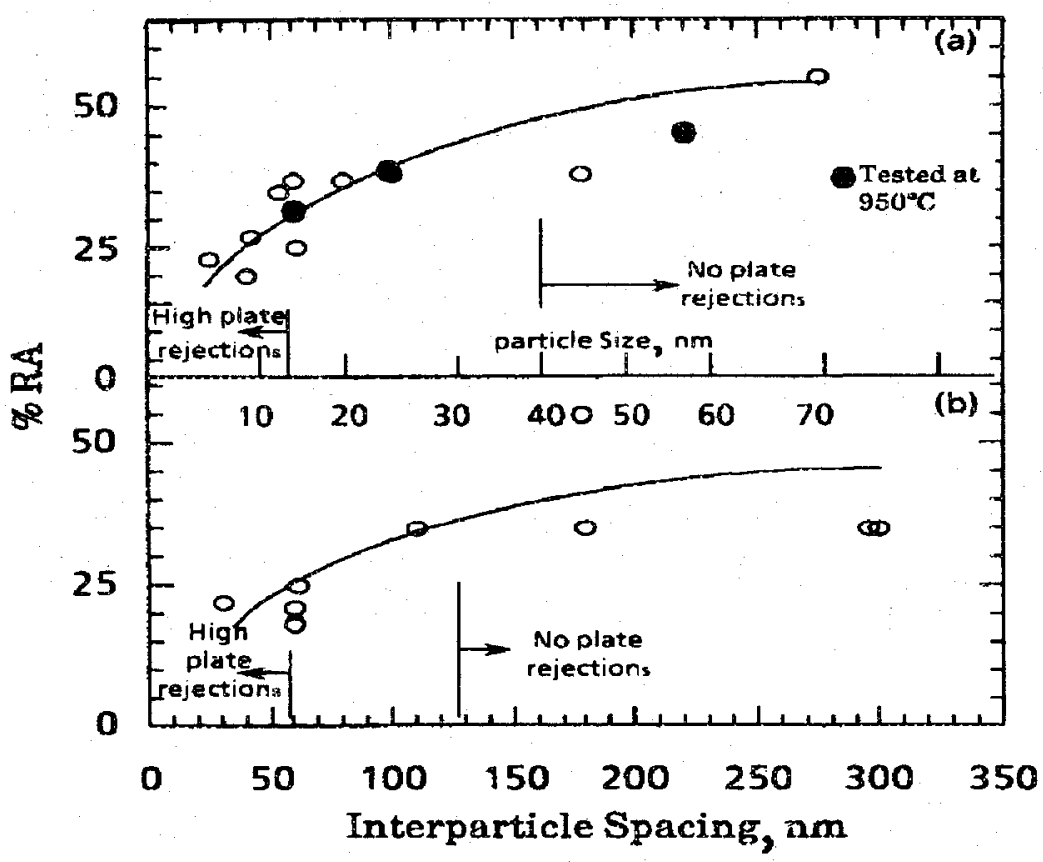

Figure 2.18. Influence of (a) particle size and (b) interparticle spacing on hot ductility of $\mathrm{Nb}$-containing steels, solution treated at $1330^{\circ} \mathrm{C}$, cooled to test temperature of $850^{\circ} \mathrm{C}$, and fractured at strain rate of $3 \times 10^{-3} \mathrm{~s}^{-1}{ }^{[3]}$

slabs had mean particle sizes and interparticle spacings of $\leq 14$ and $\leq 60 \mathrm{~nm}$, respectively. These values also indicate that transverse cracks can be avoided when the RA values $\geq 40 \%$. This clearly shows that the effect of precipitates on hot ductility depends strongly on their size and distribution. These characteristics are, in turn, controlled by composition and the thermomechanical details of the test.

It is well known that the precipitation of $\mathrm{AIN}, \mathrm{Nb}(\mathrm{C}, \mathrm{N})$ and $\mathrm{V}(\mathrm{C}, \mathrm{N})$ is accelerated by deformation compared with the rates measured in undeformed structures at the same temperature. ${ }^{[24,67-70]}$ This acceleration is mainly resulted from the introduction of favorable nucleation sites, such as dislocation networks and vacancy clusters, by the deformation process. ${ }^{[3]}$ The observation of $\mathrm{NbC}$ precipitated on dislocations following high temperature deformation in austenite supports this view. ${ }^{[50,71-73]}$

Precipitate size distributions are influenced by whether the precipitates are formed statically before testing, statically after testing, or dynamically during deformation. Slow 
cooling or heating to the test temperature, as in normalizing and holding, favors static precipitation; such particles are generally coarser than their strain induced or dynamically precipitated counterparts. ${ }^{[6,70,73]}$ Dynamic precipitation does not occur at very high testing strain rates, since deformation ceases before the incubation time for dynamic precipitation has been reached. ${ }^{[3]}$ However, static precipitation can occur subsequently in the deformed structure at rates much faster than that of static precipitation in undeformed metal, and close to those associated with dynamic precipitation. ${ }^{[68]}$

Both $\mathrm{Nb}(\mathrm{C}, \mathrm{N})$ and $\mathrm{VN}$ can precipitate rapidly during deformation at strain rates $<10^{-1}$ $\mathrm{s}^{-1},{ }^{[67,74]}$ and hence can have a very important influence on the hot ductility and transverse cracking. For steels which are solution treated and cooled to the test temperature, $\mathrm{Nb}$ is more effective in extending the ductility trough to higher temperatures (i.e. reducing the ductility) than $\mathrm{V} .^{[3]}$ This is probably because, for typical microalloy compositions, the nose temperature for $\mathrm{Nb}(\mathrm{C}, \mathrm{N})$ precipitation is at $950^{\circ} \mathrm{C},{ }^{[74]}$ whereas it is about $885^{\circ} \mathrm{C}$ for $\mathrm{VN}^{\left[{ }^{[67]}\right.}$ Furthermore, it was shown that the presence of $\mathrm{V}$ in a Nb-containing steel led to coarser and less extensive precipitation and improved the hot ductility in the temperature range $850-900^{\circ} \mathrm{C}^{[24]}$ As well, $\mathrm{V}$ precipitates randomly throughout the matrix, whereas $\mathrm{Nb}(\mathrm{C}, \mathrm{N})$ is found both at the boundaries and within the matrix. ${ }^{[53]}$ As for AIN, its formation is very slow. In fact, it has been shown that, unless the solubility product is very high, cooling from the solution temperature under continuous casting conditions (60 $\mathrm{K} \min ^{-1}$ ) will not cause the precipitation of AIN during testing, either statically or dynamically. ${ }^{[57]}$ Nonetheless, the temperature cycling that occurs during the cooling of continuously cast strands can accentuate AlN production. ${ }^{[40,56,75,76]}$ This can be very detrimental to the ductility, particularly since AIN precipitates mainly at the austenite grain boundaries. ${ }^{[57,75,76]}$

Studies of the effect of static and dynamic precipitation have led to the conclusion that, for $\mathrm{V}$ and Al-containing steels, the precipitates present before deformation are more detrimental than those formed during deformation. ${ }^{[3,57]}$ In this case, the static precipitations are more effective than the dynamic ones in reducing the hot ductility, even though they are coarser, ${ }^{[57]}$ because they are formed only at the boundaries, Figure 2.19. 
Generally, vanadium and Al-containing steels have better hot ductility than $\mathrm{Nb}$ microalloyed steels because, in the former two steels, prior precipitation when present is coarser and, in the case of vanadium, more random. ${ }^{[53]}$

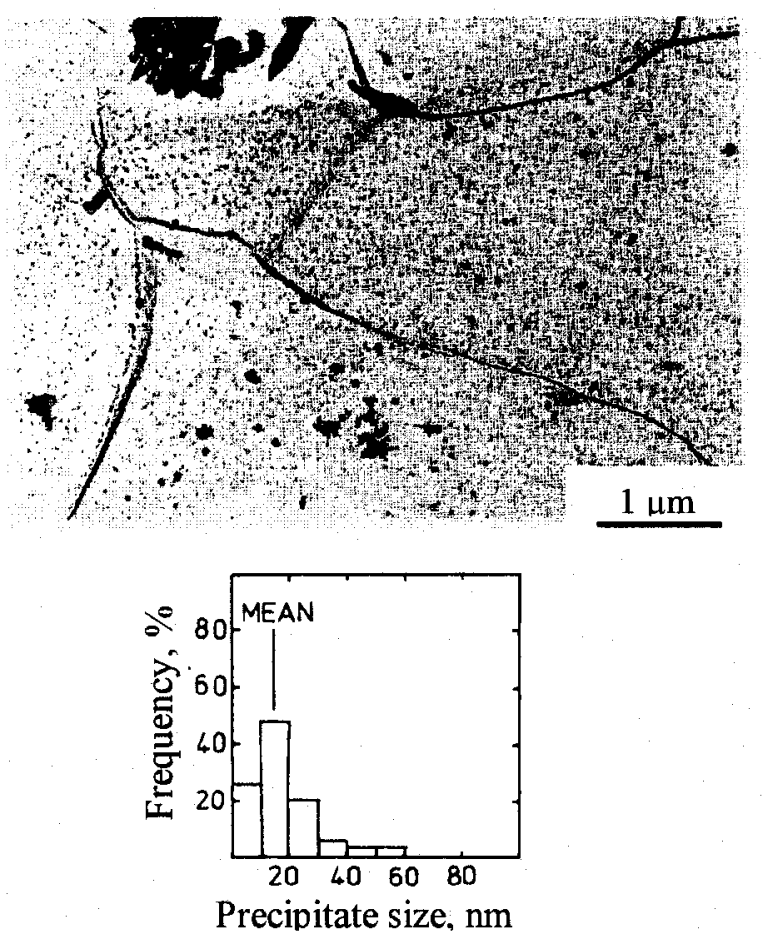

(a)
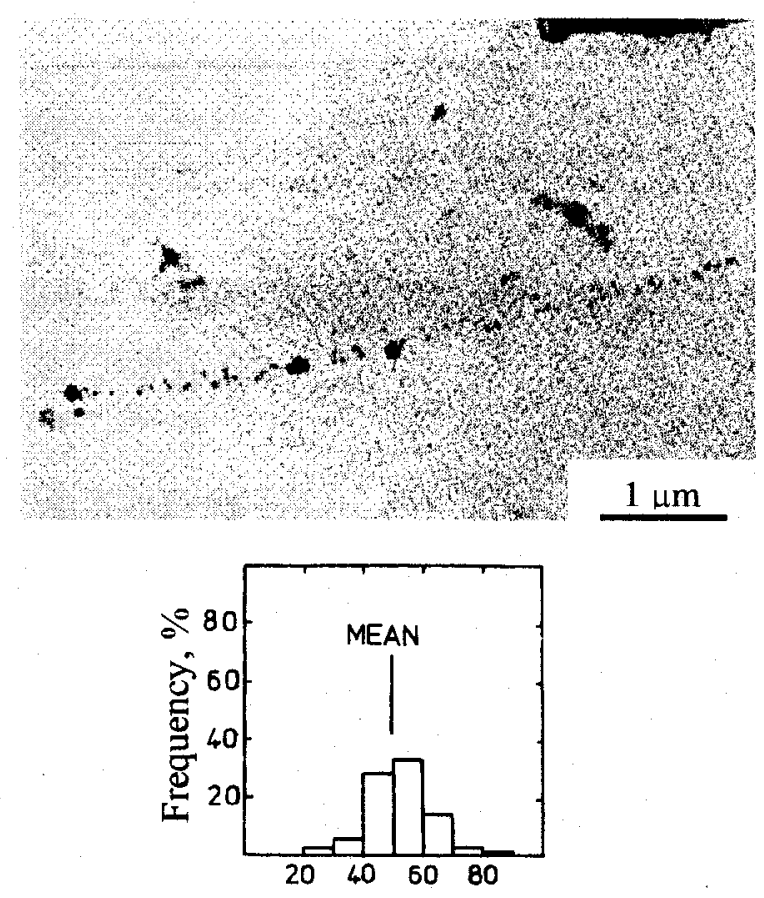

Precipitate size, $\mathrm{nm}$

(b)

Figure 2.19. Microstructures and corresponding $V(C, N)$ precipitate size distributions in $C$ $\mathrm{Mn}-\mathrm{V}-\mathrm{Al}$ steel, solution treated at $1330^{\circ} \mathrm{C}$, cooled to $850^{\circ} \mathrm{C}$, and held for (a) $1 \mathrm{~s}$ and (b) $6 \mathrm{~h}$ before testing. ${ }^{[57]}$

On the contrary, dynamic precipitation has been shown to be more effective in reducing the hot ductility in Nb-containing steels. ${ }^{[3,36]}$ This is partly because dynamic precipitation is much more extensive in Nb-containing steels. ${ }^{[57,70]}$ It also occurs in a finer form, both at the austenite grain boundaries and within the matrix, as long as the $\mathrm{Nb}(\mathrm{C}, \mathrm{N})$ is taken into solution before deformation, Figure $2.20 .^{[3,68,70]}$ The highest ductilities are displayed by these steels when the precipitates are present before deformation in a coarse form and randomly precipitated throughout the structure. ${ }^{[53]}$ This can occur by reheating $\mathrm{Nb}-$ containing steels below the $\mathrm{Nb}(\mathrm{C}, \mathrm{N})$ solution temperature (typically about $1100^{\circ} \mathrm{C}$ ), 
which coarsens the precipitates without taking any significant volume fraction back into solution.

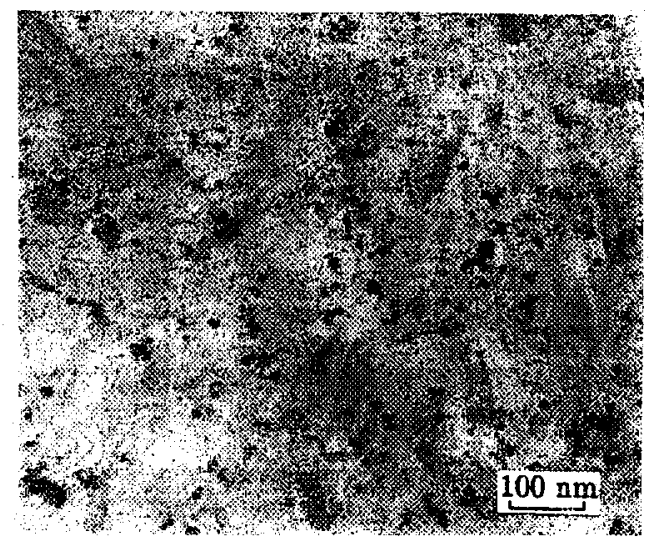

Figure 2.20. TEM micrograph of extraction replica from a steel containing $0.78 \mathrm{wt} \% \mathrm{Nb}$ deformed at $850^{\circ} \mathrm{C}$ and at $10^{-3} \mathrm{~s}^{-1}$ showing fine $\mathrm{Nb}(\mathrm{C}, \mathrm{N})$ precipitates within a grain. ${ }^{[70]}$

Finally, the effect of $\mathrm{Nb}(\mathrm{C}, \mathrm{N})$ on the hot ductility can also depend on the chemical composition of the precipitates. ${ }^{[5]}$ At a constant $\mathrm{Nb}$ level $(0.015 \mathrm{wt} \%)$, it has been found that an increase in the $\mathrm{N}$ concentration from 0.002 to $0.006 \mathrm{wt} \%$ markedly reduces the plasticity. Low $\mathrm{N}$ levels promotes the formation of $\mathrm{NbC}_{0.85}$ particles, whereas high $\mathrm{N}$ concentration lead to the precipitation of $\mathrm{NbC}_{0.6} \mathrm{~N}_{0.25}$. The higher ductilities associated with the former precipitate have been ascribed to its lower rate of precipitation in austenite.

\subsection{Influence of Composition on Hot Ductility}

Chemical composition has obviously a very marked influence on mechanical properties including the hot ductility. Since this parameter is the easiest one to adjust in steel making, most of the effort has been concentrated in this area leading to valuable results and reviews, notably by Thomas et al. ${ }^{[77]}$ and Mintz. ${ }^{[9]}$ 
In this section, the effect of alloying and some residual elements, with regard to the hot ductility, is briefly reviewed. But, before that, the relevance of tensile testing to the problem of hot ductility is discussed.

\subsubsection{Relevance of Experiment Method to Hot Ductility Evaluation}

In the evaluation of hot ductility in the laboratory, testing conditions have been made as simple as possible, incorporating only the most important casting parameters, metallurgically speaking. Based on this concept, the usual approach is to heat the specimen to the solution temperature, $\sim 1350^{\circ} \mathrm{C}$, to dissolve all microalloying and refining additions and to produce a coarse grain size reminiscent of the as cast structure. The strain rate is chosen to be the same as that used during the straightening operation, $10^{-3}$ to $10^{-4}$ $\mathrm{s}^{-1}$. The cooling rate to the tensile test temperature is also chosen to correspond to the average cooling rate, close to the surface of the strand, $\sim 60 \mathrm{Kmin}^{-1}$ for conventional continuous casting of $250 \mathrm{~mm} \mathrm{slab}^{[78]}$ and $\sim 200 \mathrm{Kmin}^{-1}$ for thin slab casting, $50 \mathrm{~mm}$ thick $\operatorname{slab}^{[79]}$.

At best, this simple test gives a semi-quantitative assessment of a steel likelihood to loss of the hot ductility. At worst, it can lead to quite erroneous predictions. Thus, it readily shows the deleterious effect of $\mathrm{Nb}$ and $\mathrm{Nb}$ and $\mathrm{Al}$ in combination, on the hot ductility, which correlates to severe transverse cracking found whenever these steels with these elements are continuously cast, Figures 2.21 and 2.22, respectively. ${ }^{[5,9,70,78]}$ Nevertheless, the effect of $\mathrm{S}$ can not be studied by this simple method and it would lead to the false conclusion that the level of $\mathrm{S}$ has no effect on the hot ductility, Figure $2.23 .^{[49,80]}$ The simple tensile test, however, can be modified to more sophisticated testing and tensile specimen can be cast in situ. This allows $\mathrm{S}$ to segregate to the interdendritic regions and precipitate out more normally and its true adverse influence be determined (Figure 2.23(b)).

Generally, with regard to microalloying additions $\mathrm{Nb}, \mathrm{V}$, and $\mathrm{Al}$, solution treatment (i.e. 


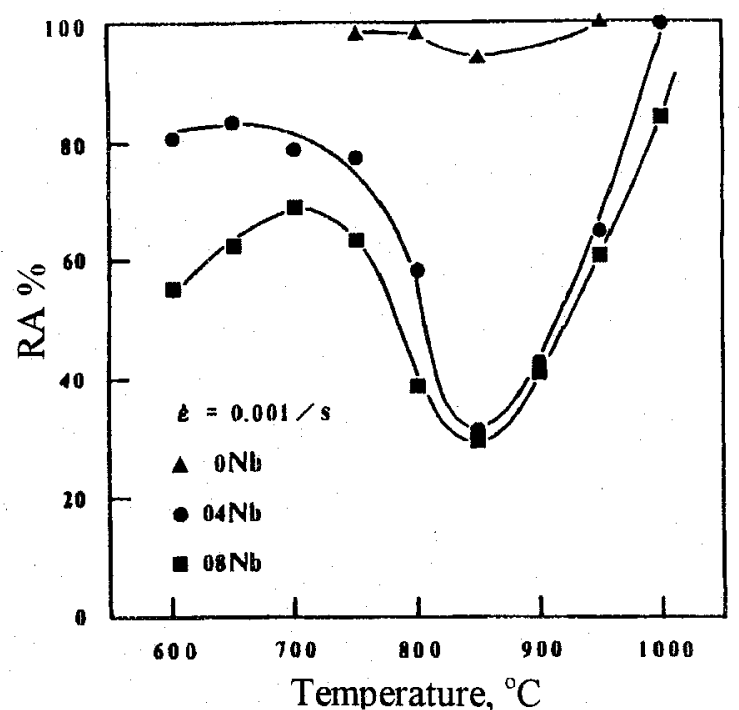

Figure 2.21. Hot ductility of steels containing different amounts of $\mathrm{Nb} .^{[70]}$

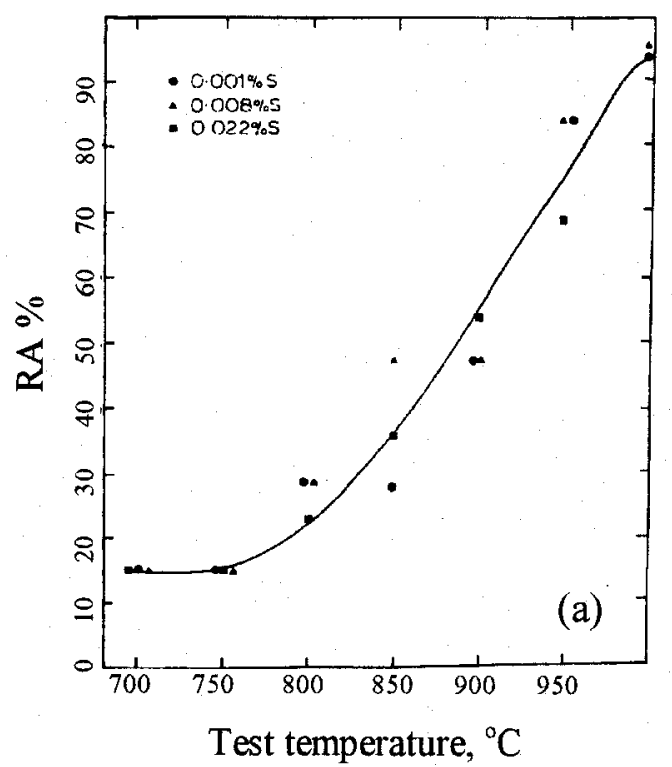

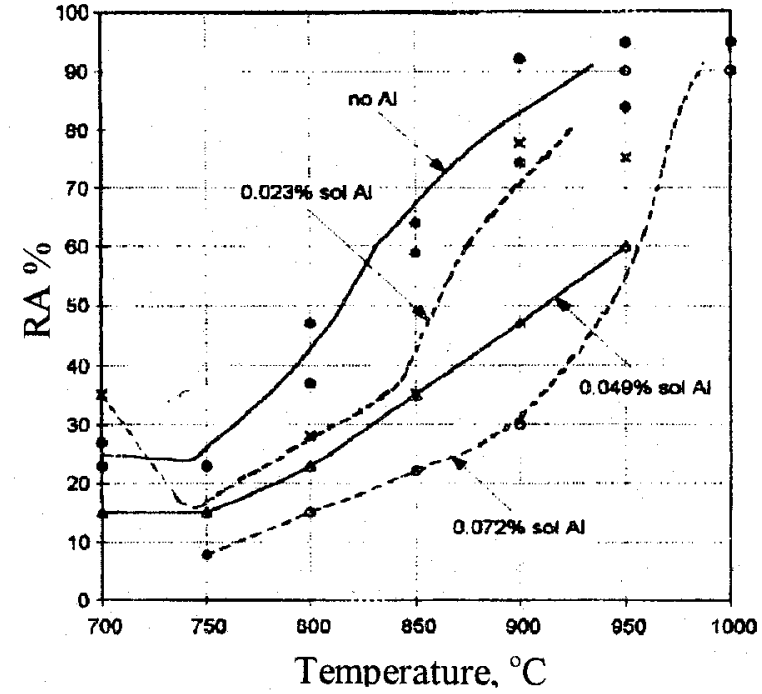

Figure 2.22. Influence of soluble $\mathrm{Al}$ on the hot ductility of $\mathrm{Nb}$ containing steels $(0.03 \%$ $\mathrm{Nb}) \cdot{ }^{[78]}$

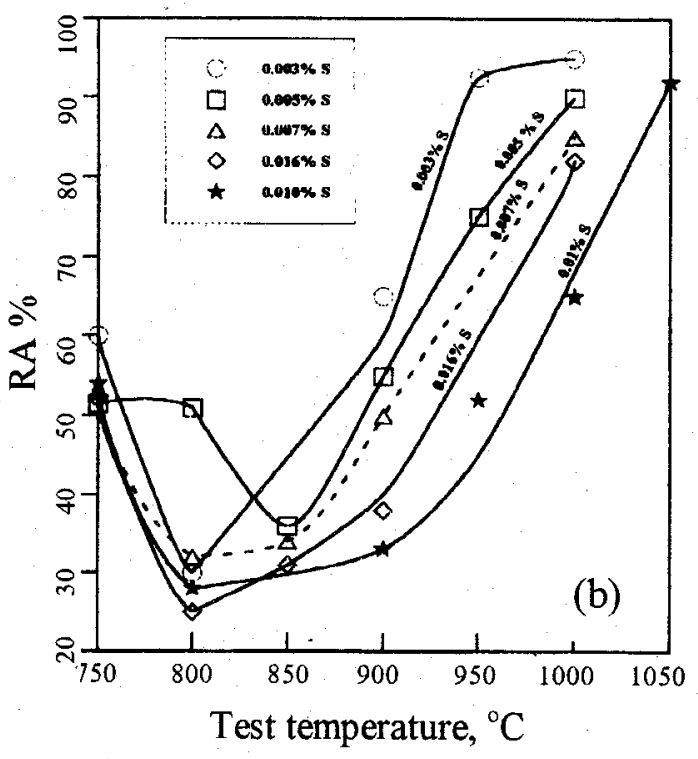

Figure 2.23. The effect of sulphur content on the hot ductility of (a) reheated ${ }^{[49]}$ and (b) as cast $^{[80]} \mathrm{C}-\mathrm{Mn}-\mathrm{Nb}-\mathrm{Al}$ steels.

heating the steel to $\sim 1350^{\circ} \mathrm{C}$ ), prior to the tensile test, has been found adequate to assess likelihood of a steel to exhibit a transverse cracking problem. ${ }^{[80]}$ On the contrary, for Ti and $\mathrm{S}$, the tensile specimens must be tested directly after in situ melting and solidification 
to ensure dissolution of the TiN particles and MnS inclusions. ${ }^{[49,80-82]}$ Provided these precautions are taken, precipitate size and distribution in the tensile specimens follows closely that found near the surface of the continuously cast slabs. ${ }^{[9,78]}$

However, even in situ casting of the tensile specimens is not ideal, as small castings in general produce neither the exact segregation patterns experienced near the surface of conventionally cast strand nor the columnar grain structure that is often present and which may be directly responsible for the ease of crack propagation during straightening. ${ }^{[3,9]}$

In the continuous casting process, cooling just below the surface of the strand is very rapid at first and reaches a minimum temperature and then rises again. The subsurface temperature prior to straightening then cycles; the temperature falling as the sprays impinge on the strand and then rises as the strand moves through the guide rolls. This oscillation of temperature has been shown to have a significant influence on the precipitation, encouraging precipitation to occur. ${ }^{[83,84]}$ It has been also proved that this oscillation affects the hot ductility significantly. ${ }^{[11,85]}$ The hot ductility deterioration because of the temperature oscillation is particularly marked in $\mathrm{Nb}$-containing steels, Figure 2.24. ${ }^{[84]}$

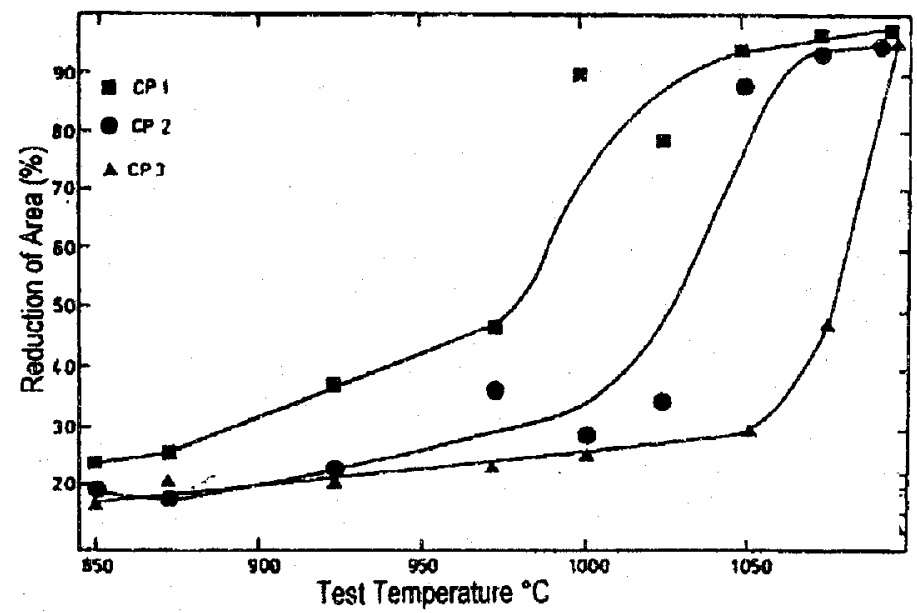

Figure 2.24. Influence of temperature oscillation on the hot ductility of a C-Mn-Nb-Al steel. (CP1 refers to normal cooling to the test temperature at $60^{\circ} \mathrm{Cmin}^{-1}, \mathrm{CP} 2$ and $\mathrm{CP} 3$ incorporated a number of temperature oscillations of amplitude \pm 50 and $\pm 100^{\circ} \mathrm{C}$, respectively). ${ }^{[84]}$ 
Although temperature cycling has a critical effect on C-Mn-Al steels, i.e. widening and deepening the trough, this may not be true for $\mathrm{Ti}$ treated $\mathrm{C}-\mathrm{Mn}-\mathrm{Al}$ steels where the $\mathrm{Ti}$ is able to remove the $\mathrm{N}$ as TiN and thus prevent any further precipitation from occurring during cycling, Figure 2.25. ${ }^{[9]}$
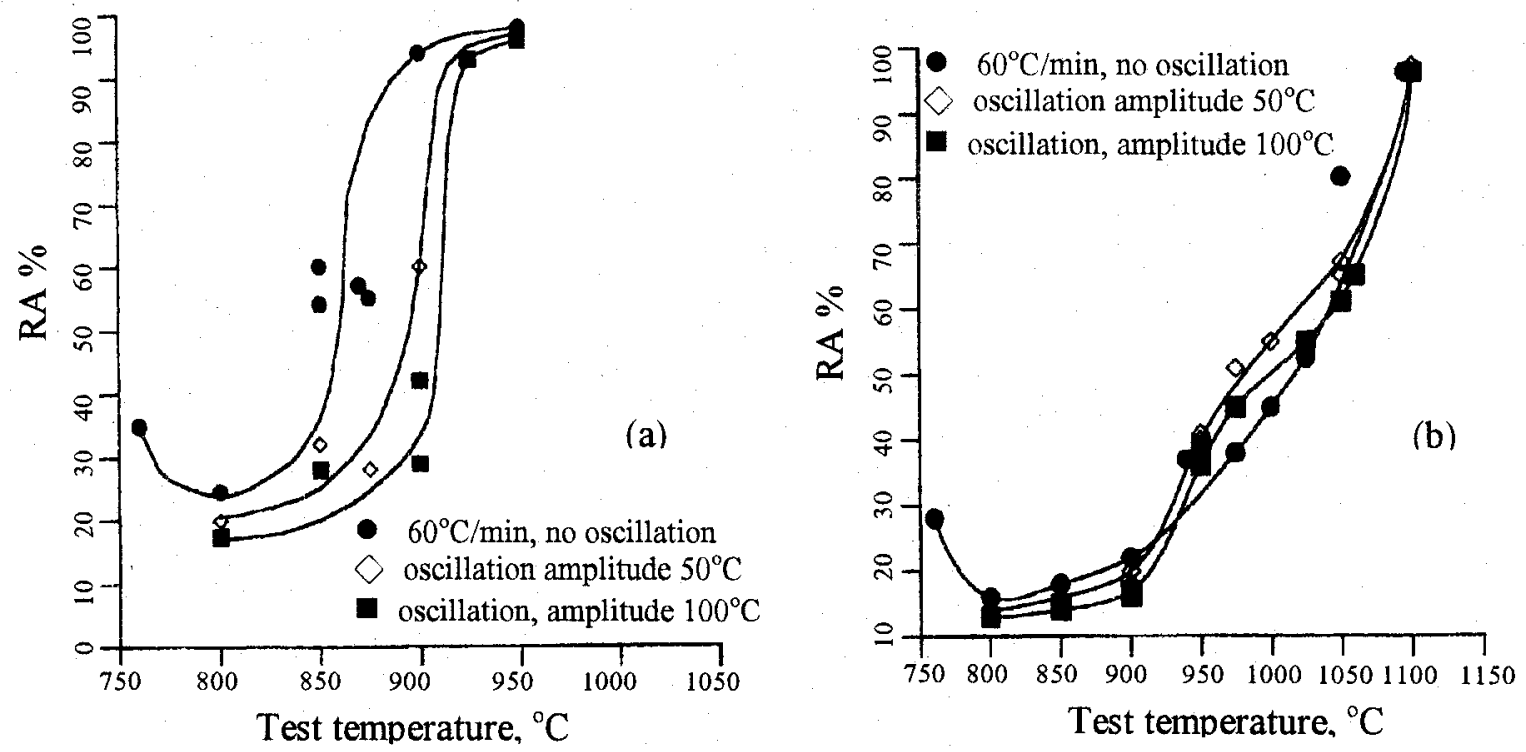

Figure 2.25. Hot ductility curves for (a) as cast $\mathrm{C}-\mathrm{Mn}-\mathrm{Al}$ and (b) as cast $\mathrm{C}-\mathrm{Mn}-\mathrm{Al}$ with a $\mathrm{Ti}$ addition. ${ }^{[9]}$

All these show that the ductility behavior under conditions, which are closer to the commercial practice, can be very different to that given by the simple hot ductility test. The condition becomes even more difficult when it comes to the peritectic steel, where there is sudden shrinkage due to the peritectic reaction.

\subsubsection{Influence of Residual and Alloying Elements}

Residuals are metallic elements that remain in steel in small quantities after refining is completed and which are not deliberately added. These elements are always present to some degree. Some elements, like copper and tin remain because they cannot be preferentially oxidized when normal steel making methods are used. ${ }^{[9]}$ 
A potential problem caused by copper and other residual elements is cracking during continuous casting, which may on occasions be related to the more classical hot shortness phenomenon. Hot shortness results directly from the fact that residual elements more noble than iron, such as copper, tin, nickel, arsenic and antimony, are not oxidized when steel is reheated. Consequently, as iron is removed preferentially from the surface layers, these residual elements build up progressively in the subscale layer ${ }^{[9]}$ Melford ${ }^{[86]}$ has proposed that in order to prevent hot shortness

$$
\mathrm{Cu}+6(\mathrm{Sn}+\mathrm{Sb})<\mathrm{k}
$$

where $\mathrm{k}$ depends on the degree of enrichment which in turn depends on the furnace atmosphere, time in furnace and temperature.

Among these harmful elements, $\mathrm{Cu}$ is the major cause of hot shortness since it can enrich to a level exceeding its solubility limit in austenite (9\%) and such an enrichment is possible under conditions of severe oxidation. At reheating temperatures in the range $1100-1200^{\circ} \mathrm{C}$, the $\mathrm{Cu}$ rich phase that precipitates is molten (melting point of copper is $1080^{\circ} \mathrm{C}$ ) and tends to penetrate the austenite grain boundary leading to surface cracks during subsequent rolling operations. ${ }^{[86]}$ On the contrary, Ni has been shown to have a beneficial effect, since it stabilizes austenite and it increases the solubility of $\mathrm{Cu}$, preventing the precipitation of $\mathrm{Cu}$. Fisher ${ }^{[87]}$ studied the effect of $\mathrm{Ni}$ additions on the prevention of the molten $\mathrm{Cu}$ rich phase and showed that the $\mathrm{Ni}: \mathrm{Cu}$ ratio must be in the range 1.5 to 2 to increase the solubility of $\mathrm{Cu}$ in austenite so that hot shortness is avoided.

It must be noted that the detrimental effect of $\mathrm{Cu}$ depends on its amount in steel. Hannerz ${ }^{[88]}$ has shown no influence of $\mathrm{Cu}$ on the incidence of slab defects, studying 0.007 $w t \% \mathrm{Cu}$ in steel. But, in other reports where residual $\mathrm{Cu}$ levels were higher, $\mathrm{Cu}$ was always a problem to surface quality. ${ }^{[89,90]}$ The residual $\mathrm{Cu}$ level in steels studied in these investigations was in the range 0.10 to $0.35 \mathrm{wt} \%$. Sn enrichment can be particularly serious since it reduces the solubility of $\mathrm{Cu}$ in austenite. ${ }^{[86]}$ Analysis of work at British Steel indicates that plate steels containing $\mathrm{Nb}$ with additions of $0.25 \% \mathrm{Cu}$ and $0.25 \% \mathrm{Ni}$ have a greater incidence of transverse cracking compared with similar grades without $\mathrm{Cu}$ 
and $\mathrm{Ni}$ additions. ${ }^{[9]}$ It should also be pointed out that intergranular cracks in continuously cast products have been associated with $\mathrm{Cu}$ pick up in the mould. ${ }^{[89,91]}$

With regard to the hot ductility, the effect of $\mathrm{Cu}$ has not been studied extensively in the temperature range 700 to $1100^{\circ} \mathrm{C} .{ }^{[2,9,88,92]}$ Hannerz ${ }^{[88]}$ could find no significant effect of copper levels up to $1 \%$ at temperatures above $700^{\circ} \mathrm{C}$, in plain $\mathrm{C}-\mathrm{Mn}$ steel reheated to $1350^{\circ} \mathrm{C}$ and cooled at $60^{\circ} \mathrm{Cmin}^{-1}$ to the test temperature in an argon atmosphere. Below $700^{\circ} \mathrm{C}$, ductility was impaired, possibly due to copper precipitation from $1 \% \mathrm{Cu}$ solution.

Nachtrab and $\mathrm{Chou}^{[2]}$ have proposed that impurity segregation to boundaries can encourage intergranular failure. Using Auger electron microscopy, they revealed S, Mn, and $\mathrm{N}$ segregation at austenite grain boundaries. However, no correlation could be established between these segregations and the ductility loss since the steel with the highest grain boundary concentration of $\mathrm{Mn}$ and $\mathrm{S}$ exhibited only a minor ductility loss. It was also found that the ductility troughs were mainly related to the microalloying precipitation, with possibly some correlation with the segregation of $\mathrm{Cu}, \mathrm{Sn}$ and $\mathrm{Sb}$ to the austenite grain boundaries. This type of segregation was found to occur during deformation. They showed that steels with $\sim 0.2 \mathrm{wt} \% \mathrm{Cu}$ gave a grain boundary segregation of $4 \%$ for $\mathrm{Cu}$. The tensile tests were carried out in vacuum so it is not surprising that the detrimental effect of $\mathrm{Cu}$ on the hot ductility could not be positively confirmed.

Mintz et al. ${ }^{[92]}$ have performed some experiments on the effect of test conditions on the hot ductility with regard to copper and nickel. No effect of $\mathrm{Cu}$ or $\mathrm{Ni}$ was found on the hot ductility when the steels were solution treated at $1330^{\circ} \mathrm{C}$ and cooled to the test temperature, regardless as to whether a protective or oxidizing atmosphere was used. Tensile specimens cast directly after melting and tested under an argon atmosphere were again found not to be influenced by compositional changes. Only when the tensile specimens were cast and allowed to cool in air was the deleterious effect of copper on the hot ductility obtained and this could be prevented by a similar addition of nickel. 
Mintz et al. ${ }^{[92]}$ did not find any evidence for $\mathrm{Cu}$ rich films penetrating along the austenite grain boundaries, ruling out conventional hot shortness as the cause for ductility loss. They explained that the deterioration could be due to fine copper sulphides (or oxysulphides) particles they observed at the boundaries. The need to have cast conditions, in order to produce these sulphides, probably arises because an increased segregation of $\mathrm{Cu}$ is required for the sulphide formation. It was also suggested that, $\mathrm{Ni}$, by increasing the solubility of $\mathrm{Cu}$ in iron, might be responsible for a reduced driving force for $\mathrm{Cu}$ precipitation.

As for tin, it has been shown that addition of $0.1 \mathrm{wt} \% \mathrm{Sn}$ seriously impairs the hot ductility of C-Mn steel. ${ }^{[9]}$ Antimony is likely to be nearly as detrimental as $\mathrm{Sn}^{[93]}$ since it reduces the solubility of $\mathrm{Cu}$ in austenite in a similar manner. ${ }^{[86]}$

There is some evidence showing that phosphorous improves the ductility of the continuously cast strand at temperatures between $700-1200^{\circ} \mathrm{C}$, provided the carbon content is less than $0.25 \mathrm{wt} \% .^{[51,78,88]} \mathrm{Mint}^{[9]}$ has also found that phosphorous up to $0.02 \%$ is beneficial for $\mathrm{C}-\mathrm{Mn}-\mathrm{Nb}-\mathrm{Al}$ steels, possibly because, although $\mathrm{P}$ is normally regarded as detrimental, it segregates to boundaries and vacant sites, preventing the precipitation of the more detrimental fine $\mathrm{Nb}(\mathrm{CN})$ precipitate from taking place. Both industrial data and laboratory work have confirmed these benefits for $\mathrm{Nb}$ containing steels. ${ }^{[9,78]} \mathrm{A}$ similar trend of phosphorous reducing the incidence of defects for microalloyed and C-Mn steels was found by Hannerz ${ }^{[88]}$ using regression analysis on mill data. Suzuki et al. ${ }^{[51]}$ studied a plain C-Mn steel with a P range of 0.003 to $0.32 \%$ and found it beneficial, the hot ductility improved by increasing the $P$ level.

However, Harada et al. ${ }^{[16]}$ have shown that transverse cracks are normally associated with very high segregation of phosphorous. Yashima et al ${ }^{[94]}$ calculated that for a steel with $0.25 \mathrm{wt} \% \mathrm{C}$, the last liquid to solidify would contain about $5 \mathrm{wt} \% \mathrm{P}$. A $1 \mathrm{wt} \% \mathrm{C}$ steel with the same $\mathrm{P}$ level would have about $1 \mathrm{wt} \% \mathrm{P}$ in the final interdentritic liquid. It has been found that the addition of $\mathrm{P}$ extended the zero ductility temperature range some $80^{\circ} \mathrm{C}$ below the equilibrium solidus temperature. This was due to $\mathrm{P}$ having segregated to the 
austenite grain boundaries, resulting in stabilization of liquid films (i.e. segregated $\mathrm{P}$ lowers the liquidus and solidus temperatures depending on the $\mathrm{C}$ content) ${ }^{[9]}$ Zero ductility corresponds to nil plastic deformation in solid. A liquid phase at grain boundaries results in zero ductility since grains separate from each other with no deformation in the grain interior.

Hence, from this discussion, it can be concluded that phosphorous is likely to improve the hot ductility of the continuously cast strand provided segregation is reduced and will make it easier to avoid transverse cracking during straightening. On the contrary, if $P$ segregates sufficiently, the interdendritic liquid will be present at a temperature well below the bulk solidus temperature.

Sulphur segregation to the austenite grain boundaries has been suggested as a possible cause of poor hot ductility in several studies. ${ }^{[95-97]}$ It has been demonstrated that segregated $\mathrm{S}$ exerts an attractive force on the electrons associated with the bonding of $\mathrm{Fe}$ atoms, reducing the strength of the boundaries in this way. ${ }^{[98]}$ In low Mn, ultra high purity steels, heated directly to the test temperature, it was found that AIN reduced the hot ductility only indirectly by pinning the boundaries, so that $\mathrm{S}$ was able to segregate to them and embrittle the material. ${ }^{[3,95]}$ Thus, when the $S$ levels were very low $(<0.001 \mathrm{wt} \%)$, the hot ductility was excellent even when high volume fractions of AIN were present, both at the austenite grain boundaries and within the matrix. ${ }^{[3]}$

Alloying elements are those that are added deliberately to steel in order to improve and control mechanical properties. Carbon is one the alloying elements that has received much attention with regard to the hot ductility. It has been well known that surface cracking susceptibility depends on $\mathrm{C}$ content in low alloy steel, Figure $2.26 .^{[66,99]}$ This is attributed to the large austenite grain size. The grain size can be very large in the vicinity of the peritectic composition, i.e. $0.18 \mathrm{wt} \% \mathrm{C}$, since there is no small amount of the second phase, i.e. the $\delta$-ferrite or liquid phases associated with the lower or higher carbon contents than the peritectic composition, respectively, to retard austenite grain growth. ${ }^{[66]}$ Note that the peritectic composition moves to lower carbon contents in steels containing 
$\mathrm{Mn}$. However, in hot tensile test of the reheated specimens without remelting, such $\mathrm{C}$ dependency of the ductility could not be recognized as shown in Figure 2.27. ${ }^{[66]}$

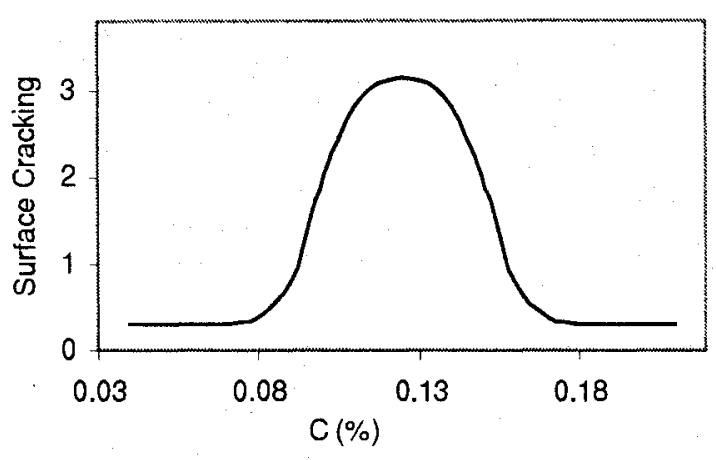

Figure 2.26. Schematic illustration showing the effect of $\mathrm{C}$ on surface cracking susceptibility of continuously cast slab. ${ }^{[66,99]}$

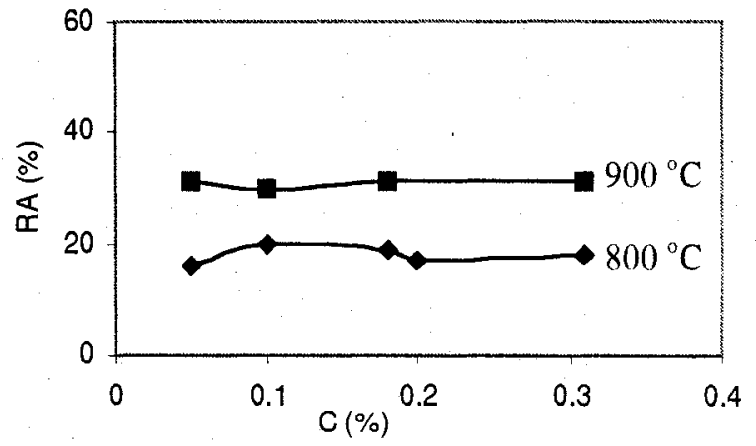

Figure 2.27. Effect of $\mathrm{C}$ content on the hot ductility. The specimens were deformed at 800 and $900^{\circ} \mathrm{C}$ after solution treatment at $1300^{\circ} \mathrm{C} \cdot{ }^{[66]}$

The surface cracking during the process of continuous casting or the direct rolling is mainly caused by the precipitation of carbonitrides or sulfides or by the segregation of impurity atoms to the austenite grain boundaries in the temperature range from austenite to austenite/ferrite duplex phase region, accompanying the intergranular fracture of austenite. ${ }^{[1,30,37,50,78,96,100,101]}$ Such ductility, as explained before, has been well known to depend largely on the grain size and to decrease inversely proportional to the initial grain size. Maehara et al. ${ }^{[66]}$ have found that the austenite grain size significantly varies with $\mathrm{C}$ content in remelted specimens, i.e. the maximum grain size was found for steels with $0.10 \sim 0.15 \mathrm{wt} \% \mathrm{C}$. This can explain the crack susceptibility in Figure 2.26.

In the case of the ductility trough, the effect of carbon is linked to the onset of the austenite to ferrite transformation, as outlined in the section 2.4.1 above. As raising the $\mathrm{C}$ level lowers the transformation temperature, it moves the trough to lower temperatures. Such behavior has been observed by many investigators in both plain C-Mn and C-Mn-Al steels. ${ }^{[25,51,88]}$ Generally, the trough curves move bodily down to lower temperatures as the $\mathrm{C}$ level is increased, but Suzuki et al. ${ }^{[51]}$ have noted that the trough is deepened as well. 
For $\mathrm{C}-\mathrm{Mn}-\mathrm{Nb}-\mathrm{Al}$ steels with $\mathrm{Nb} \leq 0.03 \mathrm{wt} \%$, it is generally agreed that $\mathrm{C}$ has little influence on the position of the trough, ${ }^{[5,50,102]}$ except at $\mathrm{C}$ levels $\leq 0.05 \mathrm{wt} \%$, when both the width and depth of the trough are reduced. ${ }^{[102]}$ This is because of the overriding influence of $\mathrm{Nb}(\mathrm{C}, \mathrm{N})$ precipitation in the austenite. ${ }^{[3]}$ In fact, the ductility deteriorates as the volume fraction of $\mathrm{Nb}(\mathrm{C}, \mathrm{N})$ precipitate increases, Figure $2.28 .^{[102]}$ Such precipitation occurs relatively rapidly during testing, so that the volume fractions approach the equilibrium levels during the long times associated with low strain rate tests. ${ }^{[102]}$ The amount of $\mathrm{Nb}(\mathrm{C}, \mathrm{N})$ precipitated at a given temperature depends on the $\mathrm{Nb}, \mathrm{C}$, and, to a lesser extent, the $\mathrm{N}$ level in steel. For a steel with $0.03 \mathrm{wt} \% \mathrm{Nb}$, when the $\mathrm{C}$ level exceeds $0.05 \mathrm{wt} \% \mathrm{C}$ there is little further increase in the volume fraction precipitated and hence ductility in the trough region is relatively insensitive to the $\mathrm{C}$ level. ${ }^{[3]}$

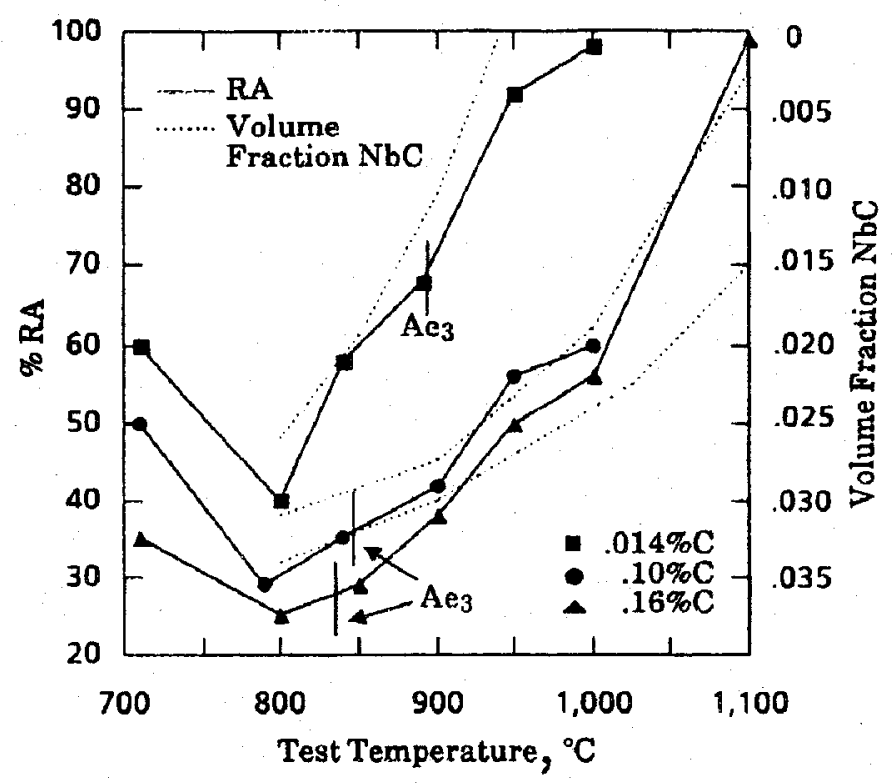

Figure 2.28. Relationship of shape and position of hot ductility curves to volume fraction of $\mathrm{NbC}$ precipitated, assuming equilibrium solubility, in steels with $0.025 \mathrm{wt} \% \mathrm{Nb}$, but with varying $\mathrm{C}$ contents. The steels were solution treated, cooled to test temperature, and tested at strain rate of $3 \times 10^{-3} \mathrm{~s}^{-1}$. $^{102]}$

Of all the microalloying elements, Titanium seems to be the most effective in keeping the RA values high, and reducing or eliminating the trough when laboratory tests are carried out on unmelted specimens, Figure $2.29 .^{[3,5,103]}$ This is because TiN and TiN-rich 
precipitates are formed at high temperatures (close to the solidus) and so tend to be coarse and randomly distributed. They are also sufficiently numerous and have a high enough volume fraction to restrain grain growth at high temperatures $\left(1350^{\circ} \mathrm{C}\right)$, while not pinning the boundaries long enough for cracks to link up. ${ }^{[3]}$ Therefore, the benefit of Ti comes from two parts; grain refinement and its ability to combine preferentially with $N$, preventing the formation of the more detrimental AlN precipitate ${ }^{[5]}$ and reducing the amount of $\mathrm{N}$ available to form $\mathrm{Nb}(\mathrm{C}, \mathrm{N}){ }^{\left[{ }^{[3]}\right.}$

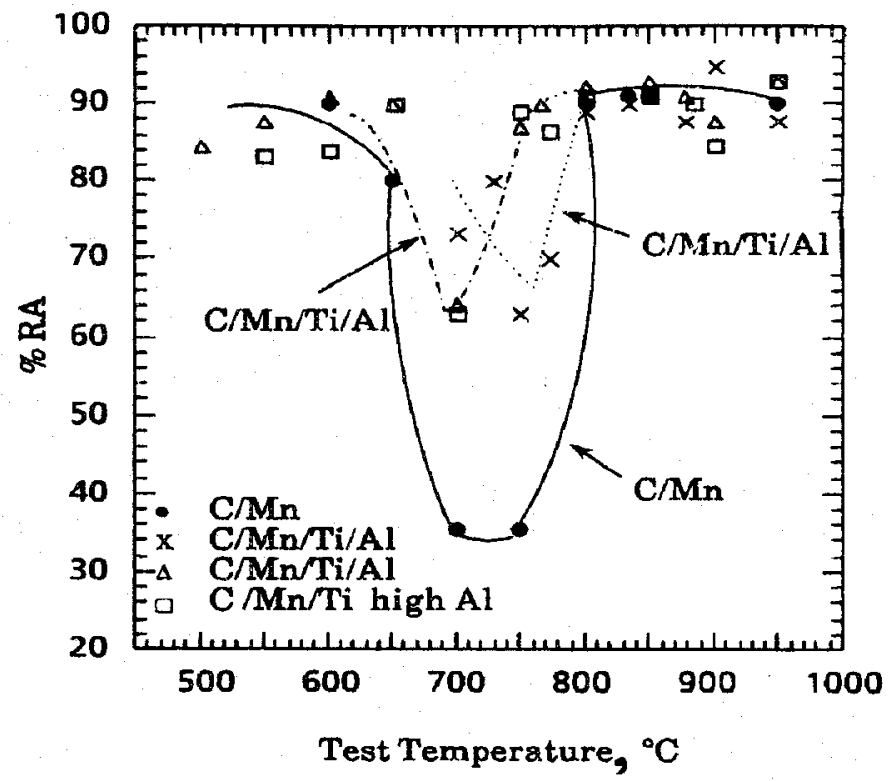

Figure 2.29. Influence of small additions of $\mathrm{Ti}(0.02-0.03 \mathrm{wt} \%)$ on hot ductility behavior of $\mathrm{C}-\mathrm{Mn}-\mathrm{Al}$ steels heated to $1330^{\circ} \mathrm{C}$, cooled to test temperature, and fractured at strain rate of $3 \times 10^{-3} \mathrm{~s}^{-1} \cdot[5]$

The beneficial effect of Ti depends on the cooling rate. Abushosha et al ${ }^{[81]}$ observed that for a $\mathrm{Nb}$-containing steel, $\mathrm{Ti}$ improved the hot ductility in the temperature range 800 $1000^{\circ} \mathrm{C}$ only when the cooling rate was slow enough, i.e. $25 \mathrm{Kmin}^{-1}$. This slower cooling rate probably allows $\mathrm{NbC}$ to precipitate out at high temperatures on the coarse TiN precipitates, thus leaving little $\mathrm{Nb}$ available for precipitation in a fine detrimental form during deformation at lower temperatures. Little improvement was observed when the cooling rate was increased to $100 \mathrm{Kmin}^{-1}$. 
Aluminium is added to steel as a grain refinement element. But, as mentioned before, it is detrimental to the hot ductility when it combines with $\mathrm{N}$ and precipitates at the austenite grain boundaries, retarding grain boundary migration. ${ }^{[104]}$ It also deteriorates the hot ductility by segregation. Using Auger electron microscopy, Edwards et al. ${ }^{[105]}$ have shown that $\mathrm{Al}$ segregates to the austenite grain boundaries during casting in such large amounts that ferrite can form at the boundaries at temperatures much higher than those encountered in typical hot tensile tests on solution treated steel. Furthermore, Vodopivec et $a{ }^{[106]}$ have suggested that cracking may be caused by the presence of a coarse dendritic structure, which is favored by increasing the level of $\mathrm{Al}$ in solution to at least $0.04 w t \%$. The fact that this explanation differs widely from that based on the precipitation of AlN again indicates the need to develop hot tensile tests that simulate the continuous casting operation more closely.

Niobium is widely used as a microalloying element to improve the mechanical properties, but often causes problems during the continuous casting process. Even though known as a ferrite stabilizer, i.e. the $\mathrm{Ae}_{3}$ temperature increases as $\mathrm{Nb}$ is added, very low additions of $\mathrm{Nb}$ retard the ferrite formation considerably, possibly by solute drag effect. ${ }^{[107]}$ Lindblom and $\mathrm{Grant}^{[108]}$ in 1971 demonstrated the detrimental effect of $\mathrm{Nb}$ especially at slow deformation rates. With regard to the hot ductility, Bernard et al. ${ }^{[100]}$ proposed that a reduced hot ductility in the Nb-bearing steel was due to suppression of dynamic recrystallization. Rois ${ }^{[109]}$ has shown that $\mathrm{NbC}$ precipitates also impose a drag force on the austenite grain boundaries. Ouchi and Matsumoto ${ }^{[5]}$ have proposed that $\mathrm{Nb}$ suppresses not only dynamic recrystallization but also dynamic recovery in the strain range below $\varepsilon_{\mathfrak{c}}$, the critical strain needed for dynamic recrystallization to commence. The latter may be one of the factors promoting intergranular fracture when the fracture strain is less than $\varepsilon_{\mathrm{c}}$.

$\mathrm{C}-\mathrm{Mn}-\mathrm{Nb}-\mathrm{Al}$ steels are the most difficult to cast continuously and the combined presence of $\mathrm{Al}$ and $\mathrm{Nb}$ is particularly detrimental. If the transverse cracks are to be avoided, the $\mathrm{Nb}$ level should be kept to the lowest value consistent with the property requirements being met in the final product. ${ }^{[3]}$ It has been shown that addition of a small amount of Ti can improve the hot ductility in Nb-bearing steels, Figure $2.30 .^{[5]}$ Ti scavenges $\mathrm{N}$ as TiN and 
less $\mathrm{N}$ is available for detrimental $\mathrm{Nb}(\mathrm{C}, \mathrm{N})$ precipitates. Besides this, the stable TiN precipitates refine the austenite grain size and this lowers the density of $\mathrm{Nb}(\mathrm{C}, \mathrm{N})$ precipitates at the austenite grain boundaries. Also it was shown that $\mathrm{NbC}_{0.85}$ is formed in $\mathrm{Nb}$ steels with low $\mathrm{N}$ content around $0.0020 \mathrm{wt} \%$ or with $0.020 \mathrm{wt} \% \mathrm{Ti}$ addition, while $\mathrm{NbC}_{0.60} \mathrm{~N}_{0.25}$ is formed in the steel with $\mathrm{N}$ content higher than $0.0050 \mathrm{wt} \%$. These different compositions of the $\mathrm{Nb}$ precipitates may cause the different precipitation kinetics in the austenite, that is, $\mathrm{NbC}_{0.60} \mathrm{~N}_{0.25}$ may precipitate more easily than $\mathrm{NbC}_{0.85}$. All of these factors contribute to improve the hot ductility in Nb-bearing steels. ${ }^{[5]}$

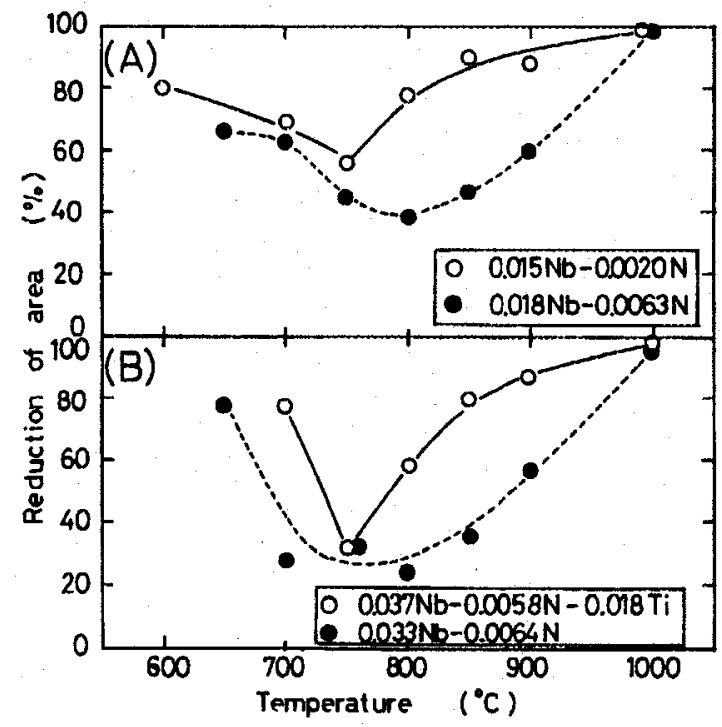

Figure 2.30. Effects of (A) $\mathrm{N}$ content and (B) Ti addition on the hot ductility of Nbbearing steels. ${ }^{[5]}$

Increasing the Nitrogen level increases the amount of $\mathrm{Nb}(\mathrm{C}, \mathrm{N})$ and $\mathrm{AlN}$ precipitated. ${ }^{[3]}$ It is expected, therefore, to have an adverse effect on the hot ductility and, indeed, an increase in the tendency to form transverse cracks has been noted, ${ }^{[3]}$ Figure 2.30 . However, the level of $\mathrm{N}$ cannot be reduced very much since it is needed to provide grain refining particles, such as AIN, in the finished product.

Vanadium steels seem to possess better hot ductilities than $\mathrm{Nb}$ steels. ${ }^{[110]}$ This is due to Vcontaining steels producing coarser precipitates than $\mathrm{Nb}$ and a greater volume fraction of 
precipitate is required to cause the ductility to deteriorate. Coarser precipitation has been shown to both reduce transverse cracking and give improvements to the hot ductility. ${ }^{[7]}$ This arises because a coarser matrix precipitation decreases the stress concentration at the boundaries, and because of the greater interparticle spacing that makes it less easy for cracks formed by grain boundary sliding to join up. ${ }^{[11]}$ In the case of $\mathrm{V}+\mathrm{Nb}$ steels, the addition of $\mathrm{Nb}$ to $\mathrm{V}$-containing steels would be expected to reduce the hot ductility. Not only would there be precipitation from VN but there would be additional precipitation from $\mathrm{Nb}(\mathrm{CN}) \cdot{ }^{[24]}$

Akben et al. ${ }^{[111]}$ examined a $0.05 \mathrm{wt} \% \mathrm{C}, 1.2 \mathrm{wt} \% \mathrm{Mn}$ steel at the $0.035 \mathrm{wt} \% \mathrm{Nb}$ and 0.15 $\mathrm{wt} \% \mathrm{~V}$ levels with $0.006 \mathrm{wt} \% \mathrm{~N}$. They showed that the kinetics of dynamic precipitation of $\mathrm{Nb}$ and $\mathrm{V}$ are similar and fast, with the $\mathrm{V}$ steel in general showing the slower kinetics. When present alone, the nose temperature was approximately $900^{\circ} \mathrm{C}$ for the $\mathrm{Nb}$ containing steel and slightly lower at $880^{\circ} \mathrm{C}$ for the V-containing steel. $\mathrm{Nb}$ precipitated out more rapidly than $\mathrm{V}$ at temperatures above $880^{\circ} \mathrm{C}$, Figure 2.31 .

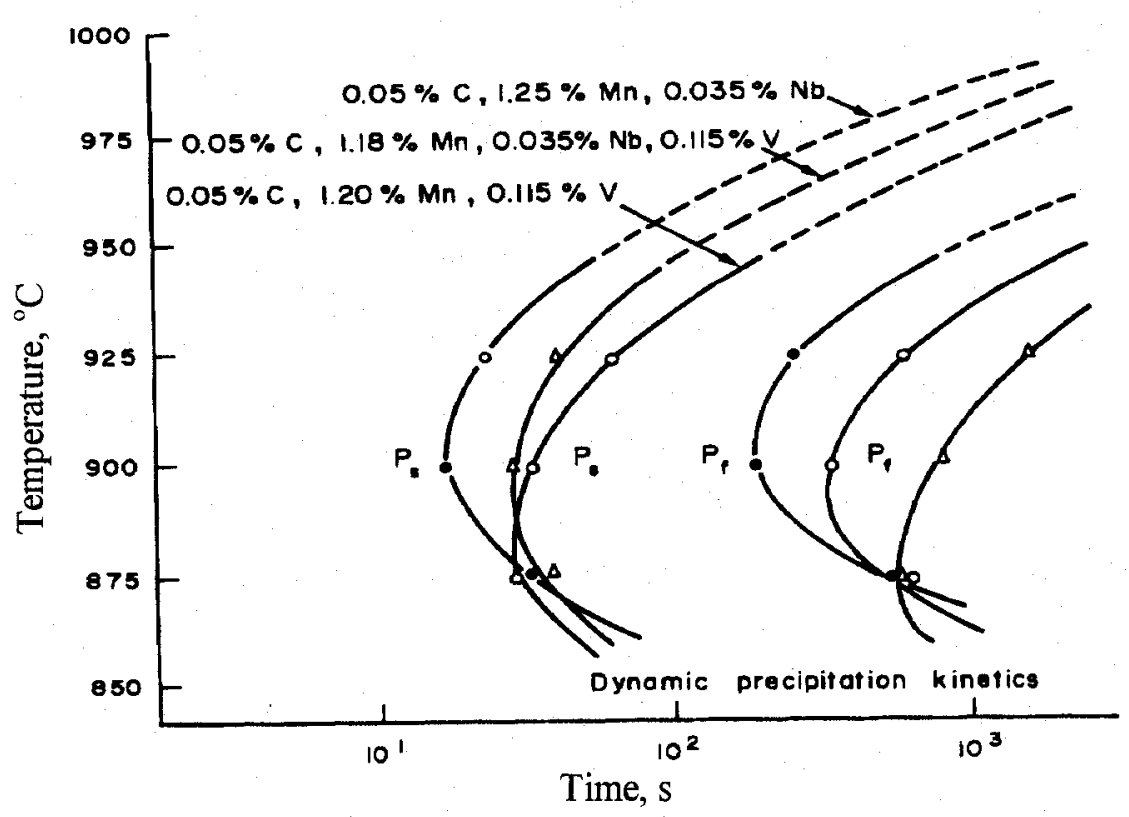

Figure 2.31. Dynamic precipitation curves for $\mathrm{Nb}, \mathrm{V}$ and combination of $\mathrm{V}$ and $\mathrm{Nb}$ steels. ${ }^{[111]}$ 
The production statistics for some steels clearly points to the beneficial effect of boron. ${ }^{[88]}$ It is evident from Figure 2.32 that the plasticity is improved by minute B additions. This may happen for the same reason as for Ti. B is also an effective nitrogen attracter and actually the Ti content is not enough to tie but half of the present $\mathrm{N}$. The rest could be tied up in BN. However, this does not seem to be the only mechanism. There might be also a similar mechanism as that considered for creep resistance austenitic stainless steel and nickel base superalloys. A number of explanations have been offered over the years, such as $B$ atoms pinning vacancies thereby slowing down grain boundary self diffusion. ${ }^{[88]}$ It is also well known that the addition of $B$ to low carbon steels retards the formation of ferrite along austenite grain boundaries by segregating to these boundaries. It is therefore expected that the addition of $\mathrm{B}$ will change the microstructure at around 700 to $800^{\circ} \mathrm{C}$ and, accordingly, the hot ductility. ${ }^{[112]}$

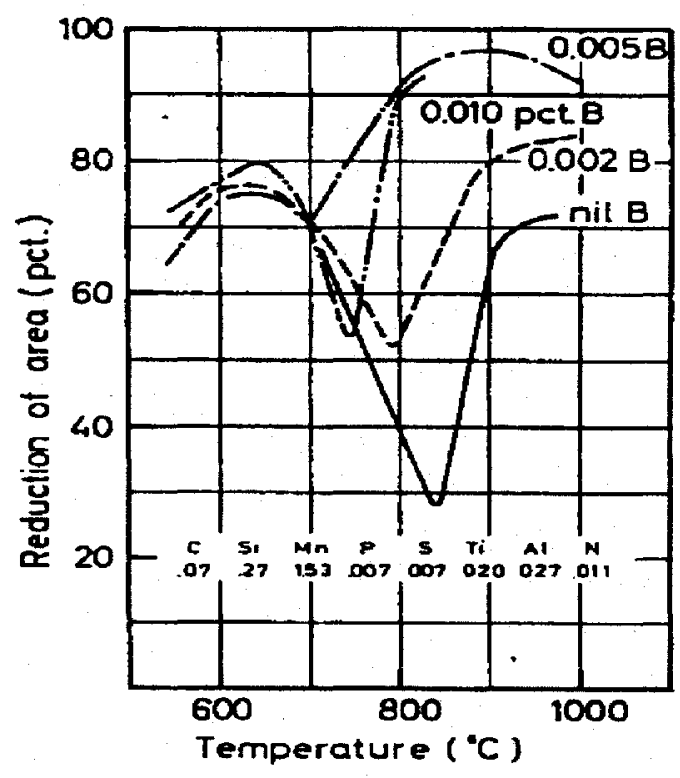

Figure 2.32. Influence of boron on hot ductility. ${ }^{[88]}$

It has been recently shown that B improves the hot ductility at low temperatures by causing more uniform deformation from grain boundaries to grain interios. ${ }^{[112]}$ Nevertheless, the beneficial effect of B at high temperatures is still to be clarified. 
Zirconium and Yttrium, as nitride forming microalloying elements, have been also shown to improve the hot ductility of Nb-containing steels at high temperatures. ${ }^{[113]}$ By adding these elements, nitride precipitation takes place at higher temperatures to yield modification of morphology, composition and nucleation site of carbonitrides, which improves high temperature ductility of the steel.

\subsection{Influence of Deformation on Hot Ductility}

As was already discussed, the surface of the steel is experiencing a rather complicated thermomechanical process, both in the liquid and solid states, while it is being cast continuously. This definitely interferes with other metallurgical phenomena taking place in the steel during solidification and cooling. Nonetheless, the investigations done on the effect of deformation on the hot ductility are limited. All of these investigations have dealt with the effect of deformation during solidification of steel (references 15 and 114, for instances). Even though, there is a limited number of investigations in which

deformation behavior of steel in the $\delta$-ferrite region has been studied ${ }^{[115-119]}$, none of them had dealt with the hot ductility problem until Akhlaghi ${ }^{[12]}$ associated this with the hot ductility.

Akhlaghi ${ }^{[12]}$ studied the effect of deformation in the proximity of the melting temperature on the hot ductility of $\mathrm{Nb}$-containing and plain C-Mn steels. He noticed that applying compressive strains in the proximity of the melting point improved the hot ductility significantly in the $\mathrm{Nb}$-containing steel, i.e. an improvement from $10 \% \mathrm{RA}$ to $100 \% \mathrm{RA}$. By contrast, it led to a decrease in the hot ductility in the C-Mn steel. Microstructural observations showed that imposing such a deformation in the proximity of the melting point in the $\mathrm{Nb}$-containing steel, caused grain refinement and fewer carbonitride precipitates present at the straightening temperature. These changes in the microstructure were suggested to be responsible for improvement of the hot ductility at the straightening point. It was also stated that imposing compression in the 'liquid+solid' region was partly responsible for such an improvement since the compression helps close solidification voids. However, there was only a $50 \%$ improvement when the deformation start 
temperature was decreased by $10^{\circ} \mathrm{C}$, and no improvement when the deformation start temperature was decreased by $30^{\circ} \mathrm{C}$. Regardless of deformation start temperature, a tensile strain imposed during solidification always appeared detrimental to the hot ductility at the subsequent straightening stage. 


\section{OBJECTIVES}

Since the advent of the continuous casting process, the control of surface cracking has been an important goal. This is related to hot ductility, and this has been a major research activity. Much of this work has concentrated on two ways to minimize crack susceptibility; (i) controlling steel chemistry and (ii) controlling cooling rate. Even though each of these categories has led to some solutions, they are not always practical. Alteration of chemistry can be at the expense of some desired mechanical properties. Also, technological limitations and desires to maximize productivity constrain the strand cooling rate. Hence, the general purpose of this work was to search for a solution to the problem through thermomechanical processing. Two grades of microalloyed steel, i.e. $\mathrm{Nb}$-containing steel and $\mathrm{Nb}$-containing steel modified with $\mathrm{B}$ were studied. Accordingly, the main objectives of the present work were,

To study the effect of thermal schedule undergone by the mid-surface of billet, including in situ melting, on the evolution of hot ductility trough.

To better understand the mechanisms under which the $\mathrm{B}$ addition to the $\mathrm{Nb}$-containing steel influences the hot ductility.

To investigate the effect of deformation, tension and compression, during steel solidification on the hot ductility at the straightening stage. 
To study the effect of deformation, tension and compression, imposed within the $\delta$ ferrite region, during cooling after solidification, on the hot ductility.

To examine and characterize the effect of deformation incorporated with the $\delta \rightarrow \gamma$ transformation, as well as in the subsequent austenite phase, on the hot ductility.

To introduce concepts to design thermomechanical processes that would alleviate or prevent the hot ductility loss during the continuous casting process. 
In this chapter, the materials are first introduced and then the experiment apparatus for hot deformation is illustrated. Finally, the thermomechanical processes and characterization techniques are elaborated.

\subsection{Experimental Materials}

A Nb-Ti microalloyed steel was chosen since it has a hot ductility problem. This grade of steel was provided by IPSCO Inc, Muscatine, Iowa. Also, two boron steels with similar amounts of $\mathrm{Nb}$ and $\mathrm{Ti}$ to those in the $\mathrm{Nb}-\mathrm{Ti}$ steel were considered to study the effect of boron on the hot ductility. The chemical compositions of these steels are shown in Table 4.1. As can be seen, the Nb-steel is low and the B-steels are ultra low carbon steels. The main alloying elements in these compositions are $\mathrm{C}, \mathrm{Nb}, \mathrm{Ti}, \mathrm{Al}$, Mo and $\mathrm{B} . \mathrm{Mn}$ is added to scavenge $\mathrm{S}$, and $\mathrm{N}$ is mainly used to from particles pinning grain boundaries and dislocations. $\mathrm{Cu}$ is a residual element coming from scrap and $\mathrm{Ni}$ is added to alleviate the harmful effect of $\mathrm{Cu}$. Most of the others are residual elements coming from the scrap used to make the steel.

These materials were in the form of continuously cast slab that had been hot rolled down 
Table 4.1. Chemical compositions of experimental steels ( $w t \%)$.

\begin{tabular}{|c|c|c|c|}
\hline Elements & $\begin{array}{c}\text { Nb-Ti steel } \\
(\mathrm{Nb} \text {-steel) }\end{array}$ & $\begin{array}{c}\text { B-steel 1 } \\
\text { (B1-steel) }\end{array}$ & $\begin{array}{c}\text { B-steel 2 } \\
\text { (B2-steel) }\end{array}$ \\
\hline $\mathrm{C}$ & 0.05 & 0.015 & 0.015 \\
\hline $\mathrm{Mn}$ & 0.95 & 1.650 & 1.650 \\
\hline $\mathrm{S}$ & 0.007 & 0.008 & 0.008 \\
\hline $\mathrm{P}$ & 0.012 & 0.009 & 0.009 \\
\hline $\mathrm{Si}$ & 0.14 & 0.230 & 0.230 \\
\hline $\mathrm{Cu}$ & 0.33 & $<0.001$ & $<0.001$ \\
\hline $\mathrm{Ni}$ & 0.12 & $<0.003$ & $<0.003$ \\
\hline $\mathrm{Cr}$ & 0.09 & 0.025 & 0.025 \\
\hline $\mathrm{V}$ & 0.012 & 0.002 & 0.002 \\
\hline $\mathrm{Nb}$ & 0.035 & 0.050 & 0.050 \\
\hline $\mathrm{Mo}$ & 0.03 & $<0.017$ & $<0.017$ \\
\hline $\mathrm{Al}$ & 0.024 & 0.020 & 0.020 \\
\hline $\mathrm{Ti}$ & 0.03 & 0.020 & 0.020 \\
\hline $\mathrm{Sn}$ & 0.015 & $<0.001$ & $<0.001$ \\
\hline $\mathrm{N}$ & 0.0092 & $48 \mathrm{ppm}$ & $50 \mathrm{ppm}$ \\
\hline $\mathrm{B}$ & - & $20 \mathrm{ppm}$ & $43 \mathrm{ppm}$ \\
\hline $\mathrm{Co}$ & 0.018 & $<0.004$ & $<0.004$ \\
\hline
\end{tabular}

to about $13 \mathrm{~mm}$ thick and $220 \mathrm{~mm}$ wide. Cylindrical specimens, with dimensions of 125 $\mathrm{mm}$ length and $9.5 \mathrm{~mm}$ diameter, were machined with the longitudinal direction in either the rolling or the transverse direction. They were threaded at both ends in order to be able to apply both tensile and compressive deformations to the same specimen, Figure 4.1.

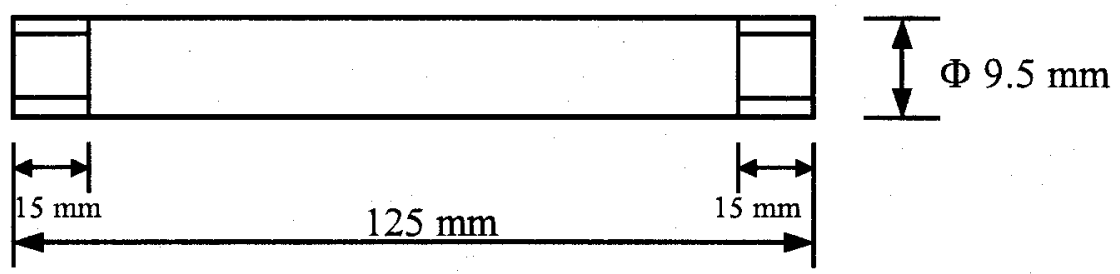

Figure 4.1. Specimen configuration. 


\subsection{Hot Deformation Equipment}

The deformation machine is a fully computerized Materials Testing Machine (MTS) using a $25-\mathrm{kN}$ load cell with adequate sensitivity. Displacement of the hydraulic actuator was measured from the output of a linear variable differential transformer (LVDT) with a total linear range of $\pm 100 \mathrm{~mm}$. The position of the actuator was controlled by deformation schedules made by Multipurpose Testware ${ }^{\mathrm{TM}} 2000$ software. Figure 4.2 demonstrates the hot deformation experimental setup.

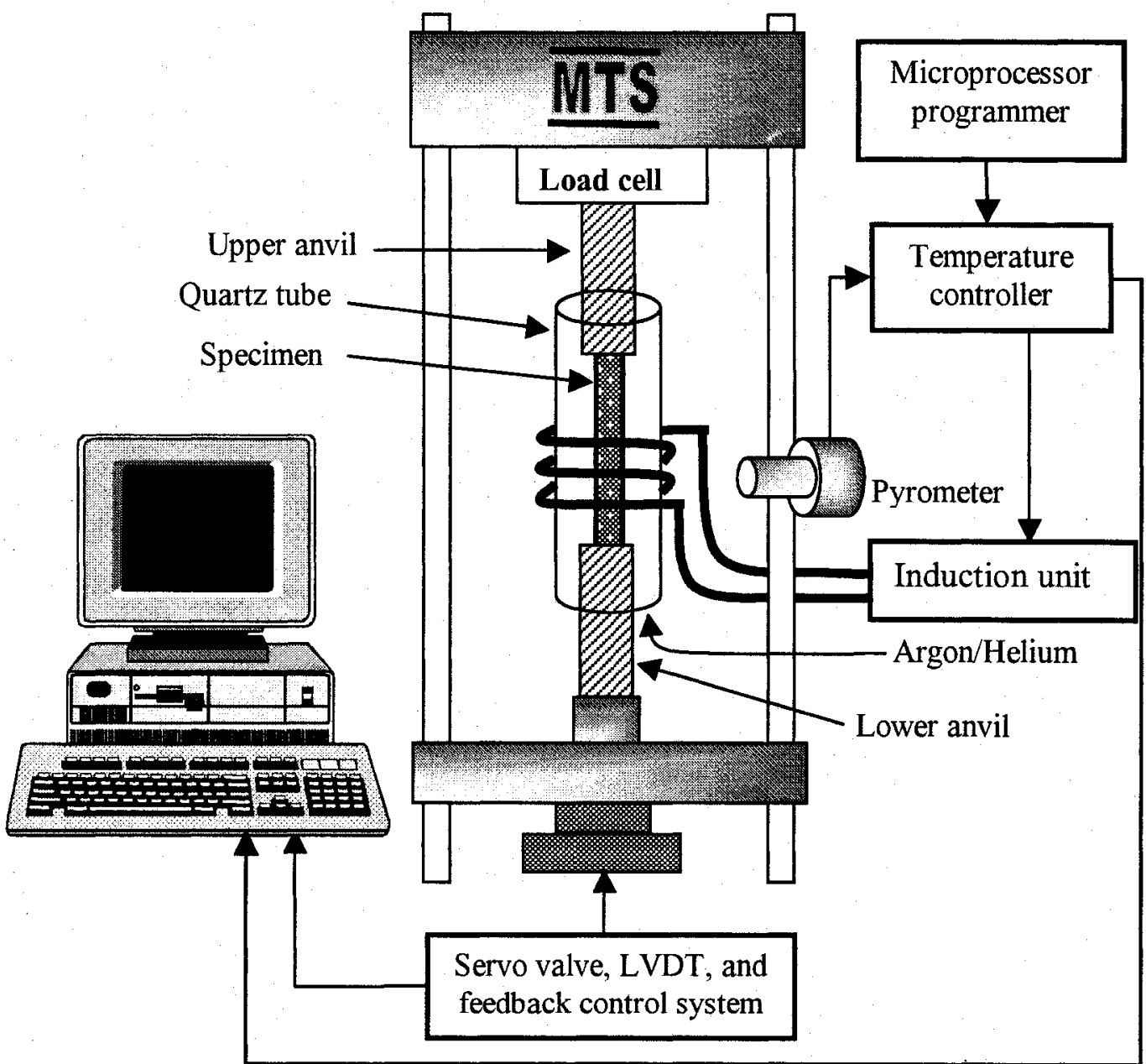

Figure 4.2. Experimental apparatus. 
For heating, an induction furnace was used. The induction unit uses microprocessor controlled MOSFET transistors that are capable of producing the rapid switching and high currents required to generate an electromagnetic field operating at frequencies of 50 $450 \mathrm{kHz}$. The water-cooled induction coil has four turns, $45 \mathrm{~mm}$ length, and $50 \mathrm{~mm}$ inside diameter. The coil is made of a copper tube with $6 \mathrm{~mm}$ outside diameter. Temperature on the mid-surface of specimen (center of the induction coil) is measured by a Maxline ${ }^{\mathrm{TM}}$ dual infrared radiation wavelength detector. This temperature reader is almost immune to error caused by undersized objects that do not fill the field of view, as well as bursts of steam, dust, etc. in the sight path. The specimen is installed and fixed (screwed) at both ends to upper and lower anvils of the deformation machine. The upper anvil is stationary and the position of the lower anvil is changeable to impose the devised deformation. In order to provide a controlled atmosphere, the specimen is enclosed in a quartz tube and a flow of argon containing 1\% hydrogen is supplied inside the quartz tube. The purpose of including hydrogen is to reduce any oxidized iron above $\sim 900^{\circ} \mathrm{C}$. Also, helium is used to achieve high cooling rate where it is required. (Figure 4.2)

Thermal schedules, composed of different ramps of heating and cooling, are programmed in a Leeds \& Northrup ${ }^{\mathrm{TM}}$ microprocessor programmer. Controlling the specimen temperature is left to the Maxline ${ }^{\mathrm{TM}}$ temperature controller connected to both the induction system and the microprocessor programmer. The controller regulates a 4-20 $\mathrm{mA} \mathrm{DC}$ signal to the induction unit by comparing the desired temperature and the instantaneous temperature of specimen. (Figure 4.2)

After fixing the specimen into the MTS, the load is set to zero and the MTS is maintained in load control mode throughout the thermal schedule, except when a strain is imposed by displacement control. In this way, thermal expansions and contractions of the specimen during heating and cooling are compensated for by displacement and the load on the specimen is sustained at around zero. This continuous adjusting is essential because the specimen upon melting cannot endure any compressive or tensile load. In other words, any significant deviation from zero load on the specimen causes the liquid to spill down. Having the advantages of liquid surface tension and electromagnetic force, from the 
induction coil, it is possible to maintain the melted part of specimen in its place by levitation for around 5-8 seconds before the solidification starts. In some cases, a shortrange movement of the melted steel was also observed in the gauge length. In all experiments, specimens were heated up to $2-3^{\circ} \mathrm{C}$ below the temperature at which the liquid was too fluid to be held. Therefore, determining the maximum heating temperature necessitated sacrificing some specimens to ascertain that the material is also melted in the center. This experimental setup enabled a melted gauge length of $15 \mathrm{~mm}$ to be obtained.

\subsection{Continuous Heating Tension and Continuous Cooling Compression Experiments}

These are two experiments developed to determine phase transformation temperatures by hot deformation. ${ }^{[120,121]}$ In the continuous heating tension (CHT) experiment, the specimen is heated up continuously while being deformed in tension. During the continuous cooling compression (CCC) experiment, using the information obtained from CHT experiment, the specimen is first melted in situ and then deformed in compression as it is cooled down.

In the CHT experiment, the specimen was first preheated up to 1200 or $1300^{\circ} \mathrm{C}$ and then, after having homogenized the temperature for 3 minutes, it was heated at a rate of 1 or $2^{\circ} \mathrm{C} / \mathrm{s}$. Simultaneously, it was subjected to a tensile deformation with a rate of $7 \times 10^{-4}$ or $3 \times 10^{-3} \mathrm{~s}^{-1}$ until it fractured. Figure 4.3 shows this schedule.

In the CCC experiment, the specimen, after being melted, was cooled at a rate of 5 or $10^{\circ} \mathrm{C} / \mathrm{s}$ and simultaneously deformed in compression at a rate of $3 \times 10^{-3}$ or $9 \times 10^{-3} \mathrm{~s}^{-1}$. The cooling and deformation rates were chosen according to the thermomechanical processes to which the specimens were expected to be subjected when examining the hot ductility. These processes will be explained later. The CCC schedule is shown in Figure 4.4. 


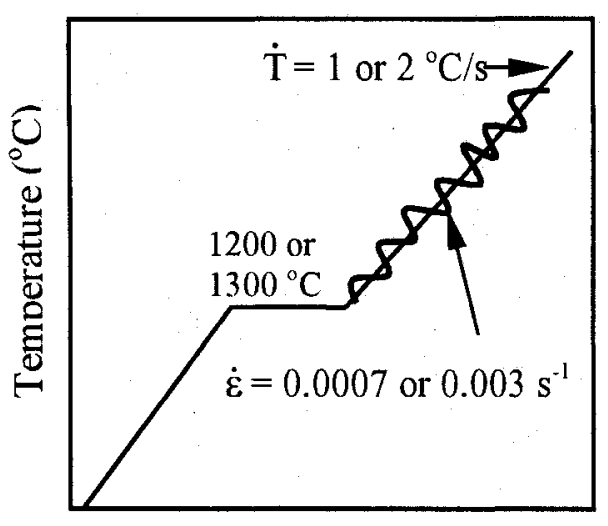

Time

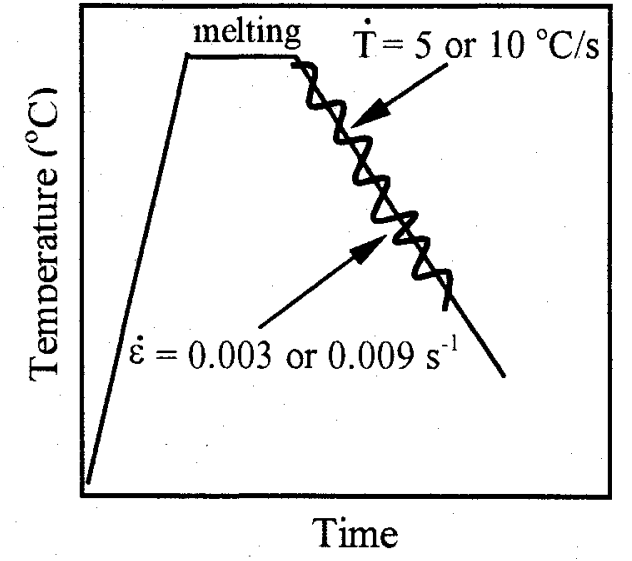

Figure 4.4. Schedule of CCC experiment.

Figure 4.3. Schedule of CHT experiment.

With these experiments, it is possible to determine thermal boundaries between different phases existing at very high temperatures, i.e. regions of liquid + solid, $\delta$-ferrite, $\delta$-ferrite + austenite, and austenite.

\subsection{Thermal Schedules}

It was pointed out in the second chapter that the thermal history can have a significant effect on the hot ductility. Here, thermal schedules, which are typical of those of the midface surface of a $10^{\prime \prime} \times 10^{\prime \prime}$ billet during continuous casting, ${ }^{[11,12]}$ were generated using the "Crack/Expert" commercial software developed by the University of British Columbia and are shown in Figures 4.5 and 4.6. Such a thermal schedule was chosen for the Bsteels since it had appeared to have a detrimental effect on a Ti-B steel. ${ }^{[1]}$

These thermal schedules show that after melting, the temperature abruptly falls down to a minimum temperature $\left(\sim 700^{\circ} \mathrm{C}\right)$, simulating the cooling effect of the mould on the surface temperature of the billet. On exiting from the mould, the billet surface temperature rebounds to a high temperature $\left(1100\right.$ and $1200^{\circ} \mathrm{C}$ in Figure 4.5 and 4.6 , respectively) due to outward diffusion of heat from the core of billet to the surface. In the subsequent stage, the temperature slightly decreases with time, due to water sprays and heat radiation at the 


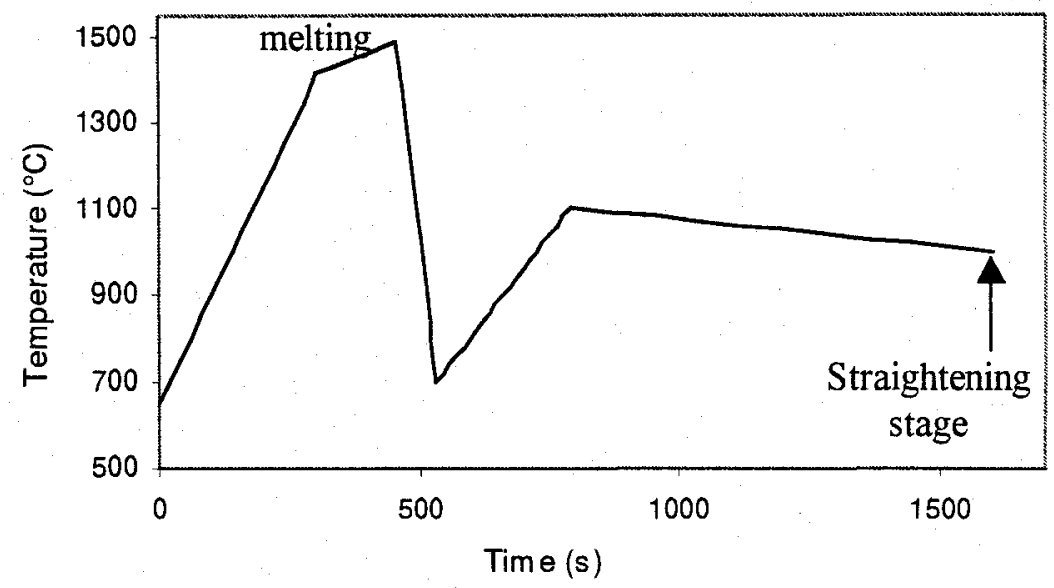

Figure 4.5. Thermal schedule applied to the B-steels. ${ }^{\left[{ }^{11]}\right.}$

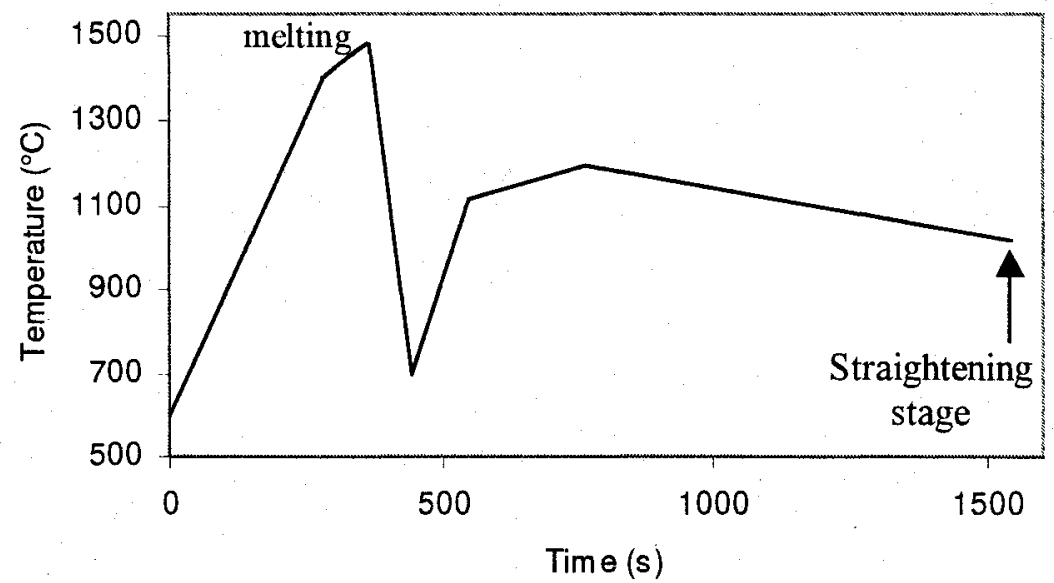

Figure 4.6. Thermal schedule applied to the $\mathrm{Nb}$-steel. ${ }^{[12]}$

surface in the secondary cooling zone. At the last stage, the billet is straightened. The specimens were subjected to these thermal schedules and, at the end, they were strained to fracture at the time, temperature, and strain rate corresponding to the straightening operation in the continuous casting process.

\subsection{Thermomechanical Processes}

Having the thermal boundaries of high temperature phases specified, it was possible to limit the deformation within each region and study the effect of such deformation on the 
hot ductility. These boundaries are superimposed on the thermal schedule on the first cooling stage in Figure 4.7.

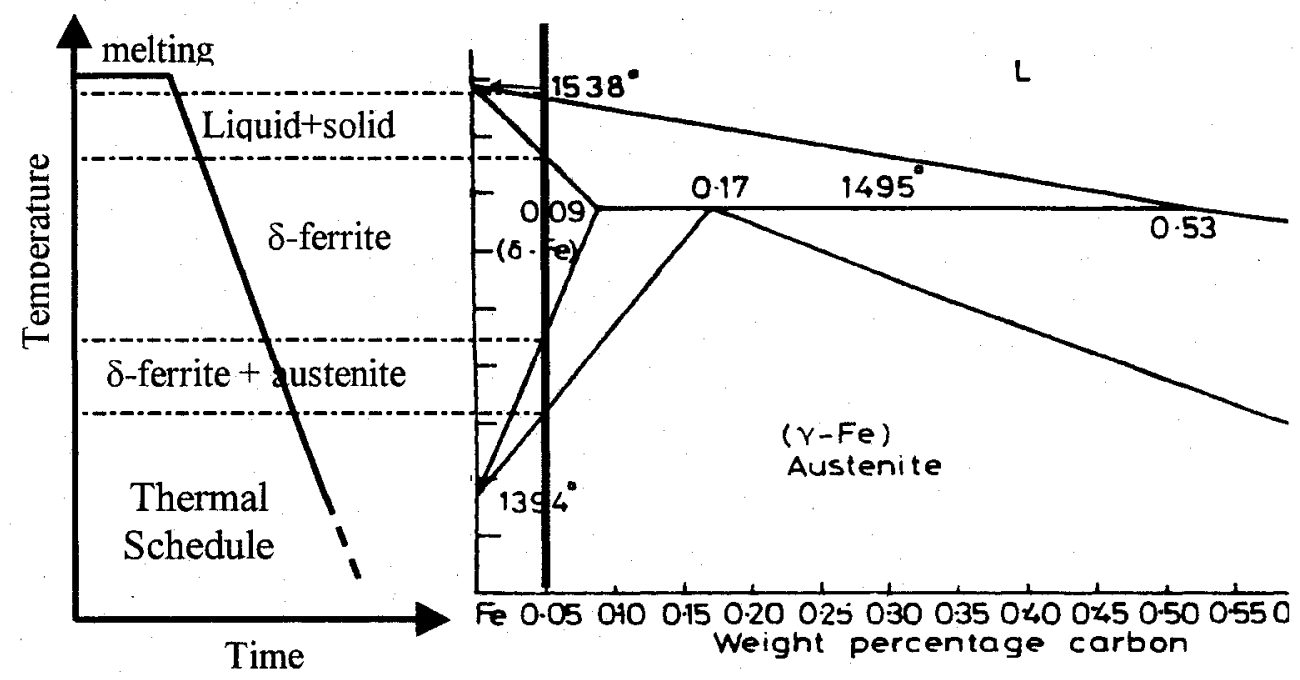

Figure 4.7. Illustration of high temperature regions on the thermal schedule.

In order to study the effect of deformation in each of these regions, tension or compression (pre-deformation) at a rate of $9 \times 10^{-3} \mathrm{~s}^{-1}$ was executed in the desired region, while the thermal schedule was proceeding. Following these pre-deformations and at the end of the thermal schedule, the hot ductility was evaluated by performing a tensile test at a rate of $5 \times 10^{-3} \mathrm{~s}^{-1}$, which is similar to that undergone by the billet surface in the continuous casting process, Figure 4.8. In addition, two other strain rates, i.e. $3 \times 10^{-3}$ and $27 \times 10^{-3} \mathrm{~s}^{-1}$, were used in the $\delta \rightarrow \gamma$ transformation region.

For instance, in order to study the effect of compression in the liquid+solid region, the compression commences as soon as the solidification starts and finishes when the solidification is completed. After completion of the compressive strain, the specimen is unloaded within one second and there is no load on the specimen as the thermal schedule proceeds toward the straightening stage, at which point the tensile test is performed. 


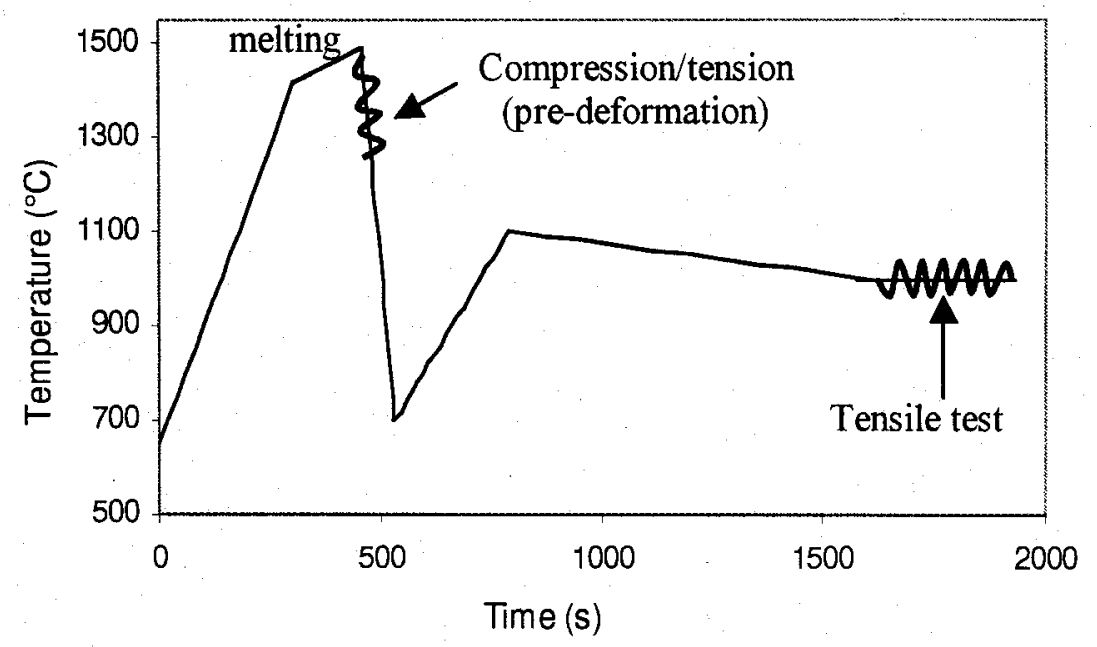

Figure 4.8. Schematic illustration of thermomechanical process and hot ductility evaluation.

In some experiments, the pre-deformation started with solidification and went through more than one region in order to study the effect of 'multi-region' on the hot ductility. Moreover, it was deemed necessary to examine the effect of deformation imposed in some other regions of the thermal schedule. These thermomechanical processes will be illustrated in the next chapter. In order to examine grain size, failure mode, and segregation, some specimens were quickly quenched at the straightening point, just before the tensile test and just after the fracture.

Reduction in area after fracture, used to quantify the hot ductility, is calculated using the following equation;

$$
R A \%=\frac{D_{f}^{2}-D_{i}^{2}}{D_{i}^{2}} \times 100
$$

where $D_{i}$ and $D_{f}$ are initial and final diameters of specimen, respectively. 


\subsection{Characterization Techniques}

\subsubsection{Optical Microscopy}

Specimens quenched before and after fracture at the straightening stage were cut longitudinally and transversely. They were ground with $\mathrm{SiC}$ abrasive papers and polished with 3 and $1 \mu \mathrm{m}$ diamond suspension. In order to reveal prior austenite grain boundaries, the B-steels were etched with $3 \%$ nital. However, this etchant did not work for the $\mathrm{Nb}$ steel. Two other etchants; Picral [ 4 gr picric acid in $96 \mathrm{ml}$ ethanol which was containing 4 drops $\mathrm{HCl}$ and 3 drops Teepol at temperature $80^{\circ} \mathrm{C}$ ] and Marshal's reagent [50\% solution of "8 gr Oxalic acid $+5 \mathrm{ml} \mathrm{H}_{2} \mathrm{So}_{4}+100 \mathrm{ml} \mathrm{H}_{2} \mathrm{O}$ " and $50 \%$ of " $30 \% \mathrm{H}_{2} \mathrm{O}_{2}$ "] were tried for the $\mathrm{Nb}$-steel, with the former appearing to be more effective in revealing prior austenite grain boundaries. The best result was obtained when the $\mathrm{Nb}$-steel specimens were etched in 'etchant \#4' [80 mL water $+28 \mathrm{~mL} \mathrm{10 \%} \mathrm{Aqueous} \mathrm{Oxalic} \mathrm{Acid} \mathrm{in} \mathrm{water}+4 \mathrm{~mL} \mathrm{30 \%}$ Hydrogen Peroxide]. Some specimens were also electro-polished in solution of $80 \%$ acetic acid and $20 \%$ perchloric acid at $30 \mathrm{~V}$ and 3-4 Am for 90 seconds. A Nikon ${ }^{\mathrm{TM}}$ optical microscope associated with Clemex vision ${ }^{\mathrm{TM}}$ image analysis software was used to perform the optical microscopy.

\subsubsection{Electron Microscopy}

The fracture surfaces, some of them cleaned ultrasonically in an ethanol bath, were examined in a JEOL JSME840A scanning electron microscope (SEM) operating at an accelerating voltage of $15 \mathrm{kV}$. Microstructures were also examined in this microscope and they were chemically microanalyzed by an EDAX x-ray analyzer.

A Hitachi S4700 cold Field Emission Gun Scanning Electron Microscope (FEGSEM) was also used to examine very fine precipitates and fine microstructural characteristics. The microscope can attain a resolution of $1.5 \mathrm{~nm}$ at $15 \mathrm{kV}$ at a working distance of $3 \mathrm{~mm}$. At an accelerating voltage of $1 \mathrm{kV}$, a resolution of $2.5 \mathrm{~nm}$ can be reached. The 
microscope is equipped with two secondary electron detectors (below the lens and above the lens detectors) and a Robinson backscattered electron detector.

The FEGSEM was operated at low and medium accelerating voltages, ranging from 1 to $10 \mathrm{kV}$, and in the magnetic mode to examine fine characteristics. Ferromagnetic characteristic of steel makes the astigmatism correction very difficult while the upper secondary electron detector is active. Hence, the microscope should be operated in the magnetic mode to alleviate the astigmatism aberration. For the secondary electron imaging, the upper detector was mostly used. However, for some specimens, especially when there was a surface topography, the image was a result of the both upper and lower detectors working simultaneously. The Robinson detector, which is utilized for backscattered electron imaging at low accelerating voltages, was used when a backscattered imaging was needed. For chemical analysis, the Oxford Instruments INCA $\mathrm{X}$-ray analysis system was employed in this microscope.

\subsubsection{Atomic Characterization ${ }^{[122-124]}$}

In order to investigate the distribution of atoms from the grain interior to the grain boundary, a LEAP microscope was used. Since this microscope has been just developed, it is necessary that its concept and advantages be explained briefly here.

The field ion microscope (FIM) was introduced in 1951 in which ionized gas particles produce an image on a screen. In 1967, the imaging gas was removed and the atom probe field ion microscope (APFIM) was invented. In this instrument, and, with the specimen tip operating as an anode, the field is increased to the point where the atoms on the surface are evaporated by the field. The tip is sharply pointed with a radius of curvature at the apex of between 10 to $200 \mathrm{~nm}$. A high voltage is applied between the tip and an image screen leading to creation of a very high electric field at the surface of the tip. Consequently, the surface atoms are ionized and accelerated to the imaging screen by the applied field. In the APFIM, the flight times of ions from the specimen to the image screen are used to identify the ions. The identity of each atom is determined based on the 
time it takes the atom to travel from the specimen to the detector. Because all the different types of atoms in the specimen have the same kinetic energy when they leave the specimen, the elements of low mass travel faster than the heavier elements and reach the detector first (the typical velocity of these atoms is approximately 300 miles per second).

In the conventional APFIM, an aperture with a virtual size of $0.2-10 \mathrm{~nm}$ is placed in the image screen to allow the ions from a specific location on the tip to pass through into a time-of-flight mass spectrometer. Because the identification of elements is based on timeof-flight, all isotopes are detected, and there are no mass limitations either at high or low masses. However, the virtual image is typically only a few atom diameters wide at the detector plane, and no positional information about the ions is recorded. Thus, data from this conventional instrument is inherently one dimensional. Unfortunately, the data collection method makes inefficient use of the sample since most of the specimen atoms that are evaporated are never analyzed.

The imaging atom probe and the wide angle atom probe are early types of threedimensional atom probes (3DAP) which were developed in response to such limitations. The 3DAP can, in principal, determine the identity and original location of every atom which hits the image screen. It has the ability to measure both the time-of-flight of a given ion in the wide angle image plane and the arrival position on that plane. In this way, both the position and identity of the atoms on the surface of the tip are determined. A schematic drawing of such an instrument is shown in Figure 4.9.

However, there are some limitations concerning the 3DAP. Conventional voltage pulsing in 3DAP creates a problem with mass resolution. There has been no previously demonstrated approach that achieves high mass resolution in a 3DAP without unduly sacrificing image size. Another limitation of atom probes is the preparation of samples into the required geometrical form. Making a sample with the desired orientation from a multilayer sample or from a semiconductor wafer can be quite complicated and often may be impossible. 


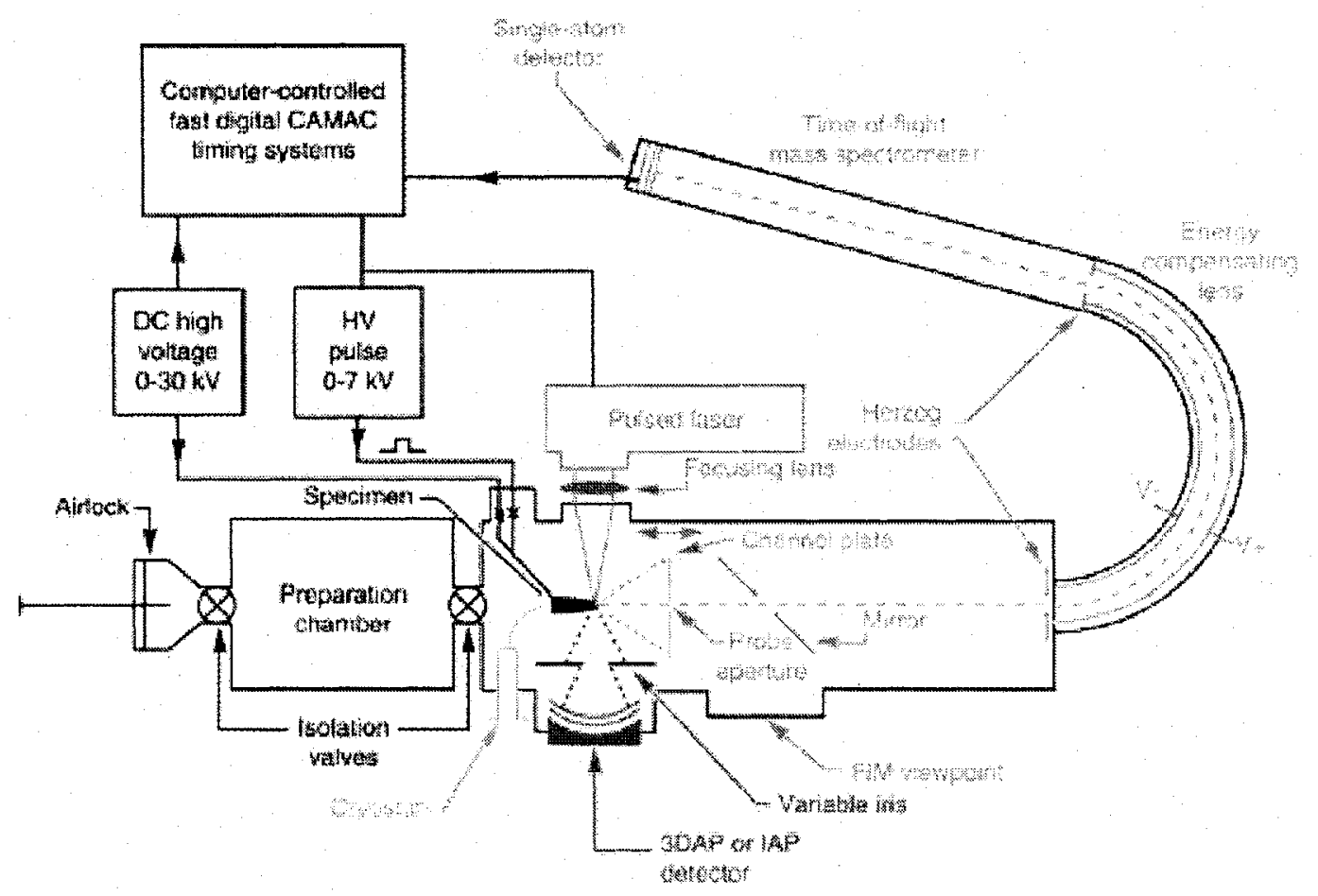

Figure 4.9. The Oak Ridge National Laboratory three-dimensional atom probe (3DAP).

In order to address these drawbacks of 3DAP, the concept of a local electrode atom probe (LEAP) was introduced in the early 1990's. This invention is capable of rapidly pulsed field evaporation or desorption of ions from a tip utilizing a local-extraction electrode positioned closely adjacent to the tip. The bias potential between the tip and the localextraction electrode is relatively low with evaporation taking place by applying relatively low over-voltage pulses between the tip and the local-extraction electrode to obtain field evaporation of ions without substantially accelerating the ions. The first commercial LEAP atom probe microscope was launched by Imago Scientific Instrument Corporation in the 2003 Microscopy \& Microanalysis Conference. This microscope analyzes materials atom by atom and produces detailed imaging and analysis in three dimensions. Its principal advantages relative to the conventional 3DAP are 1) ease and rapidity of specimen preparation (begun with microtip specimens), 2) large solid angle of collection with good mass resolution, and 3) high data collection rates (500 atoms per second). Figure 4.10 shows this microscope. 


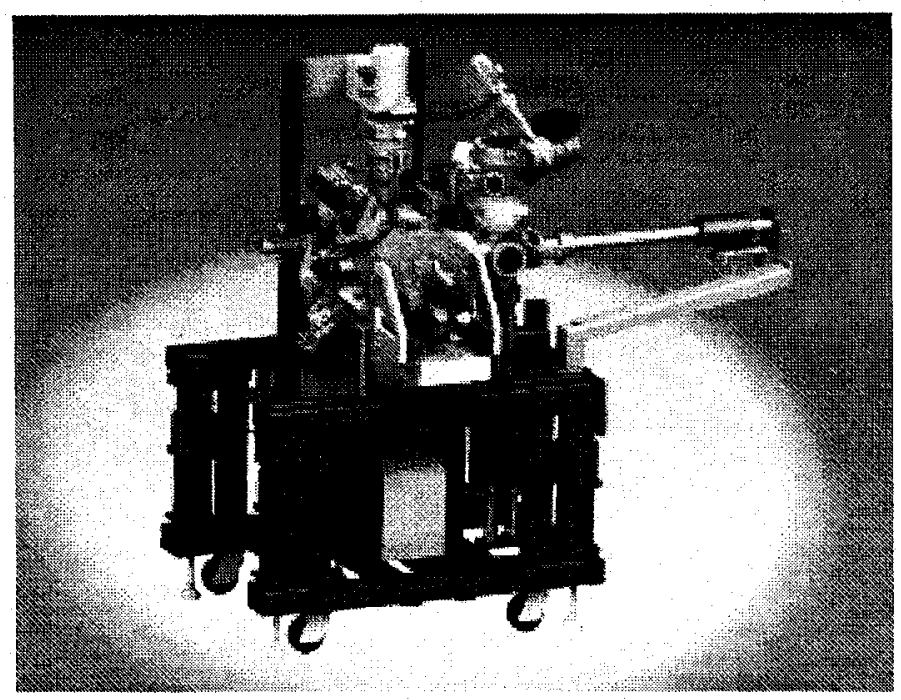

Figure 4.10. 2002 Imago Scientific Instrument Corp's LEAP microscope.

Since one of the objectives in this work is to study the effect of B on the hot ductility, two B2-steel specimens after being subjected to the thermal schedule were quenched at the straightening stage, one just before the tensile test and the other after the fracture. After removing about a $2 \mathrm{~mm}$ decarburized layer from the surface, both specimens were longitudinally cut with a diamond blade into slender pieces of $1 \times 1 \mathrm{~mm}$ cross section and about $10 \mathrm{~mm}$ height. In order to make needles from these slim specimens, they were first ground using 600 grit $\mathrm{SiC}$ abrasive paper and then electropolished in a solution of $50 \mathrm{ml}$ perchloric acid $+750 \mathrm{ml}$ ethanol $+140 \mathrm{ml}$ water for about 1 minutes at $20 \mathrm{~V}$. In this way, about 20 sharp pointed specimens were prepared for the LEAP microscopy, Figure 4.11. 


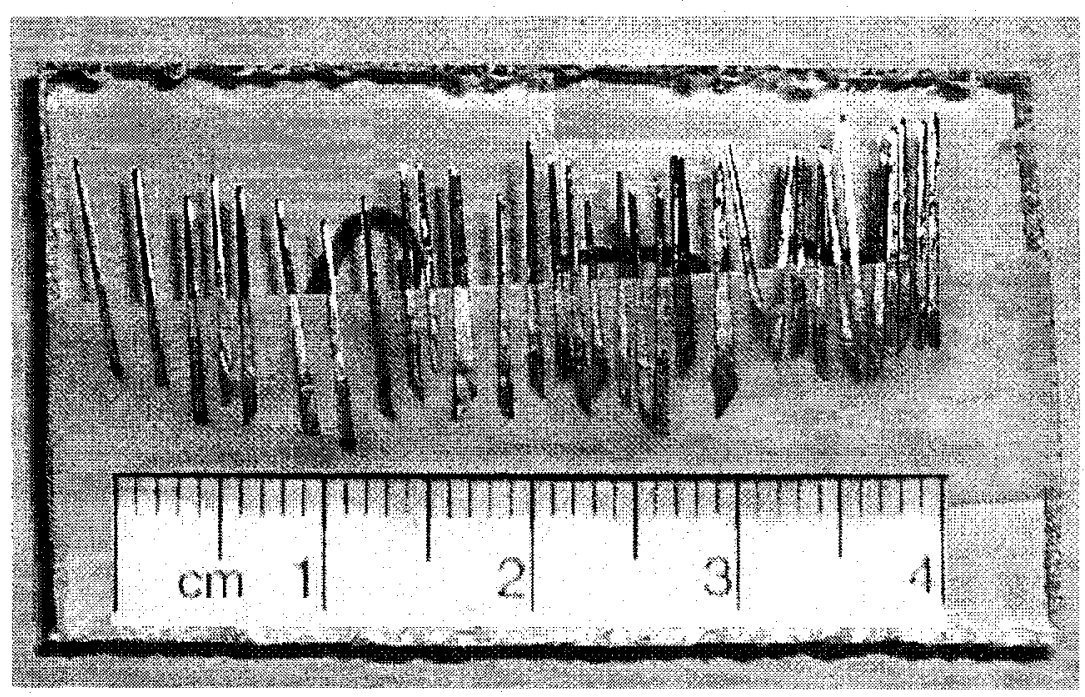

Figure 4.11. Specimens prepared for the LEAP microscopy. (B2-steel) 


\section{RESULTS}

In this chapter, the results of CHT and CCC experiments are first presented. Then, the results of the hot ductility assessment and the microstructure characterizations follow.

\subsection{CHT and CCC Experiments}

The true stress versus true strain diagrams during the CHT experiment are plotted in Figure 5.1 for both the $\mathrm{Nb}$-steel and the B-steel (the results of $\mathrm{CHT}$ and $\mathrm{CCC}$ experiments for the B-steel are attributed to the B1-steel that are similar to those of the B2-steel). Having known the instantaneous deformation time and the heating rate, the temperature corresponding to each intended stress/strain value can be determined. There are three main drops of stress. The material is strain hardened and the strain is accumulated as the deformation proceeds, leading to dynamic recrystallization in the austenite starting at ' $a$ '. This is followed by the dynamic transformation of austenite to $\delta$-ferrite that starts at ' $c$ ', where there is an abrupt drop in the strength of the material. The last drop, indicated by ' $d$ ', occurs due to $\delta$-ferrite grain boundary melting, leading to zero strength of the material. This, so-called incipient melting temperature, is also identified as the nonequilibrium solidus temperature on heating. There are also some intermediate drops, i.e. $b$ and $b^{\prime}$, that are attributed to more dynamic recrystallization processes following the first one. $^{[120]}$ 


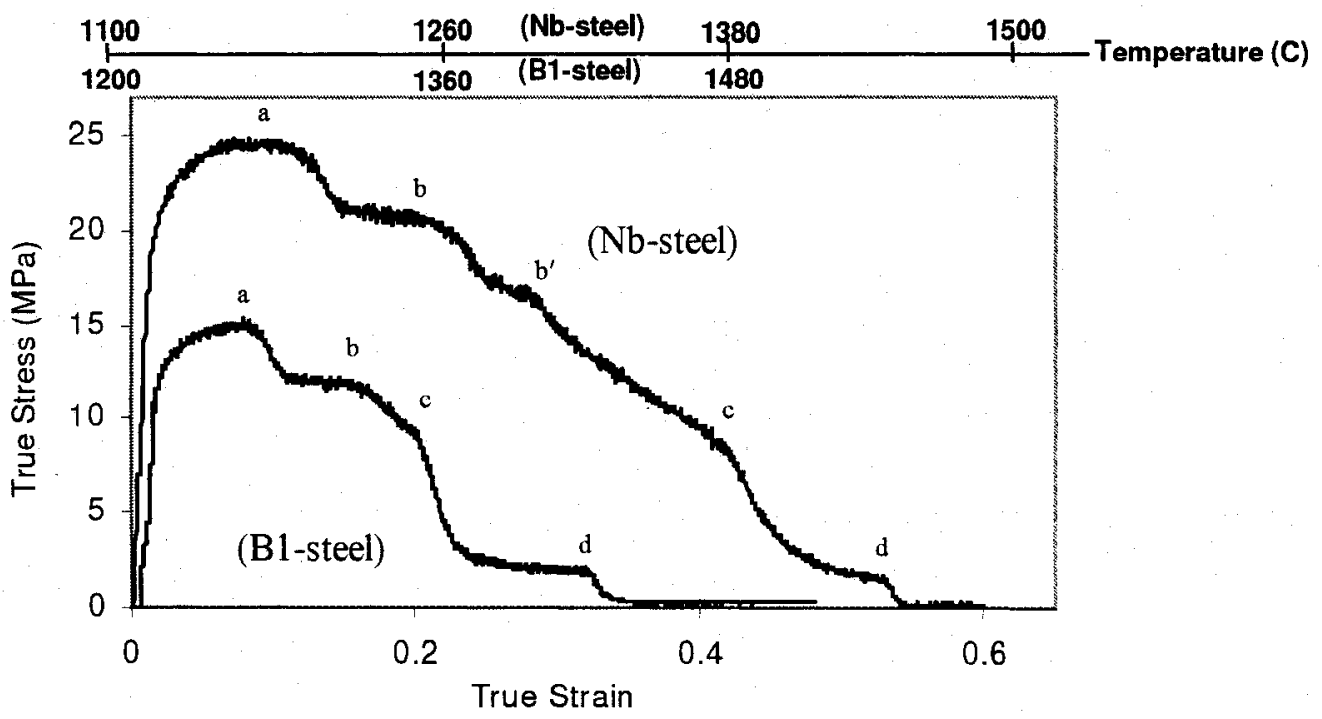

Figure 5.1. CHT experiment. The tensile deformation was started at 1100 and $1200^{\circ} \mathrm{C}$ for the $\mathrm{Nb}$-steel and the B1-steel, respectively. $\left(\dot{\varepsilon}=3 \times 10^{-3} \mathrm{~s}^{-1}\right.$ and $\left.\dot{T}=2{ }^{\circ} \mathrm{C} / \mathrm{s}\right)$

However, only one significant strength change was detected in the CCC experiment, Figure 5.2. As can be seen, both steels demonstrate a stronger behavior after a sudden change in the strength. This change in the mechanical behavior cannot be explained solely by the temperature decrease. There is a major structural change leading to this sudden load augmentation, which can be attributed to the $\delta \rightarrow \gamma$ transformation.

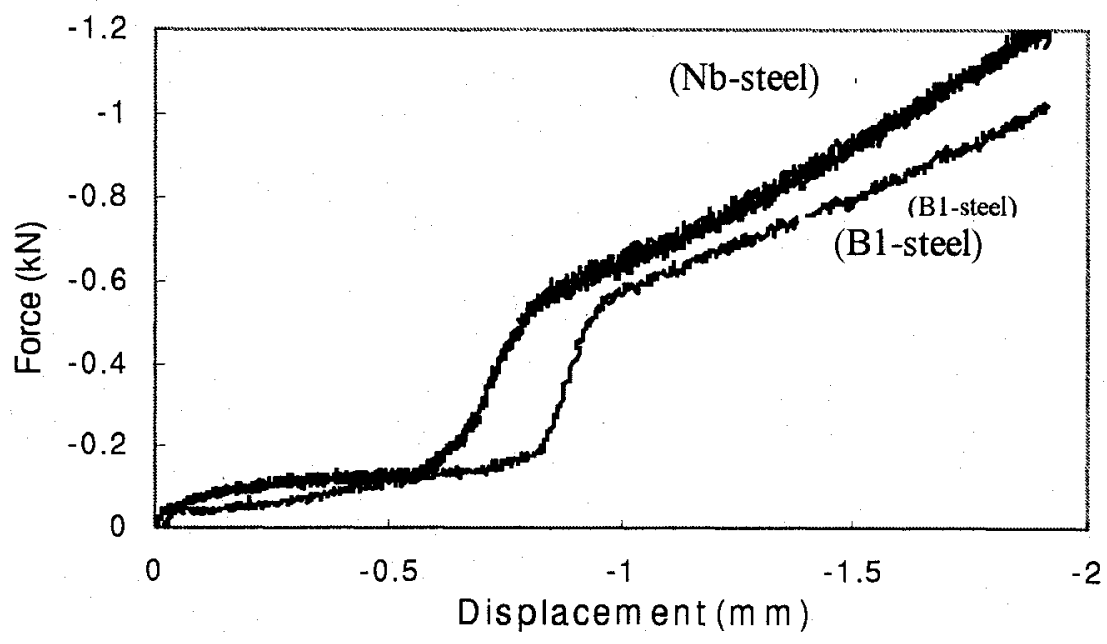

Figure 5.2. CCC experiment. The deformation was incorporated with cooling after melting. ( $\dot{\varepsilon}=3 \times 10^{-3} \mathrm{~s}^{-1}$ and $\dot{T}=10^{\circ} \mathrm{C} / \mathrm{s}$ ) 
Also, by judiciously choosing the right values for the strain rate and cooling rate, the solidus temperature on cooling can be traced, as shown in Figure 5.3, where the strength of the material suddenly increases. The strain rate was chosen according to the cooling rate and thermal contraction of the material. Furthermore, the specimen shouldn't bulge out along the gauge length during compression in the two-phase region of solid+liquid as this can influence the slope of the load change and lead to erroneous results.

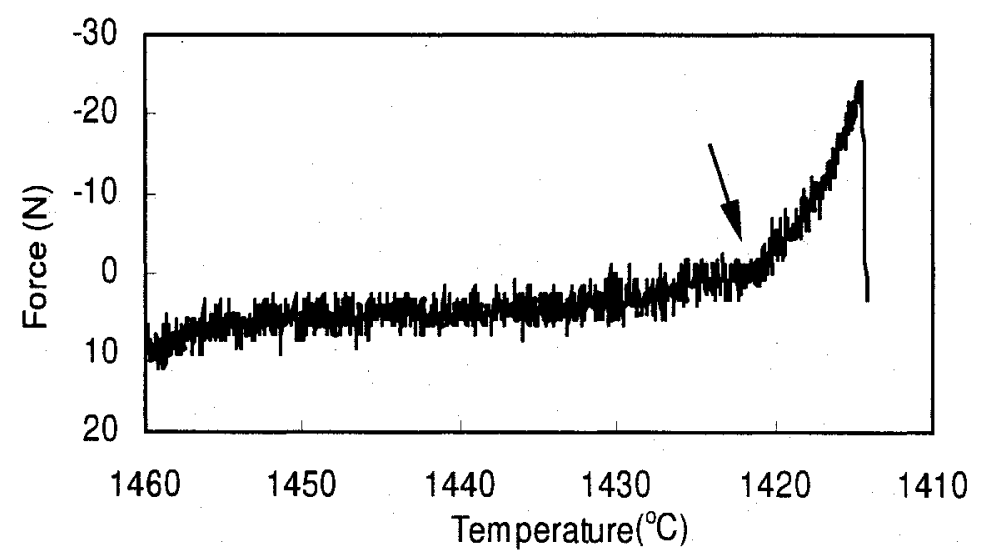

Figure 5.3. $\mathrm{CCC}$ experiment. $\dot{\varepsilon}=9 \times 10^{-3} \mathrm{~s}^{-1}$ and $\dot{T}=5^{\circ} \mathrm{C} / \mathrm{s}$. The arrow indicates the non-equilibrium solidus temperature on cooling. (B1-steel)

The results of the CHT and CCC experiments are summarized in Table 5.1. As can be seen, the solidus temperatures seem lower than expected. This is attributed to the pyrometer calibration that has to encompass a wide range of temperature, i.e. from 700 to $1500^{\circ} \mathrm{C}$, and it is impossible to achieve accuracy for the entirety of this range, especially with the presence of the quartz tube that becomes translucent at temperatures above $1350^{\circ} \mathrm{C}$. Thus, the actual specimen temperature at very high temperatures was higher than indicated by the pyrometer. Nevertheless, this would not cause any problem for the experiment end result since the main aim was to ensure that the intended deformation was applied within the intended region. For instance, if the deformation is expected to go through the transformation region, there must be a sudden increase in the strength similar to Figure 5.2. Also, if deformation is intended to be limited in the liquid+solid region, the 
Table 5.1. Results of CHT and CCC experiments.

\begin{tabular}{|c|c|c|c|}
\hline Material & $\begin{array}{c}\text { Incipient melting } \\
\text { temperature (C) }\end{array}$ & $\begin{array}{c}\text { solidus } \\
\text { temperature (C) }\end{array}$ & $\begin{array}{c}\delta \rightarrow \gamma \\
\text { start temperature }\end{array}$ \\
\hline Nb-steel & 1440 & $1430^{*}$ & 1360 \\
\hline B1-steel & 1430 & 1425 & 1350 \\
\hline
\end{tabular}

"It is an approximation as it was not determined in CCC experiments.

resultant load-displacement curve must look like Figure 5.3. In other words, where the effect of deformation is to be studied, every hot ductility test result is accompanied with a preceding result that verifies if the deformation has been executed as it had been planned. In order to ensure melting, specimens were heated up to a temperature that was $2 \sim 3$ degrees below that at which the melted steel was too fluid to be held in situ. Figure 5.4 shows some of the specimens that were sacrificed to determine this temperature.

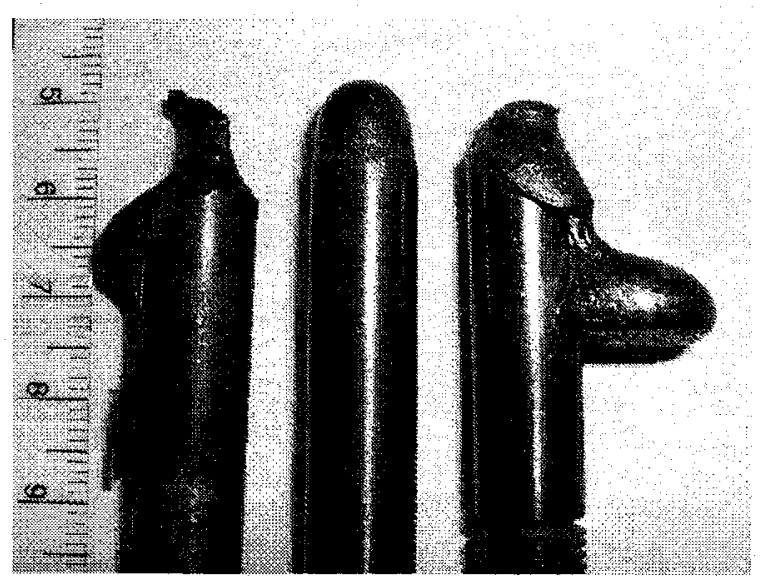

Figure 5.4. Some typical specimens used to determine the maximum temperature at which the melted steel can be held in situ.

Another point that can be seen in Table 5.1 is the lower melting temperature for the B1steel than for the $\mathrm{Nb}$-steel, which was not expected, since a lower carbon content corresponds to a higher melting temperature. This discrepancy may be ascribed to the higher Si and Mn contents in the B1-steel. Nevertheless, the relative temperature of the $\delta$ ferrite to austenite transformation is consistent with what the $\mathrm{Fe}-\mathrm{C}$ phase diagram predicts, i.e. it is lower in the B1-steel than in the $\mathrm{Nb}$-steel. 


\subsection{Hot Ductility Experiments}

\subsubsection{Effect of Thermal Schedule}

Before incorporating deformation with the thermal schedules, it was necessary to study the effect of the thermal schedules alone on the hot ductilities of the intended steels. Stress-strain behaviors of the three steels, after being subjected to their respective thermal schedules, are plotted in Figure 5.5. All three steels basically display a similar work hardening rate. However, both the B1-steel and B2-steel show higher toughness and elongation before fracture than the $\mathrm{Nb}$-steel. In order to determine the effect of melting on the hot ductility, two specimens of the $\mathrm{Nb}$-steel, one with melting and the other without melting, were subjected to the same thermal schedule, Figure 5.6. As can be seen, melting resulted in a significant loss of elongation. This readily confirms the importance of in situ melting in order to generate hot ductility results that are relevant to continuous casting. Also, in Figure 5.6, the tensile behavior of the $\mathrm{Nb}$-steel heated up to $1400^{\circ} \mathrm{C}$ (no melting) and deformed during cooling from $1400^{\circ} \mathrm{C}$ is shown for comparison. The graphs clearly show that the main effect of the deformation is an increase in the ultimate tensile strength. In conclusion, the highest toughness, i.e. integrating the stress strain curve, is attained in the specimen that was not melted and was subjected to deformation while being cooled from the highest temperature. This also shows that an improvement in mechanical properties due to very high temperature compression is not necessarily related to closing of casting defects, since specimen III (Fig. 5.6) was not melted.

Figure 5.7 shows the effect of the straightening temperature on the tensile characteristics of the B2-steel and the $\mathrm{Nb}$-steel. As expected, the strength of these materials decreases and the elongation increases by increasing the test temperature up to 1100 and $1200^{\circ} \mathrm{C}$ in the B2-steel and the $\mathrm{Nb}$-steel, respectively. Nonetheless, even though the strength follows a similar trend as the temperature rises to 1100 and $1200^{\circ} \mathrm{C}$, the elongation is reduced remarkably. As well, it can be seen that, after the peak stress, fracture occurs more gradually at higher temperatures. In contrast to the B2-steel, in the Nb-steel at test 


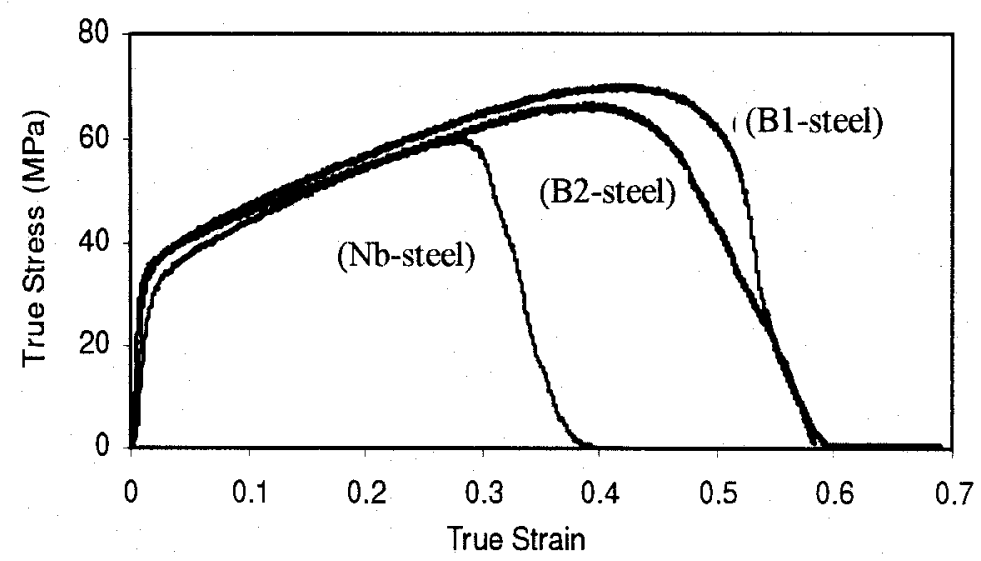

Figure 5.5. Tensile tests at the straightening stage on the specimens subjected to the thermal schedules alone.

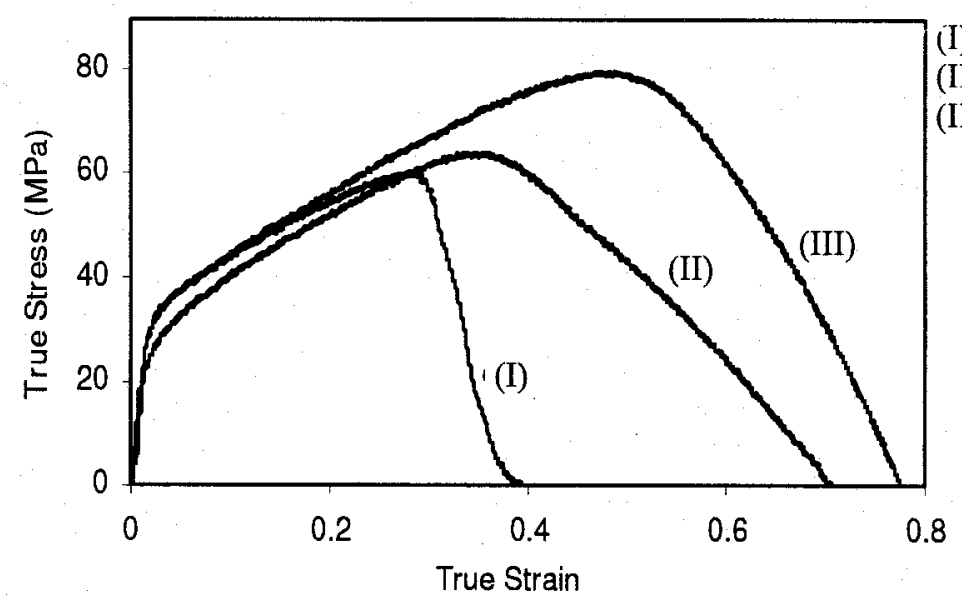

(I): heated up to $1500^{\circ} \mathrm{C}$.

(II): heated up to $1400^{\circ} \mathrm{C}$.

(III): heated up to $1400^{\circ} \mathrm{C}+$ $15 \%$ compression at $0.009 \mathrm{~s}^{-1}$ during cooling from $1400^{\circ} \mathrm{C}$.

Figure 5.6. Tensile tests at the straightening stage on the $\mathrm{Nb}$-steel specimens undergone the thermal schedule alone and the thermal schedule with pre-deformation as specified.

temperatures of 900 and $1020^{\circ} \mathrm{C}$ the stress drops in two 'stages' before the final drop that is due to the fracture, Figure 5.7(b). The first drop, indicated by an arrow, may be due to dynamic recrystallization, but this hypothesis needs to be supported by microstructural observations. 

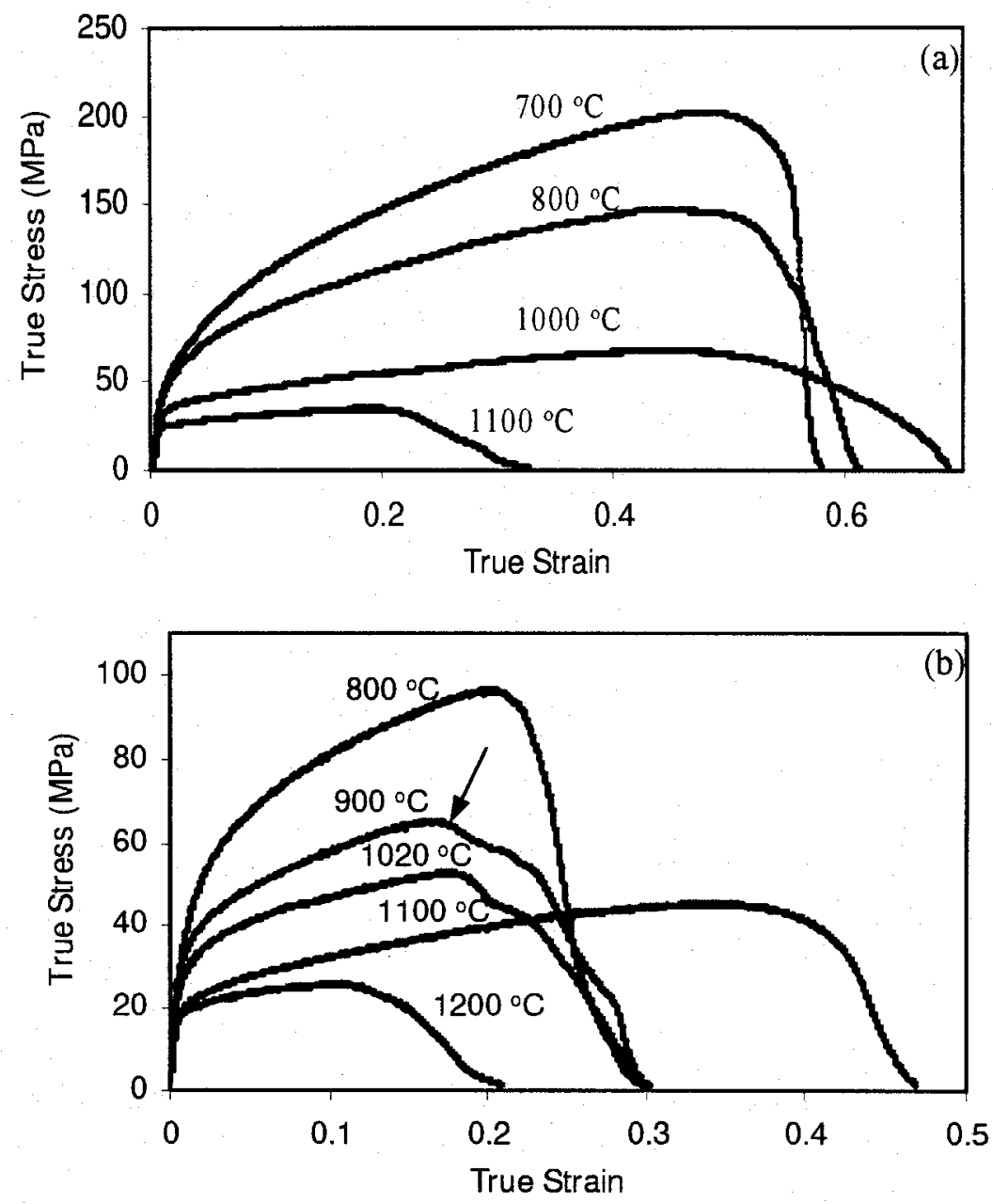

Figure 5.7. Effect of straightening temperature on tensile behavior of specimens subjected to the thermal schedules alone. (a): B2-steel. (b): Nb-steel.

\subsubsection{Effect of Pre-Deformation Associated with Thermal Schedule}

After studying the effect of thermal schedules on the hot ductility, different schedules of deformation (termed pre-compression or pre-tension) were incorporated with the thermal schedules. The subsequent effect of these thermomechanical schedules on the mechanical behavior of the steel, specifically the hot ductility, was investigated by performing tensile tests to fracture at the straightening stage. 
It was found that if pre-deformation, either compression or tension, was applied during solidification, i.e. in the liquid+solid region, over the thermal schedule, the elongation to fracture was diminished. Pre-tensile deformation gave the more detrimental result by far, Figure 5.8. However, pre-deformation in solid phases does not influence the tensile characteristics significantly in the B1 and B2 steels, comparing Figures 5.9 and 5.5. In Figure 5.9, the lower elongation and peak stress in the specimen that was subjected to pre-tension in the $\delta$-ferrite region can be attributed to a somewhat smaller cross sectional area at the straightening stage (the original diameter was considered in all calculations for true stress and strain) and possible defects created during the pre-tension. As for the specimens that experienced pre-compression in the $\delta$-ferrite and $\delta \rightarrow \gamma$ transformation regions, the strain to fracture was the same as that of the specimen subjected solely to the thermal schedule.

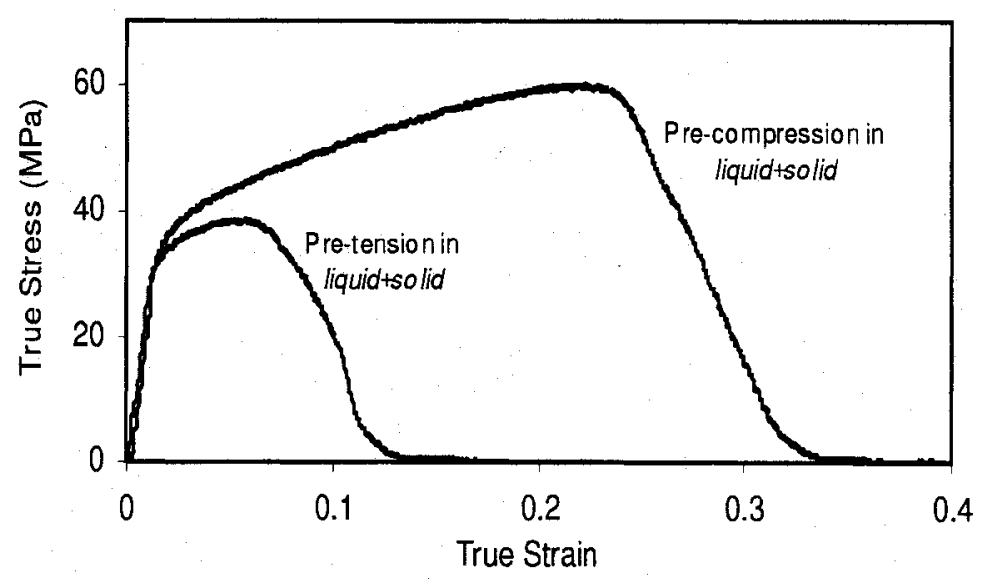

Figure 5.8. Tensile tests at the straightening stage on specimens subjected to pre-compression and pre-tension in the 'liquid+solid' region. (B1-steel)

In the $\mathrm{Nb}$-steel, pre-deformation was designed such that it crossed the thermal boundary between the three regions specified in Figure 4.7. Figure 5.10 shows the effect of different pre-deformation schedules superimposed on the thermal schedule during solidification and cooling. Curves II and III are fairly identical with the exception that curve III has extended to higher elongation. Curve I displays lower strength and 


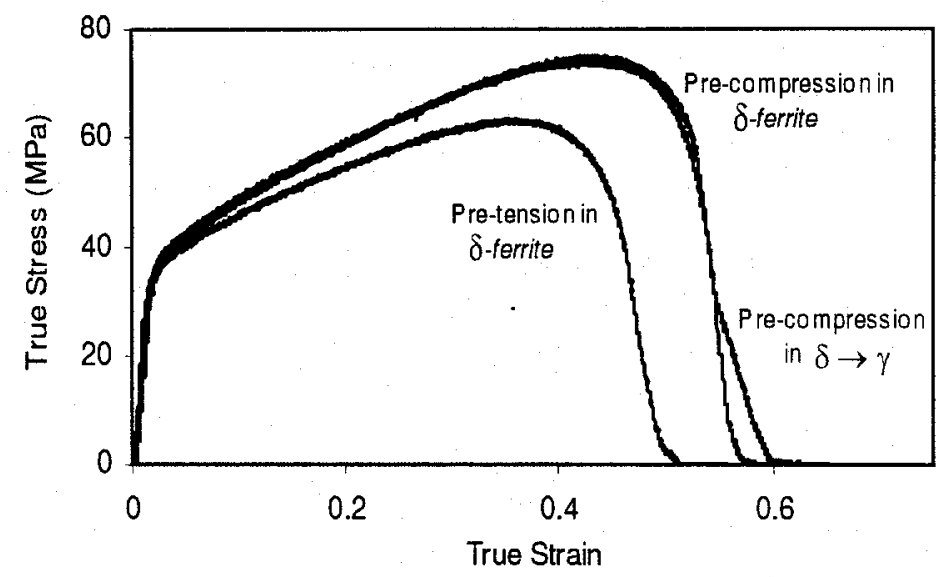

Figure 5.9. Tensile tests at the straightening stage on specimens subjected to precompression and pre-tension in $\delta$-ferrite and $\delta \rightarrow \gamma$ transition regions. (B1-steel)

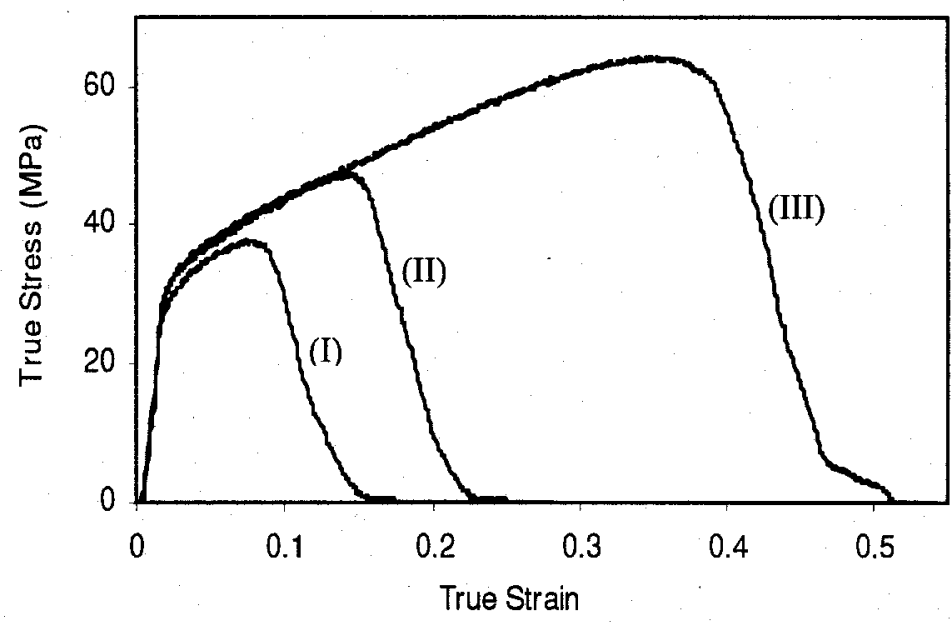

Schedules of pre-compression started with solidification (I): $\varepsilon=0.05, \dot{\varepsilon}=0.009 \mathrm{~s}^{-1}$ (II): $\varepsilon=0.1, \dot{\varepsilon}=0.009 \mathrm{~s}^{-1}$ (III): $\varepsilon=0.1, \dot{\varepsilon}=0.003 \mathrm{~s}^{-1}$

Figure 5.10. Effect of pre-compression incorporated with the thermal schedule on tensile characteristics of the $\mathrm{Nb}$-steel. All specified pre-deformations initiated with the solidification stage.

elongation to fracture. Comparing the pre-deformation schedules, it appears that increasing the pre-deformation strain in the solid phase increases the mechanical properties.

The effect of pre-deformation start temperature in the solid phases is shown in Figure 5.11. Figure 5.11(a) describes the different pre-deformation schedules in terms of the pre- 
compression flow behavior. As can be seen by the abrupt change in flow stress, in all three pre-deformation schedules the deformation began in the $\delta$-ferrite region and continued into the $\delta \rightarrow \gamma$ transition region. However, the extent of intrusion into the transformation region and the following austenite region is different in each schedule. It can be obviously seen that the $4 \%$ pre-compression initiated at $1385^{\circ} \mathrm{C}$ encompassed the whole region of transformation, i.e. started in the $\delta$-ferrite region and continued well into the austenite region. All the specimens were quickly unloaded as soon as the intended amount of deformation was attained. It seems that these pre-deformation schedules barely influenced the B1-steel tensile characteristics at the straightening stage, when compared to the effect of the thermal schedule alone, Figure 5.11(b).
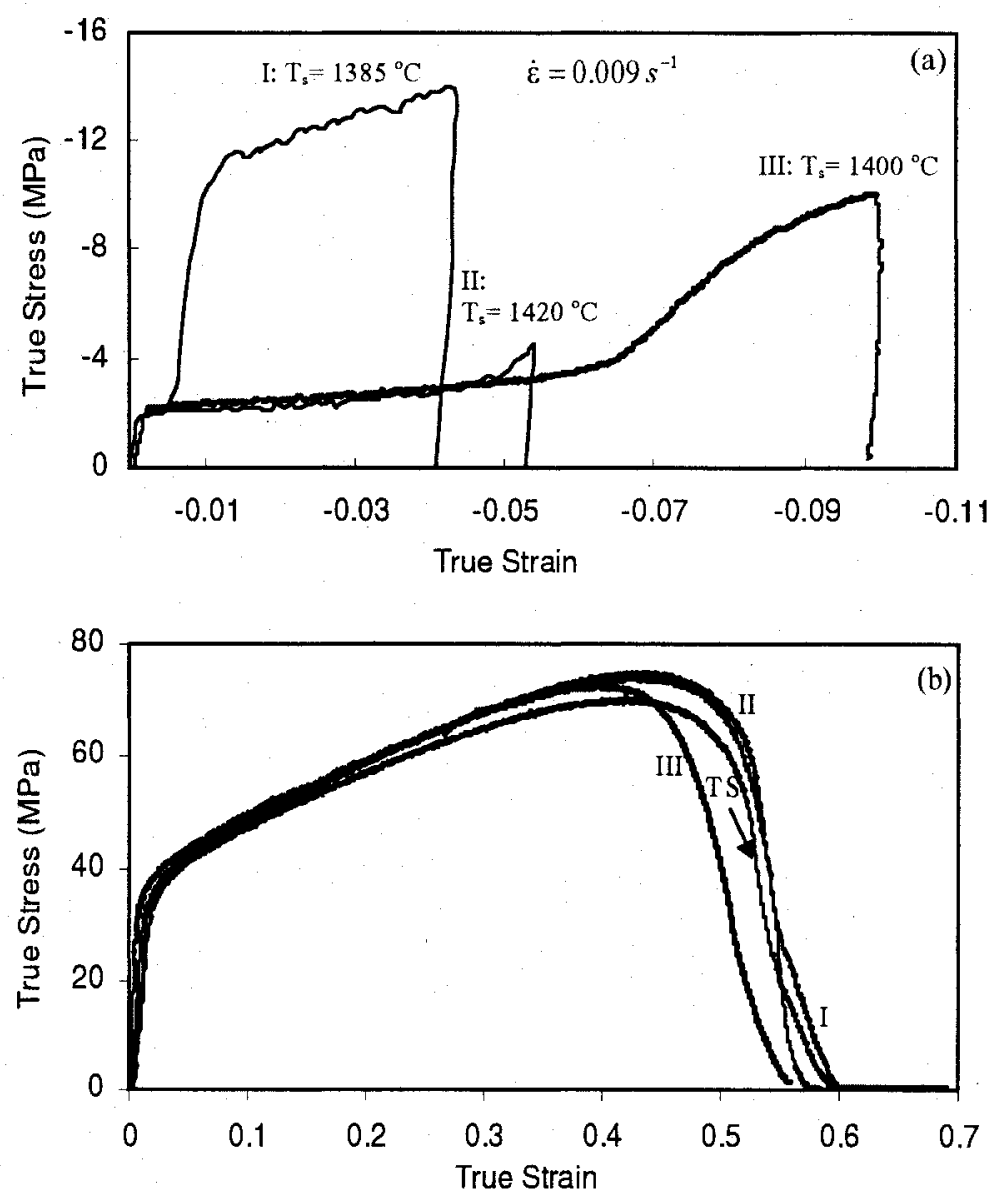

Figure 5.11. (a) Schedules of pre-deformation started at different temperatures $\left(T_{s}\right)$ over the thermal schedule. (b) Stress-strain curves at the straightening stage. I, II, and III correspond with their respective specimens in (a). TS: Thermal Schedule alone. (B1-steel) 
Pre-deformation appeared to be more influential when it was applied to the Nb-steel, as can be seen in Figure 5.12. The pre-compression characteristics are illustrated in Figure 5.12(a). The first specimen, designated by I, was deformed only in the $\delta$-ferrite region without crossing the $\delta \rightarrow \gamma$ transformation region. The pre-compression of the next three specimens began at the same temperature as for the specimen I but it went through the $\delta \rightarrow \gamma$ transformation region and continued to different extents in the austenite region. Multiple slope changes show that the deformation and the transformation coincided. The last specimen, V, was deformed when the transformation was completed, specifically; it was deformed in the single-phase austenite region. As Figure 5.12(b) demonstrates, precompression in the $\delta$-ferrite region is deleterious to the mechanical properties but beneficial if applied during the transformation and in the high temperature austenite region, as compared with the effect of the thermal schedule alone. The tensile test results obtained for the specimens which had undergone the pre-compression schedules III and IV in Figure 5.12(a) are similar to those of the specimen that was subjected to the precompression schedule II.

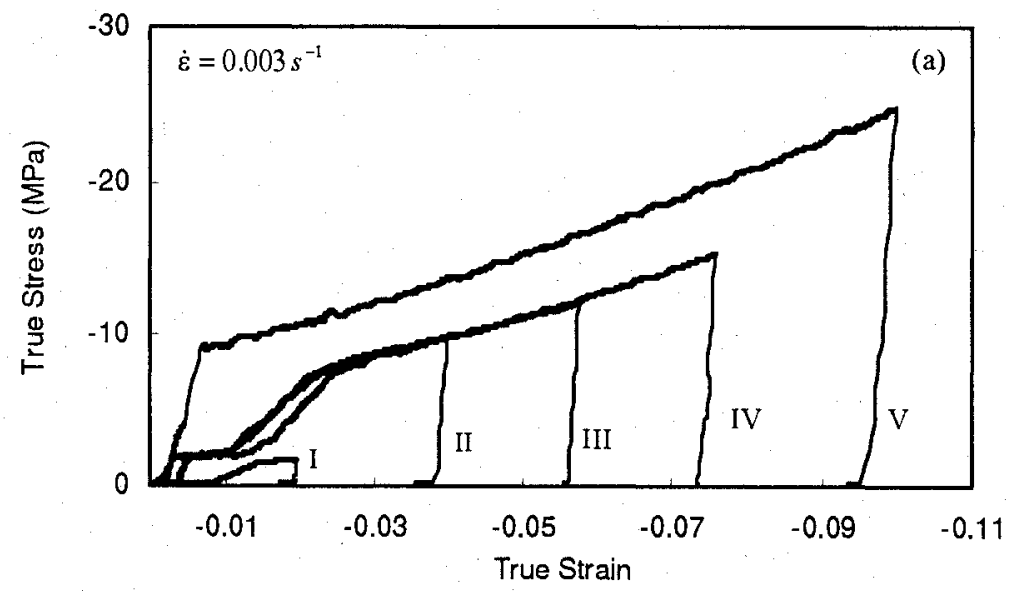

Figure 5.12. (a) Pre-compression started before (I, II, III, IV) and after (V) the $\delta \rightarrow \gamma$ transformation. (b) Tensile tests, at the straightening stage, corresponding to the predeformation schedules in (a). TS: Thermal Schedule alone. (Nb-steel) 


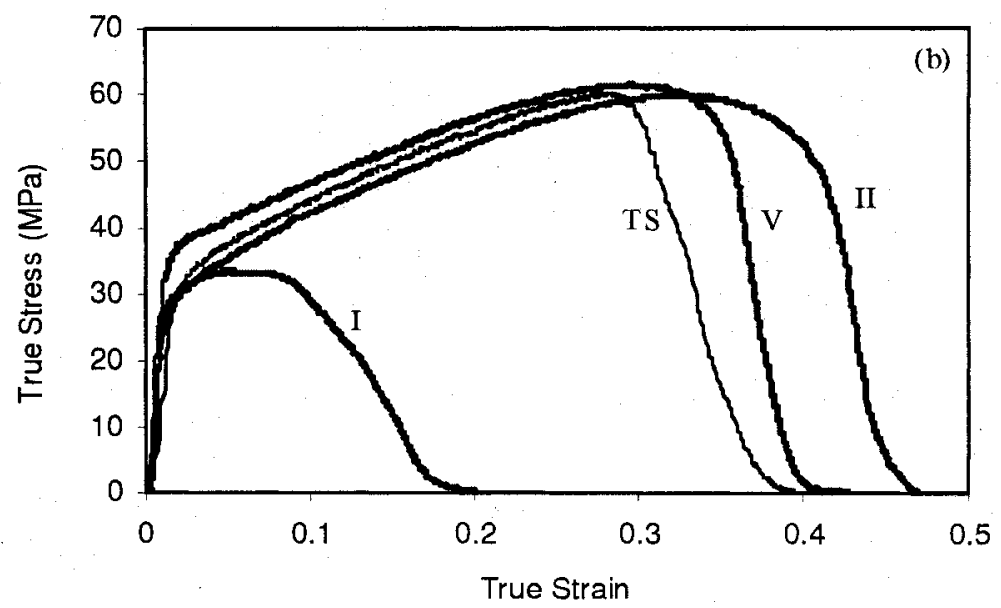

Figure 5.12, continued.

After studying the effect of pre-deformation amount, the effect of deformation rate in the vicinity of the transformation region was also examined. Figure 5.13(a) illustrates three pre-deformation schedules designed for this purpose. The amount of pre-deformation in these schedules was devised such that no perceivable bulging would occur within the gauge length during pre-compression. A strain of 0.15 was chosen for the strain rate of $0.027 \mathrm{~s}^{-1}$ to ensure that the deformation would continue into the transformation region. As can be seen in Figure 5.13(a), all three schedules were initiated in the $\delta$-ferrite region and encompassed some or the entire region in which the $\delta \rightarrow \gamma$ transition takes place. For the strain rate of $0.027 \mathrm{~s}^{-1}$, the pre-compression terminated before completion of the transformation whereas, for the strain rate of $0.003 \mathrm{~s}^{-1}$, it carried on well beyond the transformation finish temperature. Figure 5.13(b) shows that the pre-compression II has led to the greatest elongation but the highest strength was achieved by the precompression I.

In addition to the single stage pre-deformation, alternate pre-deformation schedules were also studied in the $\mathrm{Nb}$-steel. These schedules are shown in Figure 5.14. As illustrated in Figure 5.14(a), the specimens were subjected to a pre-compression $\left(\varepsilon=0.1, \dot{\varepsilon}=3 \times 10^{-3}\right.$ $\mathrm{s}^{-1}$ ) during the $\delta \rightarrow \gamma$ transformation. Then, a cyclic pre-deformation schedule, i.e. alternate 

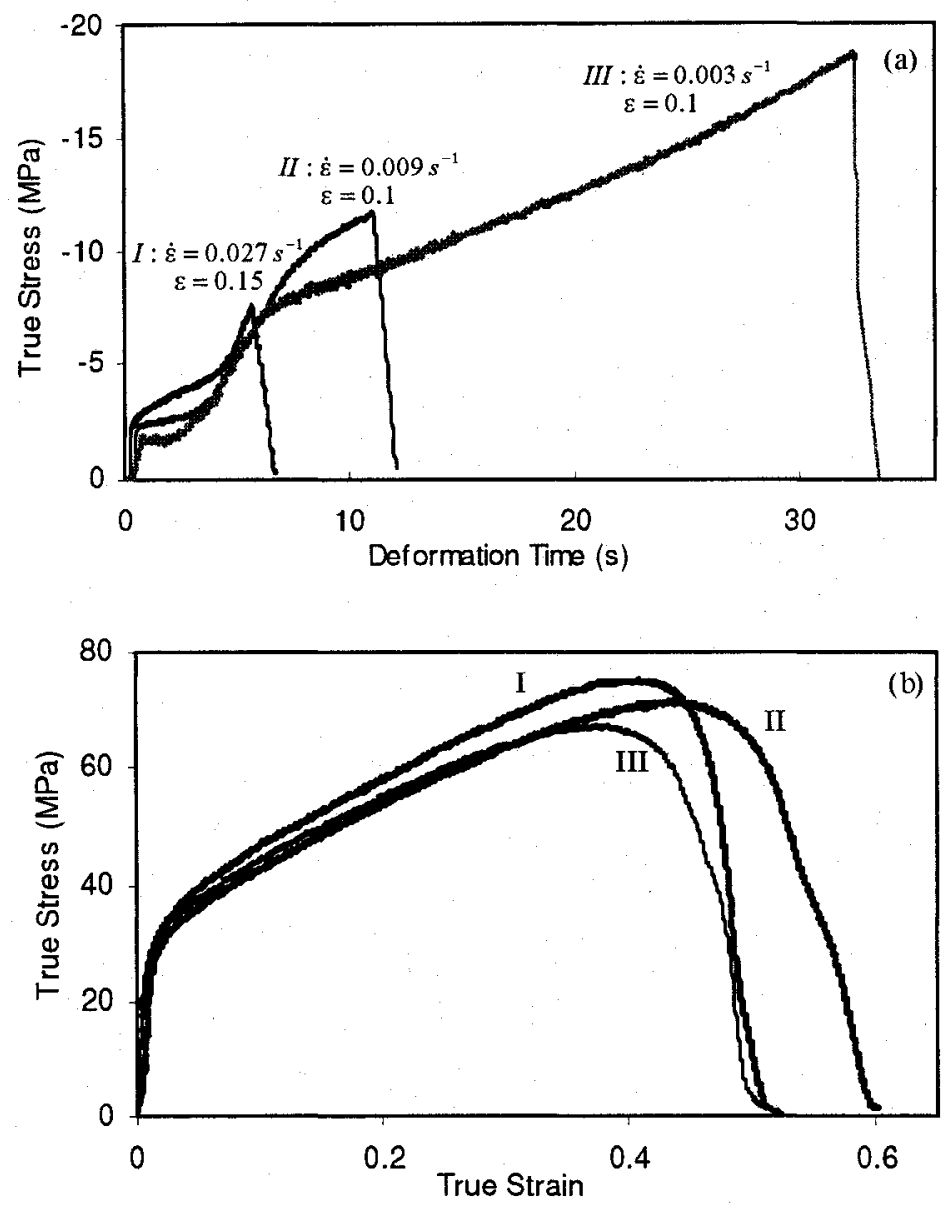

Figure 5.13. (a) Pre-compression during the $\delta \rightarrow \gamma$ transformation and, (b) corresponding tensile behavior at the straightening stage. Specimens I, II and III in (b) correspond with their respective specimens in (a). (Nb-steel)

pre-compression and pre-tension, was executed while the specimen was going through the last segment of the thermal schedule. Two identical cyclic deformation schedules, but performed at two different temperatures, i.e. schedules A and B in Figure 5.14(a), were separately applied to two specimens which had been subjected to pre-compression during the transformation. Note that the cyclic deformation was applied while the temperature was decreasing. The deformation was imposed alternately in order to prevent changing the specimen diameter while the strain is being accumulated during pre-tension or precompression. Finally, the hot ductility was evaluated, as before, at the straightening stage 

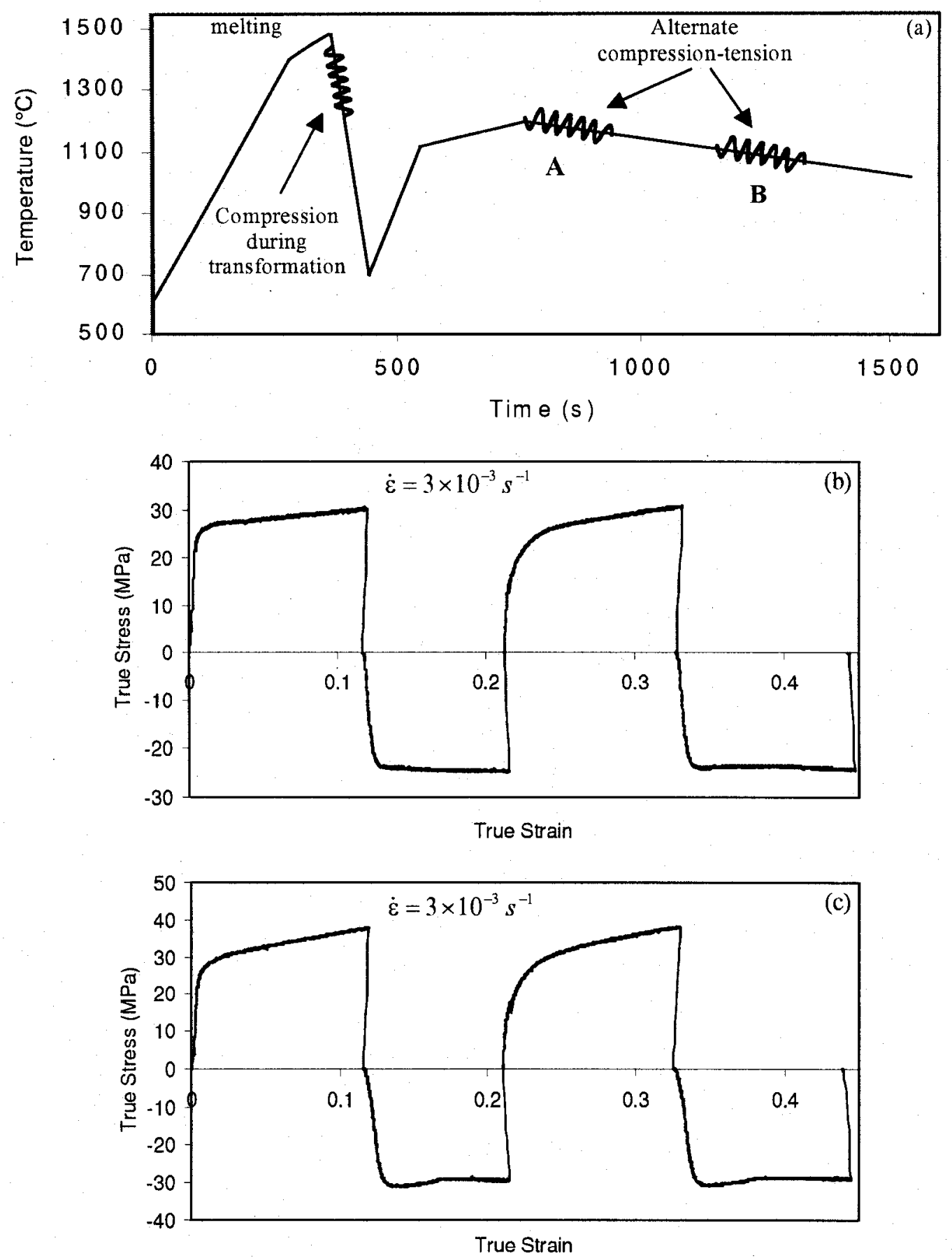

Figure 5.14. (a) Schematic illustration of cyclic deformation, following the pre-compression during the $\delta \rightarrow \gamma$ transformation. (b) and (c): cyclic stress-strain curves of deformation schedules designated as A and B, respectively, in (a). The deformation schedules A and B were separately applied to two different specimens. (d) Tensile tests, at the straightening stage, corresponding with the cyclic deformation schedules in (a). (Nb-steel) 


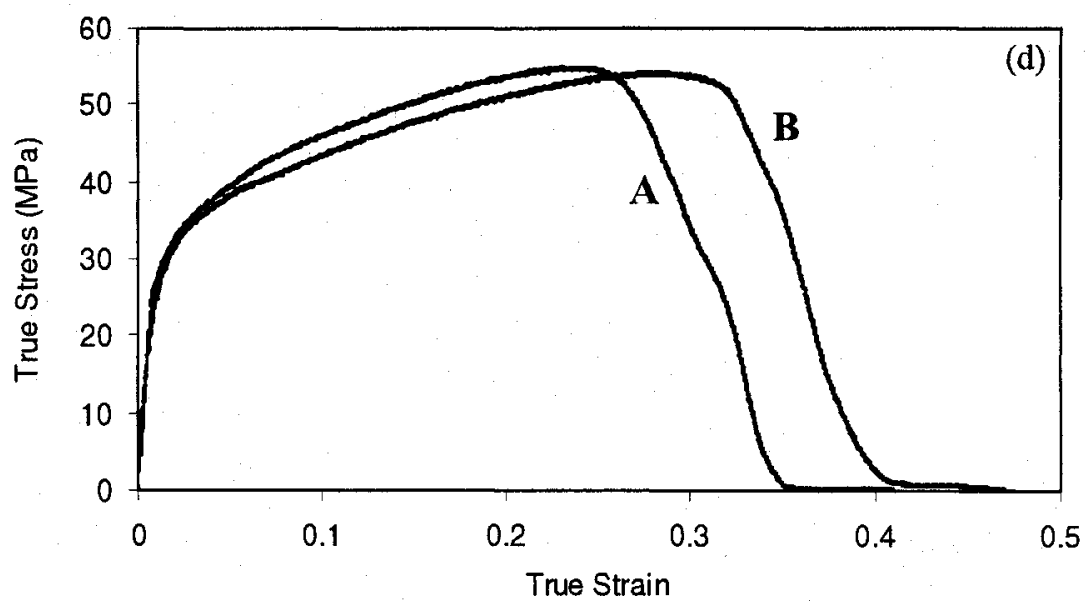

Figure 5.14, continued.

of the thermal schedule. The stress-strain curves obtained during the hot ductility test are plotted in Figure 5.14(d) and are almost similar to that of the specimen subjected solely to a pre-compression of $\dot{\varepsilon}=3 \times 10^{-3} \mathrm{~s}^{-1}$ during the transformation, the specimen III in Figure 5.13(a). However, the cyclic schedule B led to a slightly higher elongation before the fracture. Both Figures 5.14(b) and (c) display very slow work hardening rate, implying that the softening mechanisms were also underway.

\subsubsection{Hot Ductility Evaluation}

The results of the reduction in area measurements are summarized in Tables 5.2 for specimens pre-deformed in the vicinity of the 'liquid+solid' region. As can be seen, compared with the effect of the thermal schedule alone, pre-deformation during solidification is very detrimental to the hot ductility in both the Nb-steel and the B1-steel. The B2-steel reacted to pre-deformation in a similar way as the B1-steel did. The effect of pre-tension appears to be worse than pre-compression. Generally, the result shows that as long as there is a pre-deformation during solidification, the hot ductility is markedly deteriorated at the straightening stage. However, specimens in which the pre-deformation continued in the solid phase after accompanying solidification display better ductilities than the specimen subjected to the pre-deformation limited within the 'liquid+solid' 
region (Figure 5.10). As well, it seems that the more pre-deformation imposed within the solidification region, the worse the hot ductility at the straightening stage ( $8 \%$ versus $12 \%$ RA).

Table 5.2. Hot ductility of specimens pre-deformed in the vicinity of the 'liquid+solid' region.

\begin{tabular}{|c|c|c|}
\hline $\begin{array}{c}\text { Pre-deformation } \\
\text { start temperature } \\
\left({ }^{\circ} \mathrm{C}\right)\end{array}$ & $\begin{array}{c}\text { Pre-deformation } \\
\text { schedule }\end{array}$ & $\mathbf{R A} \%$ \\
\hline $\begin{array}{l}\text { No pre-deformation } \\
\text { (Figure } 5.5 \text { ) }\end{array}$ & $\begin{array}{c}\text { No pre-deformation } \\
\text { (Figure } 5.5 \text { ) }\end{array}$ & $\begin{array}{l}60 \text { (B1-steel) } \\
15(\mathrm{Nb} \text {-steel })\end{array}$ \\
\hline $\begin{array}{c}1490 \text { (B1-steel) } \\
(\text { Figure 5.8) }\end{array}$ & $\begin{array}{l}\varepsilon=0.05 \text { (tension) } \\
\dot{\varepsilon}=0.009 \mathrm{~s}^{-1}\end{array}$ & 4 \\
\hline $\begin{array}{c}1490 \text { (B1-steel) } \\
\text { (Figure 5.8) }\end{array}$ & $\begin{array}{l}\varepsilon=0.05 \\
\dot{\varepsilon}=0.009 s^{-1}\end{array}$ & 9 \\
\hline $\begin{array}{c}1481 \text { (Nb-steel) } \\
\text { (Figure } 5.10)\end{array}$ & $\begin{array}{l}\varepsilon=0.05 \\
\dot{\varepsilon}=0.009 s^{-1}\end{array}$ & 0 \\
\hline $\begin{array}{c}1481(\mathrm{Nb} \text {-steel) } \\
\text { (Figure 5.10) }\end{array}$ & $\begin{array}{l}\varepsilon=0.1 \\
\dot{\varepsilon}=0.009 s^{-1}\end{array}$ & 8 \\
\hline 1462 (Nb-steel) & $\begin{array}{l}\varepsilon=0.1 \\
\dot{\varepsilon}=0.009 s^{-1}\end{array}$ & 8 \\
\hline $1440(\mathrm{Nb}$-steel $)$ & $\begin{array}{l}\varepsilon=0.1 \\
\dot{\varepsilon}=0.009 \mathrm{~s}^{-1}\end{array}$ & 9 \\
\hline $\begin{array}{c}1481(\mathrm{Nb} \text {-steel) } \\
\text { (Figure 5.10) }\end{array}$ & $\begin{array}{l}\varepsilon=0.1 \\
\dot{\varepsilon}=0.003 s^{-1}\end{array}$ & 12 \\
\hline
\end{tabular}

* All pre-deformation schedules are compressive unless otherwise specified.

The effect of melting on the hot ductility is shown in Table 5.3. Both Figure 5.6 and the results of the RA measurements show that, in contrast to the re-melted specimen, the specimen that was re-heated even to a very high temperature and close to the melting temperature, but was not melted, is fully ductile. Also, no deleterious effect of deformation was found in the specimen that was not melted.

Table 5.3. Hot ductility of the specimens presented in Figure 5.6.

\begin{tabular}{|c|c|c|c|}
\hline Specim en & I & II & III \\
\hline RA\% & 15 & 100 & 100 \\
\hline
\end{tabular}


The hot ductility trough is plotted in Figure 5.15 for the specimens whose stress-strain curves are presented in Figure 5.7. Also, for the sake of comparison, the results of Kim et $a l .{ }^{[112]}$ on a Nb-steel containing boron reheated to $1350^{\circ} \mathrm{C}$ and cooled to different test temperatures are shown. The reason why the B2-steel generally demonstrates lower hot ductility than Kim et al.'s can be attributed to the effect of re-melting. However, it principally exhibits higher hot ductility than the $\mathrm{Nb}$-steel. The hot ductility of the $\mathrm{Nb}$-steel is much lower and it is maintained until the temperature rises to $1100^{\circ} \mathrm{C}$. There are certain temperatures for both steels above which the hot ductility starts decreasing significantly. This thermal regime, as shown in Figure 5.15, starts from 1100 and $1200^{\circ} \mathrm{C}$ for the B2steel and the $\mathrm{Nb}$-steel, respectively. The dotted segment of the $\mathrm{Nb}$-steel trough curve has not been obtained experimentally in this work because the specimens tested at $700^{\circ} \mathrm{C}$ necked and fractured outside the gauge length, i.e. in the re-heated region instead of the re-melted region. A typical specimen tested at this temperature is shown in Figure 5.16. Nevertheless, the dotted segment resembles the general trend of the hot ductility curve at temperatures lower than $800^{\circ} \mathrm{C}$ in re-heated specimens. ${ }^{[3]}$

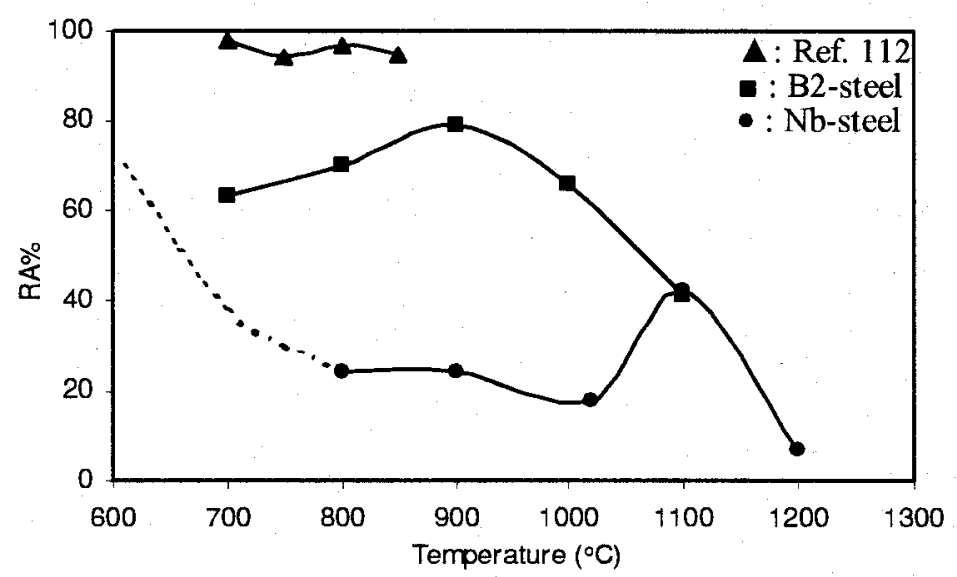

Figure 5.15. Hot ductility troughs of the $\mathrm{B} 2$-steel and the Nb-steel corresponding with the specimens shown in Figure 5.7. The results of reference 112 are also presented for comparison.

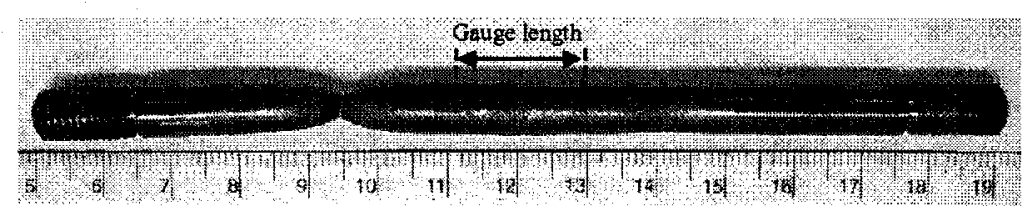

Figure 5.16. A Nb-steel specimen tested at the straightening stage at $700^{\circ} \mathrm{C}$. Necking has not occurred within the gauge length (re-melted region). 
In contrast to pre-deformation in the 'liquid+solid' region, pre-deformation in the solid phases appeared to be either beneficial or detrimental depending on the region of execution. As Table 5.4 shows, in general, applying pre-deformation in the $\delta$-ferrite region and the transformation region alters the hot ductility within a narrow range in the B1-steel. This range is much wider in the Nb-steel whose hot ductility is much lower than those of the B1 and B2 steels, Figure 5.5. Compared to the effects of the thermal schedules alone, Table 5.4 displays that applying pre-deformation in the $\delta$-ferrite region is harmful to the hot ductility, but it is beneficial when it goes through the $\delta \rightarrow \gamma$ transformation region. In this respect, the relative amount of pre-deformation experienced by $\delta$-ferrite and the transformation region dictates the hot ductility at the straightening stage. Pre-deformation in the austenite region, specimen V in Figure 5.12, shows also some beneficial effect. Nevertheless, the best result was obtained when the predeformation went through the transformation region, continuing 'sufficiently' in the austenite region, comparing specimens IV and III in Figures 5.12 and 5.13, respectively. In other words, the contributions to the hot ductility improvement of the pre-deformation in both the transformation and austenite regions must be considered to optimize the hot ductility at the straightening stage. This can be more clearly understood by comparing the RA\% values of 28,23 , and 41 in Table 5.4. Furthermore, it was found that there was an optimum combination of strain and strain rate at which the highest hot ductility could be achieved, Table 5.4. As well, it appeared that applying the cyclic deformation preceded by the pre-compression during the transformation did not change the situation from that resulted by the pre-compression alone. This can be perceived by comparing the last three values for RA in Table 5.4.

The destructive effect of pre-deformation during solidification was confirmed when the effect of pre-deformation from the 'liquid+solid' region down to the austenite region on the hot ductility was followed. Figure 5.17 shows the effect of the temperature at which pre-compression initiated over the thermal schedule. The graphs indicate that both predeformation start temperature and pre-deformation rate have influenced the hot ductility. 
Table 5.4. Hot ductility of specimens deformed in the solid and the vicinity of the transformation regions.

\begin{tabular}{|c|c|c|c|}
\hline $\begin{array}{c}\text { Deformation } \\
\text { region/schedule }\end{array}$ & $\begin{array}{c}\text { True } \\
\text { strain }\end{array}$ & $\begin{array}{c}\text { True strain } \\
\left.\text { rate (s }{ }^{-1}\right)\end{array}$ & RA\% \\
\hline \multicolumn{3}{|c|}{ B1-steel } \\
\hline Tension in delta-ferrite & 0.05 & 0.009 & 58 \\
\hline Fig. 5.11(b) (specimen I) & 0.05 & 0.009 & 66 \\
\hline Fig. 5.11(b) (specimen II) & 0.055 & 0.009 & 56 \\
\hline Fig. 5.11(b) (specimen III) & 0.1 & 0.009 & 64 \\
\hline Fig. 5.12(b) (specimen I) & 0.02 & 0.003 & 13 \\
\hline Fig. 5.12(b) (specimen II) & 0.04 & 0.003 & 27 \\
\hline Fig. 5.12(b) (specimen III) & 0.06 & 0.003 & 27 \\
\hline Fig. 5.12(b) (specimen IV) & 0.08 & 0.003 & 28 \\
\hline Fig. 5.12(b) (specimen V) & 0.1 & 0.003 & 23 \\
\hline Fig. 5.13(b) (specimen I) & 0.15 & 0.027 & 42 \\
\hline Fig. 5.13(b) (specimen II) & 0.1 & 0.009 & 53 \\
\hline Fig. 5.13(b) (specimen III) & 0.1 & 0.003 & 41 \\
\hline Specimen of Fig. 5.14(b) & $\begin{array}{c}0.1+ \\
\text { cyclic }\end{array}$ & 0.003 & 40 \\
\hline Specimen of Fig. 5.14(c) & $\begin{array}{c}0.1+ \\
\text { cyclic }\end{array}$ & 0.003 & 40 \\
\hline
\end{tabular}

The RA corresponding with the effect of the thermal schedule alone is also shown for comparison. As can be seen, the high pre-compression rate, if applied during solidification, is detrimental to the hot ductility and the severity of this effect depends on the amount of pre-compression imposed in the 'liquid+solid' region, i.e. the more precompression, the more intense the effect. On the contrary, when the pre-compression start 
temperature decreases below the solidus temperature, it seems that the higher predeformation rate is more beneficial.

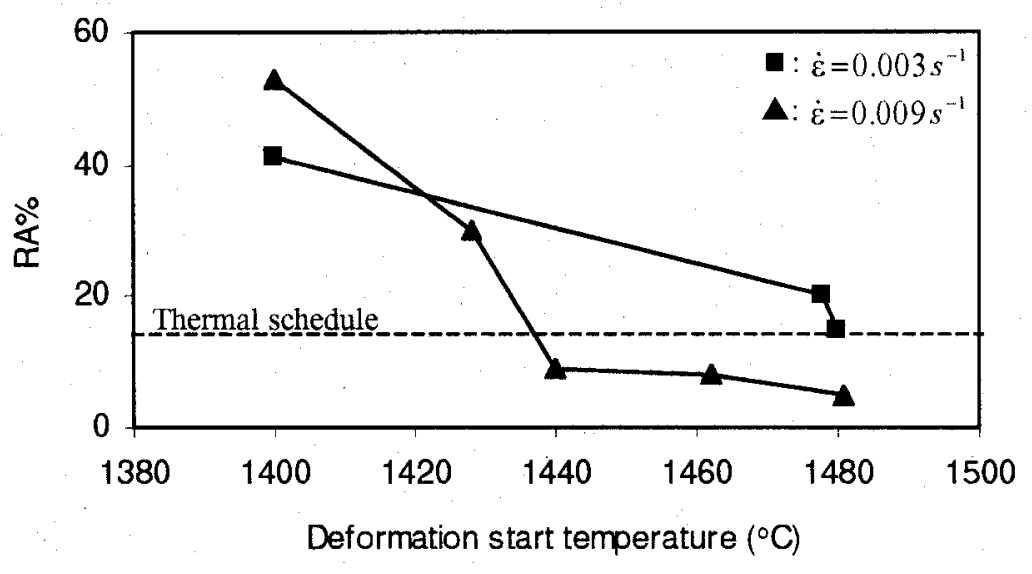

Figure 5.17. Effect of pre-compression start temperature on RA. All specimens were subjected to $\varepsilon=0.1$ pre-compression associated with the thermal schedule. ( $\mathrm{Nb}$-steel)

\subsection{Fractography and Microstructure}

\subsubsection{CHT Experiment}

The fracture surface of a specimen subjected to the CHT experiment is shown in Fig. 5.18. The dendritic structure suggests that the specimen was partially melted at the $\delta$ ferrite grain boundaries, toward the grain interiors. Therefore, the strength of the material dropped to almost zero since there was no resistance to the tension from the melting material. This corresponds with the incipient melting point in Figure 5.1. A few degrees below the incipient melting temperature, when the specimen was cooled, the liquid solidified into a dendritic structure. The fracture surface obtained for the Nb-steel at its incipient melting temperature revealed a similar structure. 


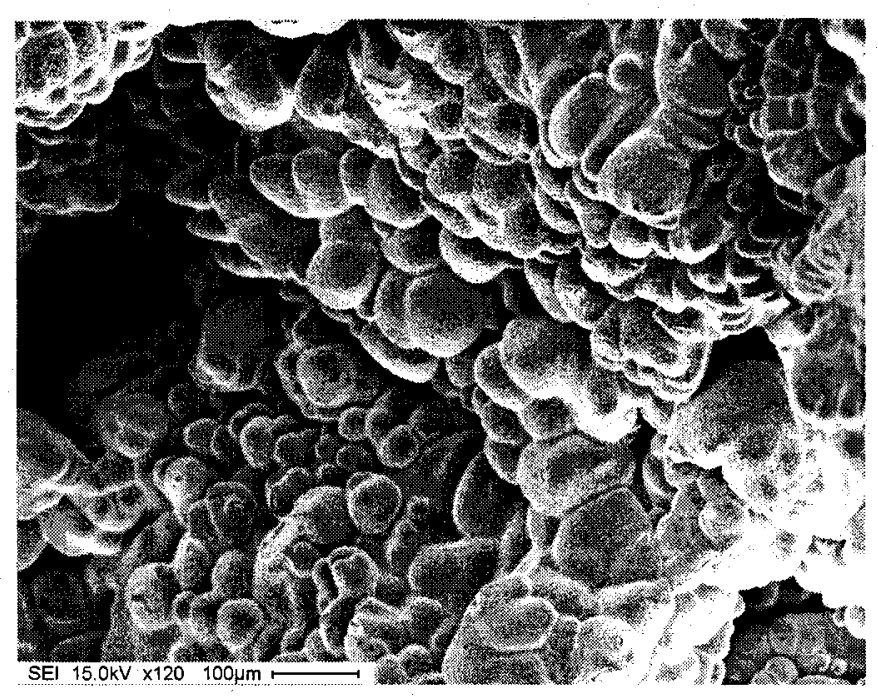

Figure 5.18. Dendritic structure of the B1-steel fractured at the incipient melting temperature in the $\mathrm{CHT}$ experiment.

\subsubsection{Effect of Thermal Schedule}

Figure 5.19 demonstrates fracture aspects of the B1-steel that was subjected to its thermal schedule alone. Figure 5.19(a) suggests that the fracture was primarily the result of a ductile failure, with some brittle characteristics. The brittleness is basically characterized with intergranular facets such as those specified by the circles in Figure 5.19(b). As can be seen, there is a considerable amount of plastic flow associated with the final fracture that is characteristic of ductility. There are also some voids and cavities at grain interfaces, Figure 5.19(c). These regions are associated with plastic deformation. However, no precipitates or inclusions were located inside the voids. Grain surfaces, where the intergranular mode is the dominant mechanism of fracture, show a fibrous structure when observed in the high resolution scanning electron microscope (FEGSEM), Figure 5.19(d). EDS analysis of these fibers revealed only signals of iron, carbon, and oxygen. The oxygen signal could have appeared because of high temperature oxidation after fracture. As can be seen in Figure 5.19(d), the fibers have a thickness of $\sim 300 \mathrm{~nm}$ and they cover almost $40 \sim 70 \%$ of the grain surface in different areas. 


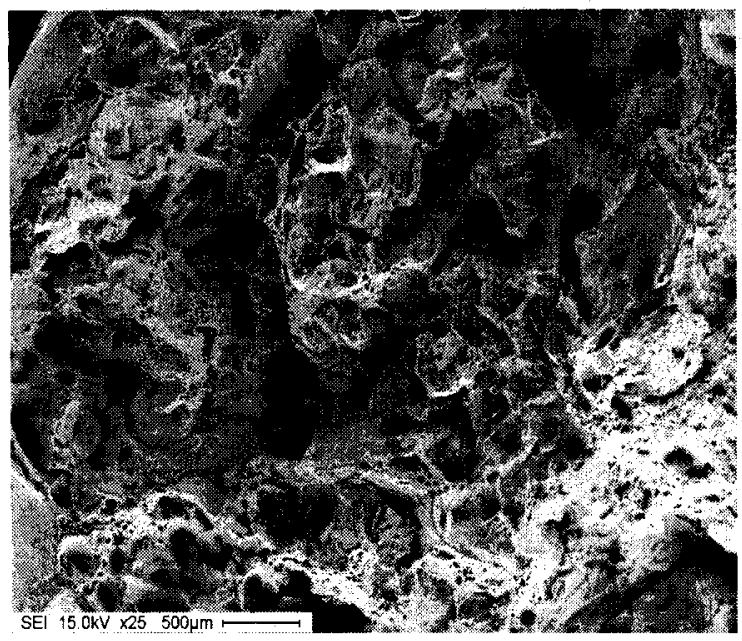

(a)

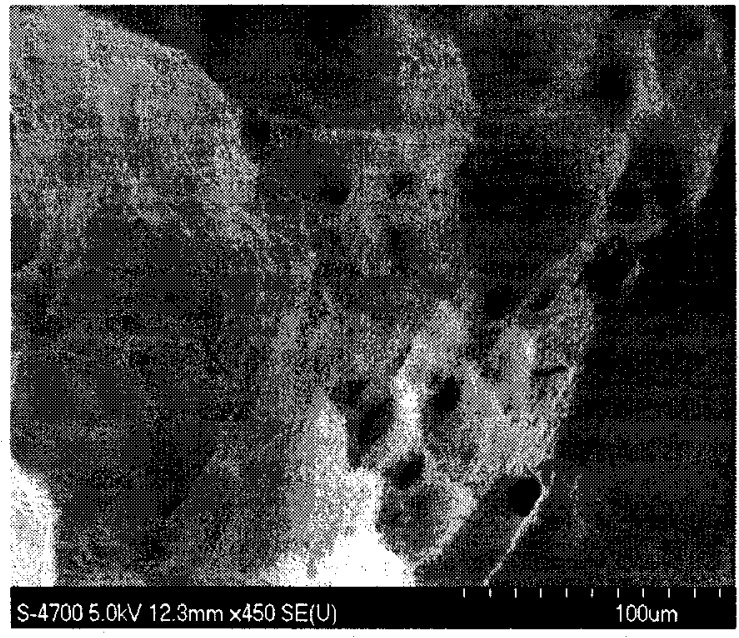

(c)

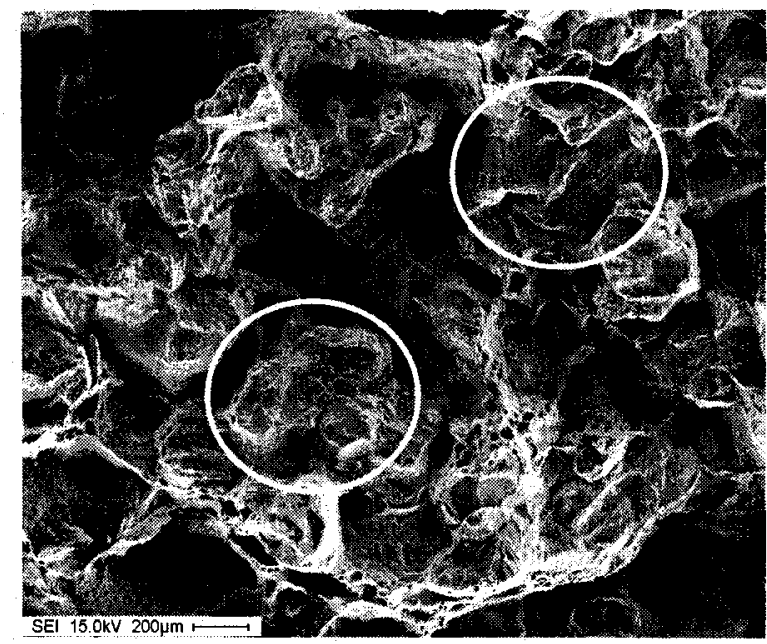

(b)

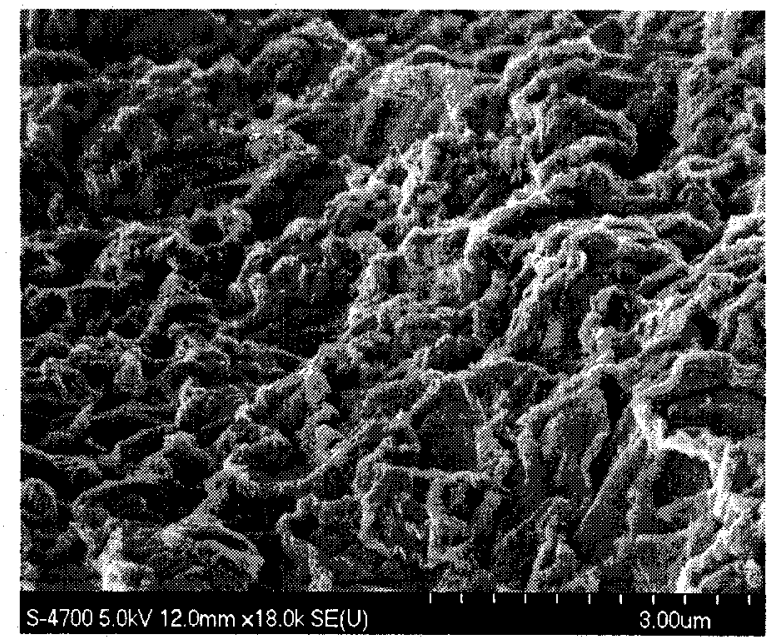

(d)

Figure 5.19. Fracture surfaces of the Bl-steel subjected to the thermal schedule alone and fractured at the straightening stage. (Corresponding with Figure 5.5)

(a): Overall observation.

(b) and (c): Higher magnifications of (a). Circles in (b) specify grain surfaces.

(d): Grain surface observed in FEGSEM.

Examination of the microstructure quenched immediately after fracture shows that the fracture was associated with grain boundary microcracking, as depicted in Figure 5.20(a). The matrix is basically bainite with some martensite islands. The microcracks have joined up in some places and made macrocracks or cavities at grain boundaries, Figure $5.20(\mathrm{~b})$. 


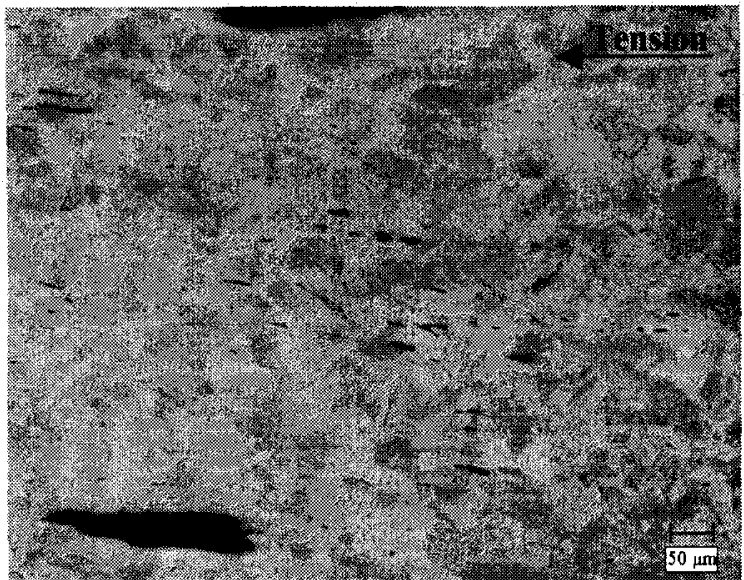

(a)

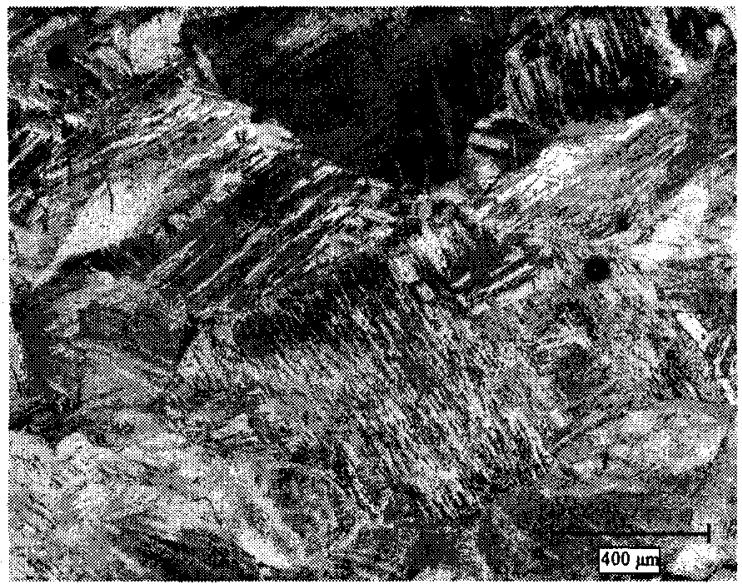

(c)

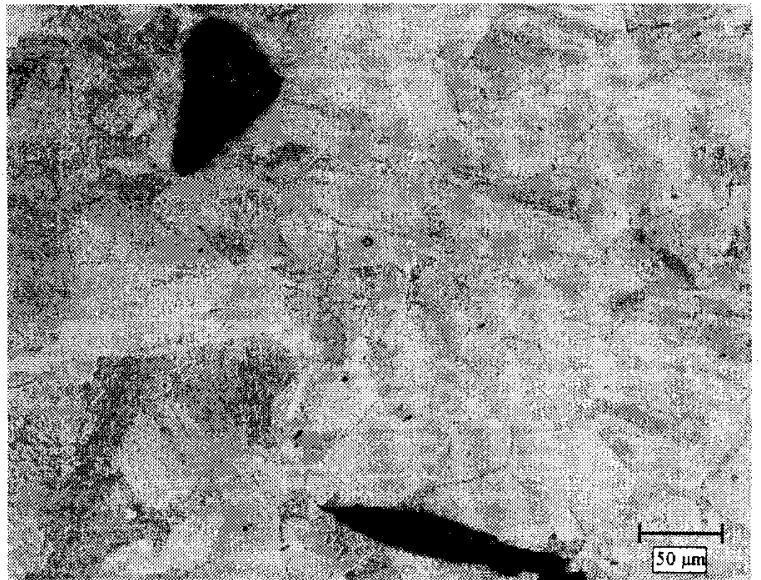

(b)

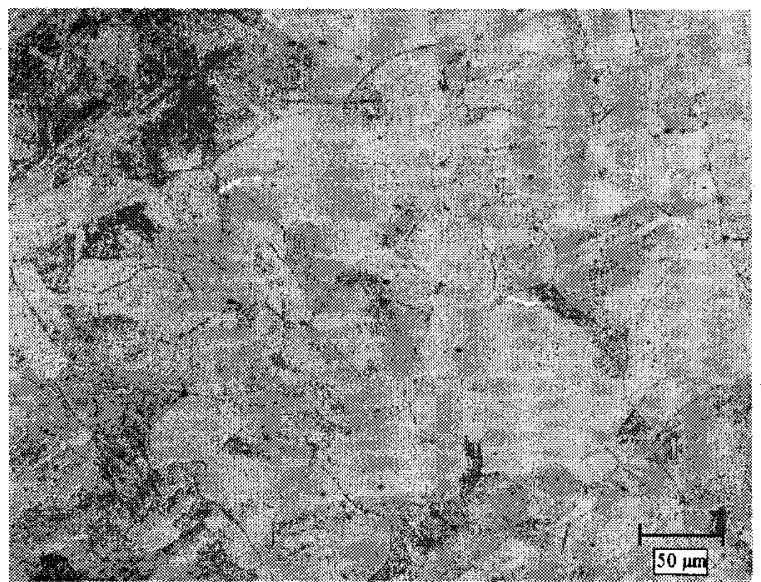

(d)

Figure 5.20. Longitudinal microstructures of the $\mathrm{B} 1$-steel, which was subjected to the thermal schedule alone, quenched after fracture at the straightening stage (at $1000^{\circ} \mathrm{C}$ ). All etched with etchant \#4.

(a): Overall observation.

(b): Higher magnification of (a).

(c) and (d): Regions far from and near the fracture surface, respectively.

The important point regarding this microstructure is that the grain size is larger in regions far from the fracture edges, but still within the gauge length, comparing Figures 5.20(c) and (d). The grain size varies from 10 to $150 \mu \mathrm{m}$ near the fracture surface whereas it is larger than $400 \mu \mathrm{m}$ at greater distances from the fracture edges. Obviously, the former grain size is too small to be a characteristic of the as cast microstructure. 
Fractography of the Nb-steel, presented in Figure 5.21, generally displays similar features to those of the B1-steel. Nevertheless, the intergranular separation is more prominent in the $\mathrm{Nb}$-steel. Moreover, the frequency of microvoids associated with the fracture is much lower than that observed in the B1-steel, as can be deduced from the microstructure shown in Figure 5.22. This may imply that the microvoids linked up together more readily in the $\mathrm{Nb}$-steel. Figure 5.22(a) also illustrates that the grain boundary microcracks are larger. In fact, no microcracks of the type observed in the B1-steel, were observed in this steel. Instead, grain boundaries near the fracture edges are basically decorated with cavities. Comparing Figures 5.20(a) and 5.22(a), it appears that cracks have formed parallel to the tensile direction in the B1-steel whereas they are normal to the tensile direction in the $\mathrm{Nb}$-steel. The matrix has a general microstructure similar to that of the B1-steel and some grains were elongated under the tension contributing to the ductility, Figure 5.22(b).

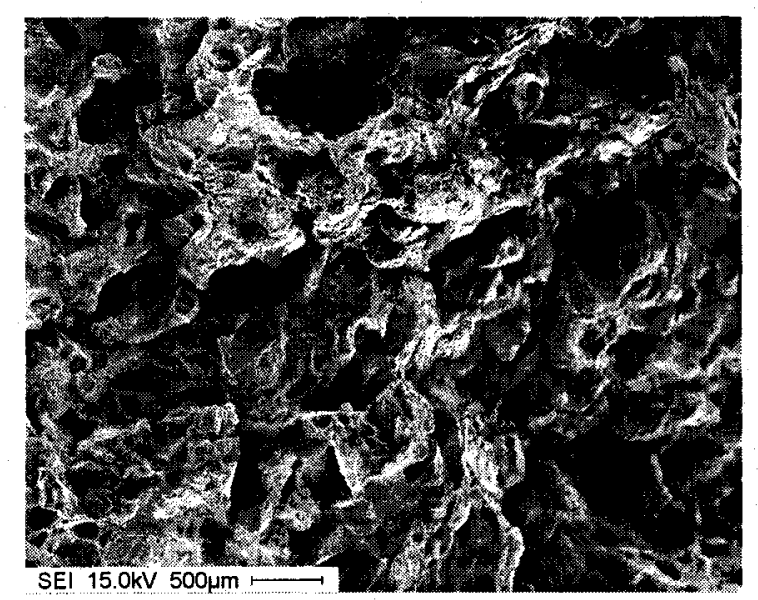

(a)

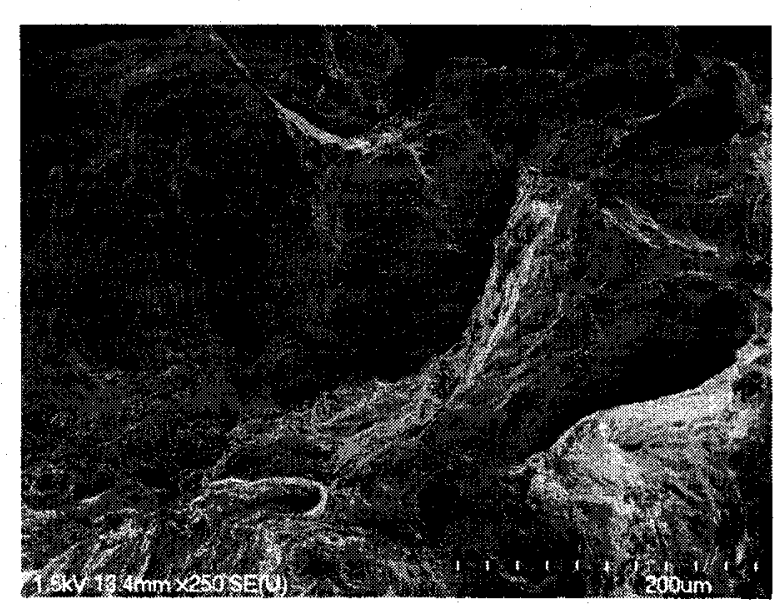

(b)

Figure 5.21. Fracture surfaces of the $\mathrm{Nb}$-steel subjected to the thermal schedule alone and fractured at the straightening stage. (Corresponding to Figure 5.5)

(a): Overall observation.

(b): Higher magnification of (a).

Examination in the FEGSEM revealed that the particles and compounds such as $\mathrm{MnS}$ and FeSi formed at grain boundaries had contributed to the cavity nucleation at grain 


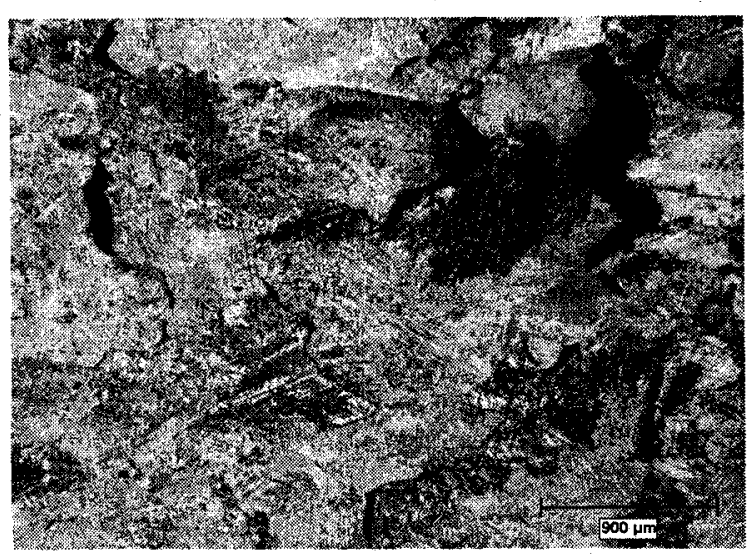

(a)

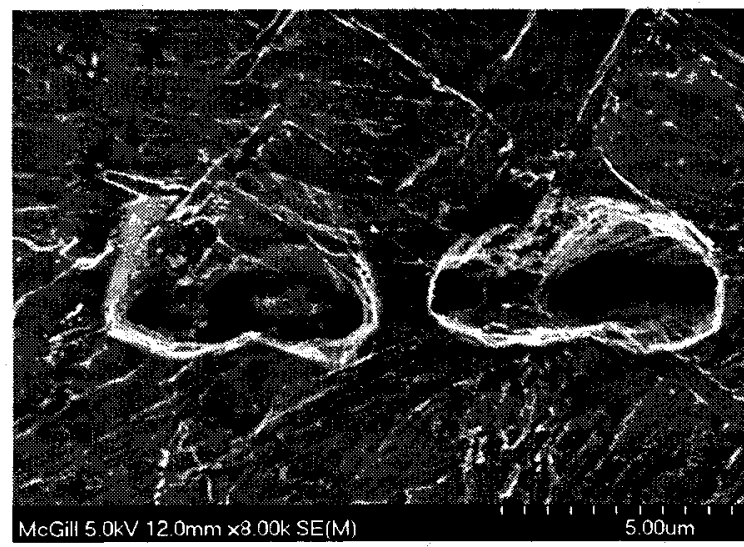

(c)

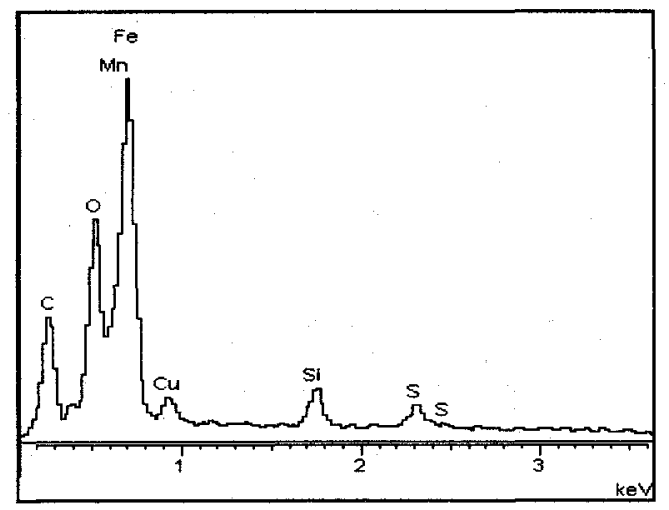

(e)

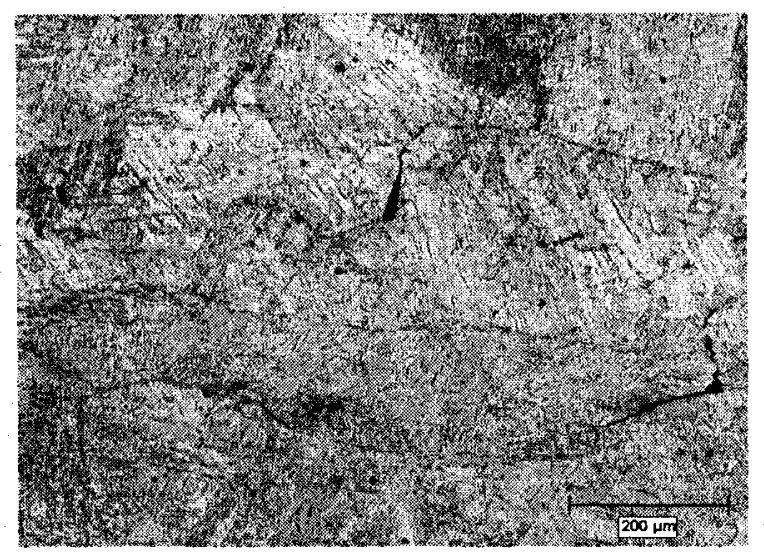

(b)

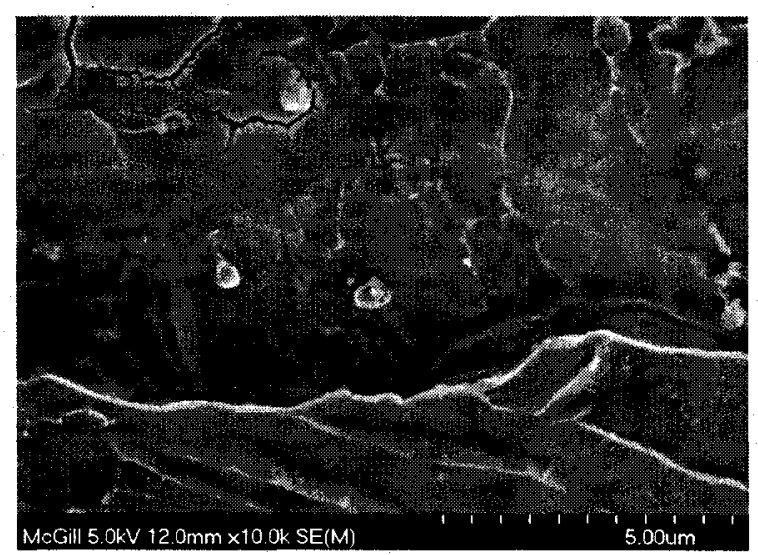

(d)

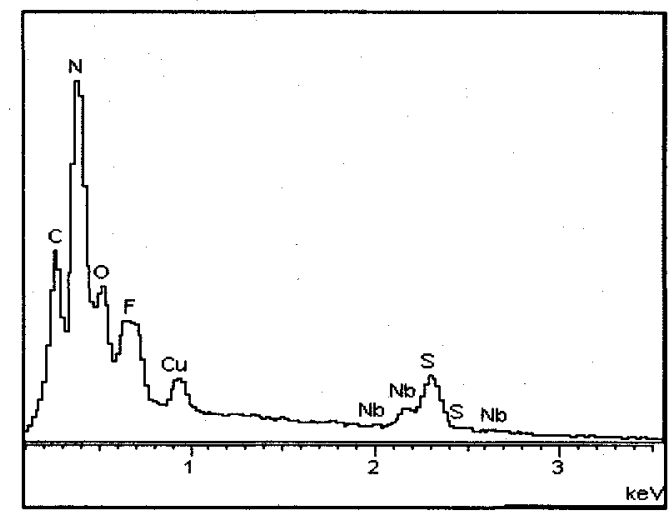

(f)

Figure 5.22. Longitudinal microstructures of the $\mathrm{Nb}$-steel that underwent the thermal schedule alone and fractured at the straightening stage (at $1020^{\circ} \mathrm{C}$ ). The specimen was quenched immediately after fracture.

(a): Overall microstructure, etched with picral.

(b): Higher magnification of (a).

(c) and (d): Electro-polished microstructures.

(e) and (f): EDS analyses of particles, inside the void and adjacent to the grain boundary, shown in (c) and (d), respectively. 
boundaries, Figures 5.22(c) and (e). In addition, $\mathrm{NbCN}$ was detected near the grain boundary crack as shown in Figures 5.22(d) and (f). This type of precipitate is usually the origin for void nucleation at a grain boundary. However, it doesn't seem to have contributed to the cracking in this case since it is not inside a void. Other signals identified in the spectrum either have come from the matrix or are elements constituting the compound on which $\mathrm{NbCN}$ might have nucleated. In contrast to the $\mathrm{B} 1-\mathrm{steel}$, there is no variation in the grain size from the fracture edges into the specimen.

Grain boundary separation is much more conspicuous in the specimen fractured at higher temperature, Figures 5.23. Much less plastic deformation occurred at this temperature. Instead, it appears that grain boundary fusion resulted in early fracture before the material tolerated any significant plastic deformation, leading to a significant loss of ductility. The dendritic structure on the grain surface shown in Figure 5.23(b) confirms this hypothesis.

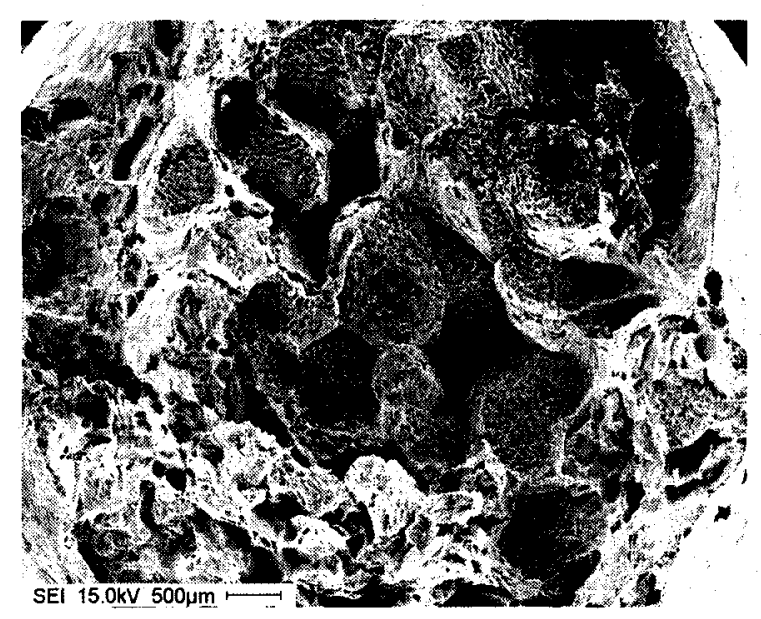

(a)

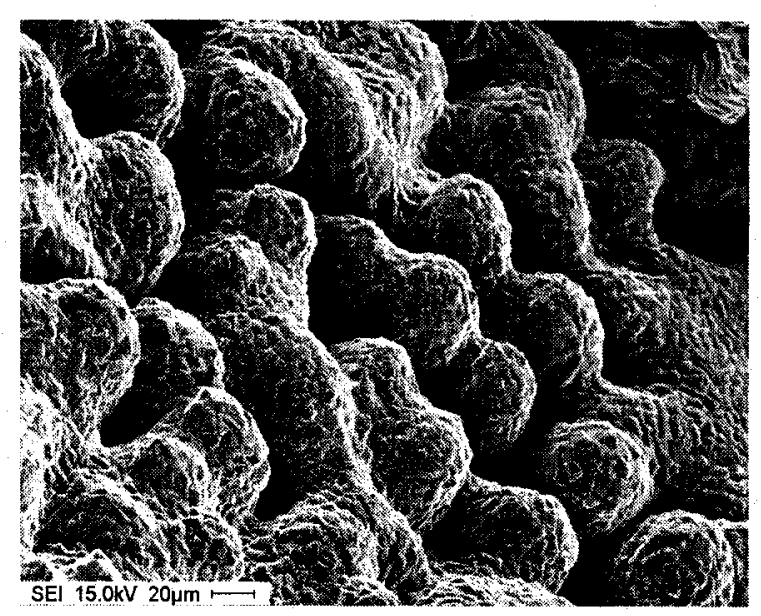

(b)

Figure 5.23. Fracture surfaces of the $B 2$-steel subjected to the thermal schedule alone and fractured at the straightening stage at $1100^{\circ} \mathrm{C}$. (Corresponding with Figure 5.15 ) (b) is a typical grain surface shown in (a).

The B2-steel microstructures quenched after fracture at different temperatures are shown in Figure 5.24. Generally, grain boundary voiding and void linkage can be considered as the mechanism of failure. Figure 5.24(a) illustrates that the thin layer of ferrite at a grain 
boundary has contributed to the void nucleation at grain boundaries. However, it was found that not all grain boundaries containing voids were decorated with ferrite. At a higher temperature, austenite grains were more elongated toward the tensile direction, Figures 5.24(b) and (c). As well, it can be seen that voids have formed mainly at grain boundaries, as well as in grain interiors. The conditions were unsuitable for ferrite to form at grain boundaries at these temperatures. As Figure $5.24(\mathrm{~d})$ displays, at $1100^{\circ} \mathrm{C}$, grain boundaries were so weak that deformation resulted in grain boundary decohesion before grains experienced any considerable deformation and they preserved their as cast equiaxed shape.

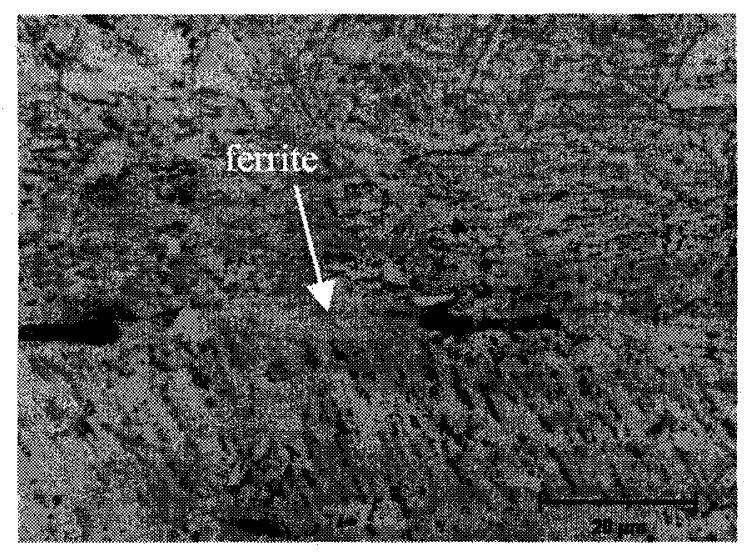

(a)

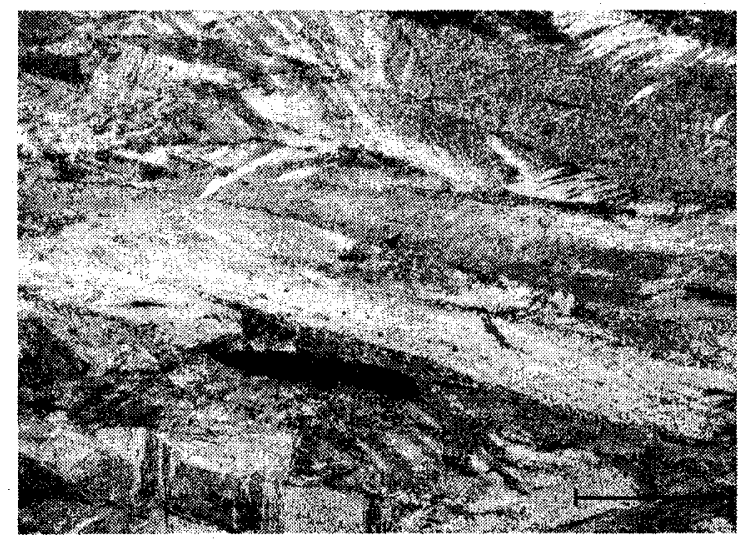

(c)

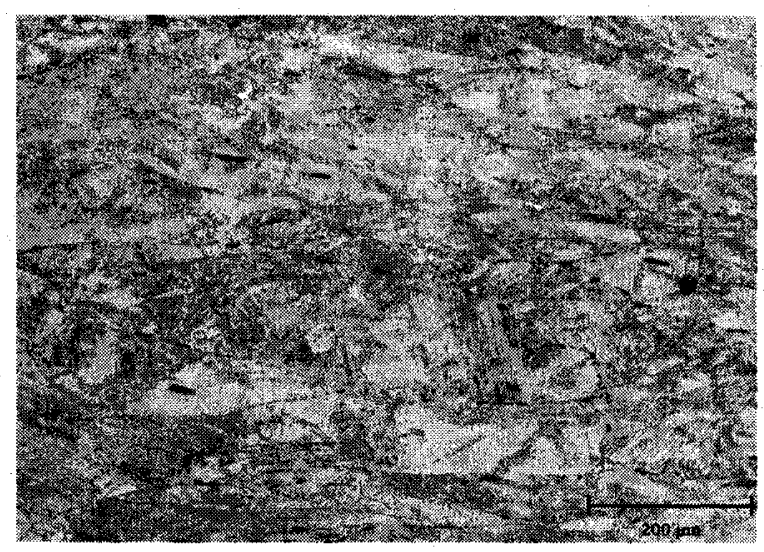

(b)

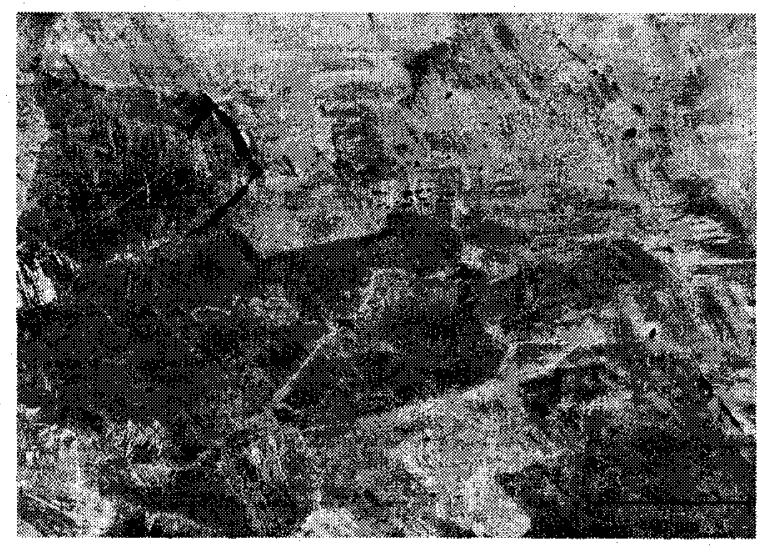

(d)

Figure 5.24. Longitudinal microstructures of the B2-steel specimens whose ductilities are presented in Figure 5.15. All quenched immediately after fracture at the straightening stage at (a) $700{ }^{\circ} \mathrm{C}$, (b) $800^{\circ} \mathrm{C}$, (c) $900^{\circ} \mathrm{C}$, and (d) $1100^{\circ} \mathrm{C}$. (a) was etched with nital and the others with etchant \#4. 
There is a similar situation for the $\mathrm{Nb}$-steel. The dendritic structure revealed in Figure 5.25 implies that, once again, grain boundary fusion was the reason for the ductility drop at $1200^{\circ} \mathrm{C}$.

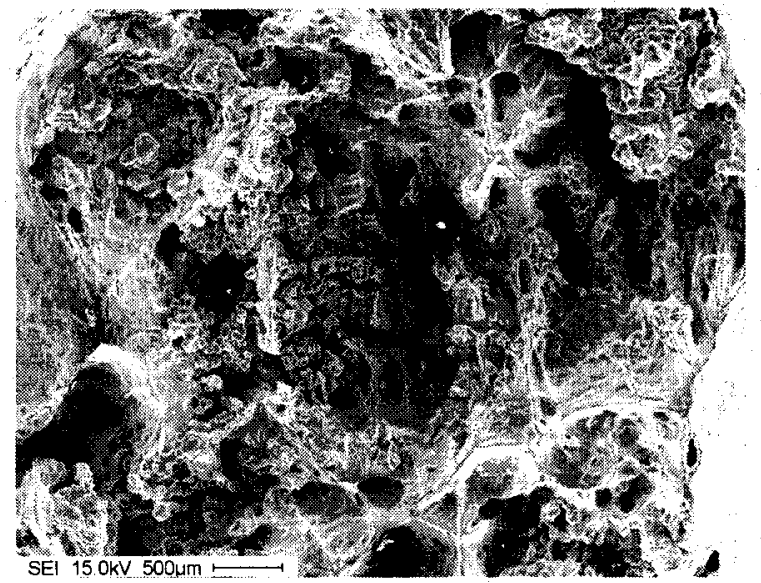

(a)

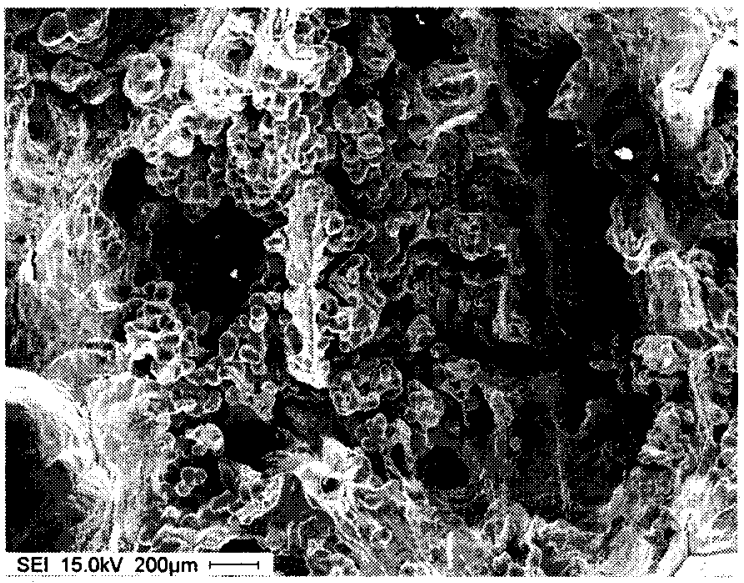

(b)

Figure 5.25. Fracture surfaces of the $\mathrm{Nb}$-steel subjected to the thermal schedule alone and fractured at the straightening stage at $1200^{\circ} \mathrm{C}$. (Corresponding with Figure 5.15).

Figure 5.26 shows microstructures of the Nb-steel specimens presented in Figure 5.15. At $700^{\circ} \mathrm{C}$, the microstructure was composed of austenite and grain boundary ferrite, as demonstrated in Figure 5.26(a) and (b). The difference in ferrite volume fraction (white areas) is due to the temperature variation from the gauge length (the highest temperature zone) to the region outside the gauge length that was at a lower temperature. As Figure 5.16 shows, necking has occurred in the latter region that had higher volume fraction of ferrite. Both specimens fractured at 800 and $900^{\circ} \mathrm{C}$ display large grains and grain boundary decohesion associated with the fracture. However, when the experimental temperature rose to $1100^{\circ} \mathrm{C}$, fracture was accompanied with austenite grain refinement, Figure 5.26(e). Further rise of temperature, Figure 5.26(f), changed the aspect of grain boundary cracks, i.e. having rounded edges and corners instead of sharp ones, and this can be taken as evidence for the initiation of grain boundary fusion, as supported by Figure 5.25. 


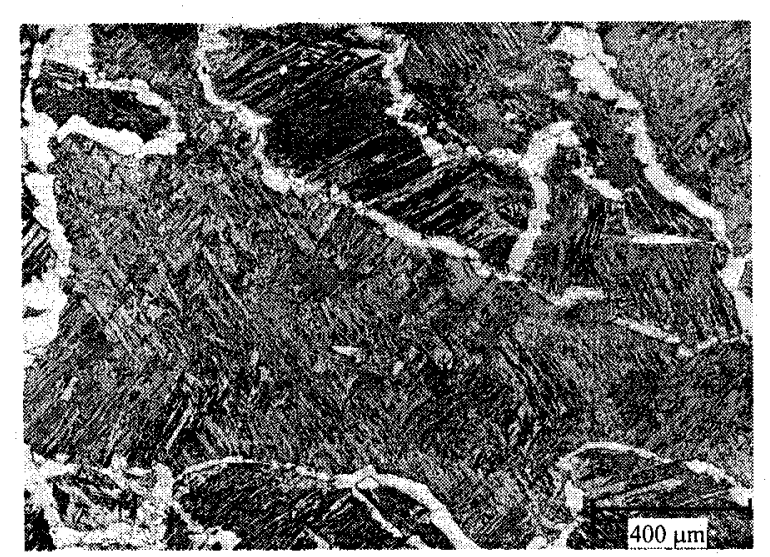

(a)

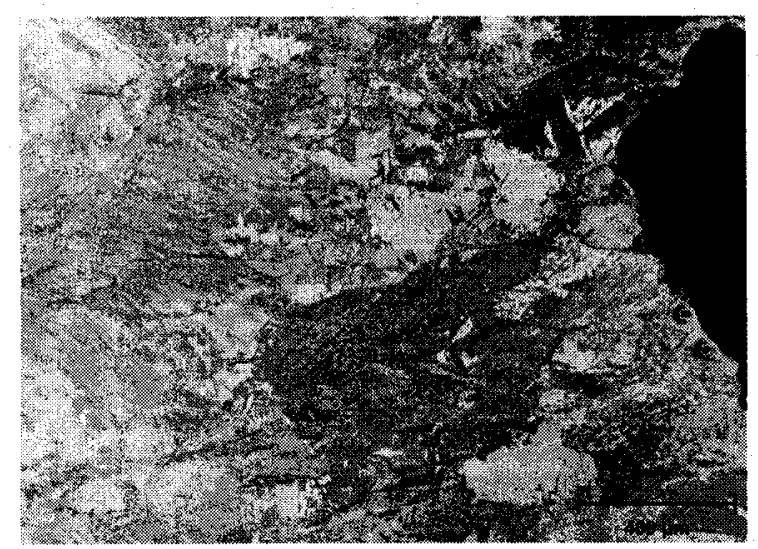

(c)

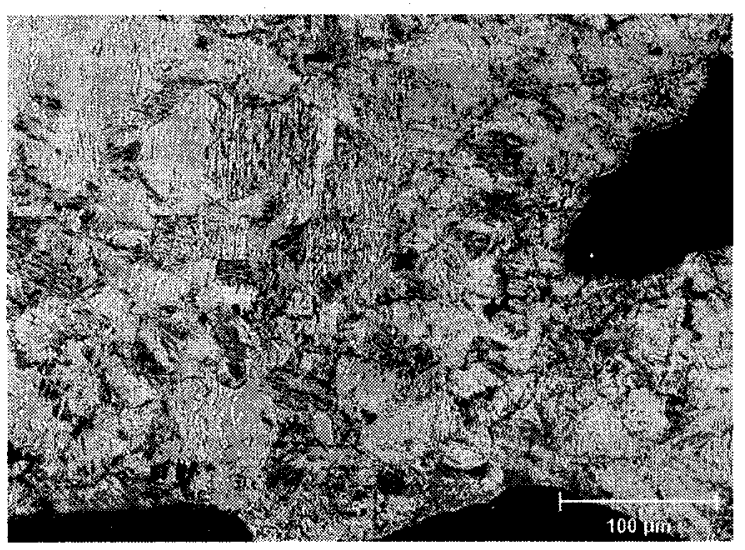

(e)

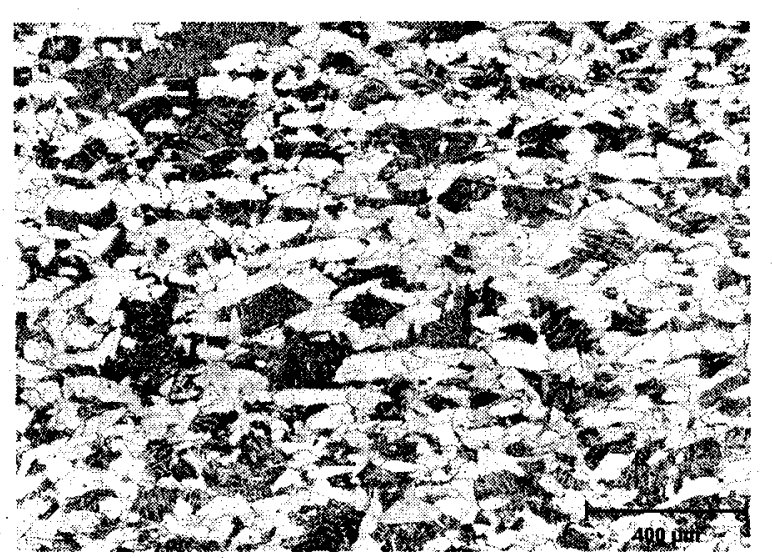

(b)

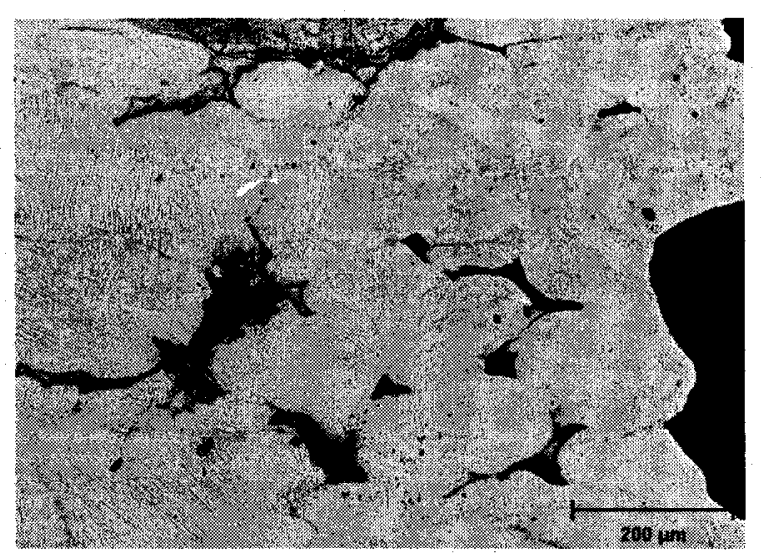

(d)

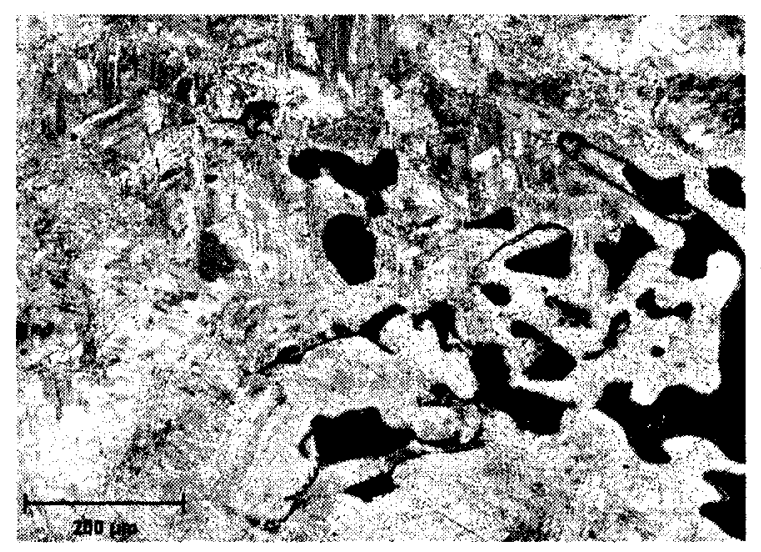

(f)

Figure 5.26. Longitudinal microstructures of the $\mathrm{Nb}$-steel specimens subjected to the thermal schedule alone and fractured at the straightening stage at (a) $700^{\circ} \mathrm{C}$ (gauge length region), (b) $700^{\circ} \mathrm{C}$ (necked region), (c) $800^{\circ} \mathrm{C}$, (d) $900^{\circ} \mathrm{C}$, (e) $1100^{\circ} \mathrm{C}$, and (f) $1200^{\circ} \mathrm{C}$. All were quenched after fracture. (a) and (b) were etched with nital and the others with etchant $\# 4$. 


\subsubsection{Effect of Deformation Associated with Thermal Schedule}

The failure mode substantially changed to mostly intergranular and the hot ductility dropped remarkably when deformation was incorporated with solidification. The fracture features shown in Figure 5.27 distinctly demonstrate this fact. Figure 5.27(a) exhibits large as cast grains and a very conspicuous grain boundary separation. It seems that grains were also elongated toward the tensile direction and the facet separation planes are parallel to this direction. Nevertheless, despite the appearance of longitudinal planes that are facetted, there is evidence of some plastic deformation on transverse planes as revealed by grain boundary cavities, Figure $5.27(\mathrm{~b})$. This indicates that the rupture was associated with void nucleation and coalescence at grain boundaries. Even though the longitudinal grain boundaries look facetted in the fracture picture, they have a fibrous appearance if observed in the FEGSEM, Figure 5.27(c). As can be seen, this is similar to that shown in Figure 5.19(d). In addition, fracture of the specimen revealed some wavy features at grain boundaries, as shown in Figure 5.27(d), which can be attributed to the fracture of a liquid film, most probably occurred during the pre-compression in the 'liquid+solid' region.

The quenched microstructure at the straightening stage, just before the tensile strain to fracture, is shown in Figure 5.28. Figure 5.28(a) shows that grain boundaries are decorated with particles and voids. Also, a high concentration of carbon was found at the grain boundary that can be attributed to carbon segregation during solidification, Figure 5.28(b). Such segregation has certainly created a discontinuity at the grain boundary. Microanalysis of the grain boundary particles, Figures 5.28(c) (f), indicates that they are mainly manganese sulfide $(\mathrm{MnS})$ and aluminum oxide $\left(\mathrm{Al}_{2} \mathrm{O}_{3}\right)$. The presence of $\mathrm{Ti}$ and $\mathrm{Nb}$ in the spectrum suggests that the nitride and/or carbide of these elements might have co-precipitated with $\mathrm{MnS}$ and/or $\mathrm{Al}_{2} \mathrm{O}_{3}$ or either has nucleated on the other. Moreover, Figure $5.28(\mathrm{~g})$ illustrates that the microstructure contains microcracks in the vicinity of the gauge length. As can be seen, these cracks are oriented along the direction of precompression. It was determined that carbon has segregated within these cracks, Figures 5.28(h) and (i). 


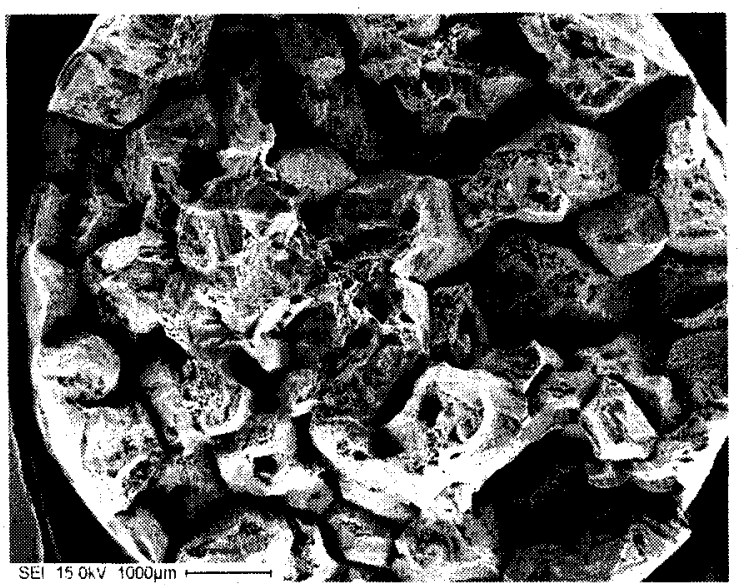

(a)

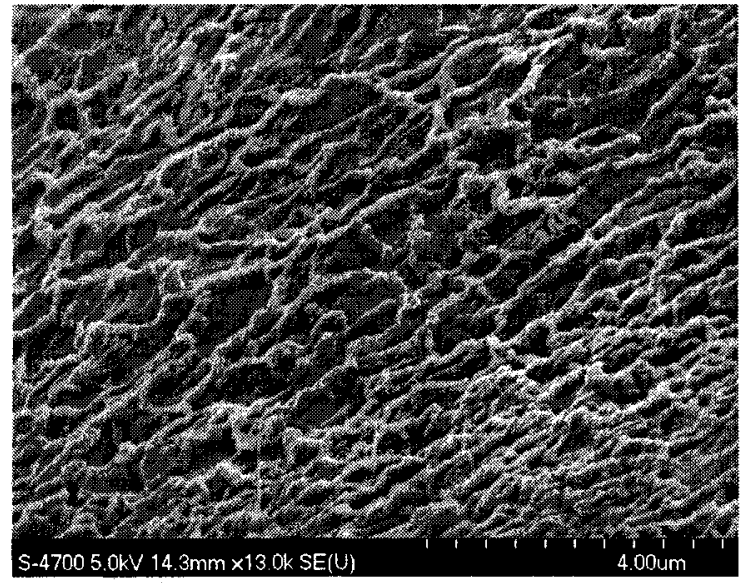

(c)

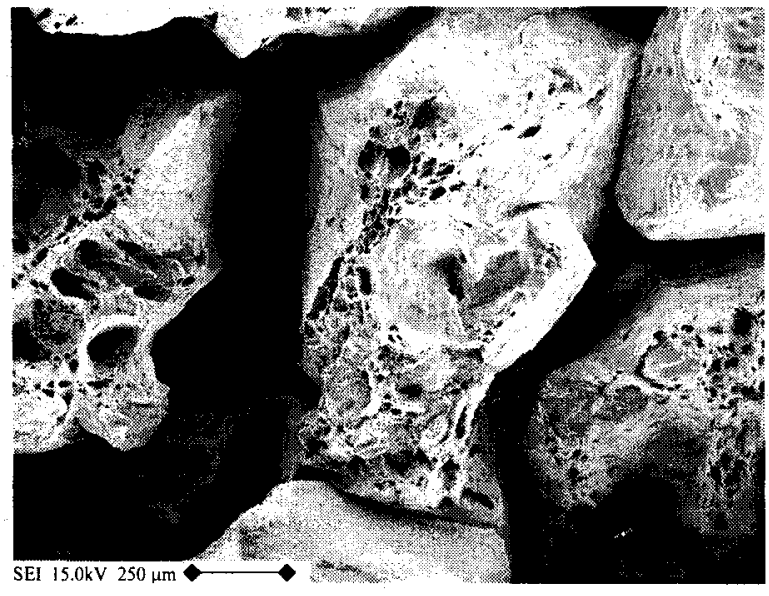

(b)

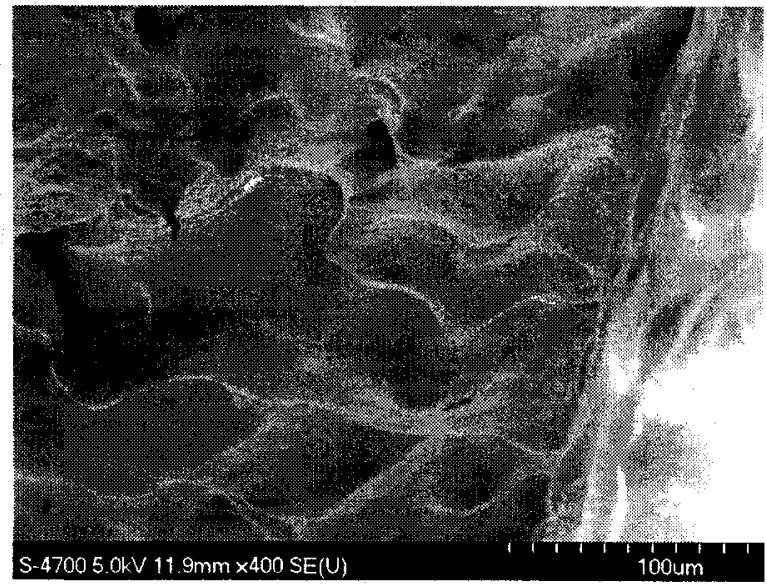

(d)

Figure 5.27. Fracture surfaces of the B1-steel at the straightening stage. The specimen had been pre-compressed in the 'liquid+solid' region. (Corresponding with Figure 5.8)

(a): Overall observation.

(b): Higher magnification of (a).

(c) and (d): Grain surfaces observed in FEGSEM.

On the contrary, the specimen subjected to pre-tension during solidification, Figure 5.29, was not strong enough to withstand adequate deformation for grains to be deformed longitudinally and they remained almost equiaxed under the tension at the straightening stage. Therefore, grain separation is not as prevalent as it is in Figures 5.27(a) and they are mainly attached together. As Figure 5.29(b) demonstrates, the grain surface is basically facetted with some small rough regions where there was a shear deformation. The rough regions have principally occurred at grain edges and corners. However, the 


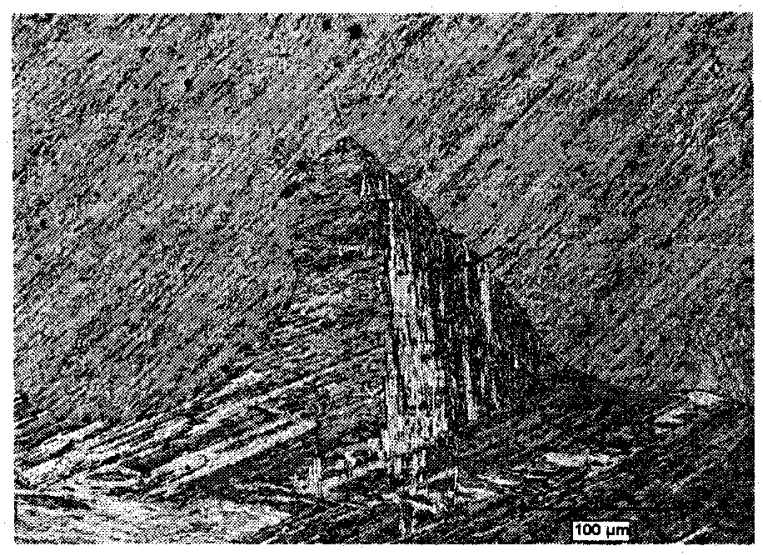

(a)

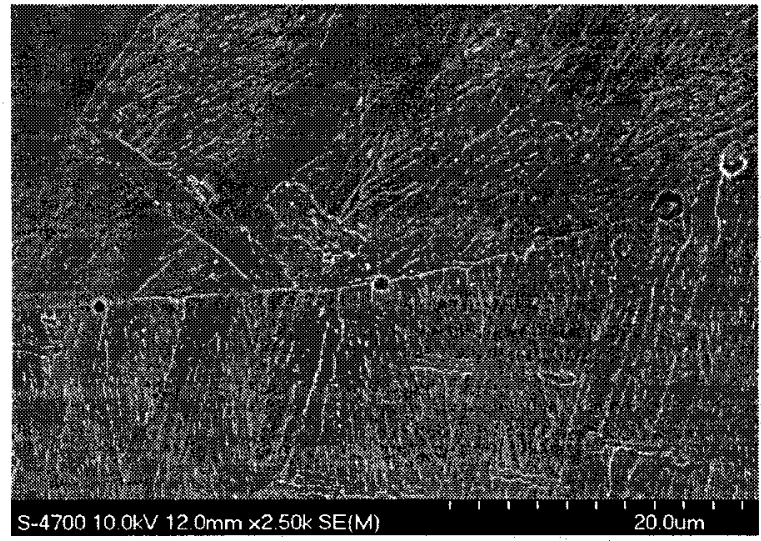

(c)

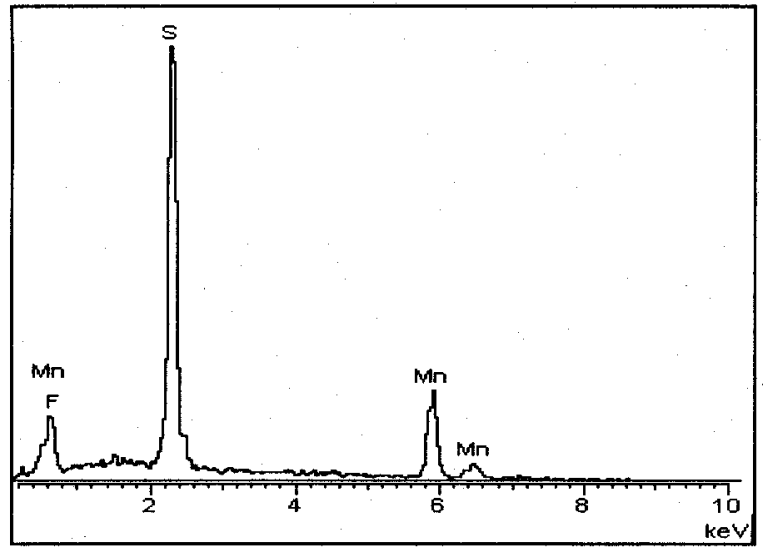

(e)

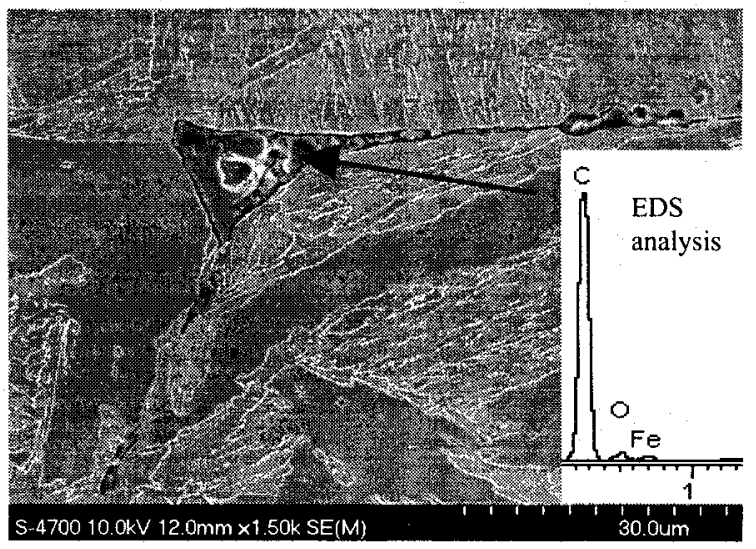

(b)

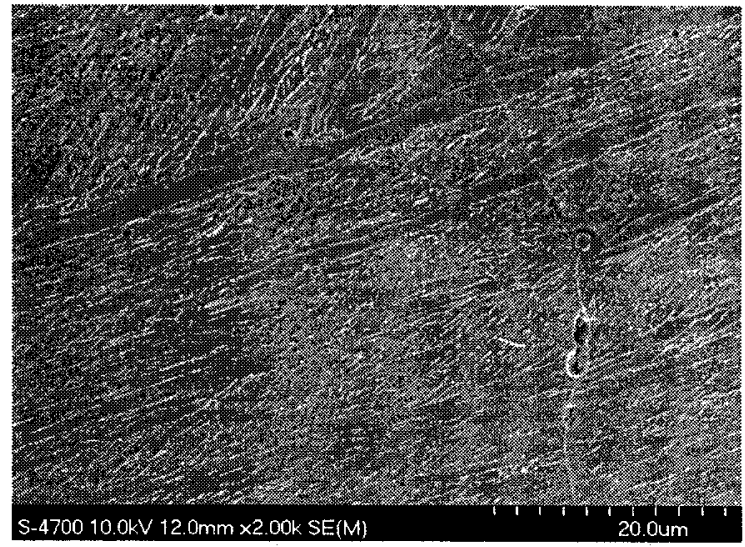

(d)

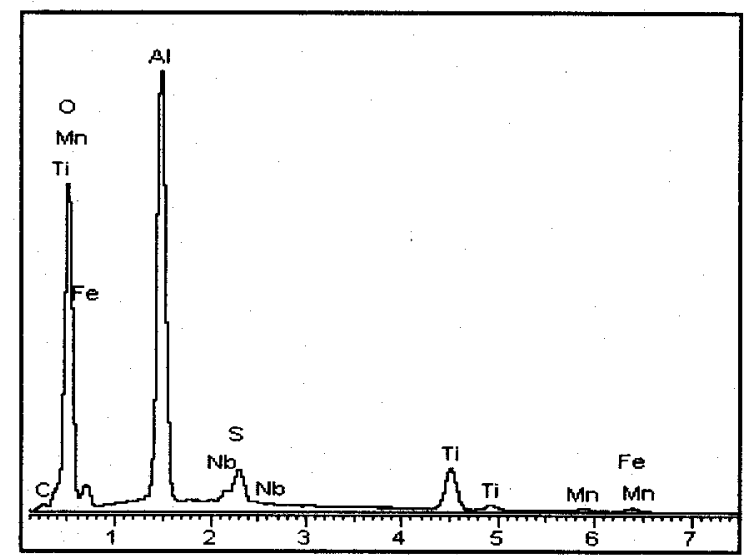

(f)

Figure 5.28. Microstructure of the $\mathrm{B} 1$-steel quenched at the straightening stage just before the tensile experiment. The specimen was pre-compressed in the 'liquid+solid' region.

(a): Overall microstructure, etched with nital.

(b), (c) and (d): Grain boundaries decorated with segregated elements and particles. Longitudinal electro-polished sections.

(e) and (f): EDS analyses of grain boundary particles shown in (c) and (d), respectively. 


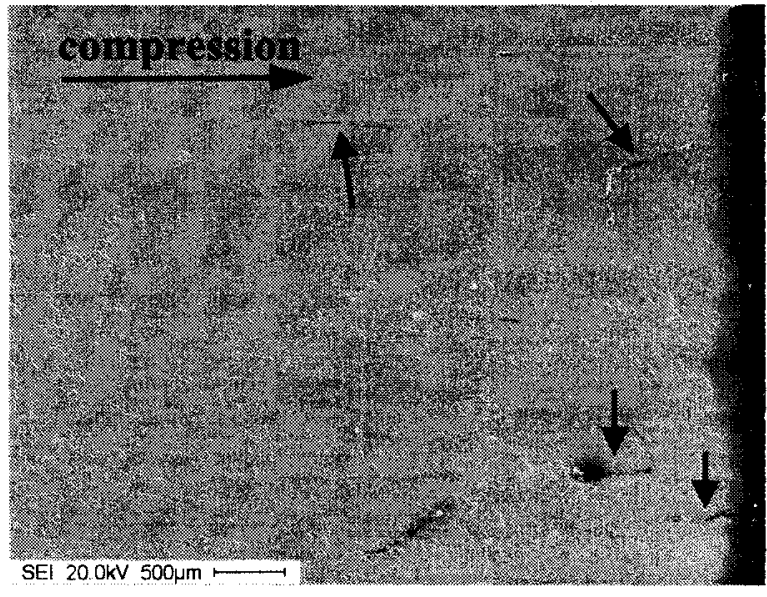

(g)

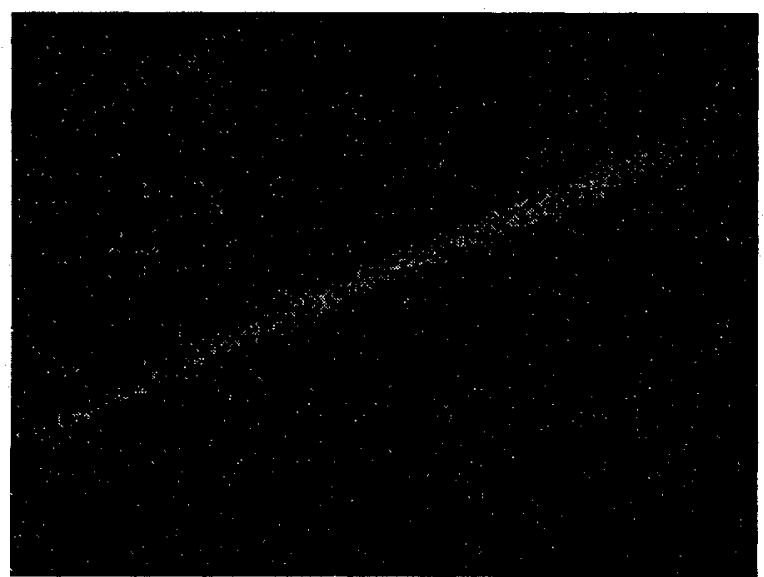

(i)

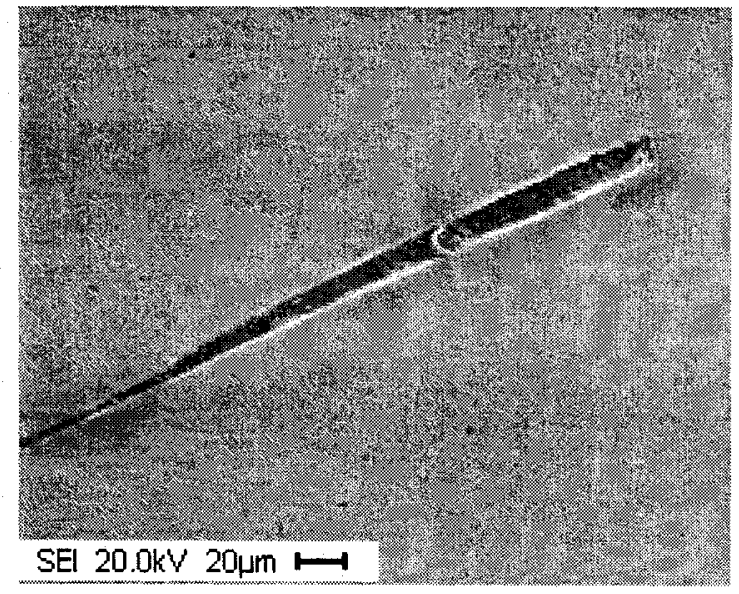

(h)

Figure 5.28, continued.

(g) and (h): Longitudinal sections of the gauge length.

(i): EDS carbon map of (h).

ratio of facet area to rough area is larger than that in the specimen that was precompressed during solidification. This implies that brittle failure was more dominant in this specimen than the one that experienced a pre-compression during solidification. This change in extent of the failure modes corresponds clearly to the increased loss of ductility due to pre-tension than pre-compression. Furthermore, the absence of voids and cavities on the fracture surface proves that void nucleation and coalescence were not associated with the failure, Figure 5.29(b). The grain facet region has a similar structure (Figure 5.29(c)) to that described for the specimen subjected to pre-compression during solidification and the specimen that experienced the thermal schedule alone. Hence, it seems that such a netlike structure is common in the B1-steel independent of the 


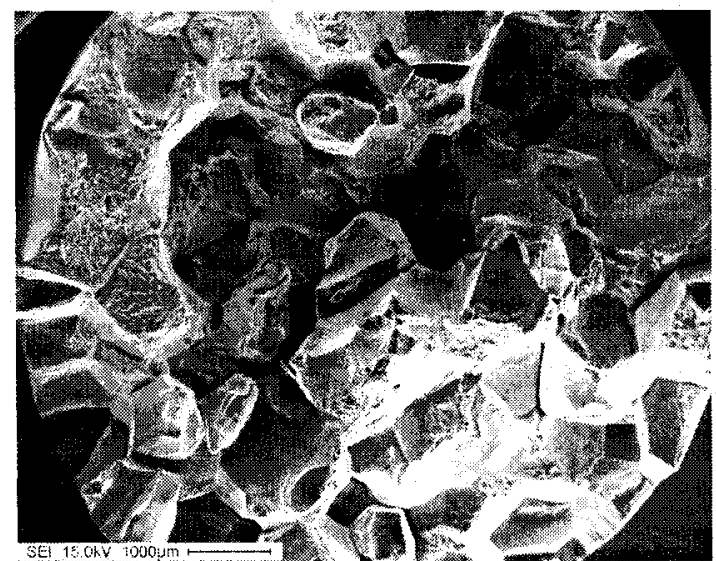

(a)

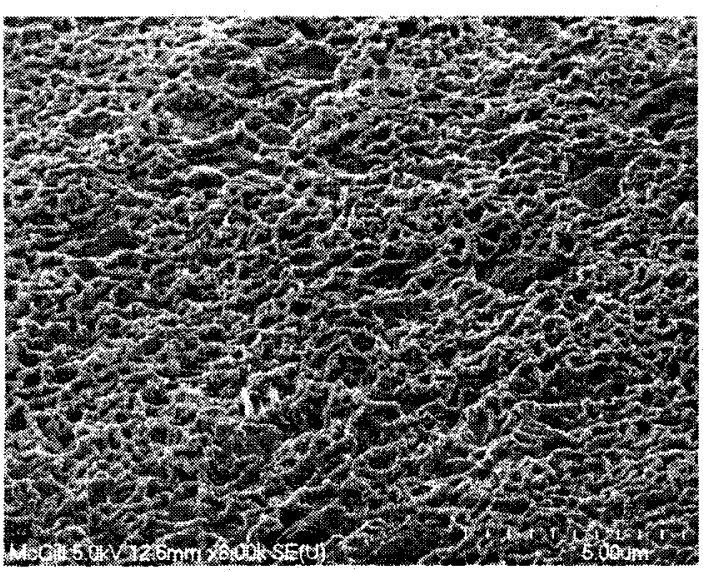

(c)

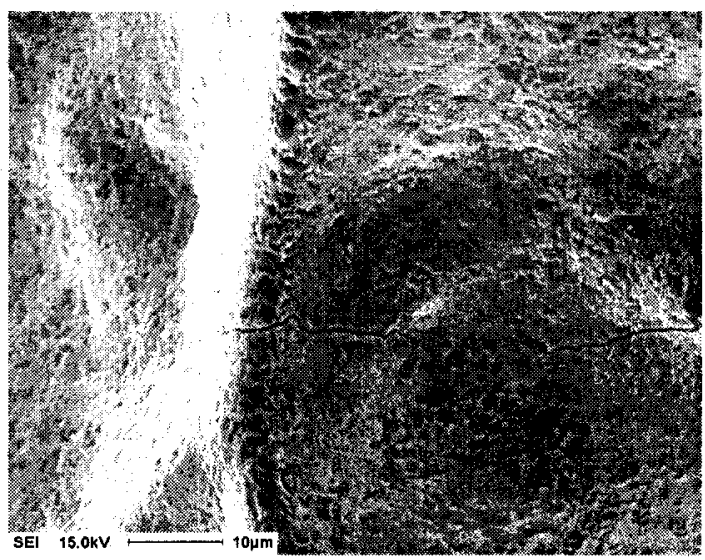

(e)

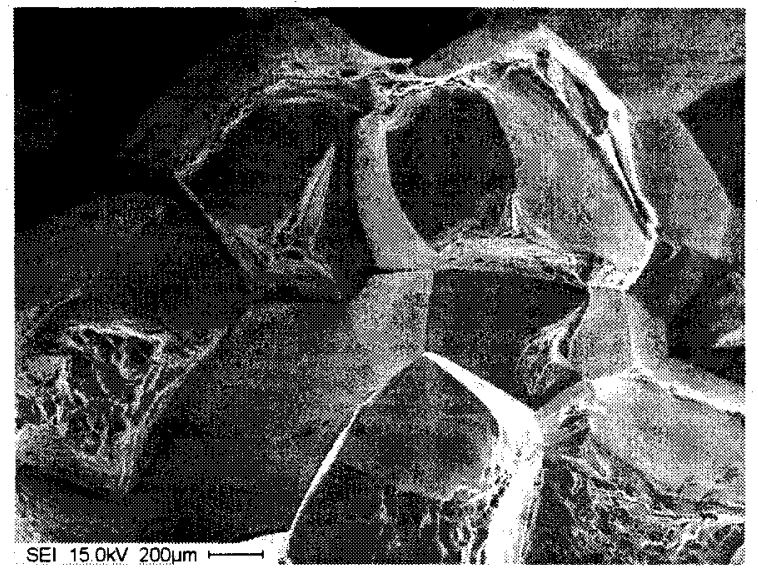

(b)

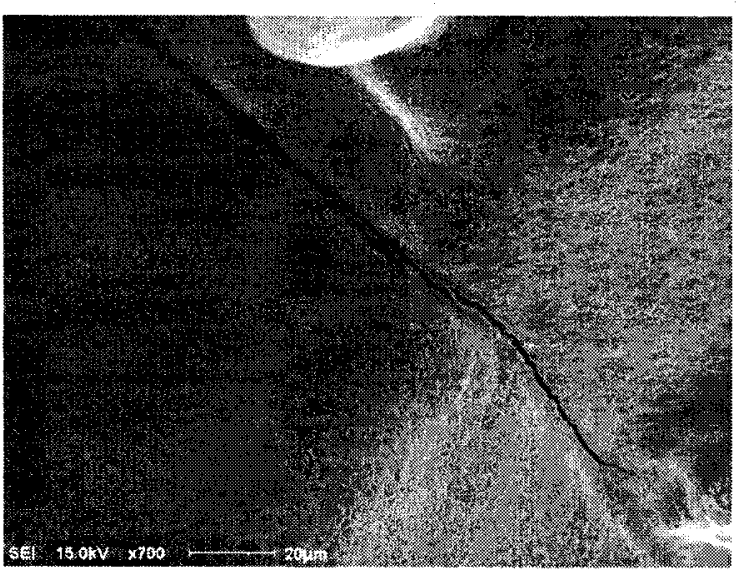

(d)

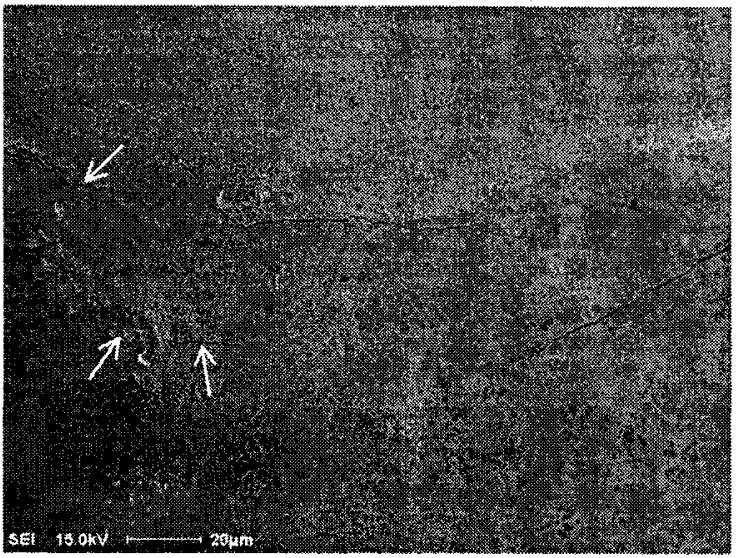

(f)

Figure 5.29. Fracture surfaces of the B1-steel at the straightening stage. The specimen had been tolerated a pre-tension in the 'liquid+solid' region. (Corresponding with Figure 5.8)

(a): Overall observation.

(b): Higher magnification of (a).

(c): Grain surface in facet region observed in FEGSEM.

(d), (e), and (f): Cracks at grain boundary and grain surfaces. Arrows indicate the cracks. 
pre-deformation. There are also some cracks observed at grain boundaries, Figure 5.29(d), and grain surfaces, Figures 5.29(e) and (f), that might have occurred either during solidification shrinkage that was confronted by the pre-tension or during the tensile experiment at the straightening stage. It should be mentioned that cracks were also observed in the rough region as Figure 5.29(e) displays.

Figure 5.30 shows the microstructure of the $\mathrm{B} 1$-steel specimen, pre-deformed in tension during solidification, and quenched at the straightening stage just before the tensile test. The matrix has the same structure as that of the specimen that had undergone the thermal schedule, i.e. basically bainite with islands of marteniste. As can be seen in Figure 5.30(b), grain boundaries are decorated with particles and voids, similar to Figure 5.28. Electro-polishing, instead of mechanical polishing, resulted in preferential corrosion and topography between the grain boundary particles and the surrounding area. Therefore, particles residing at the grain boundaries and in the matrix are readily perceived in the FEGSEM, as demonstrated in Figures 5.30(c) and (d). EDS analysis conducted in this microscope has identified $\mathrm{Mn}$ and $\mathrm{S}$ as the main elements constituting these particles, Figures 5.30(e) and (f).

The fracture surface due to the pre-compression in the $\delta$-phase region, Figure 5.31, demonstrates fairly similar features to those of the thermal schedule alone. Compared to the effect of pre-deformation during solidification, the surfaces are rougher and the configurations of some areas are akin to localized deformation, both indicating an increase in the amount of shear deformation. In addition, it is difficult to determine regions of grain boundary separation. Nevertheless, voids and cavities can still be considered as features that formed at grain boundaries, Figure 5.31(b). By observing Figure 5.19(a) and Figure 5.31(a), it appears that deformation in $\delta$-ferrite has led to finer fracture features than the thermal schedule alone.

As for the effect of pre-tension in the $\delta$-ferrite region, Figure 5.32 shows that more small cavities can be found on the fracture surface and the failure mostly resembles a ductile 


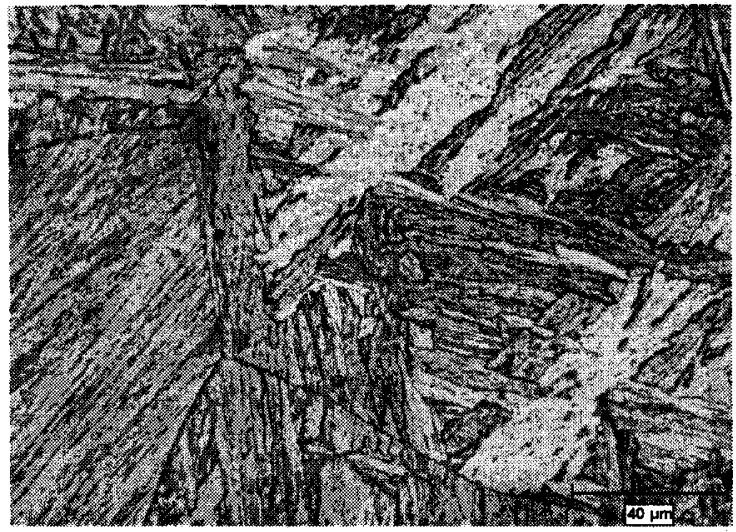

(a)

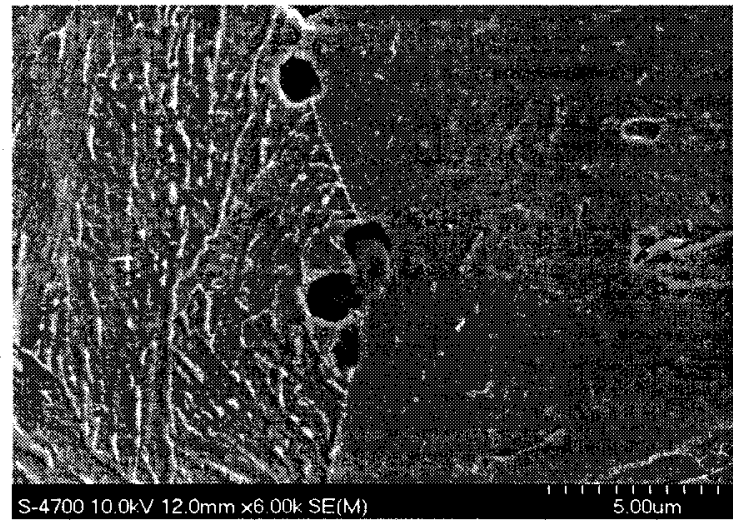

(c)

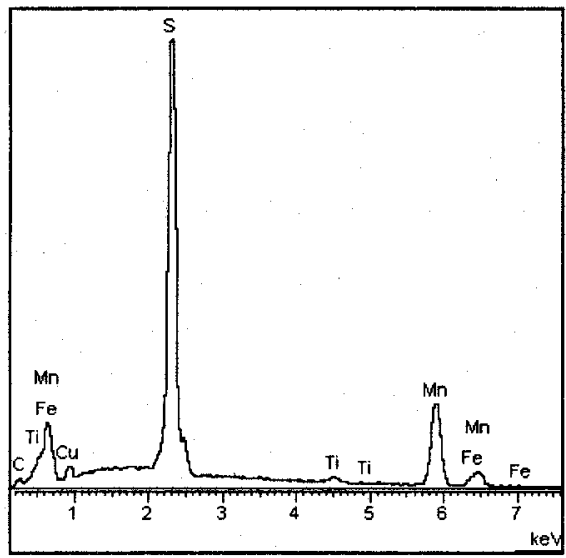

(e)

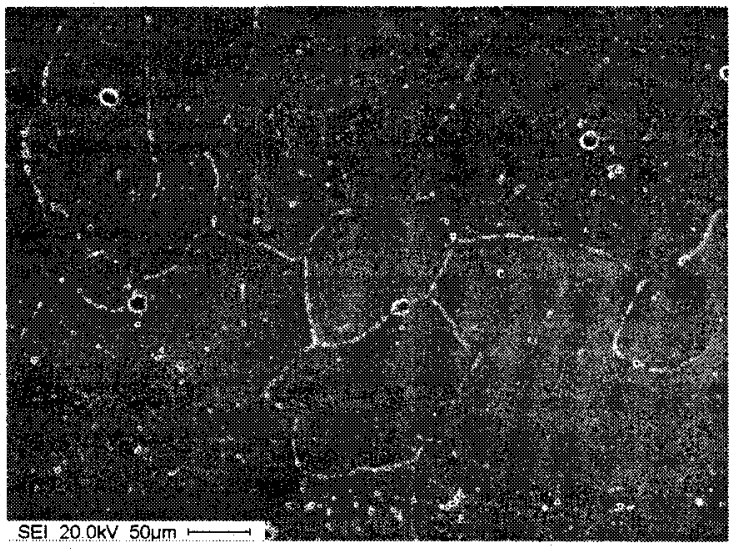

(b)

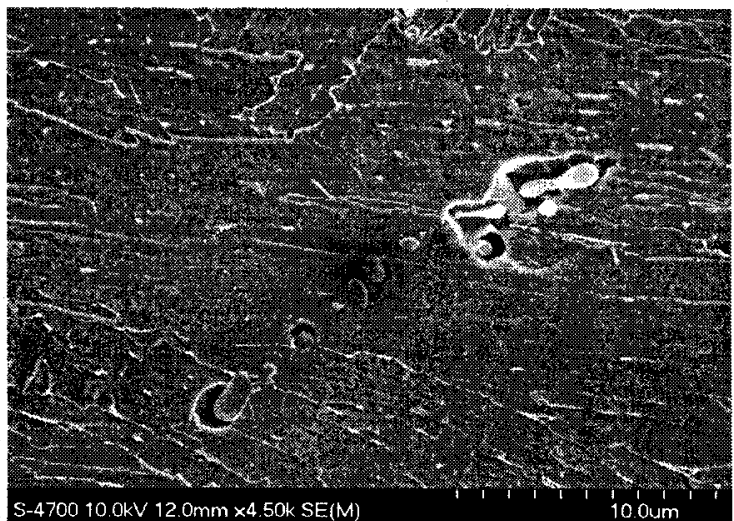

(d)

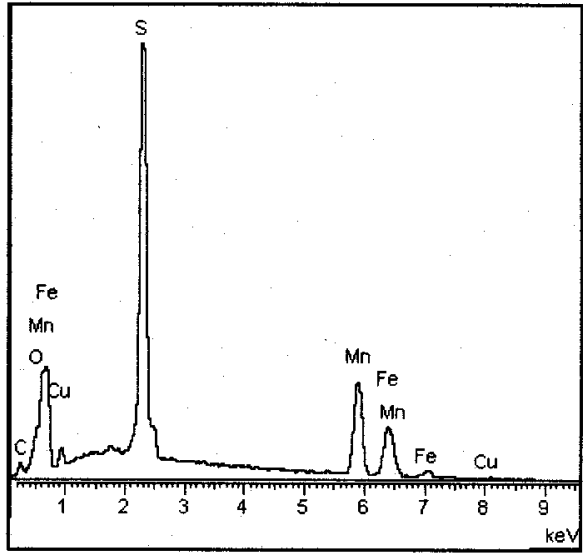

(f)

Figure 5.30. Longitudinal microstructure of the Bl-steel deformed in tension in the 'liquid+solid' region and quenched at the straightening stage just before the tensile test.

(a) and (b): Overall microstructures, etched with nital. Optical and SEM, respectively.

(c) and (d): Electro-polished structures in (a) and (b) observed in FEGSEM.

(e) and (f): EDS analyses of particles in (c) and (d), respectively. 


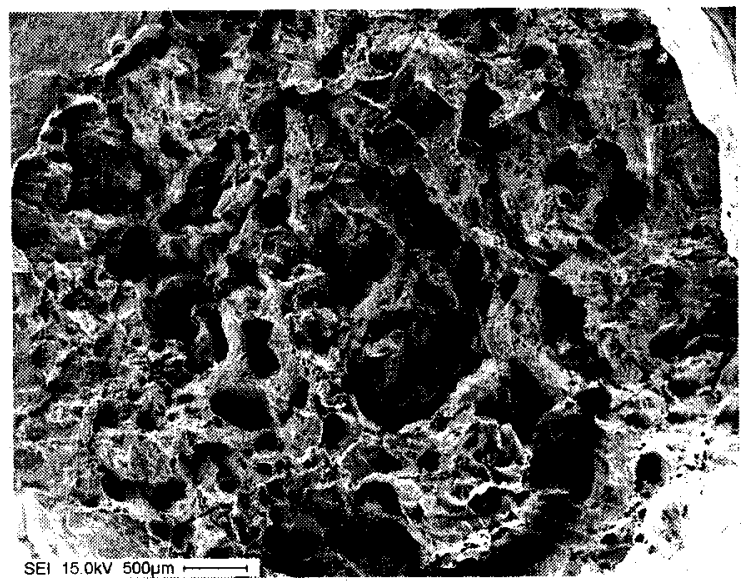

(a)

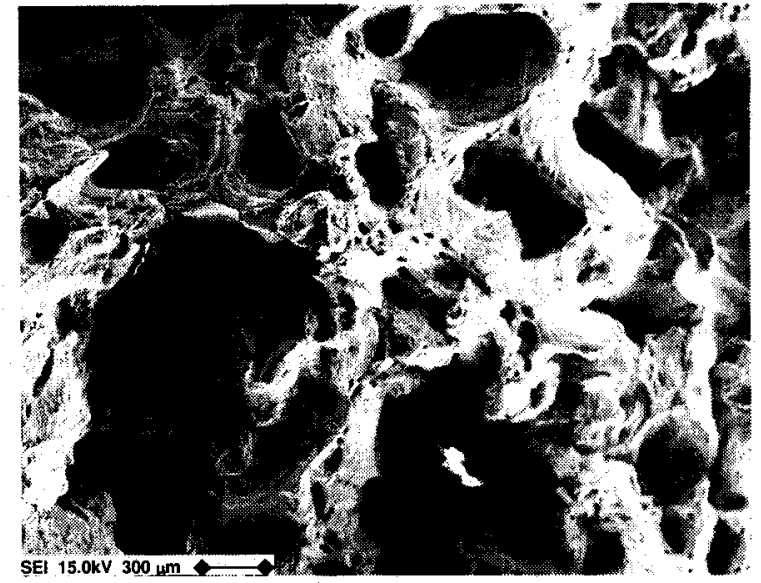

(b)

Figure 5.31. Fracture surface of the B1-steel at the straightening stage. The specimen had been pre-compressed in the $\delta$-ferrite region. (Corresponding with Figure 5.9 or specimen II in Figure 5.11)

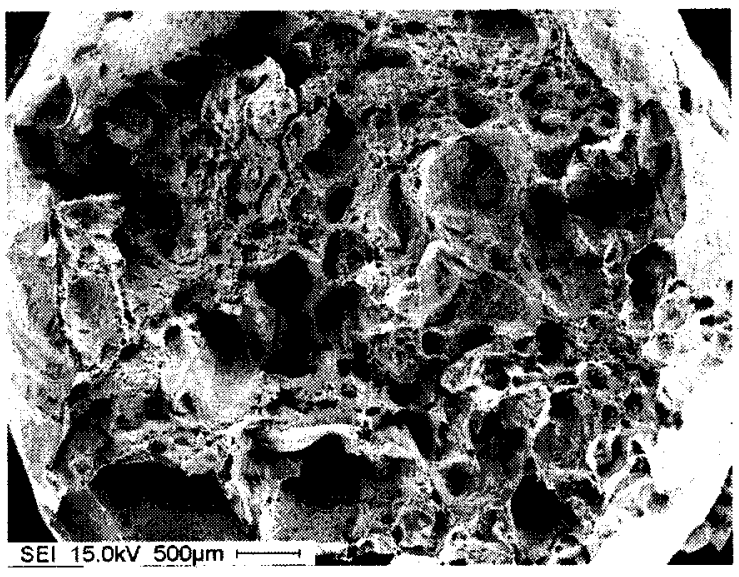

(a)

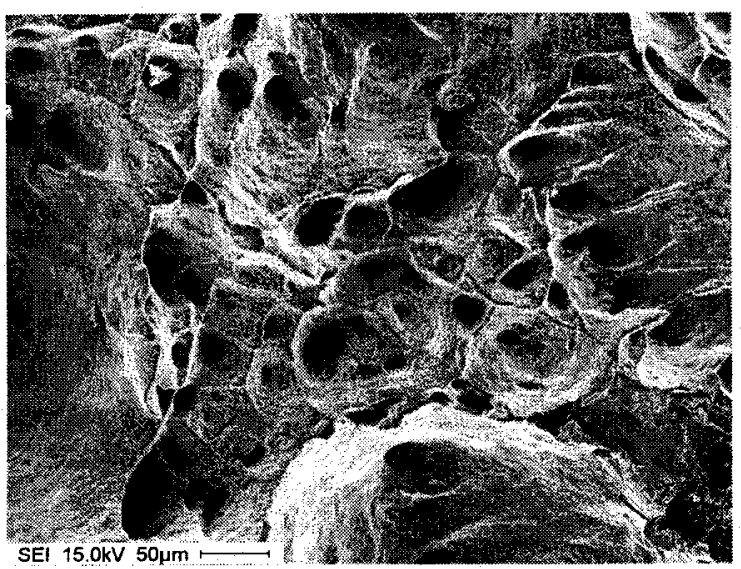

(c)

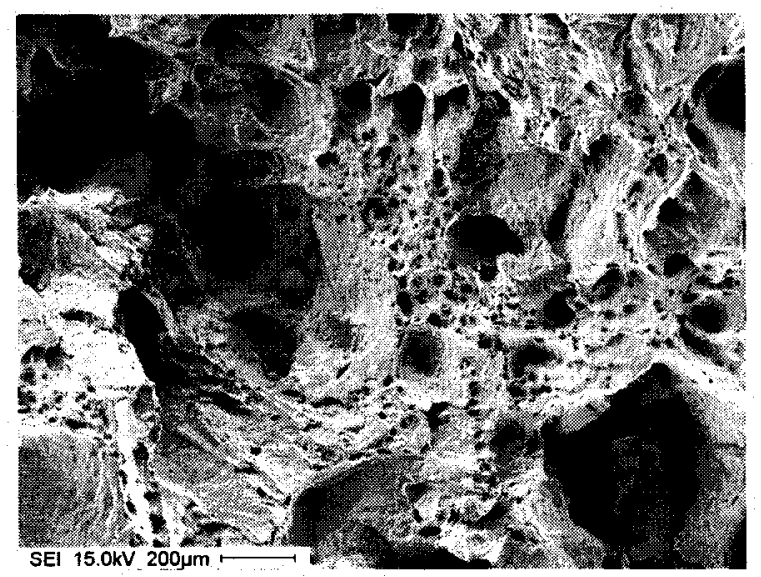

(b)

Figure 5.32. Fracture surfaces of the Blsteel, which had been pre-deformed in tension in the $\delta$-ferrite region, at the straightening stage. (corresponding with Figure 5.9)

(a) and (b): Observations at low and high magnifications, respectively.

(c): Void nucleation and coalescence at grain boundaries. 
mode. As can be seen from Figure 5.32(c), void growth and coalescence have contributed to the fracture. It should be pointed out that no precipitates/particles were found inside the voids.

Pre-deformation in the $\delta \rightarrow \gamma$ transformation region, Figure 5.33, resulted almost in a similar fracture appearance to those of the specimens deformed in pre-compression and pre-tension in the $\delta$-ferrite region. Grains can hardly be distinguished and domains with intergranular failure are few.

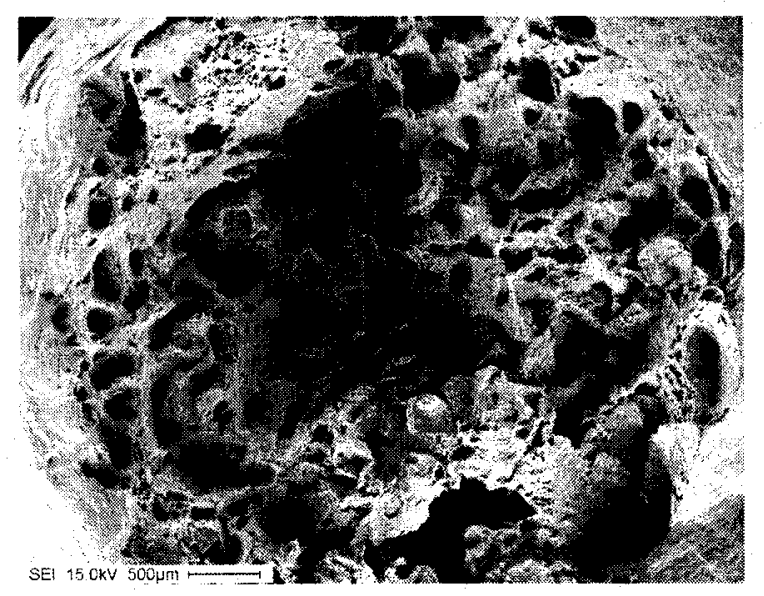

(a)

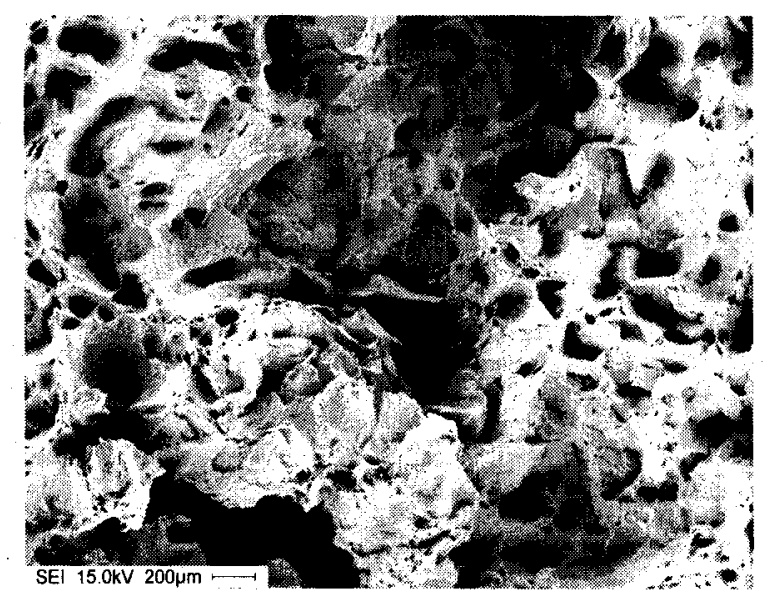

(b)

Figure 5.33. Fracture surface of the Bl-steel at the straightening stage. The specimen was precompressed in the $\delta \rightarrow \gamma$ transformation region. (Corresponding with Figure 5.9 or the specimen I in Figure 5.11)

Regarding pre-deformation during solidification in the $\mathrm{Nb}$-steel, the embrittlement was enhanced when $5 \%$ deformation was just limited to the two-phase 'liquid+solid' region (specimen I in Figure 5.10), Figure 5.34. As Figure 5.34(a) illustrates, the failure is substantially intergranular with no evidence of plastic deformation. Also, columnar grains about $1 \mathrm{~mm}$ long that formed peripherally during solidification are noticeable. The grain surfaces are composed of two distinct relatively smooth and rough regions as designated by $\mathbf{A}$ and B, respectively, in Figure 5.34(b). Examination in the FEGSEM revealed particles of irregular shape 100 to $500 \mathrm{~nm}$ in size that are dispersed on the smooth region, 
Figure 5.34(c). Characteristic $\mathrm{x}$-ray analysis of these particles identified $\mathrm{Fe}, \mathrm{Al}$, and $\mathrm{O}$ as major elements. Assuming that the Fe signal in the spectrum has come from the iron matrix, these particles can be identified as $\mathrm{Al}_{2} \mathrm{O}_{3}$. However, no precipitates were found on the rough region, Figure 5.34(d). This region displays a kind of shear-like appearance at grain boundaries, especially with cavities on the grain surfaces, as presented in Figure 5.34(b).

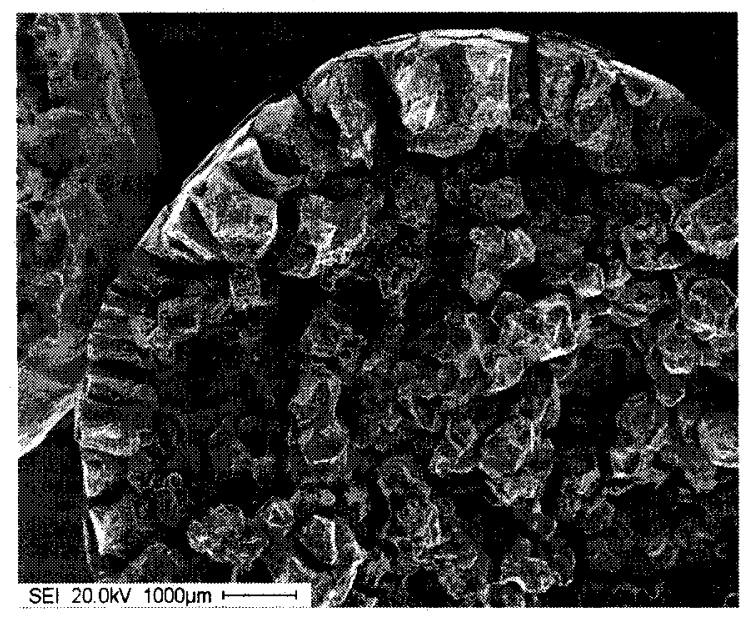

(a)

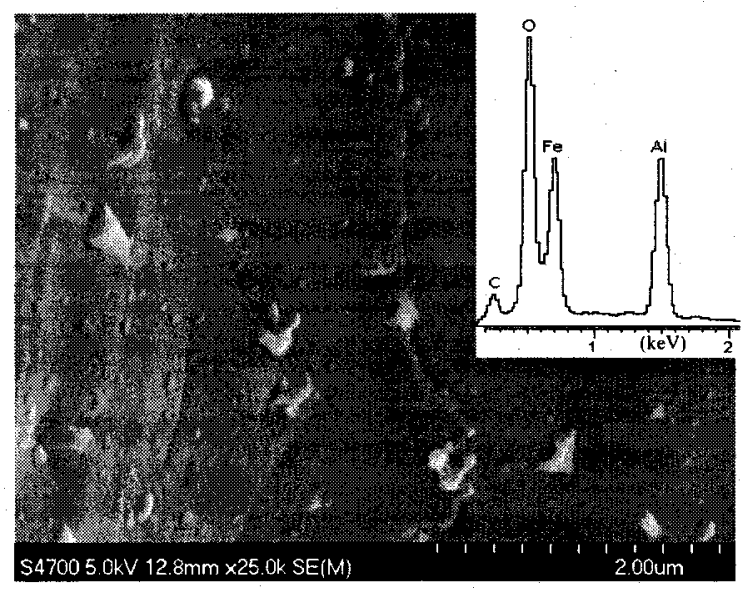

(c)

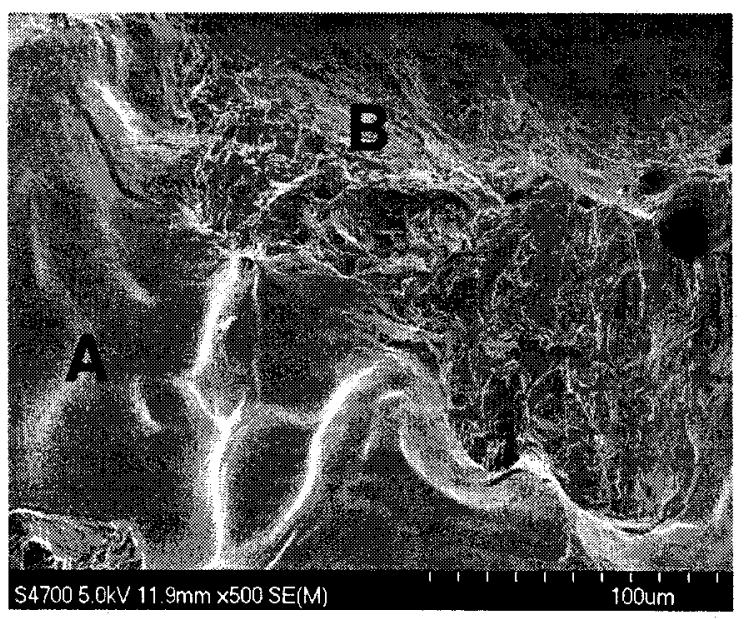

(b)

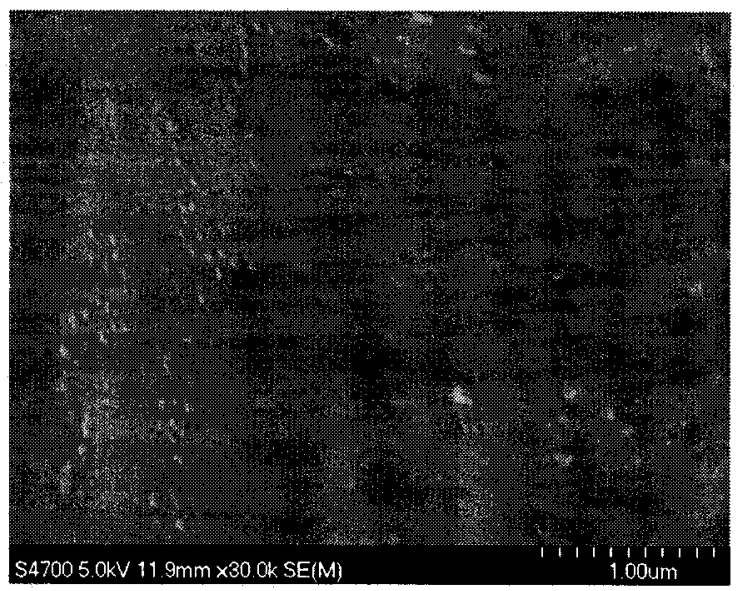

(d)

Figure 5.34. Fracture surface of the specimen I in Figure 5.10.

(a): Overall observation.

(b): Close look at grain surfaces in FEGSEM.

(c) and (d): Close look at regions $\mathbf{A}$ and $\mathbf{B}$, respectively, specified in (b) using FEGSEM. The spectrum in (c) is EDS analysis of particles shown in the same picture. 
The external surface of the specimen displayed in Figure 5.34 is shown in Figure 5.35. Figure 5.35(a) together with Figure 5.34(a) display columnar grains that have grown inward. This exterior surface characteristic is common in almost all specimens after solidification, but the grains are more clearly delineated in this specimen. Figure 5.35(b) illustrates a very explicit intergranular failure as grain boundaries are clearly delineated on the surface. Looking closely at the surface, one can identify two distinct characteristics at the grain boundaries. Figure 5.35(c) exhibits a liquid-like film, which seems pushed out intergranularly. Squeezed-out inclusions are the second characteristic that occurred on the surface during the pre-compression, Figure 5.35(d). EDS analyses of these two characteristics are shown in Figures 5.35(e) and (f). As can be seen, the liquid-like film at grain boundaries is highly concentrated in silicon and the grain boundary inclusions are composed of $\mathrm{Al}$ and some impurity elements.

When the pre-deformation start temperature was shifted down to the vicinity of the solid phases, the $\mathrm{Nb}$-steel displayed some ductile behavior, although the intergranular failure was still the dominant mode of fracture. Figure 5.36 shows the fracture surfaces of specimens that were pre-compressed in the $\delta$-ferrite region and in the proximity of the $\delta \rightarrow \gamma$ transformation region. Figure 5.36(a) is characterized by a fracture appearance that is similar to Figure 5.34(a) with some added shear-like features. These shear-like aspects definitely reflect higher ductility than the specimen in Figure 5.34. Figure 5.36(b) shows that there are also regions resembling a liquid film. On the contrary, Figures 5.36(c) and (d) exhibit features that are mostly analogous to the result of the thermal schedule alone (Figure 5.21). The grain boundary separation is quite discernible and some boundaries are separated without tolerating an appreciable shear deformation. The point that should be remarked here is that no voids, similar to those that appeared in Figures 5.32 and 5.33, can be observed on these fracture images.

Figure 5.37 shows the microstructures of the specimens presented in Figure 5.12. Generally, as can be perceived from Figures 5.37(a) (e), grain boundary decohesion is the mechanism of fracture in all of these specimens. Cracks mainly initiated at triple 


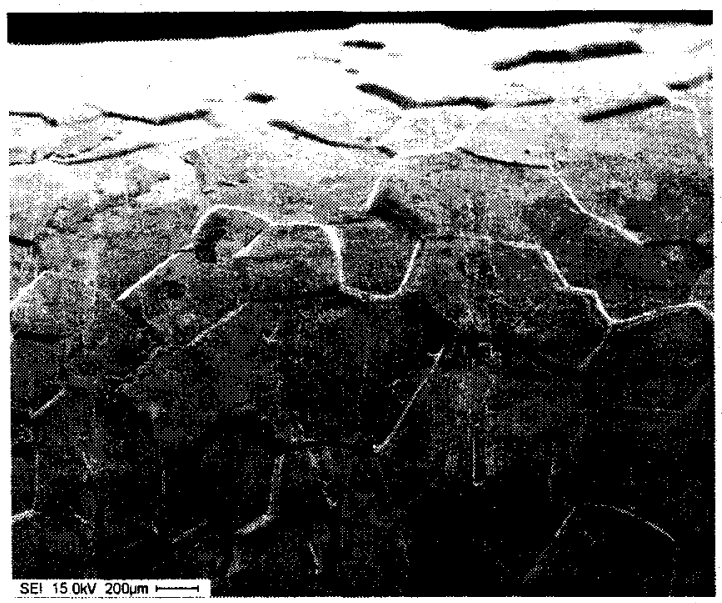

(a)

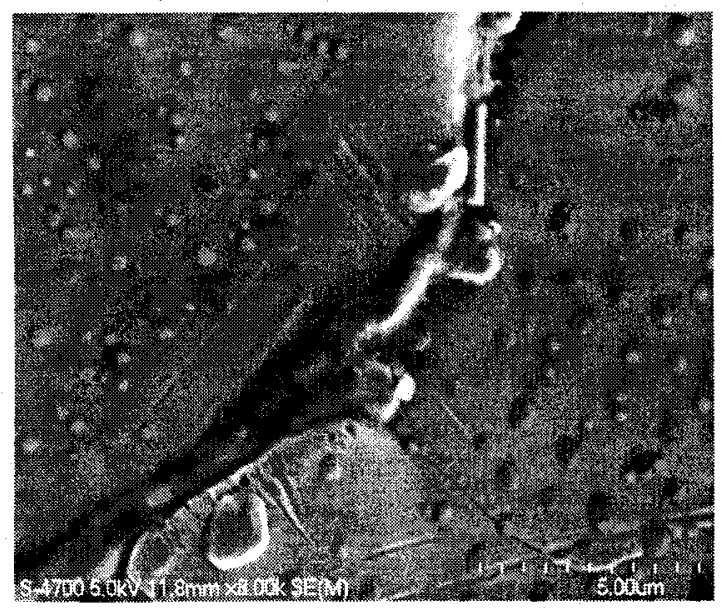

(c)

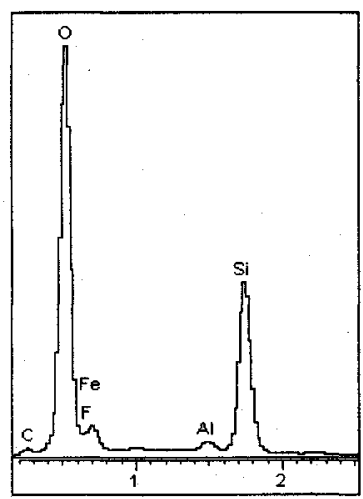

(e)

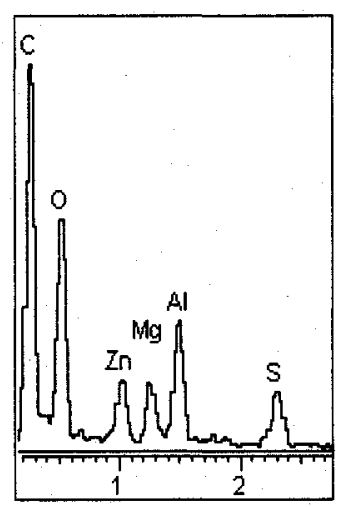

(f)

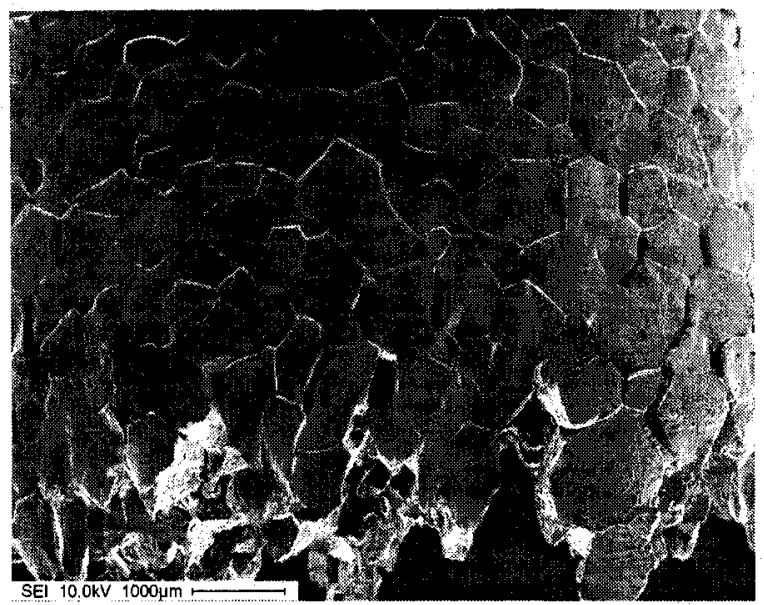

(b)

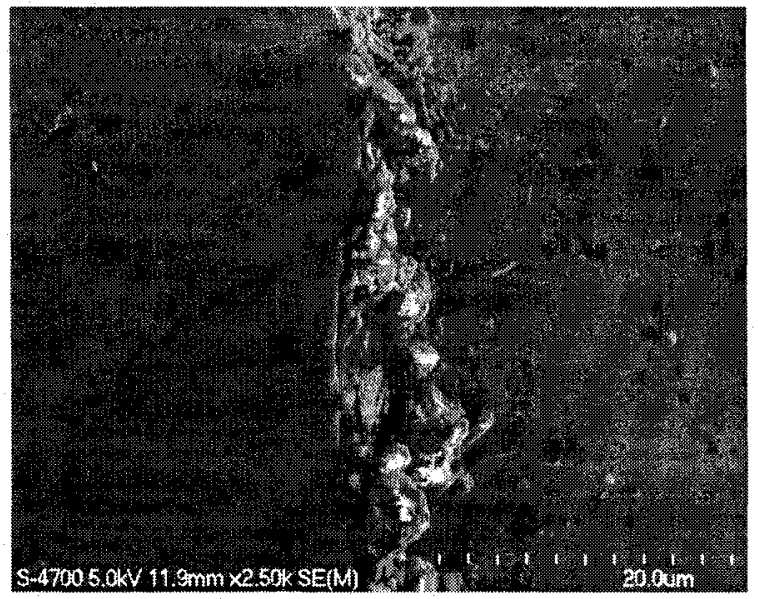

(d)

Figure 5.35. Outer surface of the $\mathrm{Nb}$-steel shown in Figure 5.34.

(a) and (b): At the straightening stage just before and after the tensile experiment, respectively. (a) is a horizontal image of the specimen.

(c) and (d): Materials entrapped at grain boundaries, observed in FEGSEM.

(e) and (f): EDS analyses of grain boundary materials shown in (c) and (d), respectively.

junction points of grain boundaries and propagated along the boundaries leading to the final grain boundary decohesion. Specimens I and V displayed almost a similar grain size 


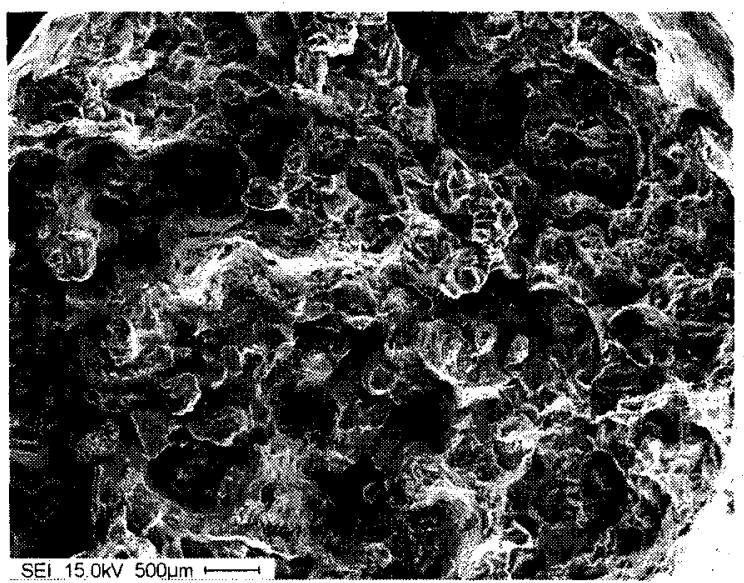

(a)

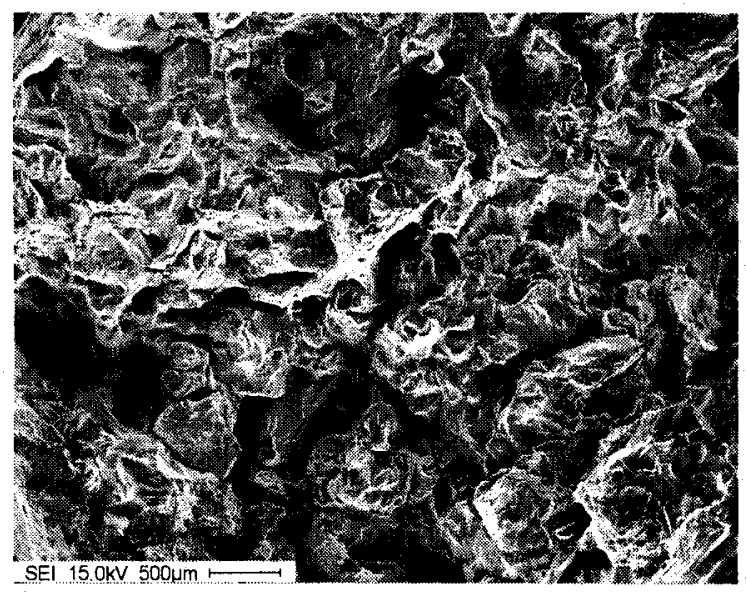

(c)

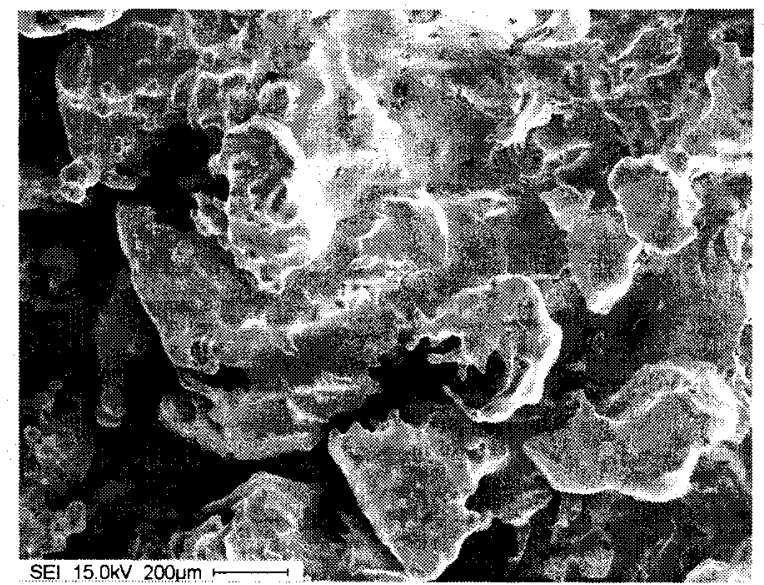

(b)

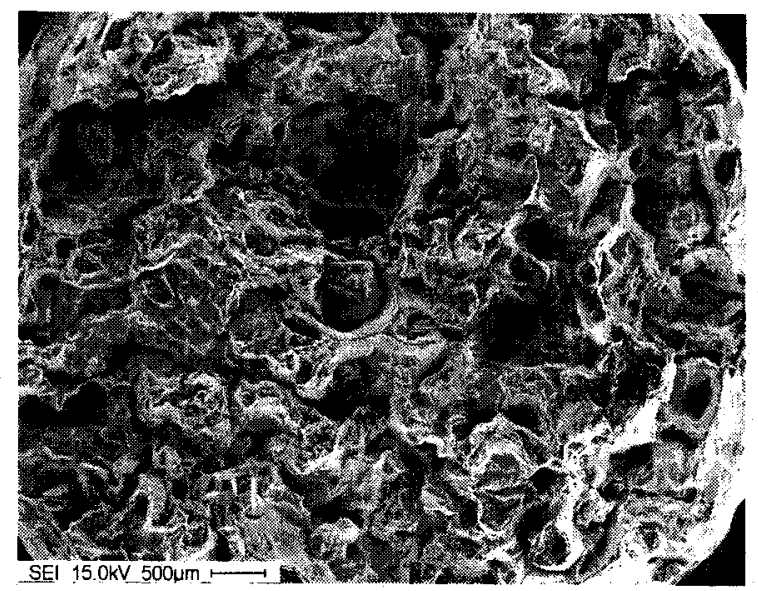

(d)

Figure 5.36. (a), (c), and (d): Fracture surfaces at the straightening stage of the specimens I, IV and V, respectively, presented in Figure 5.12. (b) is a magnified image of (a).

i.e. $\sim 500 \mu \mathrm{m}$, under the microscope. Figures 5.37(b) (d) show a smaller grain size with an average of $\sim 350 \mu \mathrm{m}$. Hence, the crack density in Figures 5.37(a) and (e) is lower.

Since pre-deformation in the vicinity of the $\delta \rightarrow \gamma$ transformation appeared to influence the microstructure and the hot ductility, the effect of pre-deformation rate during the transformation was studied. Figure 5.38 shows macrostructures of the specimens presented in Figure 5.13(b). All these three specimens exhibited a significant improvement in the hot ductility. Nevertheless, it seems that they have behaved somewhat 


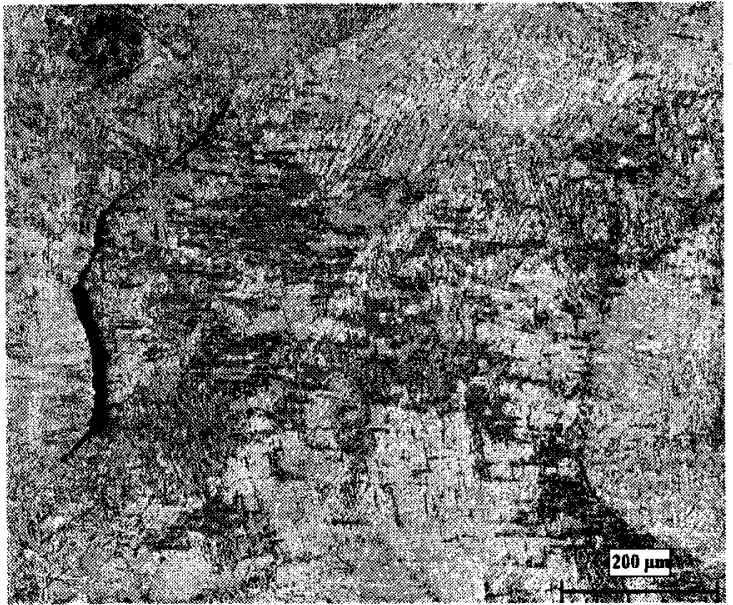

(a)

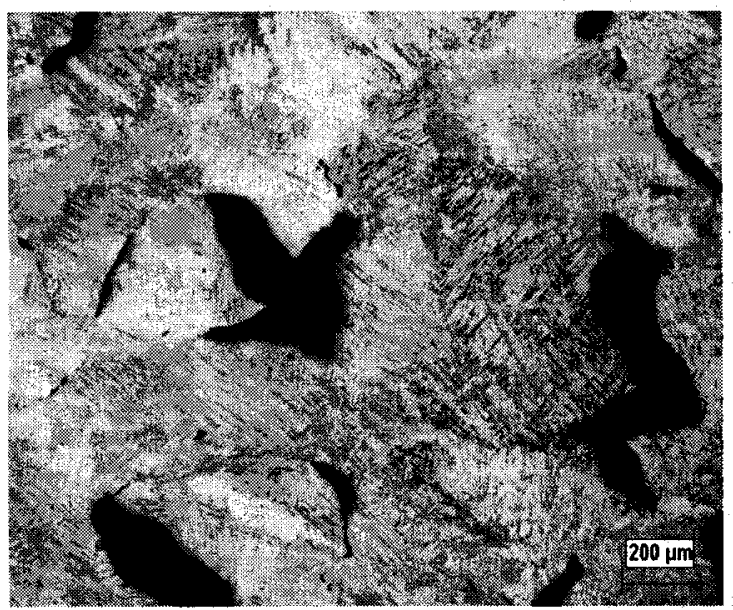

(c)

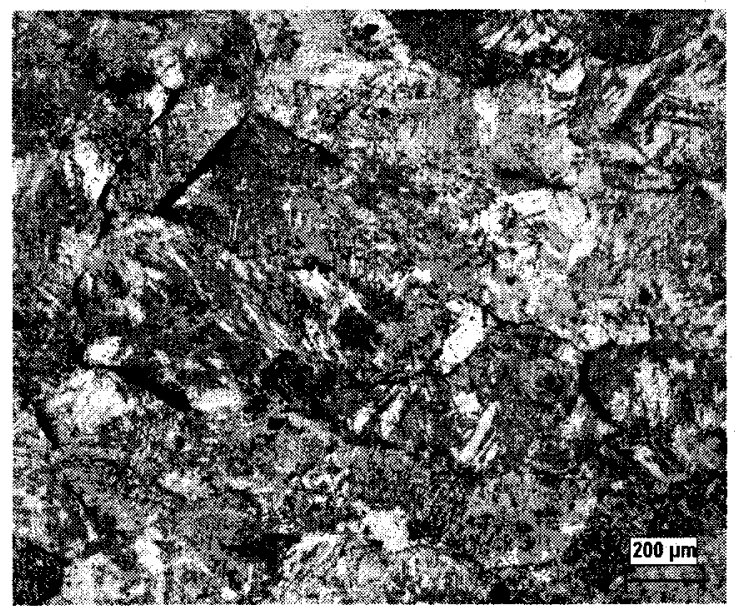

(e)

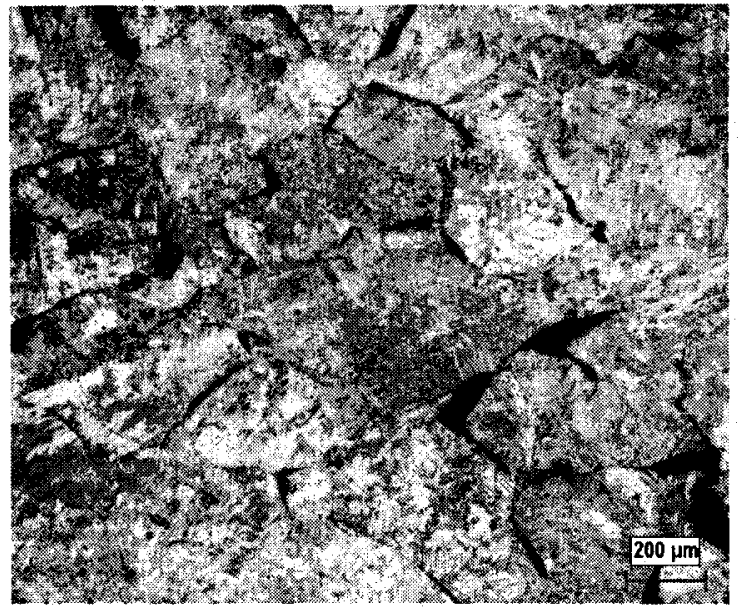

(b)

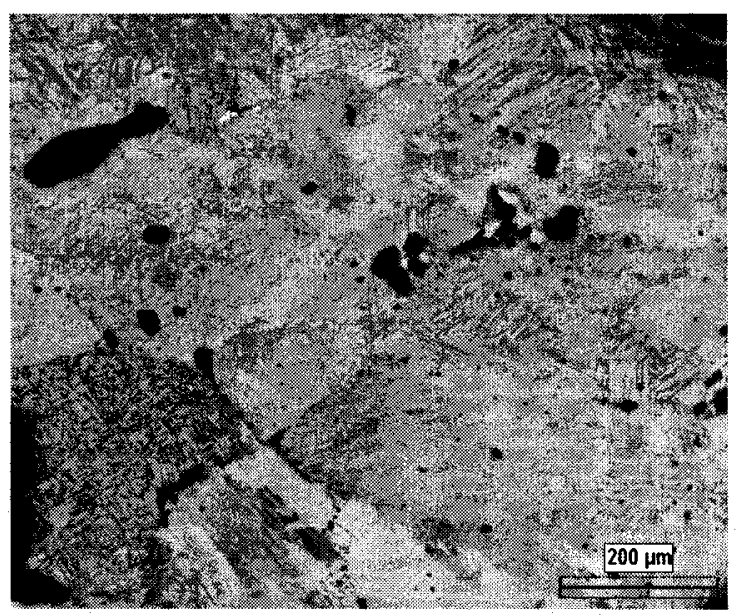

(d)

Figure 5.37. (a), (b), (c), (d), and (e): Longitudinal microstructures of specimens I, II, III, IV, and V shown in Figure 5.12, respectively. All specimens were quenched immediately after fracture at the straightening stage. All etched with etchant \#4. 
differently at the straightening stage under tension. Even though grain boundary cracking is the common mode of failure, the specimen in Figure 5.38(a) appears to have shown more susceptibility to this failure than the other two. This corresponds to less plastic deformation endured by grains. Furthermore, Figure 5.38(b) displays more stretched fracture edges indicating a more ductile characteristic. In this respect, the specimen in Figure 5.38(c) stands in the second position.

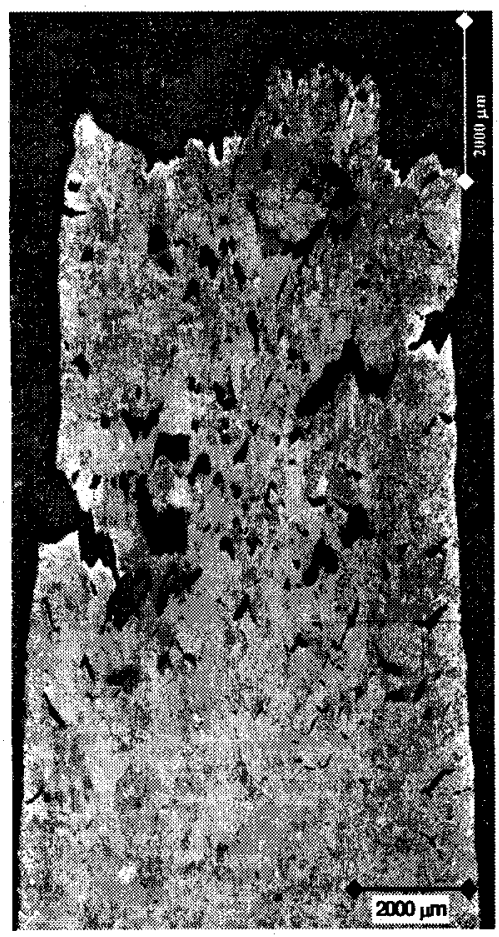

(a)

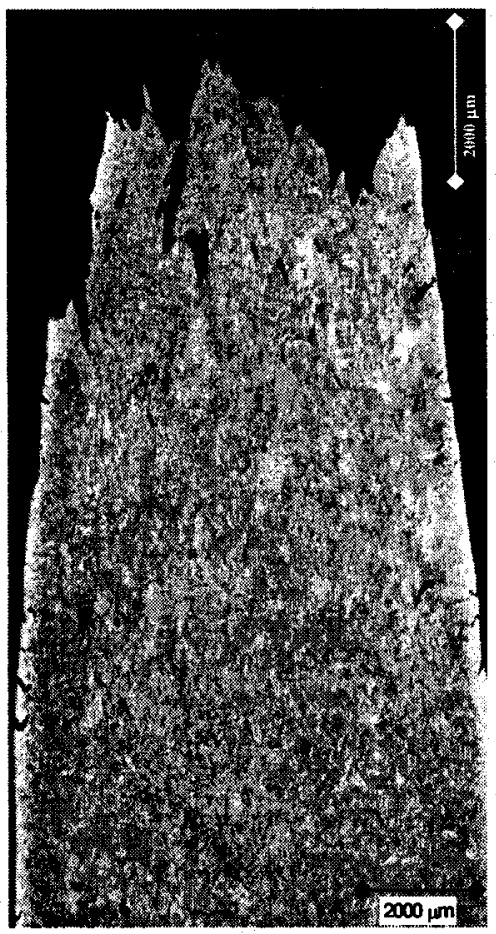

(b)

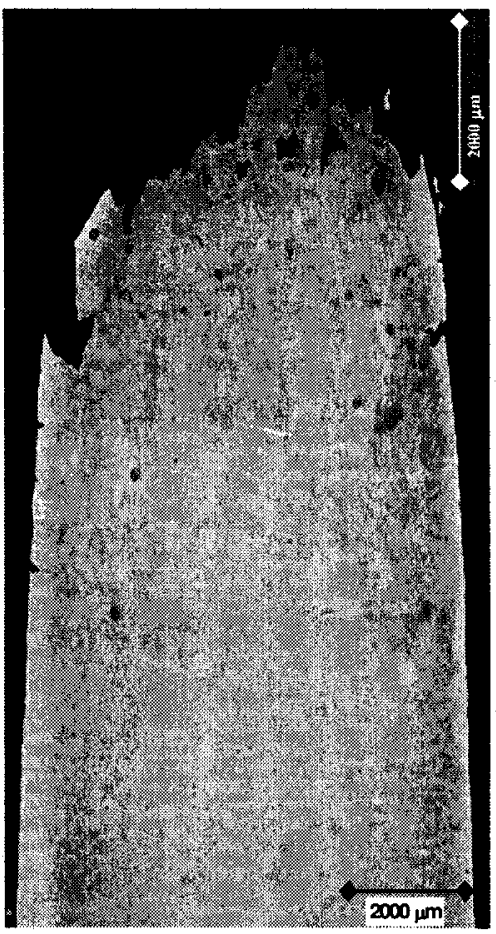

(c)

Figure 5.38. (a), (b), and (c): Longitudinal sections of specimens III, II and I, respectively, in Figure 5.13.

Figure 5.39 shows fracture surfaces of the specimens introduced in Figure 5.38. As can be seen, although grain boundary decohesion is observed in all three specimens, Figure 5.39(a) demonstrates this most conspicuously, and this is consistent with what was deduced from Figure 5.38. Figure 5.39(d) shows a typical grain boundary separation in these specimens. Another distinct difference among these images is that Figures 5.39(b) 


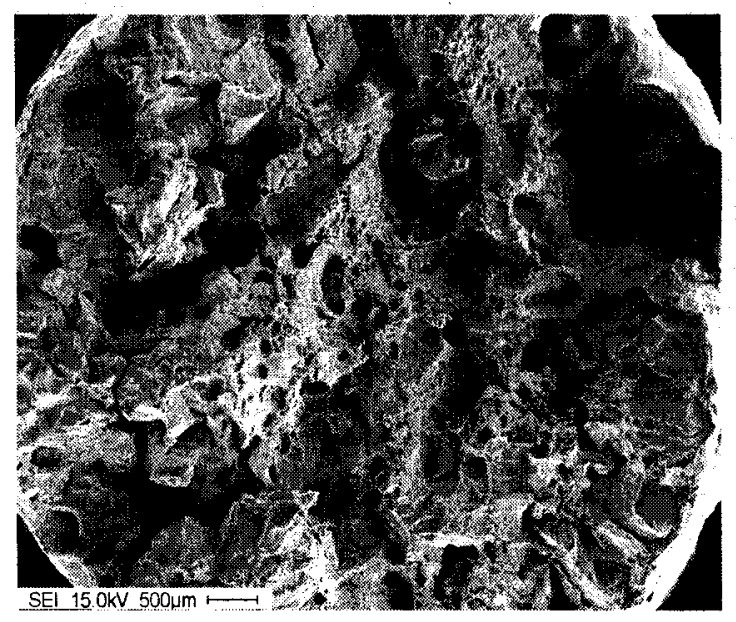

(a)

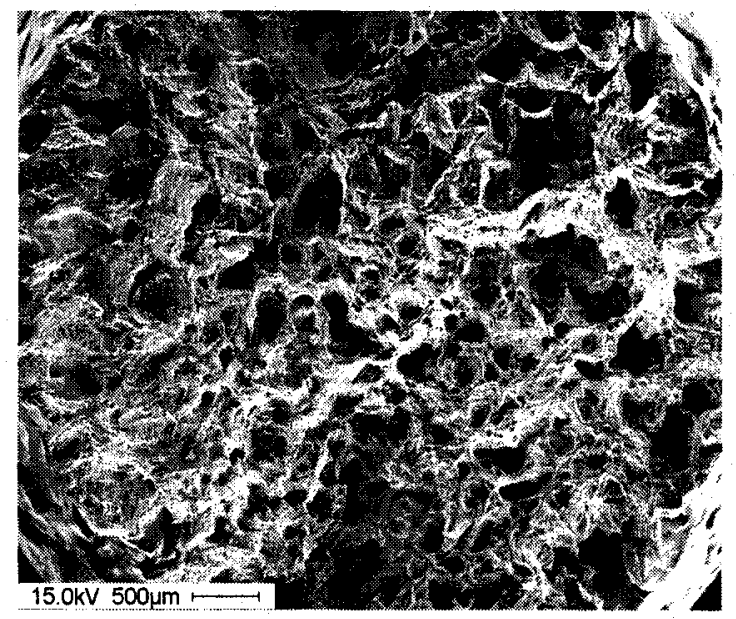

(c)

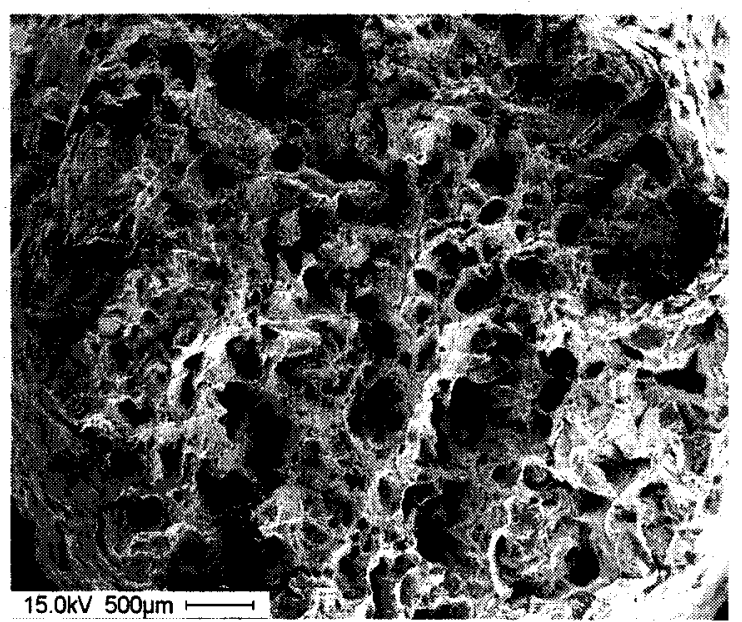

(b)

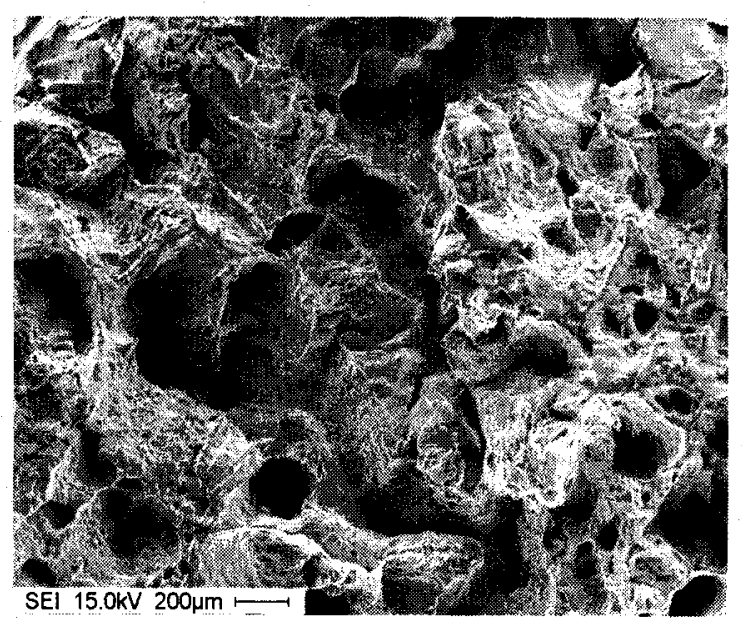

(d)

Figure 5.39. (a), (b), and (c): Fracture surfaces of the specimens III, II and I, respectively, in Figure 5.13. (d) is a magnified image of (b).

and (c) exhibit more cavities associated with the fracture as well as finer fracture features. This can be attributed to the effect of pre-compression, after solidification, on closing solidification shrinkages and voids at very high temperatures, i.e. the greater the amount of pre-compression at very high temperatures, the smaller the size of solidification voids. Accordingly, the application of pre-compression at a higher strain rate, Figure 5.39(c), is expected to have led to the smallest size of voids present in the steel at the straightening stage before the tension test. At the straightening stage, growth of the existing cavities is more favorable energetically than the nucleation of new ones. Thus, it is reasonable that 
Figure 5.39(a) displays larger and fewer cavities than the other two since the respective specimen was subjected to the lowest pre-compression rate. Based on this, large cavities at the straightening stage are classified mainly as grown solidification voids and very small ones as cavities that were formed during tension at the straightening stage.

Two distinct regions were found on the grain surfaces when the specimen in Figure 5.39(a) was examined in the FEGSEM. As Figure 5.40(a) shows, the grain surfaces are partly facetted but mostly have a rough appearance. Typical images of these characteristics are designated by the letters $\mathbf{A}$ and $\mathbf{B}$, respectively. Region $\mathbf{A}$ looks very smooth even at very high magnification and includes microvoids containing very small particles of about $50 \mathrm{~nm}$, Figure 5.40(b). Unfortunately, because of their size and the position of the grain surface, it was not possible to get enough x-ray signals to the EDS detector in order to obtain a reliable EDS analysis. Nevertheless, it seems that these particles did not play an important role in grain boundary fracture since the microvoids did not coalesce. Also, the fact that there is no evidence of shear deformation in this region, especially at the particle edge, indicates that these microvoids are not a result of tensile deformation at the straightening stage. On the contrary, region B displays a clear topography and is covered with stretched microvoids, Figure 5.40(c). Examination of this surface at higher magnification, Figure $5.40(\mathrm{~d})$, reveals that the microvoids contain particles of about $300 \mathrm{~nm}$ in size. Characteristic x-ray analysis of these particles is shown in Figure 5.40(e). Considering that iron and carbon signals have come from the matrix, this kind of particle can be characterized as $\mathrm{Al}_{2} \mathrm{O}_{3}$.

The influence of pre-deformation strain rate in the proximity of the $\delta \rightarrow \gamma$ transformation region on the fracture microstructure is shown in Figure 5.41. In comparison with the specimen of Figure 5.22 that simply underwent the thermal schedule alone before fracture, the specimens in Figure 5.41 all exhibit much smaller grain size in the neighborhood of the fracture region. Furthermore, grain boundary discontinuities are much smaller, isolated, and have oval shapes, instead of large linked-up and elongated cavities that have resulted in grain boundary cracks propagated along grain boundaries 


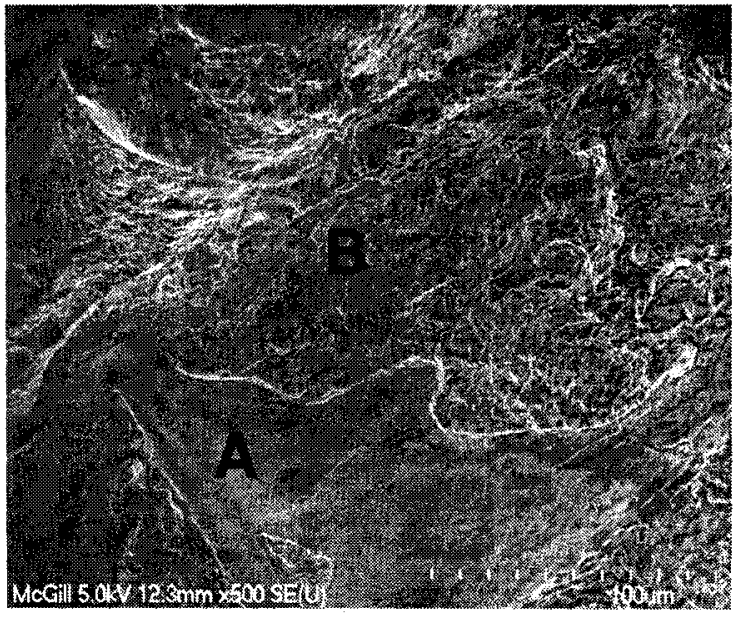

(a)

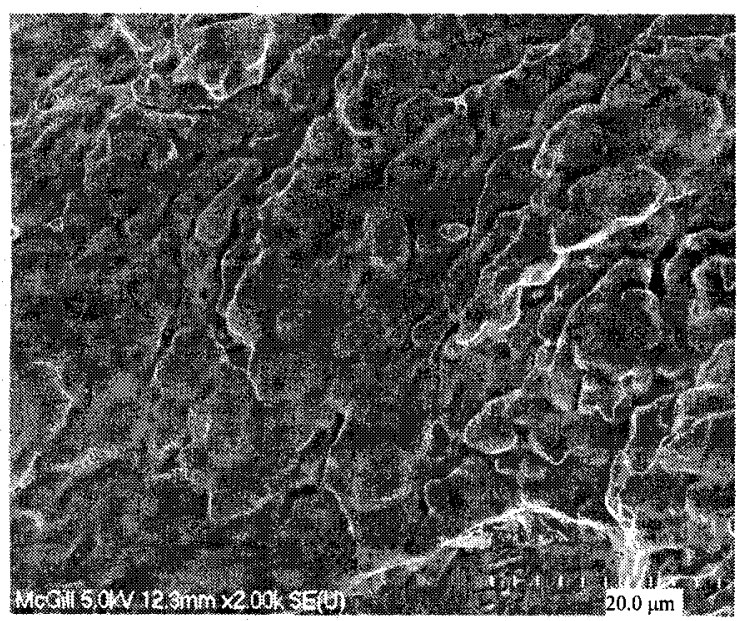

(c)

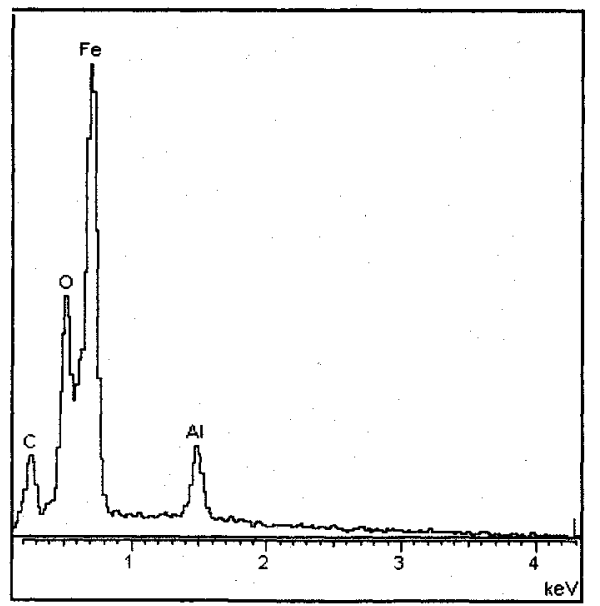

(e)

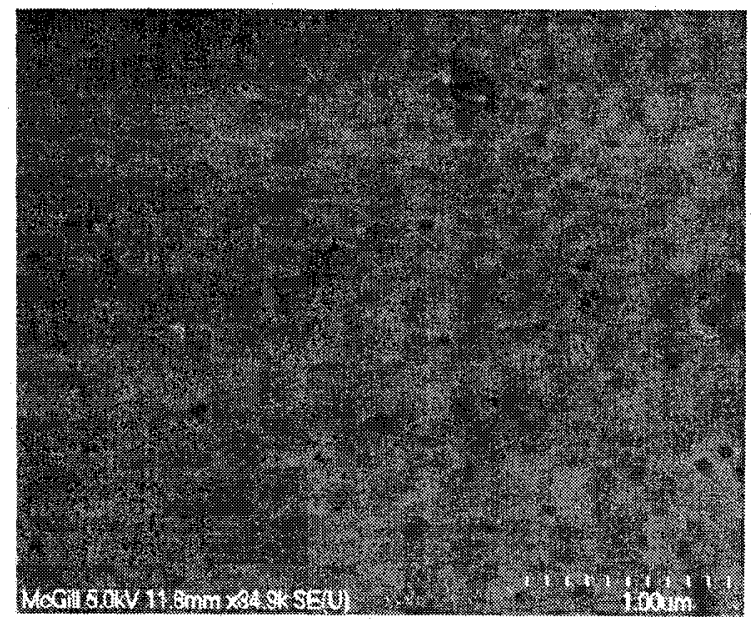

(b)

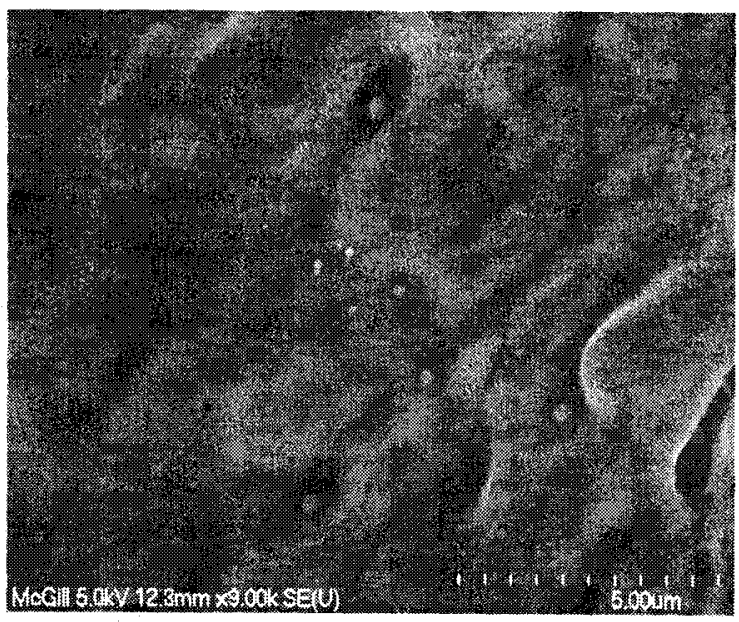

(d)

Figure 5.40. Detailed study of the grain surfaces in specimen III of Figure 5.13 in FEGSEM.

(a): Overall observation.

(b): Region $\mathbf{A}$ in (a).

(c) and (d): Region $B$ in (a)

(d): EDS analysis of particles in (d) 
(Figure 5.22). As indicated by arrows in Figures 5.41(a) and (c), these ovals can also be observed in grain interiors. The effect of strain rate on the grain size is negligible since Figures $5.41(\mathrm{a}) \sim(\mathrm{c})$ display a nearly identical general grain size.

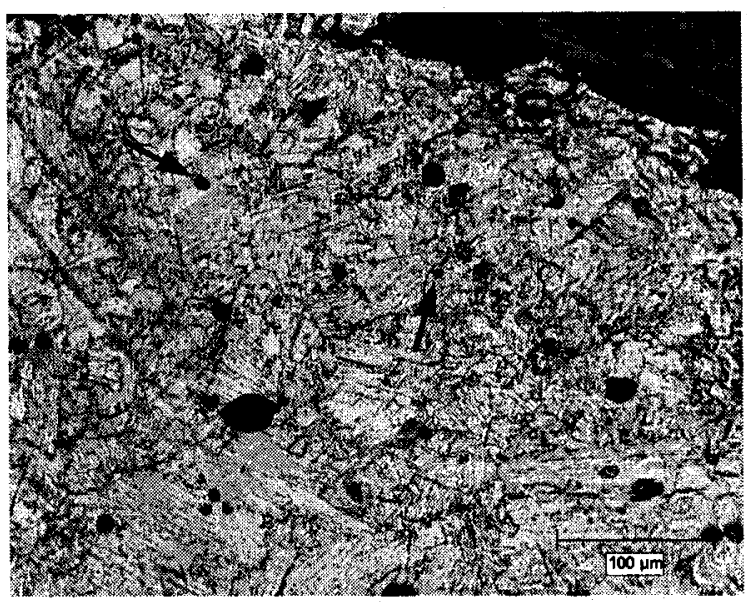

(a)

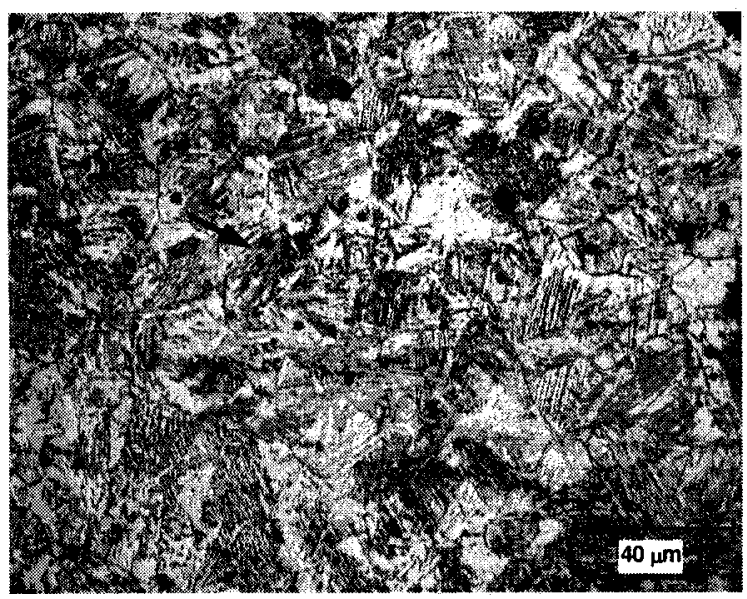

(c)

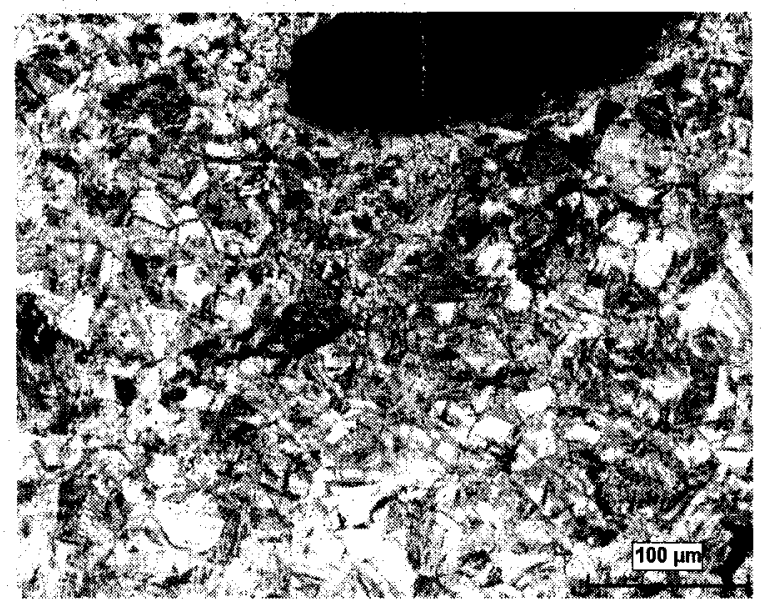

(b)

Figure 5.41. (a), (b), and (c): Respectively, longitudinal sections, near the fracture regions, of specimens III, II and I in Figure 5.13. (a) was etched in picral and (b) and (c) in etchant \#4. Arrows point to voids formed inside grains.

A similar result was found in the B1-steel. Figure 5.42(a) shows that pre-compression during the transformation resulted in a finer grain size after fracture, compared with the effect of the thermal schedule alone in Figure 5.20. Nevertheless, in contrast to the $\mathrm{Nb}$ steel, even without the aforementioned pre-compression, the grains are much smaller than the as cast grains, which are usually greater than $400 \mu \mathrm{m}$. In other words, the B1-steel subjected to the thermal schedule alone is prone to grain refinement under deformation at the straightening stage. In this case, pre-compression in the vicinity of the transformation 
appears to have helped the grain refinement during tension at the straightening stage. Another characteristic, as shown in Figures 5.42(b) (e), are the delineated lines that are oriented toward the tensile direction. These groups of parallel lines, which have been observed in some grains, are formed in individual grains without crossing grain boundaries.

In order to determine the reason for such a change in the microstructure owing to predeformation in the vicinity of the transformation, two specimens of the $\mathrm{Nb}$-steel, one subjected to the thermal schedule alone and the other pre-compressed during the transformation, were quenched at the straightening stage just before the tensile experiment. The microstructures of these specimens are compared in Figure 5.43. Figure 5.43(a) displays a coarse austenite grain size at the straightening stage after the thermal schedule alone. But, when the steel was subjected to a pre-compression going through the transformation region, the grain size decreased noticeably at the straightening stage. Figure 5.43(b) demonstrates this microstructure in which austenite grain boundaries are decorated with ferrite. For such a decoration to be achieved, the specimen was allowed to cool down until $\sim 800^{\circ} \mathrm{C}$ in an argon atmosphere before being quenched in water. Therefore, the grain refinement is considered as being caused by the pre-deformation during the transformation.

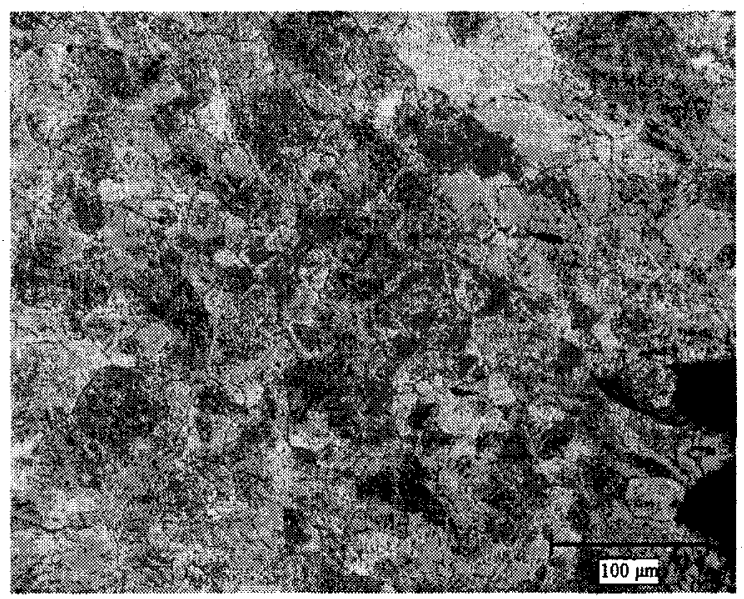

(a)

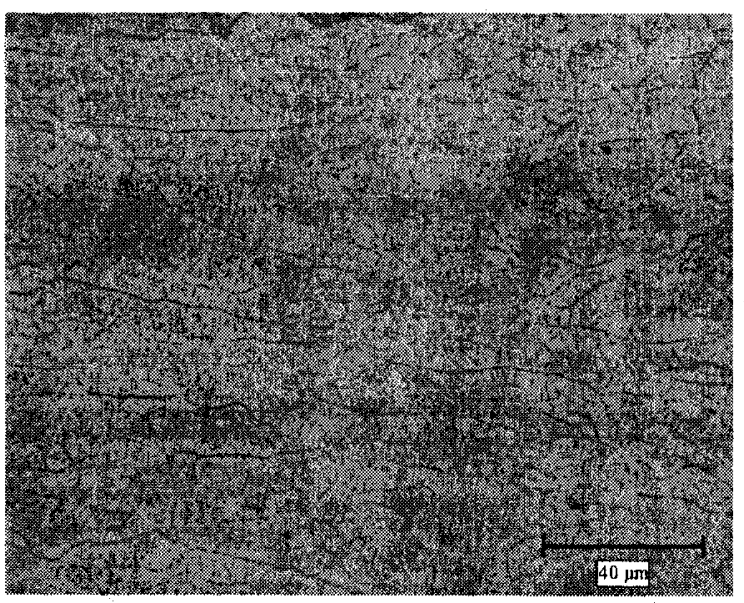

(b)

Figure 5.42. Longitudinal microstructures of the B1-steel quenched after fracture at the straightening stage. Corresponding with specimen III in Figure 5.11. Etched with etchant \#4. 


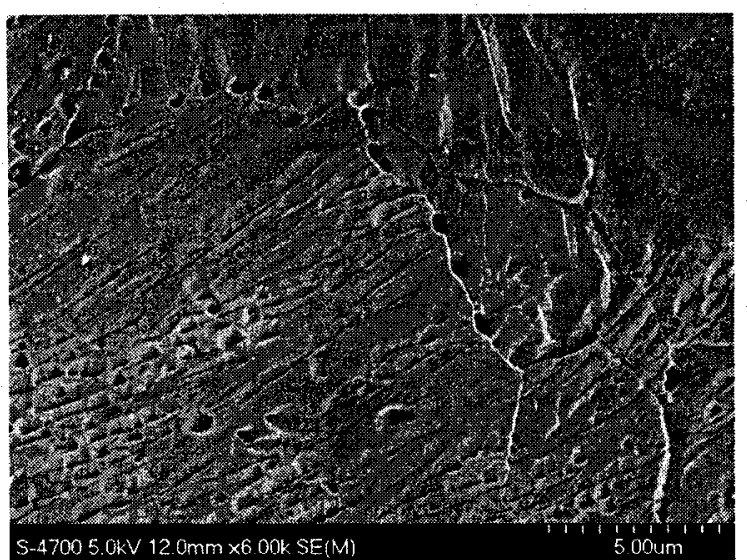

(c)

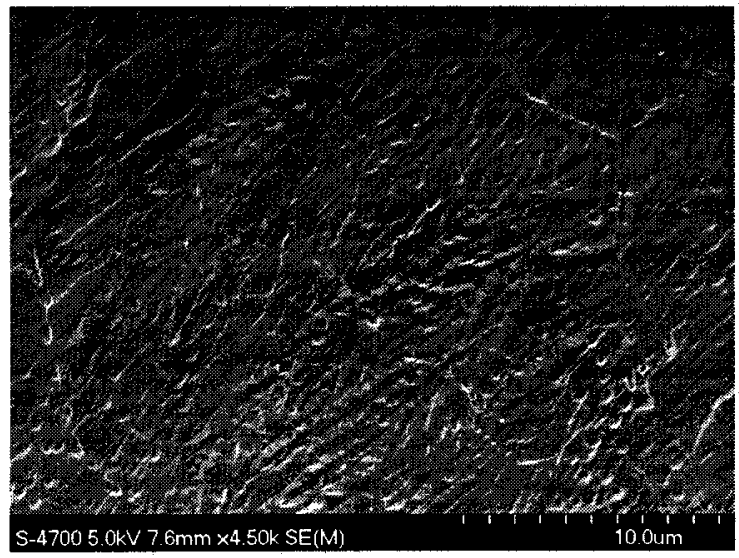

(e)

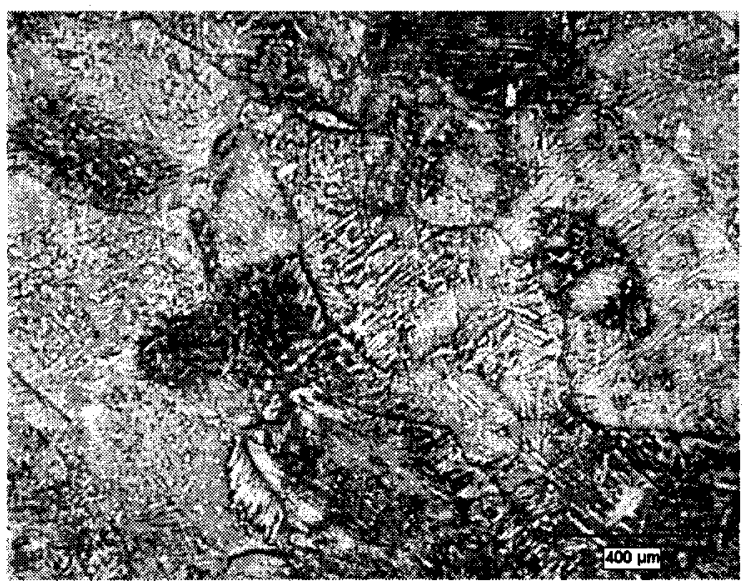

(a)

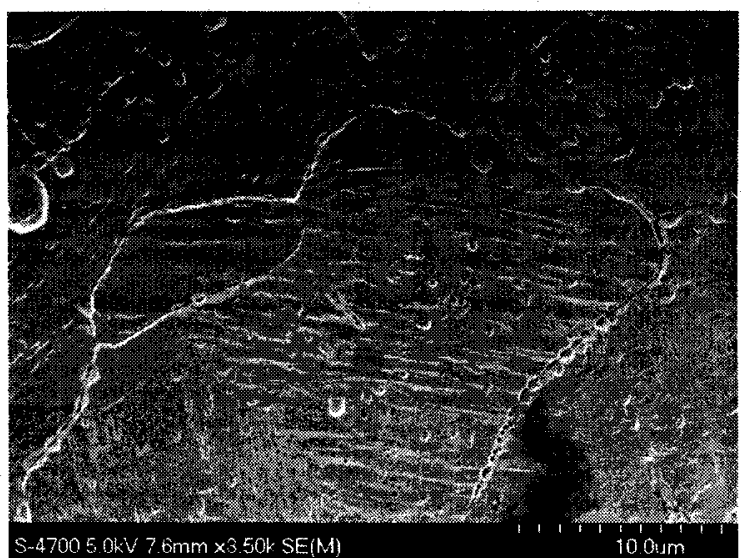

(d)

Figure 5.42, continued.

(c), (d), and (e) FEGSEM images.

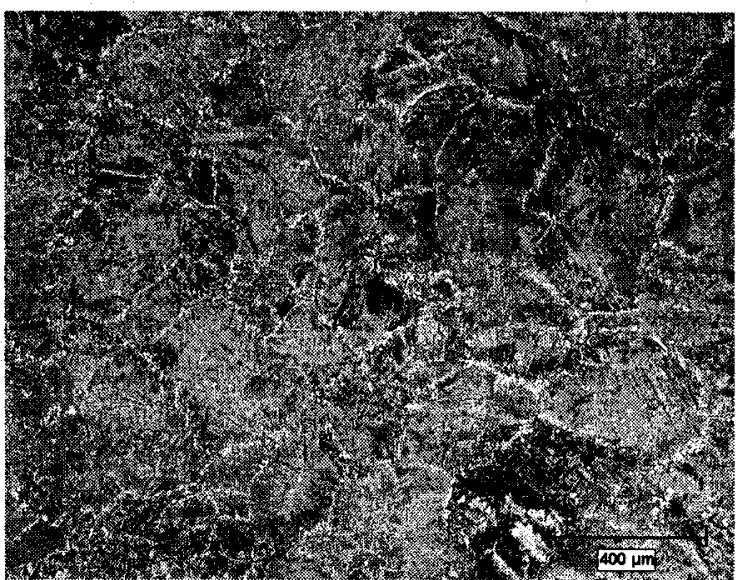

(b)

Figure 5.43. Longitudinal sections of the $\mathrm{Nb}$-steel specimens quenched at the straightening stage just before the tensile experiment. Etched with picral.

(a): After undergoing the thermal schedule alone.

(b): After undergoing the thermal schedule together with pre-deformation schedule III in Figure $5.13(\mathrm{a})$. 


\section{DISCUSSION}

In this chapter, first, the results of the CHT and CCC experiments are discussed and the fundamental bases on which these two experiments are employed to determine transformation temperatures are described. Then, the failure modes in the investigated steels are analyzed and specified. Third, the mechanism by which the boron addition to the $\mathrm{Nb}$-containing steel can lead to the hot ductility improvement is discussed. This will be followed with a discussion of the effect of deformation on the hot ductility and the mechanisms of hot ductility deterioration and improvement.

\subsection{CHT and CCC Experiments}

As shown by previous workers, the stress drops during CHT experiments are attributed to dynamic recrystallization, dynamic phase transformation, and incipient melting. ${ }^{[120]}$ However, because of their correlation with the hot ductility, they will be briefly reviewed here, with specific attention to the dynamic $\delta \rightarrow \gamma$ transformation in the CCC experiments.

Before the first drop at ' $a$ ' in Figure 5.1, austenite is being strain hardened in the plastic region as strain is being accumulated. Dynamic recrystallization starts before this point and at ' $a$ ' the rate of dynamic recrystallization is greater than the strain hardening rate, thus the stress begins to decrease. Austenite grains also grow while the temperature 
increases and dynamic recrystallization is underway. ${ }^{[120]}$ The steady state dynamically recrystallized grain size, $d$, is a function of the Zener-Hollomon parameter, $Z$, i.e ${ }^{[100]}$

$$
d=A Z^{-p}
$$

where

$$
Z=\dot{\varepsilon} \exp \left(\frac{Q_{\text {def }}}{R T}\right)
$$

In these equations, $A$ and $p$ are material constants, $\dot{\varepsilon}$ strain rate, $Q_{d e f}$ activation energy for deformation, $R$ the gas constant and $T$ absolute temperature at which deformation is executed. From these equations, it can be easily inferred that the steady state recrystallized grain size is larger at higher temperatures. Hence, the dynamic recrystallization occurring during the CHT experiments could lead to large grains as the temperature increases continually. On the other hand, it has been shown that the nature of the flow curve changes essentially from the multiple to the single peak type as $Z$ increases, i.e. with increasing strain rate or decreasing temperature. ${ }^{[125,126]}$ It has been also reported that the transition in flow curve shape is associated with a change in the type of dynamic recrystallization. Multiple peak flow appears when grain coarsening occurs and single peak flow is exhibited when the material is experiencing grain refinement. The deformation curves shown in Figure 5.1 display double and triple-peak dynamic recrystallization processes, occurring at ' $a$ ', ' $b$ ', and ' $b$ ', and this suggests grain coarsening. In addition, during the CHT experiments, the temperature is continuously rising and $Z$ is decreasing accordingly (equation 6.2). Therefore, the material approaches a larger steady state grain size regime. Note that $Q_{\text {def }}$ can be considered to be constant within a specific thermal region where there is no transformation or precipitation reaction in the austenite.

Furthermore, raising the temperature increases the kinetics of recovery. Therefore, increasing the deformation start temperature decreases the number of recrystallization peaks expected to be observed. This is why there are fewer stress drops owing to dynamic recrystallization in the $\mathrm{B} 1$-steel than the $\mathrm{Nb}$-steel, which was subjected to deformation $100^{\circ} \mathrm{C}$ higher, Figure 5.1. As well, at such a low strain rate as employed for the tension experiments, recovery, after the first dynamic recrystallization drop, is likely to alleviate 
strain accumulation, which is the driving force for dynamic recrystallization. Thus, due to the low strain rate and continuous rise in temperature, the rate of stress drop is gradually reduced, comparing the slopes of stress drops at ' $a$ ' and ' $b$ ' in Figure 5.1. In agreement with this, it was found that the number of recrystallization peaks increased when the strain rate was increased. ${ }^{[120]}$

After the dynamic recrystallization stress drops, the dynamic transformation of $\gamma$-austenite to $\delta$-ferrite takes place. At this point, the flow stress falls rapidly and significantly. The stacking fault energy and the kinetics of dynamic recovery are lower in austenite than in $\delta$-ferrite. Hence, austenite is stronger than $\delta$-ferrite. It can be reasonably assumed that the steels obey power law creep and, accordingly, the shear strength can be determined as follows; ${ }^{[127]}$

$$
\sigma_{s}=\mu\left[\frac{\dot{\gamma} k T}{A_{2} D_{\text {eff }} \mu b}\right]^{\frac{1}{n}}
$$

where $\mu$ is the hear modulus, $\dot{\gamma}$ shear strain rate, $k$ Boltzmann's constant, $D_{\text {eff }}$ effective diffusion coefficient, $b$ Burger's vector, $n$ exponent of power-law creep, and $A_{2}$ the Dorn constant. The effective diffusion coefficient can be defined as:

$$
D_{e f f}=D_{v}\left[1+\frac{10 a_{c}}{b^{2}}\left(\frac{\sigma_{s}}{\mu}\right)^{2} \frac{D_{c}}{D_{v}}\right]
$$

where $D_{v}$ and $D_{c}$ are the lattice and dislocation core diffusion coefficients, respectively, and $a_{c}$ the diffusive cross section of a dislocation core. However, at very high temperatures where lattice diffusion is dominant, the shear stress equation can be rewritten as;

$$
\sigma_{s}=\mu\left[\frac{\dot{\gamma} k T}{A_{2} D_{v} \mu b}\right]^{\frac{1}{n}}
$$


Using values for these parameters from reference 127 and calculating the dependent parameters with regard to the temperature and strain rate employed in the CHT experiments;

Table 6.1. Power law creep parameters.

\begin{tabular}{|c|c|c|}
\hline Parameter & Austenite & Delta-ferrite \\
\hline$\dot{\gamma}\left(\mathrm{s}^{-1}\right)$ & 0.005 & 0.005 \\
\hline$\mu\left(\mathrm{MN} / \mathrm{m}^{2}\right)$ & $2.6 \mathrm{e}+4$ & $1.8 \mathrm{e}+4$ \\
\hline$D_{v}\left(\mathrm{~m}^{2} / \mathrm{s}\right)$ & $5.3 \mathrm{e}-14$ & $5.3 \mathrm{e}-12$ \\
\hline$A_{2}$ & $4.3 \mathrm{e}+5$ & $7 \mathrm{e}+13$ \\
\hline$n$ & 4.5 & 6.9 \\
\hline$b(\mathrm{~m})$ & $2.58 \mathrm{e}-10$ & $2.48 \mathrm{e}-10$ \\
\hline$T(\mathrm{~K})$ & 1653 & 1653 \\
\hline
\end{tabular}

$$
\begin{gathered}
\dot{\gamma}=\sqrt{3} \dot{\varepsilon} \\
D_{\nu}=D_{0 \nu} \exp \left(\frac{-Q_{v}}{R T}\right) \\
\mu=\mu_{0}\left(1+\frac{(T-300)}{T_{M}}\left(\frac{T_{M}}{\mu_{0}} \frac{d \mu}{d T}\right)\right)
\end{gathered}
$$

(Equation 6.6)

where $\mu_{0}$ is the shear modulus at $300 \mathrm{~K}, \frac{T_{M}}{\mu_{0}} \frac{d \mu}{d T}$ the temperature dependence of the modulus, and $T_{M}(=1810 \mathrm{~K})$ the temperature used in normalizing the temperature dependence of the modulus. Also, $k=1.380 \times 10^{-23} \mathrm{JK}^{-1}$ and $R=8.314 \mathrm{Jmol}^{-1} \mathrm{~K}^{-1}$. Consequently, the shear stresses of austenite and $\delta$-ferrite at $1400^{\circ} \mathrm{C}$ are 11 and $4 \mathrm{MNm}^{-2}$, respectively. Hence, there should be a sudden drop in stress when austenite transforms to $\delta$-ferrite. The shear flow stresses of austenite and $\delta$-ferrite calculated from the experimental results, in the vicinity of $1400^{\circ} \mathrm{C}$, are 4.24 and $1.58 \mathrm{MNm}^{-2}\left(\tau_{0}=0.471 \sigma_{0}\right)$, respectively. The difference between these values and the theoretical ones are attributed to the degree of accuracy of the equations and the errors involved in the calculations and 
experiments. However, the ratio of the experimental values is in good agreement with that of the theoretical values.

A similar explanation is applied to the sudden rise of load during the $\mathrm{CCC}$ experiments (Figure 5.2). Deformation in the solid phase begins in the single phase of $\delta$-ferrite with almost no strain hardening, due to the fast kinetics of recovery in $\delta$-ferrite. This is represented as a plateau or very low slope segment of the deformation curve in Figure 5.2 before the sudden slope change, where the non-equilibrium transformation takes place. As Figure 5.13(a) illustrates, the slope of this segment is strain rate dependent and increases with strain rate. As the deformation approaches the transformation region, austenite nuclei begin to form heterogeneously at locations of strain accumulation. By the fast growth of austenite nuclei at the expense of the $\delta$-ferrite grains (or dendrites), the strength of the material increases rapidly as the austenite takes over the deformation, leading to a jump in the stress-strain curve. The rate of this jump is also strain rate dependent.

Figure 6.1 illustrates that the strength transition occurs more gradually at higher strain rates. At high strain rates, dynamic recovery in ferrite cannot catch up with strain hardening as fast as it does at lower strain rates. Therefore, more strain should be accumulated in $\delta$-ferrite at higher strain rates before the non-equilibrium transition region. (The non-equilibrium transformation is defined as the transformation that takes place over the thermal schedule when there is no deformation involved.) This higher internal strain energy can be eliminated through a predisposed $\delta \rightarrow \gamma$ transformation, i.e. an earlier strain induced transformation. Note that such transformation takes place between the equilibrium and non-equilibrium transition regions and the temperature of the former is higher. Thus, it is anticipated that the transformation, upon reaching the non-equilibrium region, proceeds mainly through the growth of pre-formed austenite grains since this is more favorable energetically than the nucleation of new grains that also requires an extra activation energy. In this case, the transformation would be more growth-controlled. 
On the other hand, if the accumulated energy is high and there is still no predisposed transformation, the number of austenite nucleation sites is increased in the nonequilibrium transformation region. This is simply because the nucleation activation energy is reduced by the strain energy and the smaller austenite embryos can pass over the activation energy barrier of nucleation. In this case, the transformation should advance mainly through nucleation rather than growth, especially since it takes place within a region which is very short $\left(<30^{\circ} \mathrm{C}\right)$ with regard to the cooling rate $\left(10^{\circ} \mathrm{C} / \mathrm{s}\right)$. In summary, the closer to the non-equilibrium region the transformation takes place, the smaller the austenite grain size is expected to be.

Obviously, a transformation that is nucleation-controlled leads to smaller austenite grains. However, it should be indicated that a minimum strain energy is needed to accelerate the transformation in the non-equilibrium transformation region. Since the transformation is also mainly growth-controlled at high strain rates, it seems reasonable to consider an optimum strain rate for achieving the smallest austenite grain size.

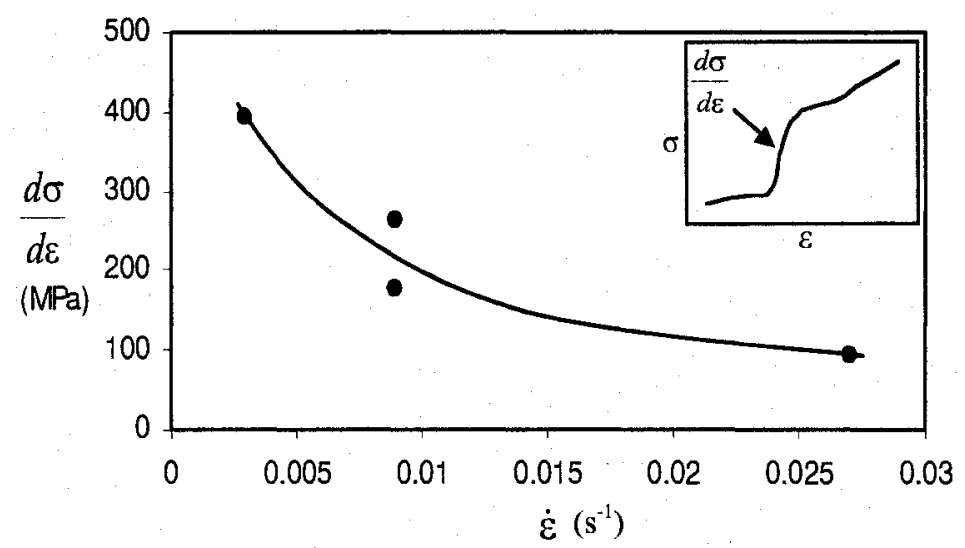

Figure 6.1. Effect of strain rate on the linear slope of the $\delta \rightarrow \gamma$ transformation region during the $\mathrm{CCC}$ experiments. $(\mathrm{Nb}-$ steel)

\subsection{Failure Mode Analysis}

As described in the previous chapter, failure in all three steels is composed of two modes: ductile and brittle, and the relative amounts of these modes are indicative of the hot 
ductility of the steel. Here, the brittleness is described as grain boundary decohesion. This is also associated with some limited and localized plastic deformation and, hence, it is different from the brittleness observed at low temperatures, which has cleavage characteristics. Such localized plastic deformation appears as 'void formation and coalescence' and 'deformation striations' on grain surfaces, leading to grain boundary separation, as shown in Figures 5.19, 5.21, and 5.32. Therefore, it is defined as an embrittlement that is a result of grain boundary separation and, in turn, due to localized plastic deformation. The failure mode analysis aims to determine the mechanism of embrittlement which causes the loss of hot ductility.

Even though the grain surface in the embrittled steel looks facetted after decohesion at low magnification as illustrated in Figure 5.19(b), the facets display some topography when observed at higher magnification in the FEGSEM, Figure 6.2. Deformation bands depicted as steps of deformation on the grain surface in Figure 6.2(b) suggests grain boundary sliding as the mechanism of embrittlement. Figure 6.2(c) shows that the procession of grain boundary separation has been somewhat assisted by grain boundary particles through void formation. Such voids could have also formed as cracks crossed over the particles. As already explained, these particles can be manganese sulfide (Figure 5.22) or aluminum oxide (Figure 5.40).

A model for such crack propagation has been suggested that is based on the stepwise sliding of a grain boundary. ${ }^{[7]}$ As schematically explained in Figure 6.3, first a small decohesion forms at the grain boundary at a high temperature and, then, it develops by plane sliding. As the deformation proceeds, more decohesions are formed and developed along the original ones, leading to void growth and further plane sliding. Topographical features similar to those specified in Figures 6.2(b) were identified as physical observations of sliding steps.

Examination of the microstructure near the fracture region, Figure 6.4, also suggests that grain boundary separation has occurred through grain boundary sliding, arrows in Figure 


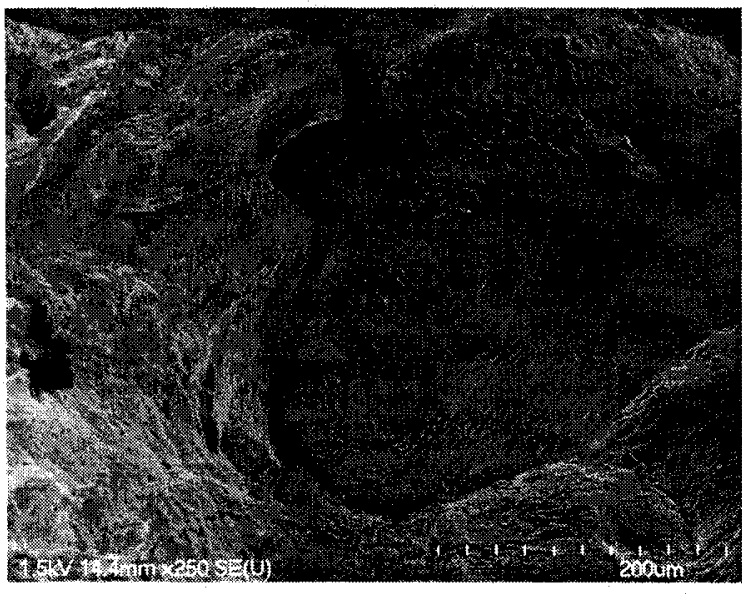

(a)

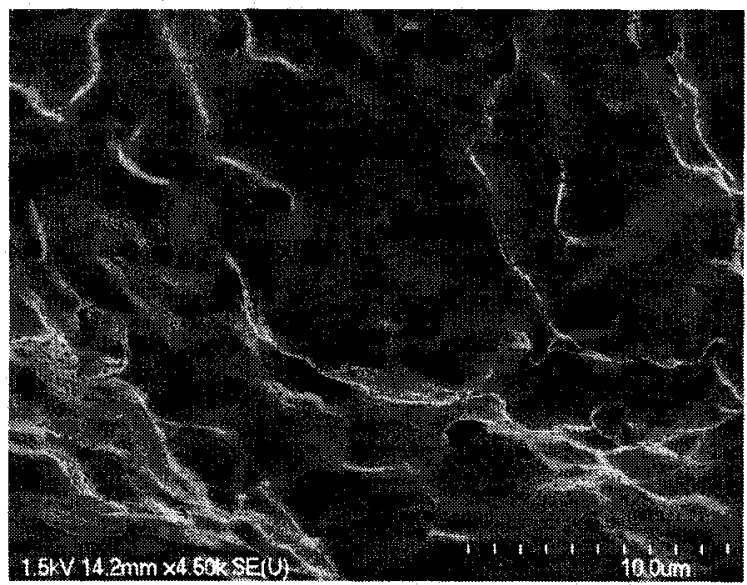

(c)

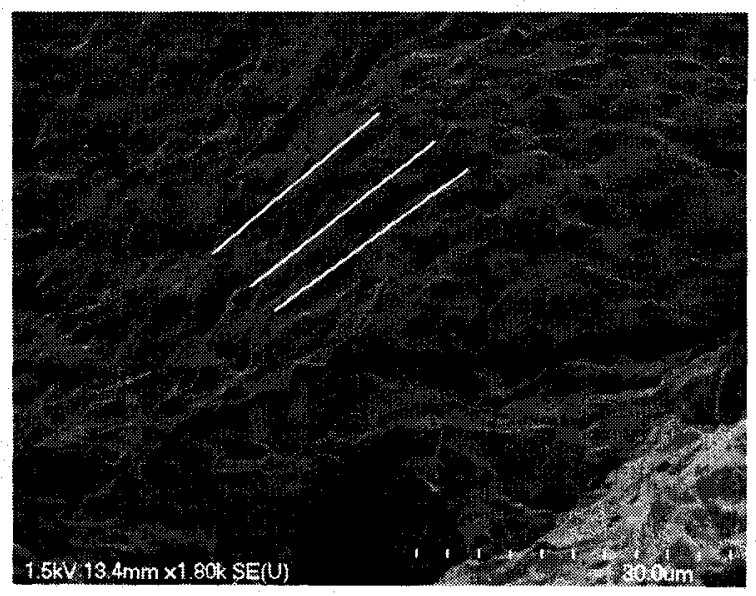

(b)

Figure 6.2. Grain boundary surface in the $\mathrm{Nb}$-steel at different magnifications. Lines in (b) indicate the steps of deformation
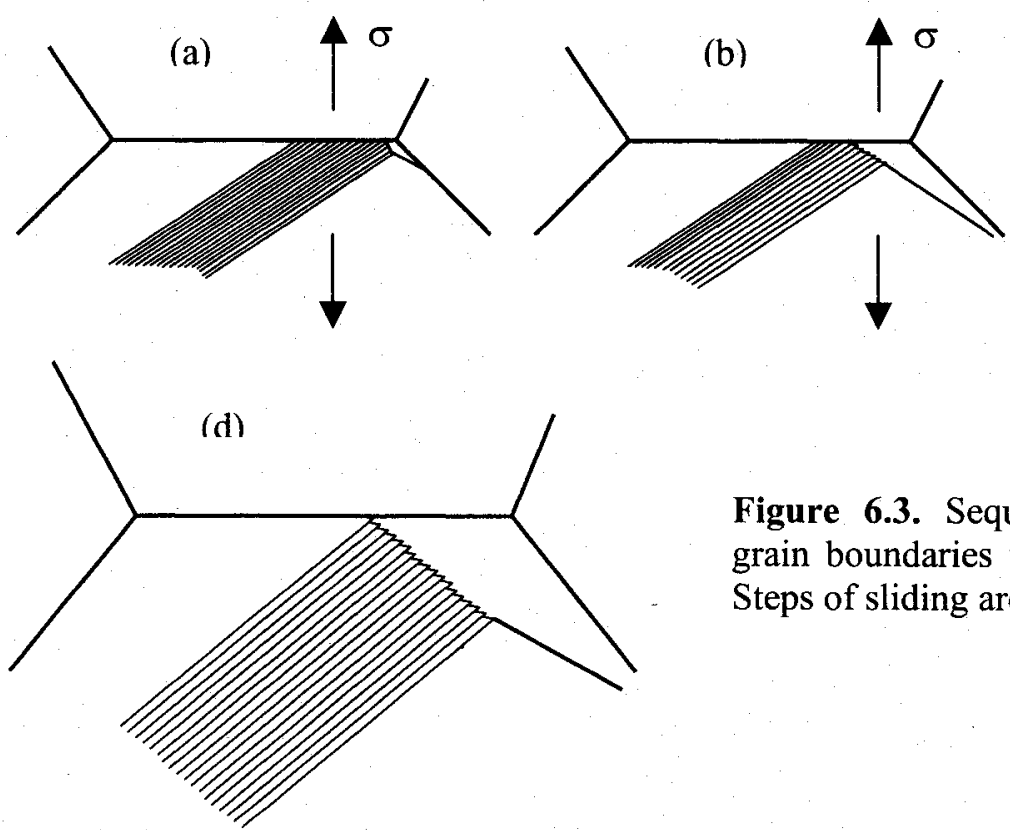

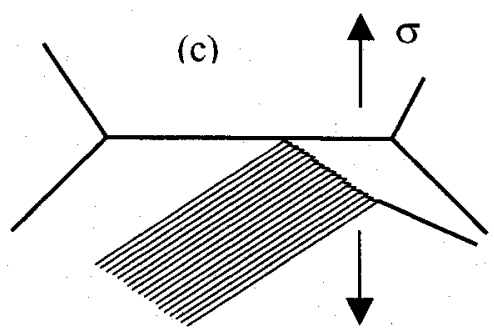

Figure 6.3. Sequences of void propagation at grain boundaries through grain boundary sliding. Steps of sliding are obviously shown in (d). ${ }^{(7)}$ 


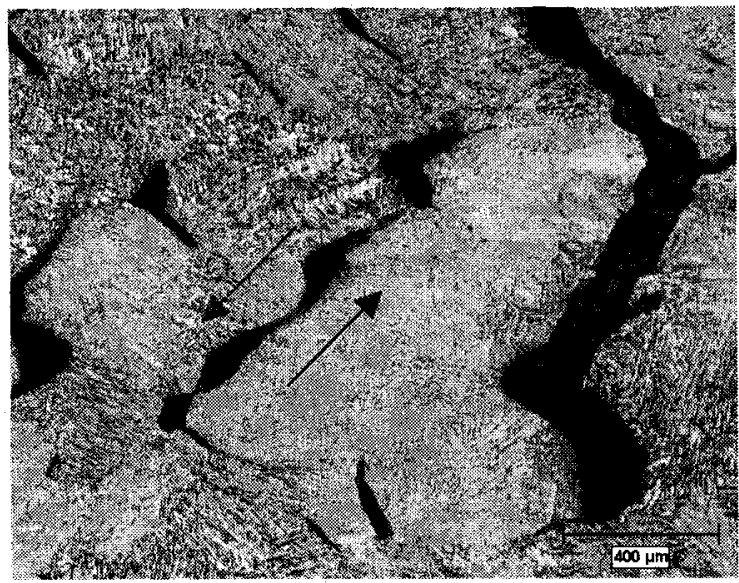

(a)

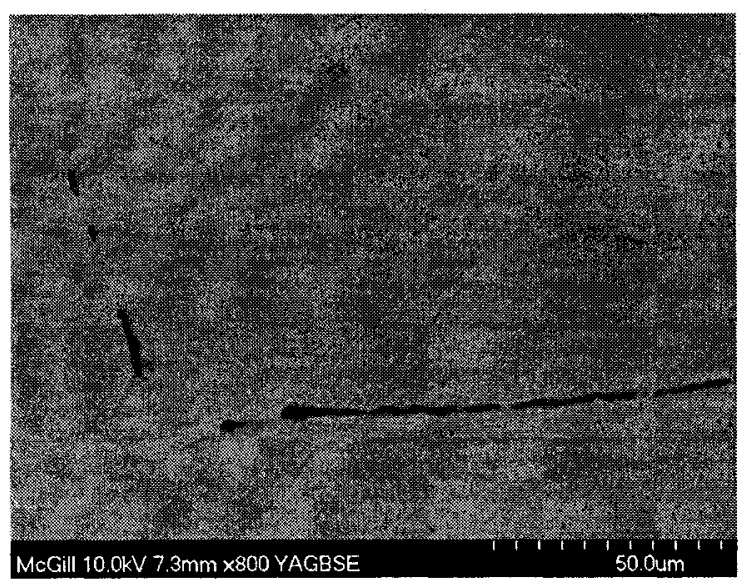

(c)

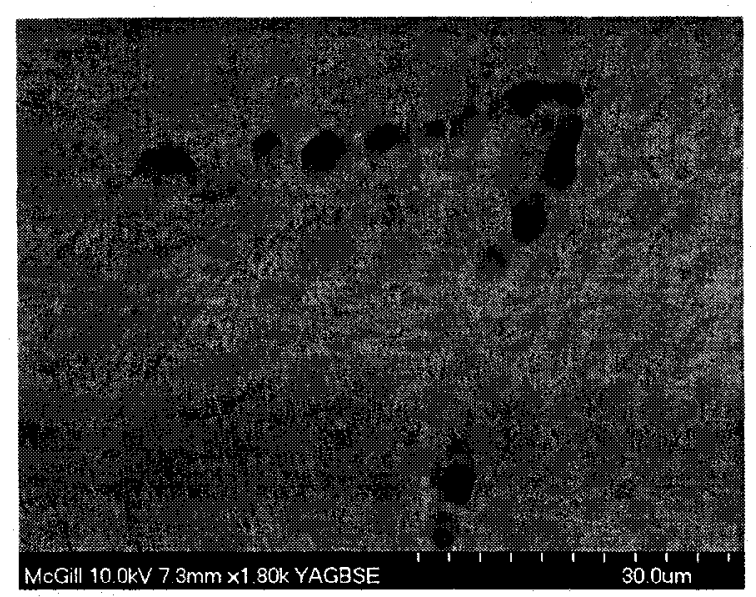

(b)

Figure 6.4. Grain boundary sliding in the $\mathrm{Nb}$-steel subjected to the thermal schedule alone. Longitudinal sections. (b) and (c) are backscattered electron images in FEGSEM.

6.4(a) indicate the sliding direction of two adjacent grains. Figures $6.4(\mathrm{~b})$ and (c) demonstrate that grain boundary cracking was a result of void formation and coalescence at grain boundaries. As can be seen, this mechanism has occurred both at grain boundary triple point junctions and along straight grain boundaries.

At this point, there remains a question as to how the grain boundary sliding, as an effective mechanism of deformation, turns into an embrittling mechanism and leads to grain boundary decohesion. In this section, this is discussed with regard to the loss of hot ductility in the $\mathrm{Nb}$-containing steels. 
It is well recognized that in polycrystalline materials, the greatest amount of plastic distortion usually occurs in the region adjoining the grain boundaries, since this region has a high density of dislocations. Therefore, it is reasonable to consider that, at high temperatures, recovery is likely to commence in the vicinity of grain boundaries long before it begins in grain interiors. This permits additional deformation to occur at grain boundaries rather than grain centers, leading to austenite grain boundary shear and sliding. Zhang et al. ${ }^{[128]}$ have shown in a computer model that the introduction of a small amount of grain boundary sliding sufficiently decreases grain interaction in the bulk plastic deformation regime, and suggested that grain boundary sliding can be a mechanism for accommodating strain incompatibility between neighboring grains. It should be also pointed out that grain boundary sliding has been considered a dominant deformation mechanism in superplastic materials. There is general agreement that more than $50 \%$ of the total strain in superplastic materials is contributed by the grain boundary sliding. ${ }^{[129,130]}$ Therefore, a significant loss of ductility and low strains to fracture, in a material in which grain boundary sliding is a deformation mechanism can be due to other phenomena interacting with grain boundary sliding, leading to such embrittlement.

Grain boundary mechanisms of deformation at high temperatures can be divided into two types. ${ }^{[131]}$ Firstly, there is the possibility of diffusional creep, in which grain elongation occurs in the direction of tensile stress by vacancy flow either through the lattice (Nabarro-Herring creep) or along the grain boundaries (Coble creep). Secondly, there is the possibility of grain boundary sliding without grain elongation, in which the individual grains slide over each other at, or in a zone immediately adjacent to, their common boundary. The first type of grain boundary sliding is adequately modeled for polycrystalline materials by the theories of Nabarro-Herring and Coble for diffusional creep, and it does not, in general, lead to cavity formation.

Basically, the second type is a more important consideration, since this may lead to intergranular failure. Models for this type of sliding are expected to be based on dislocation movement, ${ }^{[132,133]}$ rather than vacancy flow. Gates ${ }^{[134]}$ developed a mechanism in which sliding arises from the movement of structural or intrinsic grain boundary 
dislocations, and it is assumed that sliding is due to a combination of glide and climb processes. Even though this model was developed for planar boundaries in bicrystals, this concept can be applied in polycrystals. In polycrystalline materials, it is necessary to consider the role of strain accommodation at triple points. If sliding occurs by the climb and glide of dislocations in a zone adjacent to a grain boundary, the rate of sliding is governed by the rate of climb since this is the slower process. Furthermore, if sliding is not accommodated by an intragranular flow mechanism, it must be done by the opening of grain boundary cracks and cavities. ${ }^{[131]}$ In polycrystalline materials in which deformation proceeds by extensive grain boundary sliding, an important experimental observation is the formation of intragranular folds at the triple points and in this way grain boundary sliding is accommodated. ${ }^{[131]}$

Hence, it can be inferred that grain boundary sliding can lead to an embrittling mechanism by grain boundary cracking provided it cannot be accommodated by plastic deformation in neighboring grains. Relatively stronger grain interiors owing to pinned dislocations can prevent the accommodation of sliding through lattice plastic flow.

It is well documented that in the condition of slow rate-high temperature deformation, such as creep and hot ductility evaluation related to the straightening operation in continuous casting, cavities can form continuously throughout the deformation. Analysis of the problem indicates that extremely high stresses normal to a grain boundary, e.g. on the order of $\mathrm{E} / 100$, are required to nucleate a cavity. ${ }^{[135]}$ Thus, very large stress concentrations are required. These large stress concentrations can be produced at particles in sliding grain boundaries, at the intersection of slip bands and grain boundary particles, and at grain boundary triple points. However, it must be noted that, under appropriate circumstances, the generation of high stress concentrations is moderated by both powerlaw creep and diffusional creep processes, which prevents the formation of a large number of cavities at the beginning of creep. ${ }^{[135]}$ Even though voids and cracks form and grow during grain boundary sliding, necking down to a point may still occur, if the nucleation, growth and/or coalescence of voids is suppressed. This type of ductile rupture behavior is observed when voids are isolated by grain boundary migration. ${ }^{[135]}$ 
For a nucleated cavity to grow at a boundary, Dyson ${ }^{[136]}$ has proposed a model in which it is considered that there are capillarity forces (surface tension) that tend to shrink the nucleated cavity. So, the nucleated cavity must be large enough to overcome these forces and grow. For a particle of diameter $a$ in a boundary which slides a distance $\delta$ under a stress $\sigma$, cavity growth will occur only if the grain boundary sliding displacement exceeds a critical value $\delta_{c}$, defined as follows;

$$
\delta_{c} \geq \frac{1}{a^{2}}\left(\frac{2 \gamma_{s}}{\sigma}\right)^{3}
$$

where $\gamma_{\mathrm{s}}$ corresponds with the capillarity force. If the sliding distance does not exceed $\delta_{\mathrm{c}}$, capillarity forces would gradually cause the cavity to sinter closed by diffusion. According to this equation, while high normal stresses are required for the nucleation of cavities, they are not sufficient. Stable cavities require that large sliding displacements occur as well.

There is a second mechanism of void formation, as well, which is not based on grain boundary sliding and strain concentration at grain boundaries. Sricharoenchai et al. ${ }^{[70]}$, in an attempt to explain intergranular fracture in a $\mathrm{Nb}$-containing steel, proposed an embrittling mechanism that is based on the role of vacancies. Grain boundaries that are immobilized by either fine precipitates or the segregation of impurities are potential places for microvoid nucleation during high temperature deformation. At high temperatures where vacancies can diffuse easily, they are captured by grain boundary microvoids and this leads to growth of the microvoids. Therefore, the rate of void growth at grain boundaries depends on the rate of vacancy diffusion. This is a chemical process controlled by diffusion, the velocity of which increases with increase of temperature. As a result the ductility of austenite will decrease with increasing temperature as long as the grain boundaries are sessile.

Both these mechanisms consider void formation at grain boundaries as the main cause of intergranular failure. In other words, grain boundary cavitation is the direct cause for the 
low strain to fracture no matter whether it occurs by the grain boundary sliding mechanism or the vacancy diffusion mechanism.

There are two types of intergranular openings likely to occur during high temperature deformation. Wedge-shaped cracks ( $w$-type cracking) initiating mostly at grain boundaries that are aligned for maximum shear. They initiate while grain boundaries slide over each other. ${ }^{[137]}$ Figures 5.22(a) and 5.24(d) are good examples of this kind of cracking. The second type of grain boundary opening consists of round or elliptical cavities ( $r$-type cracks), which form at grain boundaries aligned normal to the tensile stress $^{[135]}$ or along the tensile direction. Figures 5.20(a) and 5.24(b) show some typical examples of this type of cracking. However, these two types of openings do not necessarily form exclusive of each other, but appear simultaneously in the same specimen under the proper conditions. ${ }^{[52]}$ Figures 5.22(a) and (b) and 6.3(b) demonstrate the coexistence of these cracks in one specimen. Complete rupture of the specimen is usually considered to be caused by the growth and coalescence of the small cavities, Figure 5.32. Nevertheless, apart from the cavity nucleation associated with grain boundary particles, cavity nucleation cannot occur in this manner unless the stress concentration exceeds the cohesive strength of the grain boundary. As pointed out before, it also cannot occur if the stress concentration at the end of the boundary is relieved by plastic flow in the grain ahead of the boundary.

An alternate mechanism that can prevent the opening of a crack at a grain boundary corner is for the boundary to migrate away from the stressed region before the stress concentration has risen to the point where a pore can form or grow large. Dynamic recrystallization in austenite is a mechanism that can prevent the formation or growth of grain boundary openings by stress alleviation. In addition, it takes pores and cavities already at grain boundaries to the grain interiors and isolates them from each other. Figures 5.26(e) illustrates how grain boundary migration due to dynamic recrystallization led to significantly fewer cavities and cracks at grain boundaries, leading to higher hot ductility, as compared with Figure 5.22(a). 
Dynamic recrystallization is expected in $\mathrm{Nb}$-containing steel in the vicinity of $1000^{\circ} \mathrm{C}$, as Figure 2.21 shows. However, it didn't occur in the $\mathrm{Nb}$-steel at the straightening stage, at $1020^{\circ} \mathrm{C}$, before fracture occurred. The recrystallization temperature is higher in as cast austenite than reheated austenite because of the larger grain size and higher supersaturation of precipitants in as cast austenite. ${ }^{[8]}$ Moreover, the alloying elements in as cast austenite are highly segregated. ${ }^{[8,138]}$ These can result in loss of hot ductility. As well, if the solute sulfur atoms remain free, they will segregate to the grain boundary precipitate/matrix interfaces as well as to the austenite grain boundaries during cooling after melting, leading to easy decohesion of the interface and the subsequent nucleation of microvoids. For steel reheated up to a high temperature without melting, it is the amount of $\mathrm{S}$ that goes back into solution and can precipitate in a fine detrimental form at the austenite grain boundaries that is effective in reducing the hot ductility. Whereas in as cast steels, it is the total S level that controls the hot ductility. ${ }^{[13]}$ The effect of melting on the hot ductility is evident in Figure 5.6 and Table 5.3.

As for the grain size, larger grain size corresponds with greater necessary amount of deformation in order for dynamic recrystallization to commence, according to the following equation ${ }^{[139,140]}$

$$
\varepsilon_{p}=A D_{0}^{p} Z^{q}
$$

where $\varepsilon_{p}$ is the peak strain in the stress-strain curve, which is roughly linearly related to the strain to initiate dynamic recrystallization, $D_{0}$ is the initial austenite grain size, $Z$ the Zener-Hollomon parameter, and $A, p$ and $q$ are constants. The precipitants, especially $\mathrm{Nb}$, can retard recrystallization both as solute and precipitate..$^{[2,5,24,50,72,141,142]}$ In Nb-bearing steels, the vacancies generated during deformation form vacancy- $\mathrm{Nb}$ atom complexes and these complexes diffuse toward and subsequently decompose at dislocation cell walls, causing $\mathrm{Nb}$ atoms to be segregated at dislocations. ${ }^{[71]}$ In this case, not only do $\mathrm{Nb}$ atoms impose a drag effect on moving dislocations, but also the local supersaturation at dislocation cell walls enhances $\mathrm{Nb}(\mathrm{CN})$ precipitation, leading to pinned dislocations and therefore inhibiting dynamic recovery as well as recrystallization. 
Also, sessile and retarded dislocations increase the resistance of austenite to plastic flow that otherwise alleviates stress concentrations at the grain boundaries while grain boundary sliding proceeds. The situation is emphasized in as cast supersaturated austenite where the solubility temperature of solutes is higher. Furthermore, grain boundary precipitates such as; $\mathrm{Nb}(\mathrm{CN}), \mathrm{MnS}, \mathrm{Al}_{2} \mathrm{O}_{3}$, and $\mathrm{AlN}$, as shown in Figures 5.22, 5.28, and 5.40 , for instance, as well as segregated impurities restrain and pin grain boundaries, providing sites for void nucleation and retarding dynamic recrystallization which would otherwise relax stress concentrations. These effects all promote void formation during grain boundary sliding. ${ }^{[5,70]}$ Note that grain boundaries with cracks have mobilities that are lower than sound grain boundaries, since cracks impose a drag force on the moving grain boundary; basically it is energetically favorable for cracks to be at grain boundaries rather than in the matrix.

\section{3. $\mathrm{Nb}-$ Steel Versus B-Steel}

\subsubsection{Hot Ductility Trough}

The steels containing B, designated as the B-steel, generally display higher hot ductilities than the Nb-steel, Figure 5.15. Similar results have been reported by Kim et al. ${ }^{[112]}$, when two $\mathrm{Nb}$-steels, one with and the other without $\mathrm{B}$, were studied. The results for the former were also presented in Figure 5.15 for comparison. The B-steel has ductilities ranging between $55 \%$ and $70 \% \mathrm{RA}$. Note that the results from reference 112 were generated by re-heating, and not re-melting, the specimens up to $1350^{\circ} \mathrm{C}$, and thus this has most likely led to higher ductilities than those obtained in this work for the B-steel. In addition, the range of low hot ductility in the $\mathrm{Nb}$-steel in this work is wider than what has been commonly observed for $\mathrm{Nb}$-containing steels, as was shown in Figure 2.21. This can also be attributed to the effect of melting and thermal history to which the specimens were subjected. The effect of thermal history will be discussed later.

Figure 5.7(b) shows that there is a stress relaxation, indicated by an arrow, in both the specimens strained at 900 and $1020^{\circ} \mathrm{C}$. This could be the peak stress of dynamic 
recrystallization in austenite, but microstructural examination did not reveal any grain refinement, as shown in Figure 5.22. Hence, this energy release may be attributed to stress concentrations that were relieved by the fast opening or propagation of grain boundary cracks and/or a sudden rupture occurring in part of the specimen. Large grain boundary cracks as were shown in Figure 5.22(a) can be the results of such an energy relaxation.

On the contrary, the microstructure of the B-steel, Figure 5.20(d), evidently demonstrates a substantially dynamically recrystallized structure at $1000^{\circ} \mathrm{C}$. However, no hump was observed on the deformation curve, Figure 5.7(a). Nevertheless, this does not necessarily rule out the occurrence of dynamic recrystallization, as will be discussed in section 6.5 . Moreover, the relatively slow rate of strain hardening at $1000^{\circ} \mathrm{C}$, Figure $5.7(\mathrm{a})$, implies that some softening mechanisms such as dynamic recovery and dynamic recrystallization may be underway. The occurrence of dynamic recrystallization at this temperature made a significant contribution to the high hot ductility of this steel. Not only are the grain boundary cracks much smaller in the B-steel than in the Nb-steel, comparing Figures 5.20 and 5.22, but they were found in grain interiors as well. The latter suggests that dynamic recrystallization had moved the grain boundaries away from the microcracks, as mentioned earlier. Furthermore, the hot ductility assessment at $900^{\circ} \mathrm{C}$, Figures $5.24(\mathrm{c})$ and $5.26(\mathrm{~d})$, clearly shows that the B-steel is more susceptible to plastic deformation as manifested by the large amount of grain elongation in Figure 5.24(c) as well as in Figure 5.24(b). No evidence of grain refinement, i.e. dynamic recrystallization, was observed at $900^{\circ} \mathrm{C}$. Also, grain boundary cracks have oval ( $r$ type cracks), and not wedge, characteristics. This implies that the B-steel comprises stronger grain boundaries and/or softer grain interiors, assuming that oval cracks form at relatively stronger grain boundaries after a considerable amount of plastic deformation (also flow saturation in the grain interior) and wedge shaped cracks at grain boundary triple junctions are likely to occur at weak grain boundaries and when plastic flow cannot proceed in grains.

Since dynamic recrystallization leads to hot ductility improvement, one may argue that the hot ductility of the B-steel, Figure 5.15 , should be higher at $1000^{\circ} \mathrm{C}$ than at $800^{\circ} \mathrm{C}$, 
simply because the former temperature was associated with dynamic recrystallization. However, there are two phenomena occurring simultaneously, grain boundary sliding and dynamic recrystallization. The former deteriorates and the latter enhances the hot ductility. At $800^{\circ} \mathrm{C}$, although dynamic recrystallization is difficult, the resistance to grain boundary sliding is higher, both of these effects being due to the lower temperature. At $1000^{\circ} \mathrm{C}$, the condition for dynamic recrystallization is fulfilled, but the steel is more susceptible to grain boundary sliding. Thus, there is an optimum hot ductility that, in this steel, is at $900^{\circ} \mathrm{C}$.

The low hot ductility persists in the $\mathrm{Nb}$-steel until the temperature rises to $1100^{\circ} \mathrm{C}$, where there is enough driving force and activation energy to trigger dynamic recrystallization. At this temperature, precipitate formation is limited and dislocations are free to glide. The grain refinement near the fracture edges in Figure 5.26(e) indicates that the hot ductility improvement is at least partly due to dynamic recrystallization. The B-steel was, by contrast, strongly embrittled at $1100^{\circ} \mathrm{C}$. A similar behavior was observed in the Nb-steel at $1200^{\circ} \mathrm{C}$. The fracture surfaces of both steels exhibited dendritic structures at grain boundaries, Figures 5.23 and 5.25, suggesting incipient melting as the embrittling mechanism. The causes for this melting has been ascribed to the microsegregation of $S$ and $\mathrm{P}$ residuals at solidifying dendrite interfaces. ${ }^{[77]}$ On the contrary, no such behavior was observed by Akhlaghi ${ }^{[12]}$ in the conventional hot ductility evaluation, including remelting, and the RA continually increased from about $5 \%$ at $900^{\circ} \mathrm{C}$ to $100 \%$ at $1300^{\circ} \mathrm{C}$. This discrepancy can be attributed to the effect of the thermal schedule used in this work, in terms of the cooling rate and temperature oscillation. Fast cooling rate can result in precipitation of low-melting liquid FeS films, instead of $\mathrm{MnS}$, at grain boundaries. ${ }^{[20]}$ Temperature oscillation is likely to diminish the hot ductility by encouraging $\mathrm{NbCN}$ precipitation leading to retardation of dynamic recrystallization. ${ }^{[84]}$

With decreasing temperature, ferrite starts to form at austenite grain boundaries, resulting in low hot ductility. However, it seems that this embrittling mechanism is not pertinent to the B-steel, or does not have a considerable influence on the hot ductility. Figure 5.24(a) illustrates, despite the fact that voids nucleated at the austenite grain boundary, the hot 
ductility is still high owing to bulk flow. It has been suggested that addition of B to the $\mathrm{Nb}$-containing steel encourages precipitation of matrix $\mathrm{Fe}_{23}(\mathrm{~B}, \mathrm{C})_{6}$ particles that act as the preferential sites for the intragranular nucleation of ferrite. In this way, hence, less ferrite is available to form at grain boundaries. ${ }^{[12]}$ This not only decreases the number of voids and cavities formed at grain boundaries, but also makes the austenite grain interior more deformable owing to the soft intragranular ferrite. The final result is an improvement in the hot ductility.

Referring to the typical hot ductility trough of the $\mathrm{Nb}$-containing steel, it was also expected that the hot ductility increased as the temperature further decreased below the ferrite start temperature. This is shown by the dashed line in Figure 5.15. As explained in chapter 2, this is because the grain boundary ferrite becomes thicker by decreasing temperature and the stress is no longer concentrated at the austenite grain boundary. Nonetheless, such a hot ductility rebound was not observed in the $\mathrm{Nb}$-steel because the experimental limitation inhibited testing at temperatures lower than $800^{\circ} \mathrm{C}$. As illustrated in Figure 5.16, the specimen pulled at $700^{\circ} \mathrm{C}$ fractured outside the gauge length occupied by the melted zone. The microstructural difference between the gauge length region and the region that was at a temperature about $100^{\circ} \mathrm{C}$ lower than that of the gauge length was shown in Figure 5.26. Occurrence of fracture in the latter region implies that, here, the strength of material is more dictated by the volume fraction of ferrite than the temperature. The absence of such a phenomenon in the B-steel is in agreement with the aforementioned postulation concerning the intragranular ferrite that reduces bulk grain strength and the volume fraction of ferrite at grain boundaries.

In addition to the effect of $\mathrm{B}$, there remains an argument concerning the hot ductilities shown in Figure 5.15, that the higher ductility is attributed to the lower carbon content in the B-steel. The effect of carbon on the hot ductility is shown in Figure 2.28. Nevertheless, it should be noted that lower carbon basically narrows the trough width by increasing the $\mathrm{Ar}_{3}$ temperature and any alteration in the hot ductility level in this small range of carbon content, i.e. the difference of carbon content in the B-steel and the $\mathrm{Nb}$ steel, is barely observed. ${ }^{[51]}$ Generally, trough curves are displaced to lower temperatures 
as the carbon level is increased. At a given temperature, the ferrite layer at austenite grain boundaries is thicker in a steel with lower carbon content. Therefore, stress concentration, and consequently void formation, at grain boundaries is alleviated, leading to a higher ductility. However, this mechanism is not viable in the B-steel since the ferrite layers found at some grain boundaries were not thick enough to prevent void formation, Figure 5.24(a). Then, the lower carbon content in the B-steel cannot really be the explanation for the higher hot ductility.

\subsubsection{Effect of Boron on Hot Ductility}

A considerable amount of research has been conducted to improve the hot ductility of $\mathrm{Nb}$ containing steels, mostly by the addition of alloying elements such as $\mathrm{Ti},{ }^{[6,79,81,113]} \mathrm{Ca},{ }^{[143]}$ $\mathrm{Zr},{ }^{[113]}$ and $\mathrm{Y}^{[113]}$. Boron has been considered as another possible element likely to improve the hot ductility in the $\mathrm{Nb}$-containing steel. Even though the beneficial effect of $\mathrm{B}$ on the low temperature trough, where two phases of austenite and ferrite coexist, was explained above by precipitates containing $\mathrm{B}$, it is not yet well understood why addition of $\mathrm{B}$ to the $\mathrm{Nb}$-containing steel leads to a better hot ductility at high temperatures where there is single austenite phase.

It has been suggested that B improves the hot ductility by reacting strongly with nitrogen in a similar way as titanium. ${ }^{[88]}$ On the other hand, it can be argued that $\mathrm{BN}$ precipitation resembles that of $\mathrm{Nb}(\mathrm{C}, \mathrm{N})$, resulting in grain boundary embrittlement. However, some production statistics clearly pointed out the beneficial influence of boron on surface quality. ${ }^{[1,88]}$ This improvement can be ascribed to several factors such as; preferential boron nitride precipitation, retardation of the austenite/ferrite transformation, which presumably avoids ferrite film formation at the austenite grain boundaries, and increasing the resistance to grain boundary sliding during straightening, which results in better creep ductility. ${ }^{[88]}$ Besides these speculations, the best defined mechanism under which $B$ improves deformability may be the one that has been observed in $\mathrm{Ni}_{3} \mathrm{Al}$. $\mathrm{Ni}_{3} \mathrm{Al}$ is extremely brittle at room temperature but addition of as little as $200 \mathrm{ppm}$ of $\mathrm{B}$ to this alloy turned it into a ductile compound. ${ }^{[144]}$ Characterization of the boron distribution 
throughout the alloy, using the atom probe field ion microscope, determined that B had segregated to grain boundaries. Based on this observation, it was suggested that boron atoms act as a type of "glue", preventing the alloy from failing. ${ }^{[145]}$

However, the effect of $\mathrm{B}$ at high temperature, may be explained by the following hypotheses.

In the $\mathrm{Nb}$-containing steel, it is known that the hot ductility trough at high temperatures is associated with fine precipitation of $\mathrm{Nb}(\mathrm{C}, \mathrm{N})$ particles at both grain boundaries and grain interiors. At low temperatures, on the other hand, poor ductility is usually associated with coarse precipitates. ${ }^{[112]}$ As well, it has been shown that the coarsening of precipitates is quite effective in improving the hot ductility of various steels at high temperatures. ${ }^{[3,79,113]}$ Hence, at first sight, the reason for better ductility in the B-steel, compared to the $\mathrm{Nb}$ steel, can be ascribed to the $\mathrm{Fe}_{23}(\mathrm{~B}, \mathrm{C})_{6}$ particles which, although at grain boundaries, are relatively coarse, ${ }^{[112]}$ and then not as much detrimental to the hot ductility. $\mathrm{Fe}_{23}(\mathrm{~B}, \mathrm{C})_{6}$ particles contain $\mathrm{N}$, as shown by Kim et al. ${ }^{[112]}$ Thus, precipitation of $\mathrm{Fe}_{23}(\mathrm{~B}, \mathrm{C})_{6}$ reduces the amounts of both $\mathrm{N}$ and $\mathrm{C}$, not only at the grain boundary but also in the grain interior, available for the precipitation of fine $\mathrm{Nb}(\mathrm{C}, \mathrm{N})$ precipitate, which is the main cause of the hot ductility loss in the Nb-containing steel. Therefore, the density of mobile dislocations is increased, as the density of dislocation pinning precipitates decreases, and the strain concentration at the austenite grain boundaries can be alleviated by flow in grain interiors.

On the other hand, since deformation is also involved, the presence of excess vacancies due to the deformation enhances the driving force for nucleation at grain boundaries. Militzer et al. ${ }^{[146]}$ studied the effect of deformation on vacancy production in a Nb-B steel. At a strain rate of $10^{-3} \mathrm{~s}^{-1}$, they noticed that a significant vacancy supersaturation could be formed at true strain about 0.003 at $1000^{\circ} \mathrm{C}$. In this case, the enhanced segregation, due to vacancy-element complexes, of precipitate forming elements can lead to an increase in the supersaturation at grain boundaries as a result of vacancy annihilation. ${ }^{[71]}$ Consequently, the chemical driving force of nucleation is increased and so is the nucleation rate. Furthermore, it is well known that, deformation leads to enhanced self-diffusivity at low strain rates $\left(<10^{-2} \mathrm{~s}^{-1}\right)$. Cohen ${ }^{[147]}$ attributed this 
enhancement to the pipe diffusion along moving dislocations. Then, the higher diffusivity during deformation may also accelerate the nucleation process as well as the diffusioncontrolled growth rate of crucial precipitants such as $\mathrm{Nb}$. As well, Djahazi ${ }^{[148]}$ showed that the $\mathrm{Nb}$ carbonitrides precipitation starts earlier in the $\mathrm{Nb}$-containing steel when $\mathrm{B}$ is present. In this case, the precipitate is of Nb-borocarbonitride type. Ultimately, a situation similar to that discussed above, i.e. coarser precipitates, can occur here owing to faster nucleation and growth. This can lead to fast depletion of strengthening elements in the matrix and decrease the relative strength of the austenite lattice to the grain boundary. Hence, when $\mathrm{B}$ is added to the $\mathrm{Nb}$-containing steel, the grain interior can also undergo an appreciable amount of deformation and relieve the stress at grain boundaries, which results in a higher hot ductility. Figures 5.24(b) and (c) can be taken as evidence for this, as compared with Figures 5.26(c) and (d).

In summary, B leads to earlier nucleation and faster growth of the precipitates containing $\mathrm{Nb}, \mathrm{N}$, and $\mathrm{C}$ and, consequently, depletion of these elements in the matrix and softer austenite lattice. Such a mechanism pertains to the thermal region where the precipitation of carbonitrides is possible, i.e. usually at temperatures lower than $1000^{\circ} \mathrm{C}$.

The second scenario is considered with respect to the B diffusion and segregation in austenite. He et al. ${ }^{[149]}$ identified two types of non-equilibrium segregation for $\mathrm{B}$ in a $\mathrm{Nb}$ B steel; segregation due to the excess vacancies produced by deformation and segregation to the recrystallized grain boundaries during grain boundary migration. Both cases lead to the retardation of recrystallization. It should be indicated that such B segregation takes place within a region about $1 \mu \mathrm{m}$ wide on either side of the boundaries (unlike equilibrium segregation, which is only a single monolayer wide), and only requires times of 10-30 s to develop. ${ }^{[150]}$ It was also noticed that the grain boundary segregation of $\mathrm{B}$ disappears, due to $\mathrm{B}$ diffusion away from the boundaries, in times of $100 \mathrm{~s}$ or more after stopping the deformation. ${ }^{[151]}$ It was observed that the addition of about 100 at. ppm of B led to a significant retardation of recrystallization in the $\mathrm{Nb}$-microalloyed steel. ${ }^{[149,152]}$ This phenomenon is caused by the presence of excess vacancies, which leads to the formation of boron-vacancy complexes. ${ }^{[153-155]}$ The complexes migrate to grain boundaries and are annihilated preferentially at the boundaries since the boron-vacancy 
binding energy, $E_{\mathrm{B}} \approx 0.5 \mathrm{eV},{ }^{[153-155]}$ is considerably higher than the boron-dislocation binding energy, but lower than the boron-grain boundary segregation energy $E_{\mathrm{gb}}$, which is estimated to be $0.65 \mathrm{eV} \cdot{ }^{[156]}$ Thus, in spite of the high dislocation density, the dissociation of B-vacancy complexes does not take place or is of negligible importance in grain interiors. Also, the diffusivity of the complexes is about one order of magnitude higher than that of solute $\mathrm{B}$ so that negligible desegregation occurs during the enrichment period. ${ }^{[155]}$ Therefore, there can be considerable $\mathrm{B}$ segregation at austenite grain boundaries during deformation. It was noticed that the B segregation is more intense at recrystallized grain boundaries than at prior austenite boundaries. ${ }^{[149]}$

Even though $\mathrm{He}$ et al. ${ }^{[149]}$ observed more retardation of static recrystallization in the $\mathrm{Nb}$ containing steel at $1000^{\circ} \mathrm{C}$ owing to the $\mathrm{B}$ addition, no carbonitride precipitates were observed at that temperature to be responsible for such an enhanced retardation. Consequently, they suggested that a solute drag effect was responsible for delaying austenite recrystallization at $1000^{\circ} \mathrm{C}$. It was also found that, even though $\mathrm{B}$ has an appreciable interaction energy with the grain boundary and a strong tendency to segregate to the grain boundary, it displays a small solute drag effect due to its high diffusivity. Hence, the higher drag effect due to the addition of $\mathrm{B}$ to the $\mathrm{Nb}$-containing steel is a result of synergism between $\mathrm{Nb}$ and $\mathrm{B}$.

Hillert and Sundman ${ }^{[157]}$ developed an approach to the solute drag effect in which the integral dissipation of free energy due to solute diffusion within the moving grain boundary is equated to the drag effect. In their model, the solute drag increases as the ratio of $\mathrm{D}^{\mathrm{GB}} / \mathrm{D}^{\mathrm{M}}$ (diffusion along grain boundaries to diffusion in matrix) decreases. Based on this model, Mavropoulos and Jonas ${ }^{[152]}$ explained the contribution of $\mathrm{B}$ in retardation of recrystallization in the $\mathrm{Nb}-\mathrm{B}$ steel as follow. The addition of $\mathrm{B}$ can increase the drag effect in three ways; (1) by increasing the matrix diffusivity of $\mathrm{Nb}$, (2) by decreasing the grain boundary diffusivity of $\mathrm{Nb}$, and (3) by simultaneously decreasing $\mathrm{D}^{\mathrm{GB}}$ and increasing $\mathrm{D}^{\mathrm{M}}$. It is obvious that in all these three cases, the $\mathrm{D}^{\mathrm{GB}} / \mathrm{D}^{\mathrm{M}}$ of $\mathrm{Nb}$ decreases, leading to larger drag effect on moving grain boundaries. 
In conclusion, the synergistic effect of $\mathrm{B}$ and $\mathrm{Nb}$ can be attributed to the formation of $(\mathrm{Nb}, \mathrm{B})$ complexes. The presence of such complexes at the new boundaries increases the solute drag force of the $\mathrm{Nb}$ atoms, decreases the boundary velocity and slows down the recrystallization kinetics of $\mathrm{B}$ modified $\mathrm{Nb}$-steel. However, the intensified $\mathrm{Nb}$ segregation to grain boundaries can lead to a less strengthened austenite lattice. Hence, comparing the $\mathrm{Nb}$-steel and the B-steel, the lattice of the former is stronger than that of the latter. Then, the grain interior is more prone to plastic flow in the B-steel. This helps alleviate stress concentrations at grain boundaries and since more dislocation activities is involved, for a given nominal strain, more driving force is available to trigger dynamic recrystallization. This explains the observation of dynamic recrystallization in Figure 5.20(d) (the B-steel) rather than Figure 5.22(b) (the Nb-steel).

However, other beneficial effects of B, i.e. increasing the resistance to grain boundary sliding and reduced creep rate, ${ }^{[158]}$ as well as its "adhesive" effect at grain boundaries that inhibits grain boundary decohesion, ${ }^{[145]}$ should also be taken into account. Moreover, since the temperature is high, the B segregation to the austenite grain boundary can be very effective in displacing phosphorus. This was observed in studies of Fe-Mn-P-B alloys with only 5-30 ppm B, in which the tendency to the intergranular fracture was suppressed effectively. ${ }^{[159]}$ The fact that the addition of small amount of B suppresses phosphorus segregation at austenite grain boundaries suggests that $\mathrm{B}$ with a large free energy of segregation, presumably about $100 \mathrm{~kJ} / \mathrm{mol}$, affects segregation of phosphorus with a free energy of about $50 \mathrm{~kJ} / \mathrm{mol}^{[160,161]}$

Therefore, the beneficial effect of adding B to the $\mathrm{Nb}$-containing steel is considered in two respects: (i) enhancement of nucleation and growth of precipitates, in the precipitation temperature range, that leads to the depletion of carbonitride precipitants in the lattice, and (ii) depletion of strengthening elements, in the dissolution temperature range of precipitants, especially $\mathrm{Nb}$, in the matrix owing to the non-equilibrium cosegregation of $\mathrm{B}$ and $\mathrm{Nb}$ to the grain boundary. The effect of $\mathrm{B}$ atoms in solute at grain boundaries can be viable in both of these scenarios. 
In order to verify these proposed hypotheses for the hot ductility improvement, it was necessary to trace the distributions of alloying elements, especially $\mathrm{B}, \mathrm{Nb}, \mathrm{N}$, and $\mathrm{C}$, from the grain center to the grain boundary of austenite. Two B-steel specimens were quenched from $1000^{\circ} \mathrm{C}$ at the straightening stage of the respective thermal schedule to freeze the positions of the alloying elements. One of the specimens was quenched just before the tensile test and the other immediately after the fracture. Atomic characterization was performed using the LEAP technique. As was explained in chapter 4, the examination area is small and it was necessary to examine several needlelike specimens in order to find a grain boundary. Unfortunately, no conclusive results have yet been achieved through examining of a few specimens. However, the current results show that the LEAP technique is a promising method for the proposed objective. Two typical distribution images of the needlelike specimens are shown in Figure 6.5. Figure 6.5(b) shows a band of high concentration of iron oxide, but it is not likely to be at the grain boundary. The presence of this oxide might be due to the specimen preparation. However, the main elements have not been analyzed yet and so this characterization is still underway.

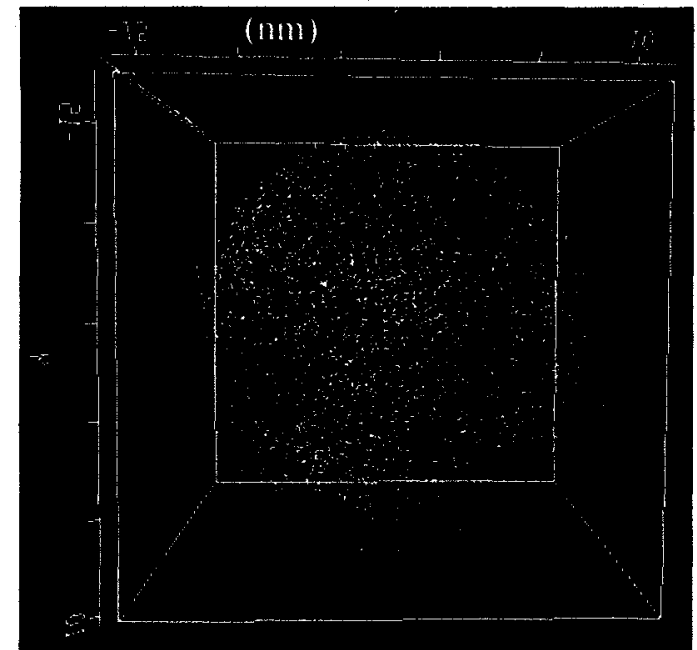

(a)

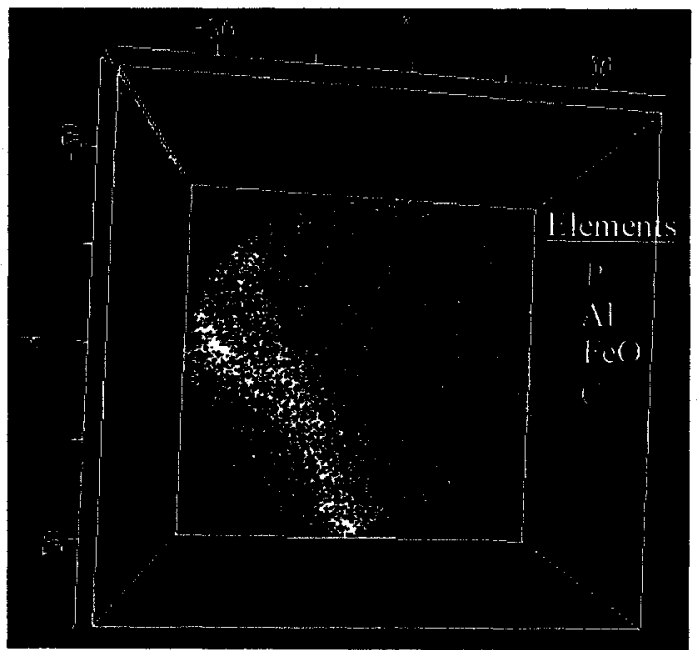

(b)

Figure 6.5. Typical images of atomic distributions in the B2-steel. (a) quenched just before the tensile test at the straightening stage, and (b) quenched immediately after the fracture at the straightening stage. Both quenched from $1000^{\circ} \mathrm{C}$. 


\subsection{Effect of Deformation During Solidification}

Comparing the deformation curves shown in Figures 5.5, 5.8 and 5.10 and also the results of hot ductility evaluation summarized in Table 5.2, it is clear that pre-deformation (either compression or tension) incorporated with the solidification has resulted in deterioration of the hot ductility and this is independent of the pre-deformation mode. As well, it is concluded that this detrimental effect is independent of composition since the ductility has been lessened in both the $\mathrm{Nb}$-steel and the B-steel.

With regard to pre-tension, such deformation could prevent solidification cavities from being closed up, and generate cracks and discontinuities in the very weak mushy region (where liquid and solid coexist). Therefore, the solidified structure contains cracks and voids, which are destructive to the hot ductility. On the other hand, at this stage, precompression could help in closing up and healing any cavities that were forming during the solidification, i.e. solidification shrinkages. However, pre-compression was also found to be detrimental, but not to the same extent as pre-tension. Considering this, it seems that small voids and discontinuities generated solely by the solidification appear to have little influence on the hot ductility.

The fracture characteristics shown in Figures 5.27 and 5.29 clearly illustrate that, for both modes of pre-deformation, the failure developed substantially through grain boundary separation with facet surfaces, as opposed to mostly sheared surfaces exhibited in Figure 5.19, where the steel had been subjected to the thermal schedule alone. Therefore, it is concluded that interactions between the pre-deformation during the solidification and other phenomena taking place in the mushy zone resulted in weakness of grain boundaries.

One possibility is that the deformation affected segregation characteristics and this led to the loss of hot ductility at the straightening stage. Segregation or enrichment of solutes and alloying elements is the most important event occurring during the solidification of 
steel. Using the Scheil equations, microsegregation resulted from solute rejection during dendritic freezing in steel can be considered as follows: $:^{[162,163]}$

$$
\begin{array}{ll}
\text { for interstitials: } & C_{l}=\frac{C_{0}}{k+(1-k) g} \\
\text { for substitutionals: } & C_{l}=C_{0} g^{k-1}
\end{array}
$$

where $g$ is volume fraction of remaining liquid in any given volume element of the solidifying mass, $C_{0}$ initial solute concentration at $g=1, C_{l}$ solute concentration in the enriched liquid, and $k$ is solid/liquid equilibrium solute distribution ratio. The solute distribution ratios in dilute solutions of $\mathrm{X}$ in selected systems of Fe-X are listed in Table 6.2. Using these values of $k$ in equations 6.11 and 6.12 , segregation profiles for the $\mathrm{Nb}$ steel during solidification can be determined and are shown in Figure 6.6. Similar profiles can be obtained for the B-steel. However, the intensity of carbon segregation is less in the latter.

Table 6.2. $k$ values for some elements. ${ }^{[163]}$

\begin{tabular}{|c|c|}
\hline Solute $\mathrm{X}$ & $k=[\% \mathrm{X}]_{\delta} /[\% \mathrm{X}]_{l}$ \\
\hline $\mathrm{Al}$ & 0.6 \\
\hline $\mathrm{C}$ & 0.2 \\
\hline $\mathrm{H}$ & 0.27 \\
\hline $\mathrm{Mn}$ & 0.74 \\
\hline $\mathrm{N}$ & 0.27 \\
\hline $\mathrm{Nb}$ & 0 \\
\hline $\mathrm{O}$ & 0.27 \\
\hline $\mathrm{P}$ & 0 \\
\hline $\mathrm{Si}$ & 0.08 \\
\hline $\mathrm{S}$ & 0.6 \\
\hline $\mathrm{Ti}$ & 0.04 \\
\hline
\end{tabular}

When solute concentrations in the interdendritic liquid become sufficiently high, reactions may occur between the solutes resulting in the formation of oxide, silicate, oxysulphide inclusions, and gas bubbles. An important reaction in the impurity enriched interdendritic liquid is the precipitation of $\mathrm{MnS}$ inclusions. In the vicinity of the liquidus 


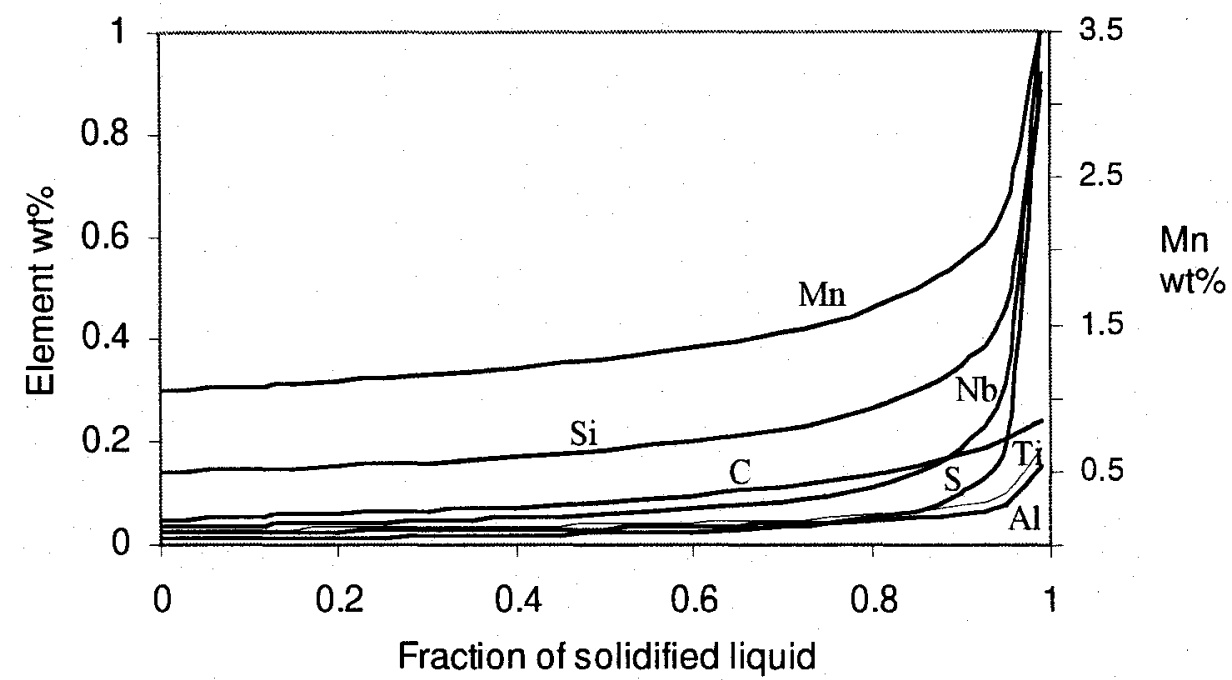

Figure 6.6. Interdendritic solute enrichment in the $\mathrm{Nb}$-steel during solidification, if there is no reaction between elements during solidification.

temperatures, the solid $\mathrm{MnS}$ solubility product $[\% \mathrm{Mn}][\% \mathrm{~S}]$ is about $0.92 .^{[163]}$ Then, as $\mathrm{Mn}$ and $\mathrm{S}$ profiles in Figure 6.6 suggest, $\mathrm{MnS}$ obviously precipitates in the interdendritic liquid, especially during the later stages of solidification. In the case of rapid rates of solidification, as in the thermal schedule, the local equilibrium reaction may not prevail and some liquid 'FeS' may precipitate in the last liquid to freeze. This can happen even though the ratio of $\mathrm{Mn} / \mathrm{S}$ in the steel is greater than the critical value for $\mathrm{MnS}$ to precipitate. $^{[163]}$ Such reaction has been shown to deteriorate the hot ductility of steel. ${ }^{[20]}$ Some evidence for a combination of FeS and MnS on fracture surfaces have been already reported and a mechanism that requires the precipitation of FeS in lieu of $\mathrm{MnS}$ during cooling from high temperatures has been proposed. ${ }^{[20]}$

TiN is also an important precipitate, especially in the microalloyed steel. The solubility product of this precipitate in the liquid steel is given by. ${ }^{[10]}$

$$
[\mathrm{Ti}][\mathrm{N}]=10^{5.9-16586 / \mathrm{T}}
$$

This solubility limit, for the $\mathrm{Nb}$-steel, is plotted in Figure 6.7 in terms of $\mathrm{Ti}$ versus interdentrically segregated $\mathrm{N}$ during the solidification. Also, for comparison, the amount 
of Ti segregated interdendritically is plotted. As can be seen, the amount of Ti available in the interdendritic locations is far beyond what is needed for TiN to precipitate in the liquid. Consequently, TiN is expected after about $20 \%$ completion of the solidification. Therefore, during the solidification, most of the remaining $\mathrm{N}$ in solution will precipitate as TiN in the interdendritic liquid, which subsequently becomes the $\delta$-ferrite and austenite grain boundaries. The particles of TiN seated at austenite grain boundaries will be the preferential sites upon which $\mathrm{NbC}$ will precipitate during further cooling of the steel. ${ }^{[113]}$ Large TiN cubes in steel, in which the product of [Ti][N] was lower than the solubility product in the liquid state, has confirmed significant segregation for both $\mathrm{Ti}$ and $\mathrm{N}$ in liquid. ${ }^{[10,164]}$ Furthermore, EDS analysis results from many large cuboidal carbonitrides precipitates have shown that they have a titanium-rich core surrounded by a niobium-rich skin. ${ }^{[164]}$ This explains why $\mathrm{Ti}$ and $\mathrm{Nb}$ are detected at some grain boundary particles in Figure 5.28(f).

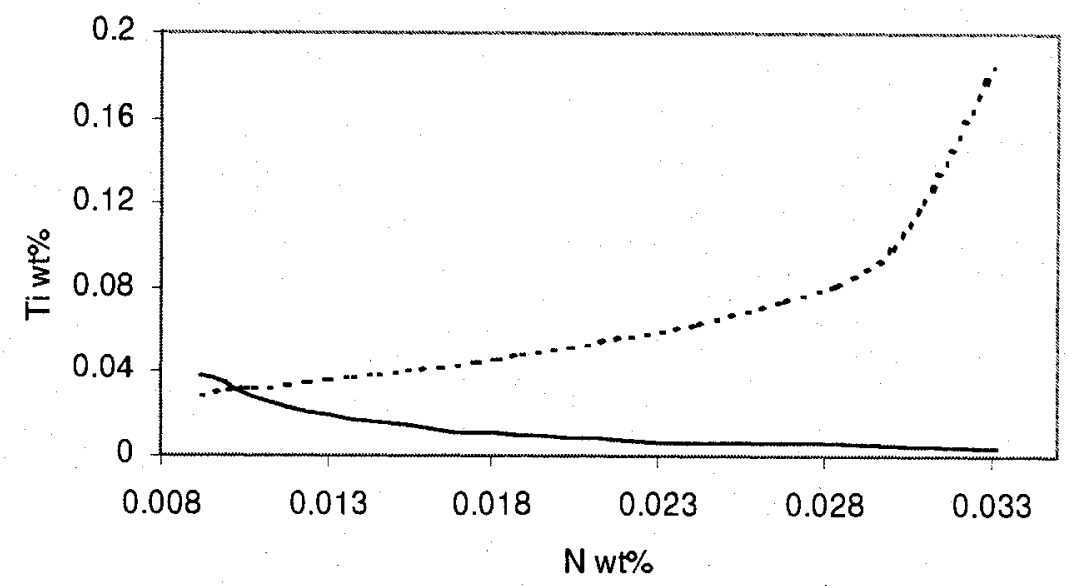

Figure 6.7. Solid line; solubility limit of TiN versus interdendritically segregated $\mathrm{N}$ from 1500 to $1430^{\circ} \mathrm{C}$. Dashed line; interdendritically segregated Ti versus segregated $\mathrm{N}$. (the $\mathrm{Nb}$-steel)

$\mathrm{Al}$ and $\mathrm{Si}$ both decrease the liquidus temperature in steel. The rate of this reduction is 2.5 and $14^{\circ} \mathrm{C} / \mathrm{wt} \%$ for $\mathrm{Al}$ and $\mathrm{Si}$, respectively. In addition, Si reduces the surface tension of iron liquid by $30 \mathrm{mNm}^{-1} / \mathrm{wt}^{0}{ }^{[163]}$ Certainly, these effects are more intense in the later percentages of liquid being solidified since it is highly segregated of these elements. 
Based on this information, the effect of pre-deformation is explained as follows. In the first cooling segment of the thermal schedules, the solidification starts with formation of dendrites and columnar grains growing toward the center of specimen, Figure 5.34(a). Thus, the remaining liquid is confined inside a solidified shell as shown schematically in Figure 6.8(a). As the solidification proceeds inside the shell, the liquid between grains becomes more and more enriched of alloying elements (Figure 6.6). This segregated liquid is shown in Figure 6.8(a) at both horizontally and vertically growing grain boundaries. The segregated liquid is also more fluid mostly because of segregated $\mathrm{Si}$. This was confirmed by EDS analysis of the liquid solidified between grains, where a high concentration of $\mathrm{Si}$ was detected, Figure 5.35(e). The occurrence of the oxygen signal in that spectrum is probably because of surface oxidation. On the other hand, according to the $\mathrm{Fe}-\mathrm{Si}$ equilibrium phase diagram, ${ }^{[165]}$ and the relative amount of $\mathrm{Si}$ to $\mathrm{Fe}$, a $\mathrm{Fe}-\mathrm{Si}$ eutectic compound is likely to form at $1200^{\circ} \mathrm{C}$. Therefore, some liquid at grain boundaries might have a delayed solidification till $1200^{\circ} \mathrm{C}$.

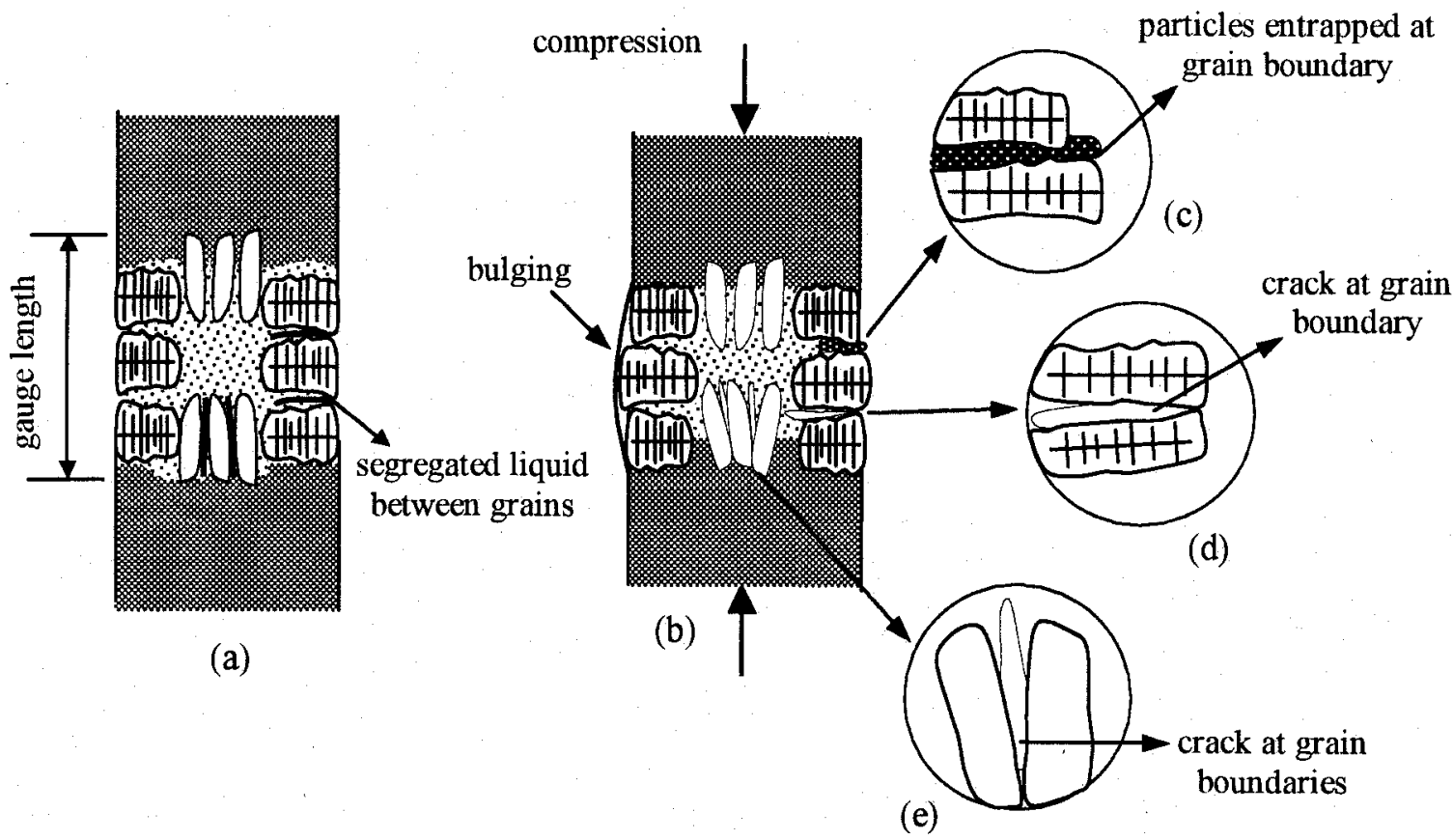

Figure 6.8. Mechanism of crack formation and loss of grain boundary strength due to precompression during solidification. 
When such a solidifying structure is subjected to a compressive deformation longitudinally, the solidified shell bulges out horizontally owing to the internal hydrostatic pressure from the liquid to the solidified shell, as shown schematically in Figure 6.8(b). Simultaneously, the liquid is extruded into grain interspaces and transfers and accumulates particles and inclusions at grain boundaries. When the solidification is completed, these accumulated particles remain at grain boundaries leading to severely weakened grain boundaries. This is illustrated in Figures 5.35(d) and 6.8(c). Here, the accumulation of particles plays the main role in weakening grain boundaries and particles distribution due to equilibrium solidification does not necessarily lead to any considerable loss of hot ductility. Also, in addition to particles, the highly segregated liquid is compressed and sheared between horizontal grains leading to grain boundary cracks upon completion of the solidification, Figure 6.8(d). Typical examples of this are shown in Figures 5.28(b) and (h) where high segregation of carbon was determined inside cracks at grain boundaries. Furthermore, during pre-compression, the liquid is pushed between grains growing longitudinally and, hence, inclining them horizontally toward the bulging direction of the gauge length region, Figure 6.8(b). This, at later stages of solidification, results in discontinuities at the grain boundary segregated liquid and, consequently, intergranular cracks in the resultant solid. This is illustrated in Figure 5.27(d) and schematically in Figure 6.8(e). Note that such cracking occurs because solid and liquid are adjacent to each other, and this is the liquid that endures the most deformation and is sheared and cracked during solidification.

On the other hand, the movement of liquid along its interface with the solid could make diffusion difficult through the solidification front. This can lead to two adverse consequences. Firstly, the solute concentration in the liquid will be more severe than when the liquid is stationary. Therefore, all the detrimental effects due to segregation are more intense. Itoyama et al. ${ }^{[15]}$ investigated the effect of oscillations during solidification in the continuous casting and proposed that the pressure change can alter the amount of enriched molten steel in interdendritic regions, although no specific mechanism for the interaction between deformation and segregation was offered. Salvadori et al. ${ }^{[166]}$ studied the effect of liquid agitation (stirring) on the segregation ratio and found that the stirring 
enhances intergranular segregation during the steel solidification. However, the exact interaction between deformation/agitation in liquid and segregation patterns has not yet been well documented. The second potential defect, because of the moving liquid, is that a strong bond between current and new solids, at the solidification front, could be difficult to be established, especially during the later stages of solidification. In this respect, the final consequence is a weakened grain boundary. Grain boundary separation resulting in grain surfaces with liquid-like appearances, demonstrated in Figure 5.34, can be attributed to these phenomena.

One interesting aspect regarding the grain surface is a fibrous structure covering the grain surface. This is shown in Figures 5.19(d), 5.27(c), and 5.29(c). This structure was observed in almost all specimens subjected to the thermal schedules alone and the thermal schedules incorporated with pre-deformation. Hence, it would appear that predeformation was not necessary to form such fibers. Meanwhile, no clear explanation can be suggested for such a grain boundary structure. It may be a usual as cast grain boundary structure observed in a very high resolution electron microscope. As well, it may be a second phase solidified/formed on the grain surface during the solidification and/or cooling. ${ }^{[167,168]}$ However, only iron, carbon, and oxygen were detected in the EDS analysis of these fibers. As the specimens were air cooled or quenched in water after the fracture, the presence of oxygen is rather unlikely to be ascribed to a grain boundary phase formed before the fracture.

Two different regions on grain surfaces in Figure 5.34(b) suggest that there must have been two different modes that contributed to the final fracture. The facet region, designated by A (Figure 5.34(c)), contains irregular shaped particles 100 to $400 \mathrm{~nm}$ in size. Characteristic $\mathrm{x}$-ray analysis revealed $\mathrm{Fe}, \mathrm{Al}$, and $\mathrm{O}$ as major constituents. Assuming that the Fe signal in the spectrum has come from the iron matrix, these particles can be characterized as $\mathrm{Al}_{2} \mathrm{O}_{3}$. Suzuki et al. ${ }^{[1]}$ detected similar precipitates on austenite grain surfaces in a plain carbon steel subjected to in situ melting and fractured intergranularly at temperature range of $900 \sim 1200^{\circ} \mathrm{C}$. They also reported corresponding grain boundary dimples associated with the fracture. However, in the current work, it seems that grain 
boundaries were too weak to withstand the load needed for void nucleation and growth at the precipitates and grain boundaries separated before formation of voids. This is also consistent with the values obtained for the reduction in area for this specimen and those obtained for the specimens of Suzuki and co-workers', being 0 and $\sim 20 \%$, respectively. As explained before, the liquid movement during solidification can be considered as a cause for this severe grain boundary weakness. On the contrary, no precipitates were found on the rough region, designated by B, Figure 5.34(d). Overall, this area demonstrates shear-like appearance with some cavities, Figure 5.34(b). This implies a stronger grain boundary, as opposed to region A. Therefore, it can be concluded that the failure, at grain boundaries, initiated at region $\mathrm{A}$ and extended to region $\mathrm{B}$. In other words, region A behaved as a grain boundary crack that propagated through region $\mathrm{B}$ leading to an early rupture.

The presence of segregated low melting point phase entrapped between dendrites, because of deformation, was also observed and explained by other investigators. Harada et $a l .{ }^{[16]}$ studied the effect of bending deformation in the mould in the continuous casting process and proposed that the deformation can cause the segregated liquid to be entrapped between dendrites that leads to cracking during subsequent deformation processes. Barber and Perkins ${ }^{[169]}$ proposed a finite element model to approximate the strains resulted from bulging, roll misalignment, and bending of the semisolid strand during continuous casting. They concluded that, in order to prevent internal cracking, casting machines should be designed and operated such that the total strain at each position in the strand is minimized. More recently, Han et al. ${ }^{[170]}$ developed mathematical models for strain analysis and microsegregation during continuous casting of slab. They showed that the interaction between deformation and segregation during solidification leads to internal cracking of slabs.

As for the detrimental effect of tensile deformation during the solidification, the mechanism of hot ductility deterioration is much less complicated. Pre-tension during the solidification can readily create cracks at the remaining liquid. Here, even though segregation can interact with pre-tension, its interaction does not seem necessary to 
produce a detrimental result since the pre-tension is deleterious enough by itself to decrease the hot ductility markedly.

The intensity of such deleterious effect of pre-deformation during solidification depends on both the strain rate and the temperature at which the pre-deformation starts. Figure 5.17 obviously demonstrates that lower strain rates are less detrimental. As can be seen, at strain rate $0.009 \mathrm{~s}^{-1}$, the pre-compression is detrimental and its effect does not change considerably as long as it starts within the solidification region. It should be noted that the pre-compression, in this case, started in the solidification region and it continued in the solid region, i.e. true strain 0.1 was applied during cooling at a rate of $10^{\circ} \mathrm{C} / \mathrm{s}$ (the first cooling segment of the thermal schedule). Comparing these results with that of specimen I in Figure 5.10, in which the pre-compression was limited within the solidification region, and the respective RA value in Table 5.2, it seems that continuing the precompression into the solid region alleviates somewhat the severity of the detrimental effect of the pre-compression imposed within the solidification region. At the lower strain rate, $0.003 \mathrm{~s}^{-1}$, no detrimental effect from the pre-compression during the solidification was observed. Consequently, the more pre-deformation applied during solidification, the worse the hot ductility. In this respect, pre-deformation in the solid region appears beneficial no matter if it has been initiated during solidification or after completion of solidification, Figure 5.17. This will be discussed in the next section.

\subsection{Effect of Deformation after Solidification}

\subsubsection{Effect of Deformation in $\delta$-Ferrite Region}

Pre-deformation applied in the $\delta$-ferrite region during cooling does not have significant influence on the hot ductility at the straightening stage, but, if anything, it tends to be deleterious. Table 5.4 shows that, in the B-steel, $5 \%$ pre-deformation in the $\delta$-ferrite region led to a slight loss of the hot ductility, with no real difference between pre-tension 
and pre-compression. A similar result was obtained in the $\mathrm{Nb}$-steel for $2 \%$ precompression, Table 5.4 and Figure 5.12.

The specimens deformed in the $\delta$-ferrite region demonstrate both finer and larger fracture features, Figures 5.31 and 5.32, than those of the specimen subjected to the thermal schedule alone. Even though the finer fracture features suggest a higher ductility, the larger ones are the indicative of a lower ductility and the relative amount of these fracture characteristics indicates the steel general ductility. This explains why the pre-deformation in the $\delta$-ferrite region did not considerably alter the hot ductility from that developed by the thermal schedule alone. However, the mechanism of failure is still grain boundary separation through void formation and coalescence at grain boundaries, as was shown in Figures 5.32(b) and (c). The finer characteristics can be attributed to the closure of solidification shrinkages and cavities during the pre-compression. Thus, new voids were required to nucleate at grain boundaries to proceed the grain boundary separation. It should be emphasized that such fine characteristics cannot be ascribed to (dynamic) recrystallization, i.e. grain refinement, since dynamic recovery easily relieves the strain accumulation in $\delta$-ferrite. In fact, it has been found that the flow behavior of $\delta$-ferrite almost follows a horizontally straight line. ${ }^{[16,117]}$ This is evident in the flow curves shown in Figures 5.11(a) and 5.12(a) for $\delta$-ferrite. On the other hand, large cavities can be grown-up solidification defects, i.e. voids, under the tension at the straightening stage.

Figures 5.36(a) and (b) illustrate that some mushy films were deformed during the precompression of $\delta$-ferrite, since the pre-compression started too close to the nonequilibrium solidus temperature. Hence, this can be considered as the reason for the poor mechanical behavior at the straightening stage, shown in Figure 5.12 for specimen I.

Conclusively, pre-deformation in the $\delta$-ferrite region has a little influence on the hot ductility and such effect is ambivalent. If pre-deformation is applied too close to the nonequilibrium solidus temperature (as defined in Figure 5.3), it may break freshly solidified regions at grain boundaries that are still too weak to withstand any deformation. In this way, the pre-deformation appears detrimental to some extent. In contrast, if there is no 
breakage of mushy film at grain boundaries, closure of solidification shrinkages under pre-compression can lead to slight improvement in the hot ductility. These effects are controlled by both the amount of deformation and the deformation rate. Nevertheless, the effect of pre-deformation in the $\delta$-ferrite region is rather negligible in comparison with the effect of deformation during the solidification and the $\delta \rightarrow \gamma$ transformation.

\subsubsection{Effect of Deformation in $\delta \rightarrow \gamma$ Transformation Region}

Pre-deformation during the $\delta \rightarrow \gamma$ transformation significantly influenced the hot ductility at the straightening stage, especially in the $\mathrm{Nb}$-steel. Table 5.4 showed that such predeformation can lead to $6 \%$ and $25-37 \%$ improvement in the hot ductility at $1000^{\circ} \mathrm{C}$ and $1020^{\circ} \mathrm{C}$ in the B-steel and the $\mathrm{Nb}$-steel, respectively. Figure 5.43 showed that the predeformation incorporated with the transformation led to a smaller grain size at the straightening stage. As well, the high hot ductility in the B-steel, subjected to the thermal schedule alone, was explained to be due to dynamic recrystallization, Figure 5.20(d). Hence, dynamic recrystallization at the straightening stage is expected to have begun earlier in the B-steel specimen that was pre-deformed during the transformation than the specimen subjected to the thermal schedule alone. The recrystallized grains are also smaller in the former, Figure 5.42(a). Consequently, the smaller initial grain size and, therefore, the earlier dynamic recrystallization are considered as the reasons for the hot ductility improvement in the B-steel. The earlier dynamic recrystallization leads to an earlier isolation of grain boundary cavities that postpones the void linkage at grain boundaries.

The smaller amount of hot ductility improvement in the B-steel than the Nb-steel can be attributed to the fact that dynamic recrystallization occurred in the B-steel also without a pre-deformation during the transformation. On the contrary, no dynamic recrystallization was observed in the $\mathrm{Nb}$-steel subjected to the thermal schedule alone. Hence, dynamic recrystallization might have contributed to the hot ductility improvement in the Nb-steel after it was pre-deformed during the transformation. 
The specimens deformed during the transformation display finer fracture features than the specimen subjected to the thermal schedule alone, comparing Figures 5.39 and 5.21. Figure 5.40(a) revealed two distinct regions on the grain surface; the facetted region, identified as $\mathrm{A}$, and the rough region, identified as $\mathrm{B}$. As can be seen in the latter, the roughness is because of dimples formed at $\mathrm{Al}_{2} \mathrm{O}_{3}$ particles. This is in agreement with the result found by Suzuki et al. ${ }^{[1]}$ in specimens cooled, from the melting temperature, to the fracture temperature. Elongated dimples in Figure 5.40(d) implies that they have been formed under shear stress. Therefore, the grain boundary sliding led to void nucleation and elongation at grain boundaries.

The pre-deformation during the transformation also resulted in grain refinement during the tensile deformation at the straightening stage, comparing Figures 5.22 and 5.41. Consequently, dynamic recrystallization was a viable mechanism that led to the hot ductility improvement in the $\mathrm{Nb}$-steel. In the specimen subjected to the thermal schedule alone, the grain size near the fracture region varies from 282 to $891 \mu \mathrm{m}$ with an average of $586 \mu \mathrm{m}$. Also, the grain aspect ratio (length/width) is calculated to vary between 2.1 and 4.6. On the contrary, the specimen deformed during the $\delta \rightarrow \gamma$ transformation, Figure 5.41(a), displays a grain size range between $9.5 \sim 42 \mu \mathrm{m}$ with an average of $32 \mu \mathrm{m}$ and the grain aspect ratio changes from 2.3 to 7.9 . The greater grain aspect ratio indicates that more deformation was endured in the grain interior. In addition, there are no grain boundary cracks, like those that were shown in Figure 5.22(a). Nevertheless, small and isolated grain boundary cavities are present. This is in agreement with Figures 5.21 and 5.39 with regard to the fact that the specimens deformed in the transformation region exhibit more but smaller cavities on the fracture surface than the specimen solely subjected to the thermal schedule.

Even though the specimens were quenched within one second after fracture, it may be argued that such a grain refinement is mostly due to metadynamic recrystallization rather than dynamic recrystallization. The former has also faster kinetics. To consider such an argument, the microstructure was examined in more detail. 
In Figure 6.9, irregular grain boundaries, instead of straight boundaries, at the fracture region, indicate that cracks were arrested and changed their growth paths iteratively before turning into large cracks. Since as cast structure is made up of long and rather straight grain boundaries, the only possible reason for this tortuous fracture path is nucleation of new grains at grain boundaries along which crack propagation was underway. Furthermore, the outward projection of very small grains on the fracture edge implies that these grains had formed before the decohesion of their common boundaries with the grains on the opposite fracture edge. An arrow in Figure 6.9 indicates a typical of these grains. On the other hand, at such a low strain rate, i.e. $5 \times 10^{-3} \mathrm{~s}^{-1}$, it is unlikely that as much recrystallization as that depicted in Figure 6.9 can be ascribed to the metadynamic process. It has been shown that metadynamic recrystallization is a strain rate dependent phenomenon and its kinetics in the $\mathrm{Nb}$-containing steel is described as follow; ${ }^{[171]}$

$$
t_{0.5}=(12[N b]+0.5) \times 10^{-4} Z^{-0.84} \exp \left(\frac{403000}{R T}\right)
$$

where $t_{0.5}$ is the time for $50 \%$ recrystallization, $Z$ is the Zener-Hollomon parameter, and $R$ and $T$ have their usual definitions. By substituting $Z$ with equation 6.2, equation 6.13 can be rewritten as follows:

$$
t_{0.5}=(12[N b]+0.5) \times 10^{-4} \dot{\varepsilon}^{-0.84} \exp \left(\frac{Q}{R T}\right)
$$

where $Q=Q_{\text {marx }}-0.84 Q_{\text {def }}$. For two Nb-containing steels, with 0.023 and $0.07 \mathrm{wt} \% \mathrm{Nb}$, examined in Ref. 171, $Q$ was found to be $92 \mathrm{~kJ} / \mathrm{mol}$. Using this value and by solving equation 6.14 for the $\mathrm{Nb}$-steel, $t_{0.5}$ is approximated to be 47 seconds at $1000^{\circ} \mathrm{C}$. Consequently, recalling that the specimen was quenched by water impingement within one second after the fracture, the level of metadynamic recrystallization would be much less than that shown in Figure 6.9. 


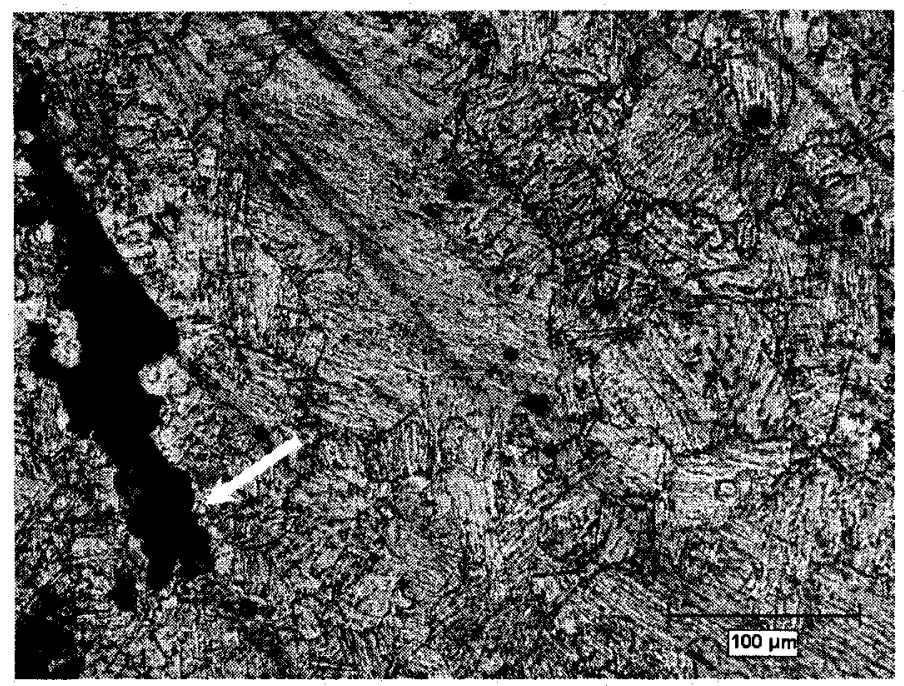

Figure 6.9. Microstructure near the fracture region in the specimen III in Figure 5.13. Etched with picral.

In addition, it was noticed that some small grains, $\sim 25 \mu \mathrm{m}$ mean grain size, have grain aspect ratios of as large as 7 . Obviously, such deformed grains had formed during the deformation, i.e. they are products of the dynamic recrystallization. However, the absence of a hump on the stress-strain curve, Figure 5.13(b), should still be addressed and the occurrence of dynamic recrystallization needs to be verified from the stress-strain curve in the $\mathrm{Nb}$-steel.

Although dynamic recrystallization is usually indicated by the appearance of a peak on the stress-strain curve, it is actually initiated at a 'critical strain' that is smaller than the strain corresponding to the stress peak. ${ }^{[55,126]}$. Thermodynamically speaking, there is a critical amount of stored energy needed for the initiation of dynamic recrystallization. From a microscopic point of view, two simultaneous processes govern the formation of substructure during deformation. ${ }^{[172]}$ Generation and accumulation of dislocations is the first process during which the energy is stored. The second or counterpart process is the relaxation process involved in the motion, rearrangement and annihilation of lattice defects, e.g. dislocations and vacancies. Based on these phenomena, Poliak and Jonas ${ }^{[172]}$ established a critical kinetic condition for the initiation of dynamic recrystallization with 
regard to the thermodynamics of irreversible processes. If the total work done along a particular irreversible path and the total work stored in the material in the form of the dislocation substructure are $W_{t o t}$ and $W_{s t}$, respectively, an increment of dissipative work during plastic flow, $\delta W_{d}$, is defined as follow;

$$
\delta W_{d}=\delta W_{t o t}-\delta W_{s t}
$$

where the increment of actual irreversible work performed during the deformation is given by $\delta W_{t o t}=\sigma . \mathrm{d} \varepsilon, \sigma$ and $\varepsilon$ being stress and strain, respectively. The dissipative work is linked to the entropy. Equation 6.15 was further developed and they finally concluded that the critical state for the onset of dynamic recrystallization corresponds to an inflection point in the $\theta-\sigma$ curve, where $\theta=\frac{\partial \sigma}{\partial \varepsilon}$. In other words, at this point

$$
\frac{\partial}{\partial \sigma}\left(\frac{\partial \theta_{c}}{\partial \sigma}\right)=0
$$

where $\theta_{c}$ is the strain hardening rate at the onset of dynamic recrystallization. It should be notified that the association of onset of dynamic recrystallization with the point of inflection on the $\theta(\sigma)$ curve was first proposed by Ryan and McQueen ${ }^{[173]}$ in 1990. However, they did not give a physical reasoning for this assumption.

The consideration proposed by Poliak and Jonas is based on the thermodynamic instability of the microstructure in terms of internal energy and entropy and it does not talk about the instability of the microstructure (substructure). Gottstein et al. ${ }^{[174]}$ recently utilized a "Three Internal Variables Model", which assumes that the deformed state comprises a cellular structure with a high dislocation density in the cell walls. The cell walls, in turn, enclose cell interiors of considerably lower dislocation density. This model, which is based on the criterion of irreversible thermodynamics proposed by Poliak and Jonas, considers three state variables, namely the mobile dislocation density and the stored dislocation densities in the cell interiors and the cell walls. Gottstein et al. concluded that the critical conditions for dynamic recrystallization can be associated with the conversion of rigid cell walls to mobile subboundaries owing to extensive dynamic 
recovery. Their predicted results showed good agreement with the criterion proposed by Poliak and Jonas, i.e. the 'one-parameter critical condition'. Considering such a good agreement, they suggested that one internal parameter is dominant, namely the one that most strongly affects the flow stress at large strains. In this respect, the "Three Internal Variables Model" approaches the "one-parameter model" behavior, so that essentially the flow stress is represented in terms of the total dislocation density.

In these two models, the initiation of dynamic recrystallization was studied with regard to thermodynamic and microstructural instabilities, respectively, and good consistency was observed between experimental (the thermodynamic model) and simulation (the microstructural model) results. It should be emphasized that both models consider the critical condition for the initiation of dynamic recrystallization regardless of the hump on the stress-strain curve. In fact, the presence of stress peaks in constant strain rate flow curves is considered as the sole reliable indication of the initiation of dynamic recrystallization since the attainment of the critical condition $\left(\sigma_{c}\left(\varepsilon_{c}\right)\right)$ does not reveal itself in the flow curve, which remains smooth prior to and beyond the critical point. This is why flow curves without well-defined stress peaks are generally believed to pertain to mechanical behavior with dynamic recovery as the only restoration mechanism. Nevertheless, dynamic recrystallization takes place in many materials even though no clearly defined stress peaks are observed in laboratory flow curves, examples of such materials include $\mathrm{Nb}$-microalloyed low carbon and austenitic stainless steels. ${ }^{[173,175]}$ In order to deal with this subject, Poliak and Jonas ${ }^{[176-178]}$ recently applied their "oneparameter approach' to constant and varying strain rate hot deformation processes to accurately identify the occurrence of dynamic recrystallization.

Figure 6.10 shows schematically a classical stress-strain curve in which dynamic recrystallization is easily discerned. The parameters of dynamic recrystallization, i.e. critical and peak stresses and strains, are also illustrated in the Figure. Nevertheless, this is not the case in the deformation curves presented in Figure 5.13(b), in which dynamic recrystallization is questionable. Therefore, the purpose is to verify the occurrence of dynamic recrystallization in these specimens using the concept of the thermodynamics of 
irreversible processes. It should be emphasized that this concept has been only used in compression experiments so far. Even though it should be applicable in tensile experiments, cautions should be considered when dealing with materials in which grain boundary decohesion and deformation localization are mechanisms of fracture since these can affect the strain hardening behavior. As well, it should be used carefully as a material approaches its necking stage.

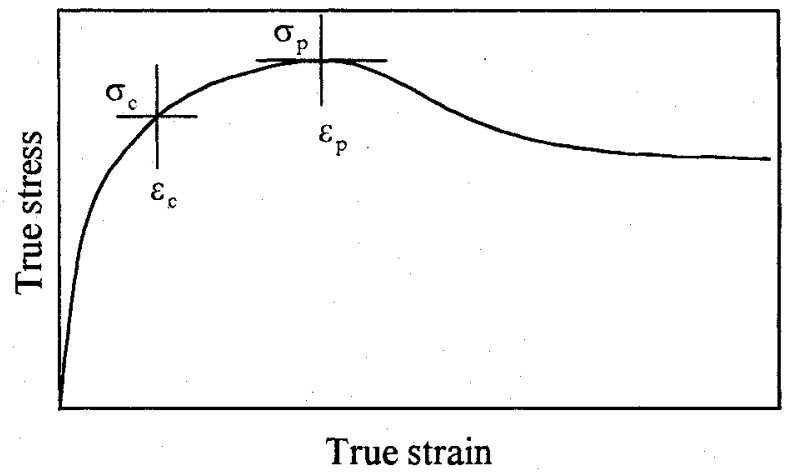

Figure 6.10. Constant strain rate stress-strain curve typical of dynamic recrystallization.

Since load cells being used in the deformation processes do not usually render exact instantaneous values, but very short range fluctuations around the real load, stress-strain curves are not very smooth, as can be seen in Figure 5.13(b). This appears as iteratively positive and negative strain hardening, even though strain hardening is always positive before the highest point on the curve. Therefore, if the strain hardening is to be evaluated, the first step is to filter out and best approximate the experimental deformation curve with a polynomial of appropriate order. This has been done for specimens I, II, and III in Figure 5.13(b) and the polynomial equations, together with their respective degrees of fit goodness $\left(\mathrm{R}^{2}\right)$, are as follows (note that these equations describe only the strain hardening segment of the deformation curves, i.e. from the yield point up to the maximum stress);

(Equation 6.17)

(II) $\begin{aligned} & \sigma=-2130.6 \varepsilon^{4}+1840.8 \varepsilon^{3}-630.67 \varepsilon^{2}+202.18 \varepsilon+26.976 \\ & R^{2}=0.9998\end{aligned}$ 
(III) $\begin{aligned} & \sigma=-4555.1 \varepsilon^{4}+3962.6 \varepsilon^{3}-1271.7 \varepsilon^{2}+284.92 \varepsilon+27.285 \\ & R^{2}=0.9996\end{aligned}$

(Equation 6.19)

In Figure 6.11, the stress-strain curves corresponding to the polynomial equations are compared with their respective experimental curves. As can be seen, the regressed curves exhibit excellent agreement with the experimental curves.

The flow stress dependence of the strain hardening rate $\left(\theta=\frac{\partial \sigma}{\partial \varepsilon}\right)$ is illustrated in Figure 6.12 for these specimens. The strain hardening rate decreases rapidly with stress increase at low stresses, i.e. at early stages of plastic deformation, Figure 6.12(a). As the flow stress increases, the rate of decrease in $\theta$ decelerates until the critical stress, i.e. $\sigma_{c}$, corresponding to the onset of dynamic recrystallization is reached. According to equation 6.16 , the inflection point in the $\theta-\sigma$ plot serves as an indication for initiation of dynamic recrystallization. Afterwards, $\theta$ again starts to decrease rapidly at an increasing rate. This quantity tends to infinity as the flow stress approaches its peak value, $\sigma_{p}$, at $\theta=0$. Note that $\sigma_{\mathrm{p}}$ does not necessarily correspond to the dynamic recrystallization peak in tension as it may be due to the flow localization, i.e. the ultimate tensile strength. Figure 6.12(a) also shows that there is a slight increase in $\theta$ after the inflection point in specimen $I$. This is most probably due to some experimental errors since the strain hardening rate does not increase while dynamic recrystallization is underway. For the same reason, the minimum of $\left(-\frac{\partial \theta}{\partial \sigma}\right)$ occurs in the negative region of the graph rather than the positive region, as shown in Figure 6.12(b). With regard to this error and the concept of the 'one-parameter approach', the inflection point in specimen I, the initiation of dynamic recrystallization, occurs where $\left(-\frac{\partial \theta}{\partial \sigma}\right)=0$. 

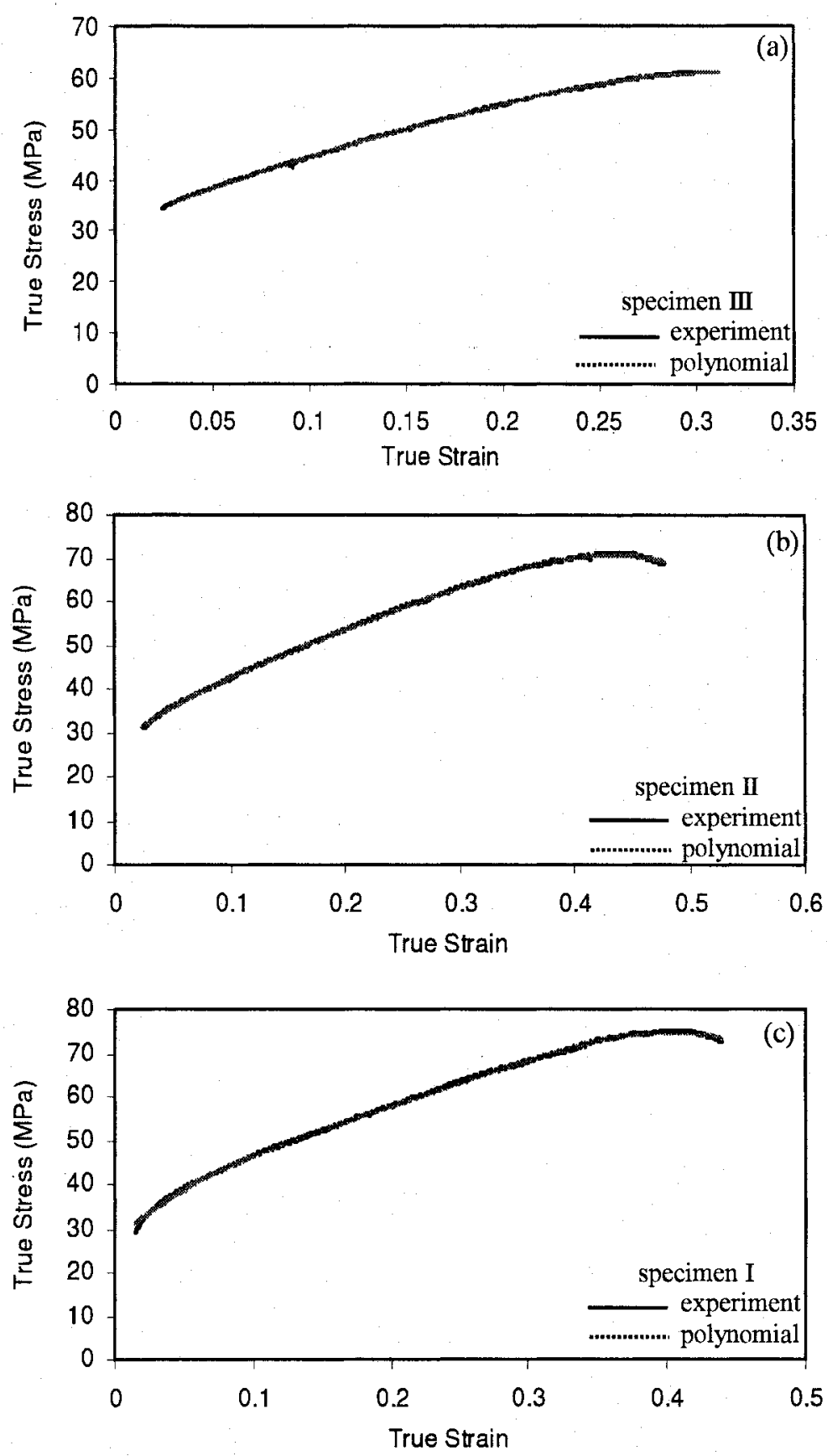

Figure 6.11. Comparison of experimental stress-strain curves of the specimens in Figure 5.13(b) with those obtained by their respective polynomials. (a), (b), and (c) correspond with specimens III, II, and I, respectively. 

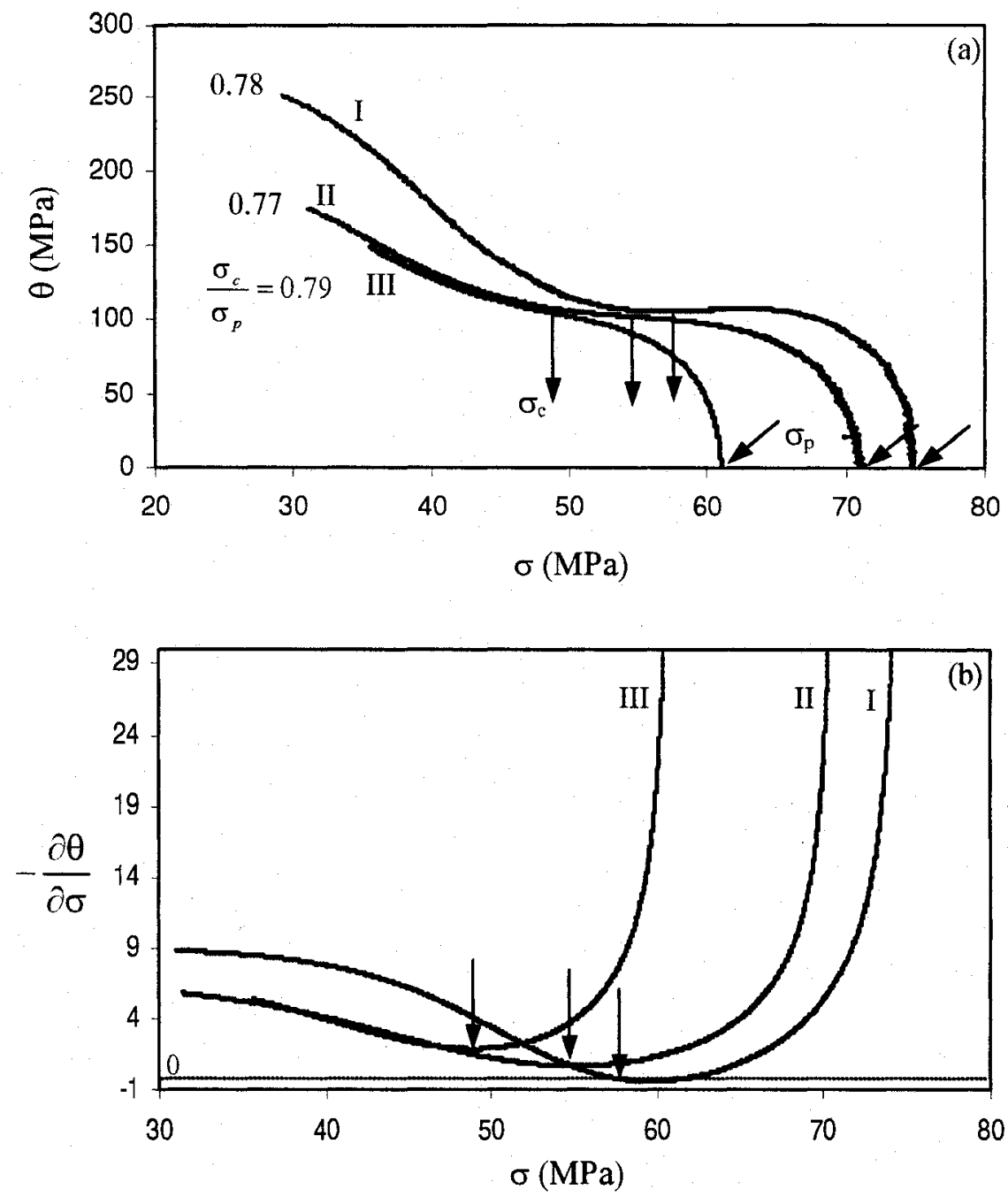

Figure 6.12. Strain hardening rate plots for the specimens introduced in Figure 5.13(b). I, II, and III correspond with the same specimens in Figure 5.13.

It is also noticed that both $\sigma_{\mathrm{c}}$ and $\sigma_{\mathrm{p}}$ increase with the rate of pre-compression applied during the $\delta \rightarrow \gamma$ transformation, from specimen III to specimen I in Figure 5.13. This is partly because of larger diameters in the specimens subjected to faster deformations during the transformation (as mentioned before, the initial diameter was considered in calculation for the true stress). At higher strain rates, more compressive deformation is applied at higher temperatures where the material is more susceptible to bulging. This results in somewhat larger cross section and slightly greater force is needed to deform the material. This is why the deformation curve of specimen I, which was subjected to the 
highest pre-compression rate, is above the other two in Figure 5.13(b). However, this does not affect the strain hardening rate in the material.

Furthermore, by definition, the normalized strain hardening rate, $\gamma_{\dot{\varepsilon}}$, is ${ }^{[176]}$

$$
\gamma_{\dot{\varepsilon}}=\frac{1}{\sigma}\left(\frac{\partial \sigma}{\partial \varepsilon}\right)_{\dot{\varepsilon}}=\frac{\theta}{\sigma}
$$

On the other hand, at the onset of dynamic recrystallization ${ }^{[172]}$

$$
\left(\frac{\partial \theta}{\partial \sigma}\right)_{\dot{\varepsilon}, c}=C \gamma_{\dot{\varepsilon}, c}=C \frac{\theta_{c}}{\sigma_{c}}
$$

where $C$ is a constant. In the logarithmic form, equation 6.21 can be rewritten as

$$
\left(\frac{\partial \ln \theta}{\partial \ln \sigma}\right)_{\dot{\varepsilon}, c}=C
$$

This equation indicates that the $\ln \theta-\ln \sigma$ plot must also display an inflection at the onset of dynamic recrystallization. As well, since ${ }^{[172]}$

$$
\left(\frac{\partial \theta}{\partial \sigma}\right)_{\dot{\varepsilon}}=\left(\frac{\partial \ln \theta}{\partial \varepsilon}\right)_{\dot{\varepsilon}}
$$

the $\ln \theta-\varepsilon$ plot must also exhibit an inflection at the onset of dynamic recrystallization. Consequently, in order to determine $\sigma_{c}$ and $\varepsilon_{c}$ precisely, it is necessary to determine the minimum in $\left|-\frac{\partial \theta}{\partial \sigma}\right|$ or the minima in $\left|-\frac{\partial \ln \theta}{\partial \ln \sigma}\right|$ and $\left|-\frac{\partial \ln \theta}{\partial \varepsilon}\right|$. These determinations are illustrated in Figures 6.13 and 6.14 for $\sigma_{c}$ and $\varepsilon_{c}$, respectively. As can be seen, the values for $\sigma_{c}$ are consistent with those obtained from the $\left(-\frac{\partial \theta}{\partial \sigma}\right)$ plot. $\varepsilon_{\mathrm{p}}$ is also defined in Figure 6.14 and follows the same trend as $\varepsilon_{\mathrm{c}}$ does. 

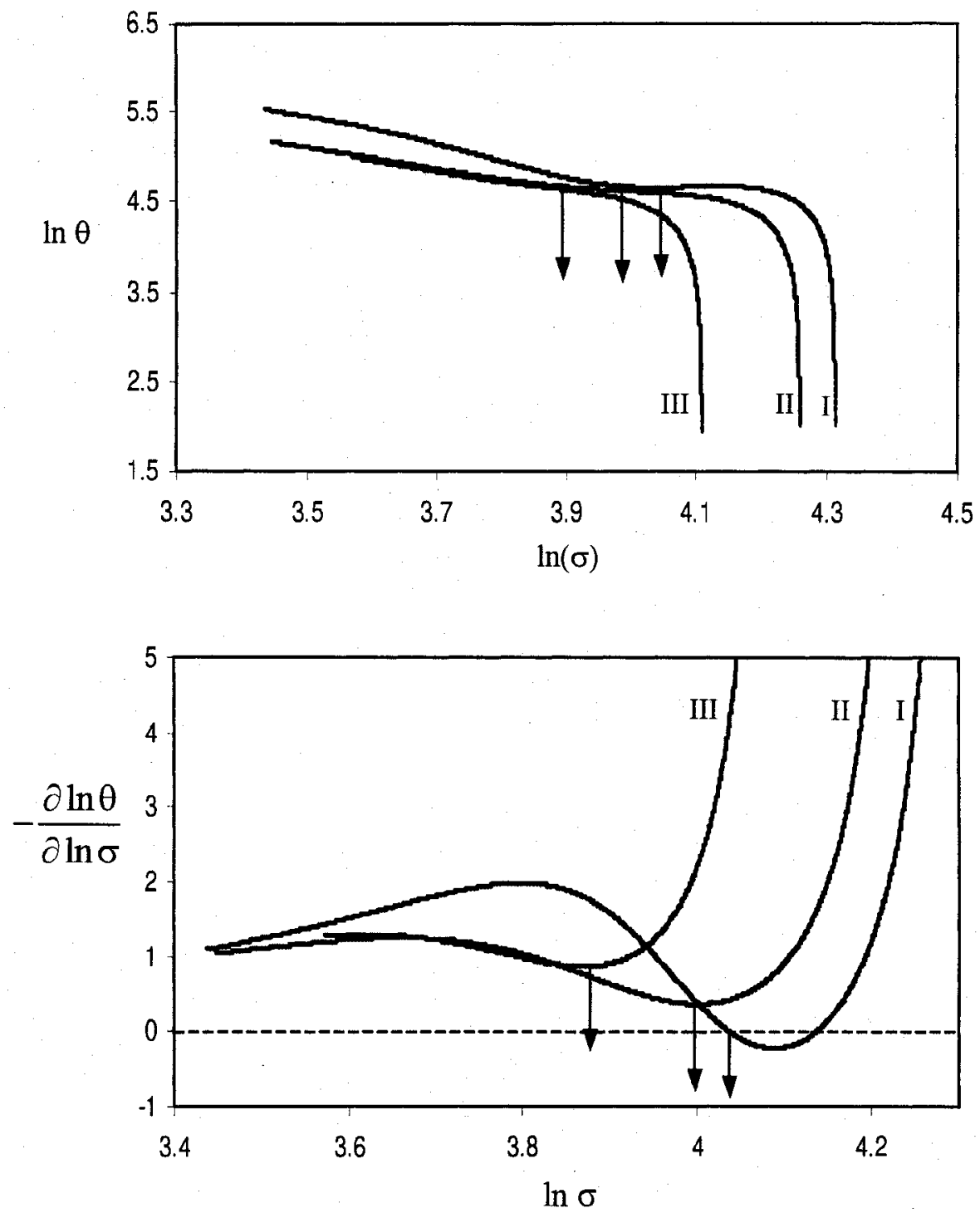

Figure 6.13. Determination of critical stress in the specimens of Figure 5.13. (I, II, and III correspond with the same specimens in Figure 5.13.)

As Figures 6.12 and 6.14 show, the critical stress and critical strain ratios, $\sigma_{d} / \sigma_{\mathrm{p}}$ and $\varepsilon_{\mathrm{d}} / \varepsilon_{\mathrm{p}}$, remain fairly constant at about 0.78 and 0.48 , respectively. These values are consistent with the values reported by Poliak and Jonas, as being 0.85 and 0.5 respectively, obtained in compression experiments for a Nb-containing steel. ${ }^{[176,177]}$ The small difference between the $\sigma_{\mathrm{d}} / \sigma_{\mathrm{p}}$ values may be partly attributed to the histories of the materials studied 

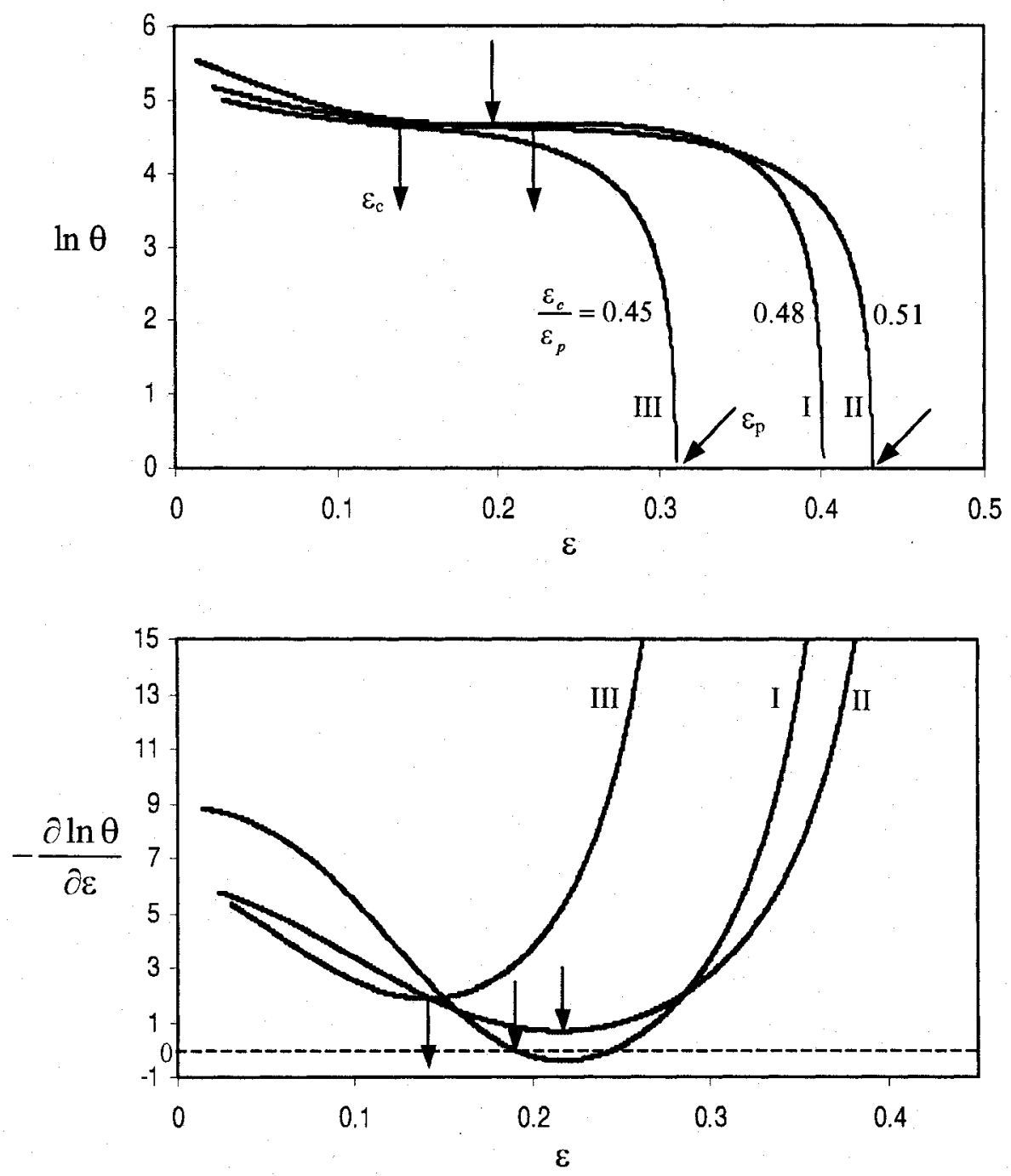

Figure 6.14. Determination of critical strain in the specimens of Figure 5.13. (I, II, and III correspond with the same specimens in Figure 5.13.)

in this work and theirs, i.e. as cast versus pre-heated specimens, respectively. The mode of deformation, i.e. tension versus compression, is unlikely to have any effect on the material flow behavior as long as the deformation is uniform. This applies to the absence of a dead zone and barreling during compression and the absence of necking and deformation localization during tension. Unfortunately, it is not presently possible to accurately distinguish if $\varepsilon_{\mathrm{p}}$ is attributed to dynamic recrystallization or the formation of pores and cracks in the examined specimens, i.e. specimens I III in Figure 5.13. 
It should be noted that there are striking qualitative similarities in the $\theta-\sigma$ behavior associated with dynamic recrystallization and that displayed when flow localization occurs in tension. The onset of both dynamic recrystallization and flow localization (necking) manifest themselves through the appearance of an inflection point in the $\theta-\sigma$ curve. Figure 6.15 shows the strain hardening behavior of the $\mathrm{Nb}$-steel and the B-steel under conditions that dynamic recrystallization did not take place. Nevertheless, both the $\theta-\sigma$ and $\ln \theta-\varepsilon$ curves exhibit inflection points. These inflections can be attributed to flow localization and/or grain boundary decohesion. Comparing the values of $\sigma_{\mathrm{c}} / \sigma_{\mathrm{p}}$ and $\varepsilon_{\mathrm{d}} / \varepsilon_{\mathrm{p}}$ in Figures 6.15(a) and (c) with those in Figures 6.12(a) and 6.14(a), it appears that $\sigma_{c}\left(\varepsilon_{c}\right)$ is closer to $\sigma_{\mathrm{p}}\left(\varepsilon_{\mathrm{p}}\right)$ in the case of flow instability and/or grain boundary decohesion (failure). Therefore, in tension, an inflection point being too close to the ultimate tensile strength most probably represents the onset of failure. As well, the peak strain corresponds to the strain at the ultimate tensile strength when there is a sharp decrease in stress after the peak, as shown in Figure 5.5. On the contrary, the peak strain is likely to be ascribed to dynamic recrystallization if the stress decreases slowly after the peak or there is another peak following the first one, situations similar to those illustrated in Figure 5.6 (specimen III) and Figure 5.1, respectively. Conclusively, these results show that, in order to verify the occurrence of dynamic recrystallization in tensile experiments, $\varepsilon_{d} / \varepsilon_{p}$ seems to be a reliable measure to begin with, i.e. $\varepsilon_{d} / \varepsilon_{p}>0.6$ is less likely to be attributed to dynamic recrystallization. Then, the microstructural examination should be performed to confirm the tensile strain hardening behavior. Figure 6.16 shows the strain hardening behavior of the B-steel in which a considerable amount of dynamic recrystallization occurred at the straightening stage (Figure 5.42). Even though, the values of $\sigma_{d} / \sigma_{p}$ and $\varepsilon_{d} \varepsilon_{p}$ are greater than those determined for the $\mathrm{Nb}$-steel in Figures 6.12 and $6.14, \varepsilon_{d} \varepsilon_{p}$ is less than 0.6 and in agreement with the suggested criterion for dynamic recrystallization in tension.

Assuming that the peak strains in Figure 6.14 are attributed to the dynamic recrystallization, the initial grain sizes of specimens I-III, Figure 5.13(b), can be calculated. Equation 6.10 explains the dependency of $\varepsilon_{\mathrm{p}}$ on the experimental conditions, 

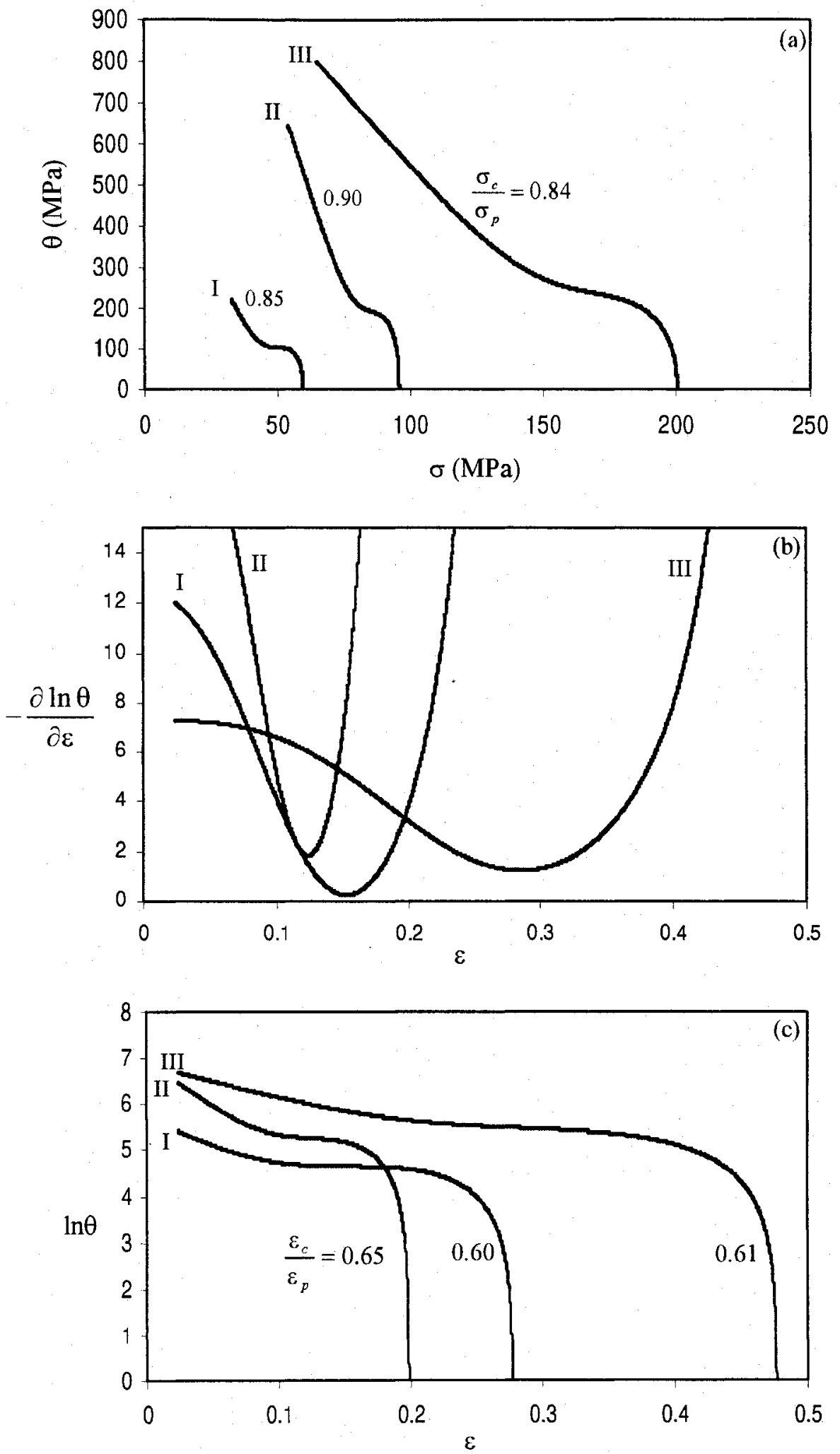

Figure 6.15. Strain hardening behavior of (I): the $\mathrm{Nb}$-steel in Figure 5.5, (II): the $\mathrm{Nb}$-steel fractured at $800^{\circ} \mathrm{C}$ in Figure $5.7(\mathrm{~b})$, and (III): the B-steel fractured at $700^{\circ} \mathrm{C}$ in Figure $5.7(\mathrm{a})$. (Absence of dynamic recrystallization) 

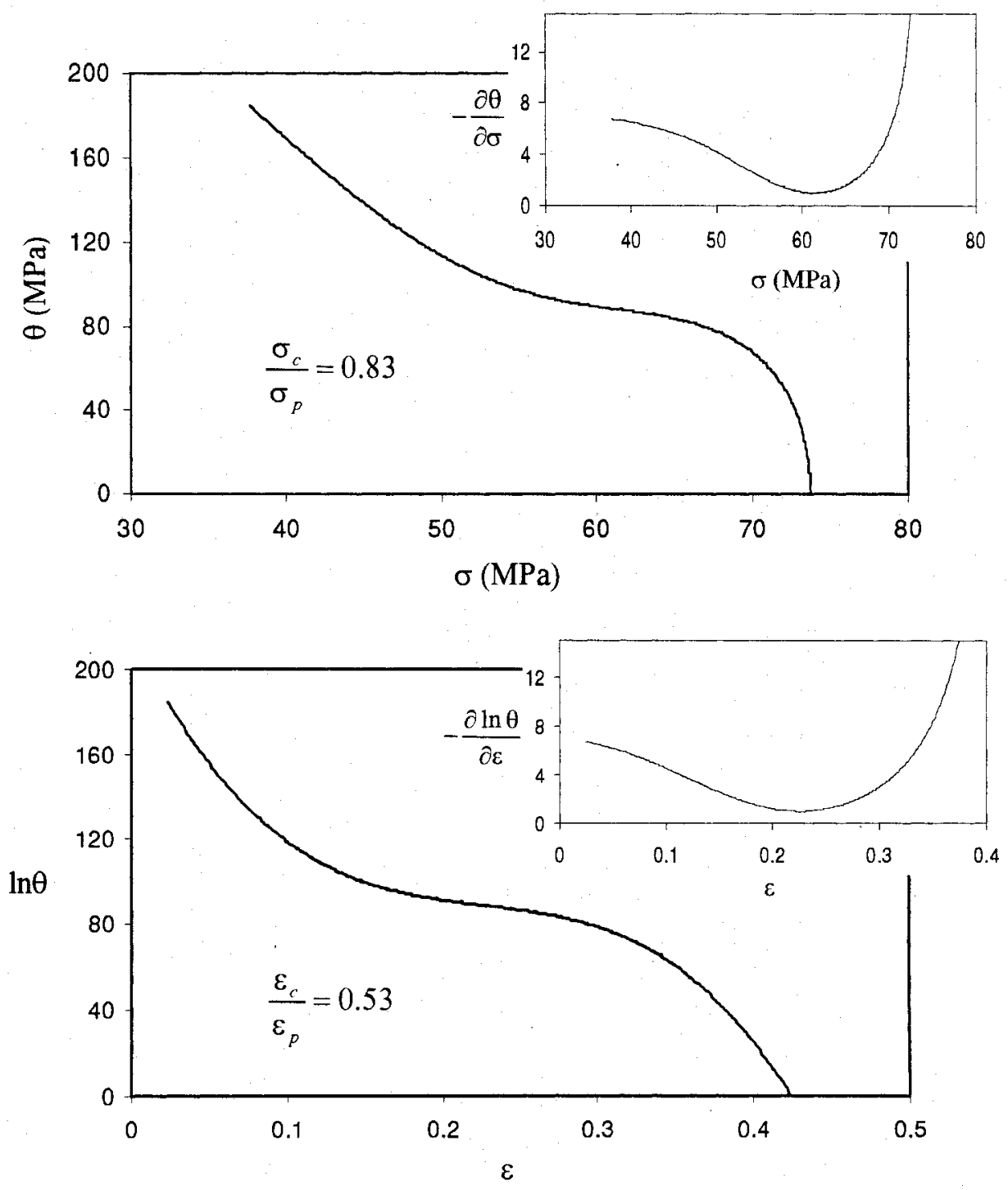

Figure 6.16. Strain hardening behavior of the B-steel after pre-compression in the $\delta \rightarrow \gamma$ transformation region, corresponding with specimen III in Figure 5.11(b).

i.e. strain rate and temperature. Since both the strain rate and temperature were constant at the straightening stage, hence, the initial grain size was the only parameter varying among the specimens. It was found that, in a microalloyed steel containing $0.03 \mathrm{wt} \% \mathrm{Nb}, \varepsilon_{\mathrm{p}}$ can be approximated as ${ }^{[139,140]}$ 


$$
\varepsilon_{p}=5.8 \times 10^{-4} d_{0}^{0.5} Z^{0.16}
$$

In addition, in a series of steels in which dynamic recrystallization was studied, it was found that the activation energy of deformation is approximated as ${ }^{[140]}$

$$
\begin{aligned}
Q_{d e f}= & 297+641[\% \mathrm{Nb}]+123[\% \mathrm{Mo}]+[\% \mathrm{Ni}] \\
& -111[\% \mathrm{Cr}] \quad(\mathrm{kJ} / \mathrm{mol})
\end{aligned}
$$

With regard to the $\mathrm{Nb}$-steel chemistry, $Q_{\text {def }}$ is calculated to be $313 \mathrm{~kJ} / \mathrm{mol}$, which is very close to the value $(319 \mathrm{~kJ} / \mathrm{mol})$ reported by Poliak and Jonas for a Nb-bearing low carbon steel that showed dynamic recrystallization. ${ }^{[176]}$ Therefore, using equation $6.2, Z$ at the straightening stage is $2 \times 10^{10} \mathrm{~s}^{-1}$ and the initial grain size can be easily approximated. The results are summarized in Table 6.3. The smaller average initial grain size calculated for specimen III, which was pre-compressed at $\dot{\varepsilon}=3 \times 10^{-3} s^{-1}$ during the $\delta \rightarrow \gamma$ transformation, than the average grain size in Figure 5.43(b), i.e. $\sim 220 \mu \mathrm{m}$, is partly attributed to the errors included in the calculation of the activation energy. This difference may also imply that the real $\varepsilon_{\mathrm{p}}$ is greater than the peak strain specified in Figure 6.14, i.e. the ultimate tensile strength peak preceded the recrystallization peak. Furthermore, it should be indicated that all these models have been developed for re-heated structures and not for as cast structures. The significant differences between as cast and re-heated structures have been already discussed and, in particular, it was mentioned how the as cast structure affects dynamic recrystallization. This is a subject that needs to be studied in detail.

Table 6.3. Dynamic recrystallization parameters for the specimens in Figure 5.13(b).

\begin{tabular}{|c|c|c|c|c|c|c|c|}
\hline specimen & $\sigma_{\mathrm{c}}(\mathrm{MPa})$ & $\varepsilon_{\mathrm{c}}$ & $\sigma_{\mathrm{p}}(\mathrm{MPa})$ & $\varepsilon_{\mathrm{p}}$ & $\sigma_{\mathrm{c}} / \sigma_{\mathrm{p}}$ & $\varepsilon_{\mathrm{c}} / \varepsilon_{\mathrm{p}}$ & $\mathrm{d}_{0}(\mu \mathrm{m})$ \\
\hline I & 58 & 0.19 & 74 & 0.4 & 0.78 & 0.48 & 240 \\
\hline II & 55 & 0.22 & 71 & 0.43 & 0.77 & 0.51 & 277 \\
\hline III & 48 & 0.14 & 61 & 0.31 & 0.79 & 0.45 & 144 \\
\hline
\end{tabular}

As a conclusion, dynamic recrystallization at the straightening stage is taken as the reason for the improvement of hot ductility. The onset of recrystallization was also verified by 
the 'one-parameter approach'. Comparing Figures 5.43(a) and (b), it is obvious that the pre-deformation during the $\delta \rightarrow \gamma$ transformation has led to a grain refinement and, subsequently, the finer grain microstructure at the straightening stage has encouraged dynamic recrystallization. Such grain refinement could have occurred either by the accelerated $\delta \rightarrow \gamma$ transformation or the static/dynamic recrystallization of austenite after completion of the $\delta \rightarrow \gamma$ transformation. Or, both mechanisms, i.e. dynamic transformation and recrystallization, might have participated in the grain refinement process so that the latter followed the former.

Considering the RA values in Table 5.4 and comparing specimens I and II in Figure 5.12, which were respectively pre-compressed in the $\delta$-ferrite and the $\delta \rightarrow \gamma$ transformation regions, there is an improvement in the hot ductility from 13 to $27 \%$ when the predeformation goes through the transformation region. In addition, no further improvement occurs due to extension of the pre-deformation, up to 0.08 true strain, after completion of the transformation. Hence, it appears that $13 \%(28-15)$ is the maximum improvement attainable solely by the accelerated transformation. This also agrees with the microstructure shown in Figure 5.37, where there is a grain refinement owing to the predeformation applied during the transformation. On the other hand, pre-deformation after the transformation resulted in only 8\% (23-15) improvement in the hot ductility, specimen $\mathrm{V}$ in Figure 5.12. Considering the grain size, this improvement in the hot ductility can be attributed to the elimination of solidification shrinkages by compression Then, the sum of improvements due to the pre-deformation during the transformation and the predeformation after the transformation is $21 \%$, provided these two pre-deformation schedules have been applied separately to two different specimens. This is less than at least $26 \%$ (41-15) improvement in the hot ductility after the application of 0.1 true strain continuous pre-deformation, started before and continued after the transformation (specimen III in Figure 5.13). Consequently, the synergistic effect of the accelerated transformation and (dynamic) recrystallization after the transformation has led to such improvement. In other words, the accelerated transformation generated smaller austenite grains whose sizes were further decreased by the subsequent recrystallization. Even though dynamic recrystallization has invariably played the major role in the second stage 
of the grain refinement process, the possible contribution of metadynamic/static recrystallization cannot be ruled out, especially since the temperature was high enough to provide the necessary activation energy. The very small grains in Figure 5.43(b) can be ascribed to this phenomenon.

Accordingly, more deformation applied after the transformation would produce smaller grains by increasing the nucleation sites for recrystallization grains. This explains the different initial grain sizes approximated in Table 6.3, where specimen III tolerated the greatest amount of pre-deformation after completion of the transformation. Moreover, the effect of the transformation rate explained in Figure 6.1 should also be taken into account. In this respect, specimens I and II appear almost identical as there is technically little difference between their initial mean grain sizes, as compared to that of specimen III, which experienced the fastest rate of $\delta \rightarrow \gamma$ transformation. However, a larger initial grain size was expected in specimen I than in specimen II since, in the former, not only the strength transition during the $\delta \rightarrow \gamma$ transformation proceeded at a slower rate, Figure 6.1, but also there was almost no deformation imposed after completion of the transformation.

Furthermore, despite the larger initial grain size, specimen II had a somewhat higher ductility than specimen III. Since there is no microstructural information to explain this, there may be another phenomenon stimulated by the pre-deformation in the proximity of the transformation region. An alteration in the segregation pattern could be a possible explanation since grain boundary migration occurs. As far as $\mathrm{Nb}$ and $\mathrm{Ti}$ are concerned, it has been shown that the $\delta \rightarrow \gamma$ transformation does not change the segregation patterns during cooling after solidification. ${ }^{[179]}$ Nonetheless, the idea of segregation alteration may not be yet ruled out. This may seem reasonable since not only the transformation was assisted by deformation, i.e. less activation energy was required for the transformation, and there were two successive grain boundary migration processes, i.e. dynamic transformation and recrystallization, but also the temperature was very high providing high diffusion rates. Hence, the grain boundary might have been stronger owing to fewer detrimental precipitates and decreased level of segregation. As well, the higher strain rate, especially in the $\delta$-ferrite region, could lead to the closure of solidification cavities. Based 
on this, larger amounts of pre-deformation applied during and after completion of the transformation corresponds with higher hot ductility at the straightening stage. On the other hand, considering the bulging and buckling of specimen during compression, there is a practical limit for the amount of pre-compression. Therefore, there seem to be optimum amounts of pre-compression, applied during and after completion of the transformation, which leads to the highest hot ductility without affecting the shape uniformity of specimen. Note that bulging along the gauge length can cause the tensile deformation at the straightening stage to be concentrated outside the region that has tolerated the pre-compression. Also, the tensile deformation is not uniform if the specimen is buckled. Among the experimented specimens, specimen II that was subjected to the pre-compression at $\dot{\varepsilon}=9 \times 10^{-3} \mathrm{~s}^{-1}$, Figure 5.13 , represents the optimum condition of pre-compression.

If large amounts of pre-deformation can be applied after the $\delta \rightarrow \gamma$ transformation with no limitation, i.e. no problem of bulging and buckling, the rate of pre-deformation should be designed with regard to $Z$ values since this parameter determines if dynamic recrystallization results in grain refinement or grain coarsening at the steady state. ${ }^{[126]}$ Dynamic recrystallization at low $Z$ values would coarsen grains whereas it leads to smaller grains at high $Z$ values. Such a phenomenon also depends on the initial grain size. Hence, the resultant grain size from the dynamic transformation should first be determined. Then, according to the $Z-d_{0}$ graph corresponding to the $\mathrm{Nb}$-containing steel, the minimum strain rate leading to grain refinement in the vicinity of $1300^{\circ} \mathrm{C}$ can be specified. A typical Z-do graph is shown in Figure 6.17.

Unfortunately, information on the metallurgical phenomena taking place in the proximity of the $\delta \rightarrow \gamma$ transformation region is very limited, and based on this inadequate knowledge, some of the aforementioned hypotheses are difficult to be verified. In order to study the segregation patterns, specimens are required to be quenched very fast in the vicinity of the $\delta \rightarrow \gamma$ transformation region and atomic distributions must be studied from the grain interior to the grain boundary. Accomplishing this objective demands special 


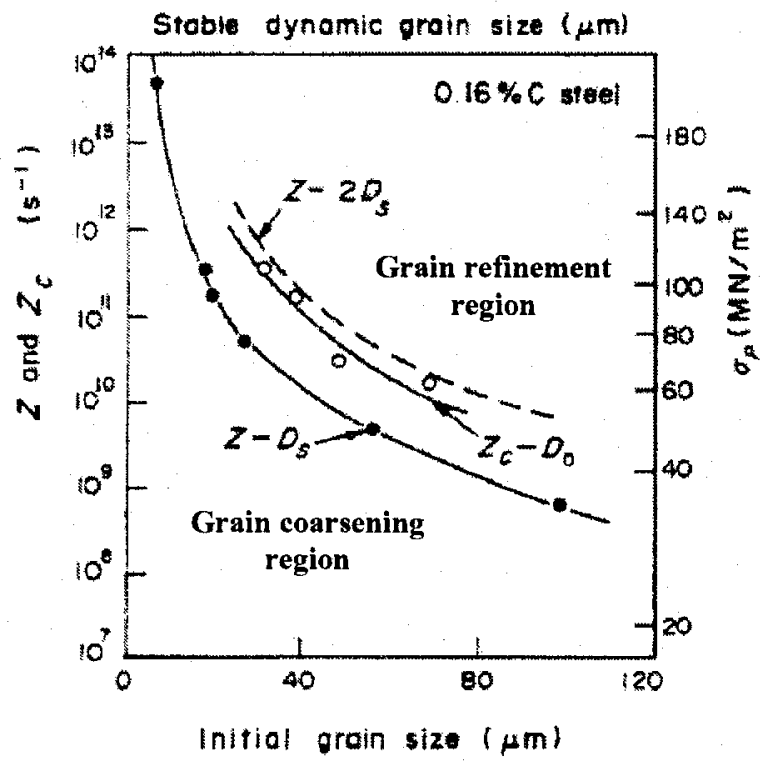

Figure 6.17. Dependence of $Z$ on initial grain size in a $0.16 \% \mathrm{C}$ steel. ${ }^{[126]}$

experimental apparatus that provide very fast quenching on the deformation machine. Also, some quenched specimens are required to be fractured intergranularly and the segregation be studied at the grain boundary using Auger electron microscopy. In order to most utilize dynamic recrystallization, its kinetics need to be studied at very high temperatures after the $\delta \rightarrow \gamma$ transformation.

Pre-compression during the $\delta \rightarrow \gamma$ transformation gave rise to similar behavior in the Bsteel, resulting in a smaller austenite grain size. This reduced the critical strain for dynamic recrystallization and led to a smaller recrystallized grain size at the straightening stage, Figure 5.42. Figure 5.42(b) displays some lines oriented in a direction nearly parallel to the tension. Looking meticulously at these lines, it can be seen that they have formed perpendicular to each other in some region. Hence, they are unlikely to be prior austenite grain boundaries since such orthogonal configuration for grain boundaries is not favorable energetically. On the other hand, they are too close to each other to have formed as cast grain boundaries. Examination in the FEGSEM, Figures 5.42(d) and (e), revealed that these lines are appeared to be the base of steps formed within grains, most probably due to the bainite transformation. Small voids at grain boundaries shown in Figures 
5.42(c) and (d) are attributed to the accommodation of grain boundary sliding after saturation of deformation in grain interiors.

\subsubsection{Effect of Cyclic Deformation after Pre-deformation in $\delta \rightarrow \gamma$ Transformation Region}

Since the grain refinement due to the pre-deformation incorporated with the $\delta \rightarrow \gamma$ transformation improved the hot ductility, it was reasonable to anticipate more improvement with increasing grain refinement. For this, the pre-compression during the transformation was followed by a cyclic deformation, as illustrated in Figure 5.14. The purpose of applying such cyclic deformation was to accumulate the strain in order to stimulate recrystallization. Nevertheless, no improvement more than that achieved solely by the pre-compression during the transformation was attained, Table 5.4. Both Figures 5.14(b) and (c) display dynamic softening that is more evident in the compression cycles (leveled plastic region). The compression cycles in Figure 5.14(c) also demonstrate stress peaks. At the first glance, these peaks encourage the idea of dynamic recrystallization that had to be initiated at a strain well before the peak strain. Since this strain is relatively small and no peak is evident in the tension cycle, such a drop in stress is most probably because of the specimen buckling during the compression. This was partly confirmed by visual observations during the experiment. In addition, there is no stress peak around $1200^{\circ} \mathrm{C}$ where the specimen was less susceptible to buckling, Figure 5.14(b). The critical strain at $1100^{\circ} \mathrm{C}$ will be discussed later in this section. The softening has also appeared as lower yield point in the following tensile half-cycles. Nevertheless, the Bauschinger effect should also be taken into account. As well, it should be denoted that reversal deformation can delay dynamic recrystallization. ${ }^{[180]}$ Therefore, the amount of strain required to initiate dynamic recrystallization during cyclic deformation is larger than that required during monotonic deformation.

There is a possibility that the cyclic deformation applied around $1200^{\circ} \mathrm{C}$ has produced some defects such as cavities and cracks at grain boundaries. Such defects could have contributed to the low hot ductility at $1200^{\circ} \mathrm{C}$, i.e. at the beginning of the last step of the 
thermal schedule, where the RA was only 17\% (Figure 6.18). This implies that tension is deleterious at this stage of the thermal schedule. The fracture surface shown in Figure 6.18(b) indicates that the loss of hot ductility here is due to the same reason as explained in section 6.3.1, i.e. grain boundary separation due to grain boundary fusion. However, the value of RA found here is higher than that calculated for the specimen tested at $1200^{\circ} \mathrm{C}$ at the straightening stage of the thermal schedule, Figure 5.15. This means that the steel is more embrittled during the last thermal regime of the thermal schedule, possibly because of the grain growth occurred in the course of 14 minutes holding to the straightening stage.
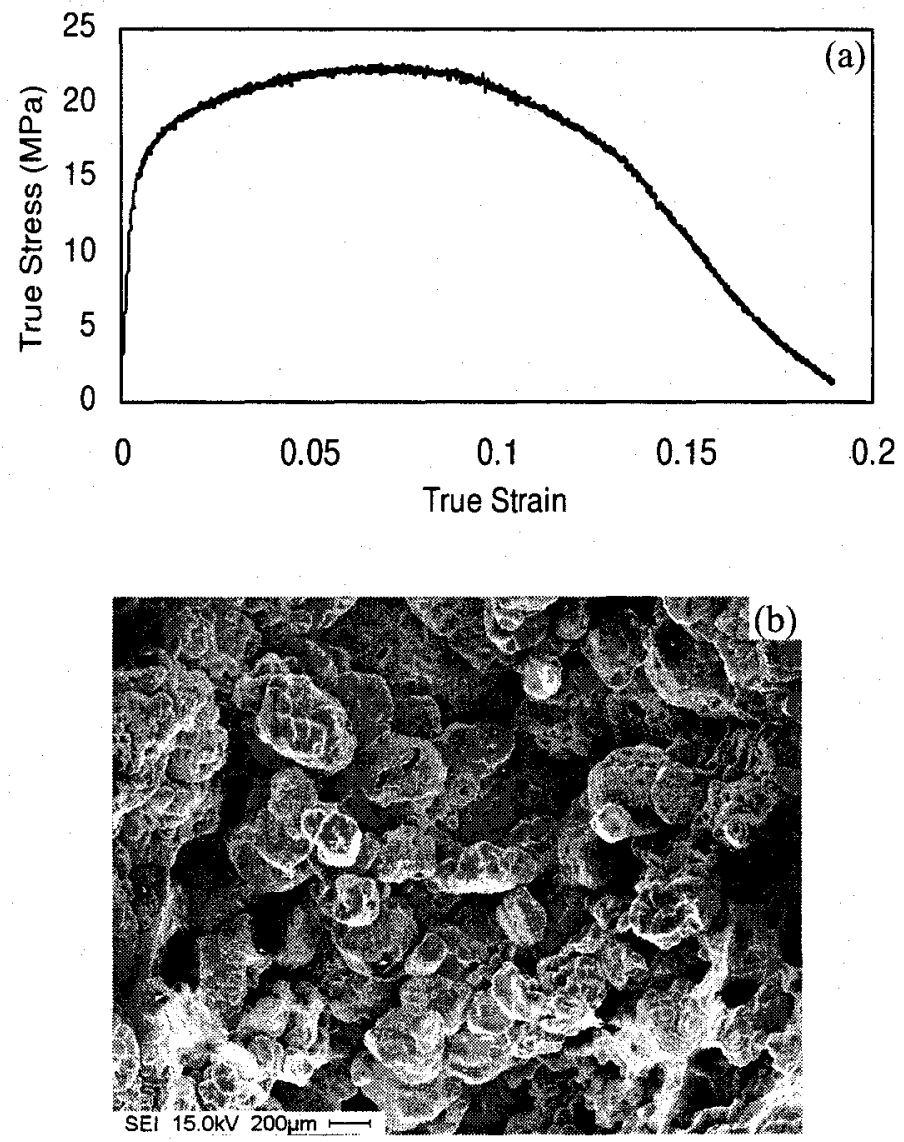

Figure 6.18. Isothermal tensile test at $1200^{\circ} \mathrm{C}$, the beginning of the last step on the thermal schedule. (Nb-steel) 
The $\mathrm{Nb}$-steel appeared embrittled at $1200^{\circ} \mathrm{C}$ and the same is expected in the B-steel according to Figure 5.15. In spite of this, Fujita et al. ${ }^{[138]}$ recently showed the occurrence of dynamic recrystallization, leading to a good ductility, at $1250^{\circ} \mathrm{C}$ in an as cast C-Mn$0.018 \% \mathrm{Ti}$ steel cooled slowly $(0.4 \mathrm{~K} / \mathrm{s})$ to the test temperature. This discrepancy can be attributed to the chemical composition, especially the difference in $\mathrm{Nb}$ and $\mathrm{Ti}$, as well as the thermal schedule that was employed in this work and was incorporated with a much faster cooling rate $(10 \mathrm{~K} / \mathrm{s})$ after melting. First of all, $\mathrm{Ti}$ is beneficial to the hot ductility since it scavenges nitrogen. ${ }^{[81]}$ Secondly, fast cooling rates lead to the hot ductility deterioration through encouraging finer $\mathrm{TiN}, \mathrm{Nb}(\mathrm{CN})$, and $\mathrm{AIN}$. precipitates ${ }^{[23,79]}$ and precipitation of low-melting liquid FeS films at grain boundaries in lieu of $\mathrm{MnS} .^{[163]}$ Thirdly, the temperature oscillation in the thermal schedule is likely to deteriorate the hot ductility by enhancing $\mathrm{NbCN}$ precipitation and, consequently, retarding dynamic recrystallization. ${ }^{[84]}$ Finally, it has been shown that columnar grains are detrimental to the hot ductility. ${ }^{[63]}$ This kind of grain was observed in both the $\mathrm{Nb}$-steel and the B-steel (Figure 5.34, for instance). However, no such grains were observed in the microstructure presented by Fujita et al., mainly because of the much slower cooling rate they employed during the solidification. Therefore, it is not surprising that the hot ductility in the Nbsteel remains low at $1200^{\circ} \mathrm{C}$ as it has been subjected to a much faster cooling rate and temperature oscillation before reaching the test temperature.

Mode of deformation should also be taken into account. In other words, dynamic recrystallization in the specimen of Figure 6.18 is expected to occur provided it is deformed in compression all the way. Consequently, the absence of dynamic recrystallization during the cyclic deformation is because the tensile half-cycle created cracks at grain boundaries. These cracks propagated upon further straining and this inhibited the strain accumulation in grain interiors, which provides the necessary driving force for dynamic recrystallization. On the contrary, the strain was expected to be accumulated in tension at $1100^{\circ} \mathrm{C}$ since the microstructure at this temperature has already shown the occurrence of dynamic recrystallization at the straightening stage, Figure 5.26(e). Therefore, more grain refinement and, consequently, higher hot ductility was anticipated in the specimen subjected to the cyclic deformation in the vicinity of $1100^{\circ} \mathrm{C}$, 
Figure 5.14(c), following the pre-compression during the transformation. However, this did not happen, Table 5.4. Then, the question is whether the cyclic deformation triggered dynamic recrystallization in the vicinity of $1100^{\circ} \mathrm{C}$.

Using equation 6.24 , it was calculated that the critical strain at $1100^{\circ} \mathrm{C}$ and $\dot{\varepsilon}=3 \times 10^{-3} \mathrm{~s}^{-1}$ in the specimen pre-deformed during the transformation, i.e. $d_{0}=220 \mu \mathrm{m}$, is about 0.12 . In this calculation, the conversion ratio of $\frac{\varepsilon_{c}}{\varepsilon_{p}}=0.48$ was used. This critical strain is greater than the 0.1 strain corresponding to each half-cycle in Figure 5.14(c). On the other hand, the reversing nature of deformation prevents complete accumulation of strain from one half-cycle to the other half and it also helps dislocation annihilation at high temperatures. Accordingly, for a given amount of strain, the dislocation density would be less in reversal deformation than monotonic deformation. As a result, one may say that dynamic recrystallization was barely triggered during the cyclic deformation and there was no further grain refinement during these cycles. Hence, there was no further improvement in the hot ductility.

In the absence of pre-deformation during the transformation, the critical strain at $1100^{\circ} \mathrm{C}$ and $\dot{\varepsilon}=5 \times 10^{-3} \mathrm{~s}^{-1}$, i.e. the straightening stage, is determined to be 0.18 , using the 'oneparameter approach'. This is shown in Figure 6.19. Based on this, the strategy to achieve the highest possible hot ductility at the straightening temperature of $1020^{\circ} \mathrm{C}$ in the $\mathrm{Nb}$ steel involves a pre-compression in the proximity of the $\delta \rightarrow \gamma$ transformation region followed by another compression in the proximity of $1100^{\circ} \mathrm{C}$ over the last step of the thermal schedule. The main purpose of the first pre-compression is to reduce the critical strain in order for dynamic recrystallization to commence at lower strain than 0.18 during the second compression. For the second compression, $Z$ at $\dot{\varepsilon}=3 \times 10^{-3} \mathrm{~s}^{-1}$ and $\mathrm{T}=1100^{\circ} \mathrm{C}$ is calculated to be $2 \times 10^{9} \mathrm{~s}^{-1}$ (equation 6.2). There was a grain refinement at the straightening stage for both conditions of $Z=2 \times 10^{10} \mathrm{~s}^{-1}$ and $d_{0} \approx 220 \mu \mathrm{m}$ (Figure 5.41(a)) as well as $Z=4.14 \times 10^{9} \mathrm{~s}^{-1}$ and $d_{0} \approx 586 \mu \mathrm{m}$ (Figure 5.26(e)). Moreover, it was found that the steady state grain size is about $50 \mu \mathrm{m}$ for $Z=5 \times 10^{10} \mathrm{~s}^{-1}$ in a Nb-containing steel. ${ }^{[126]}$ Based 
on this information and the typical $Z-D_{s}$ profile shown in Figure 6.17, a $Z-D_{s}$ plot for the $\mathrm{Nb}$-steel would resemble the graph shown in Figure 6.20. Therefore, the $\mathrm{Nb}$-steel was most probably in the grain refinement region for the condition of $Z=2 \times 10^{9} \mathrm{~s}^{-1}$ and $d_{0} \approx 220$ $\mu \mathrm{m}$ (Figure 5.14(c)). This condition is identified by ' $x$ ' in Figure 6.20. Such grain refinement can be definitely attained if $Z$ is increased to $2 \times 10^{10} \mathrm{~s}^{-1}$ or more, i.e. increasing the strain rate. Even though both compression and tension would behave in this manner, tension should be avoided since it is likely to produce grain boundary microvoids and microcracks. This is why compression is advantageous over tension.
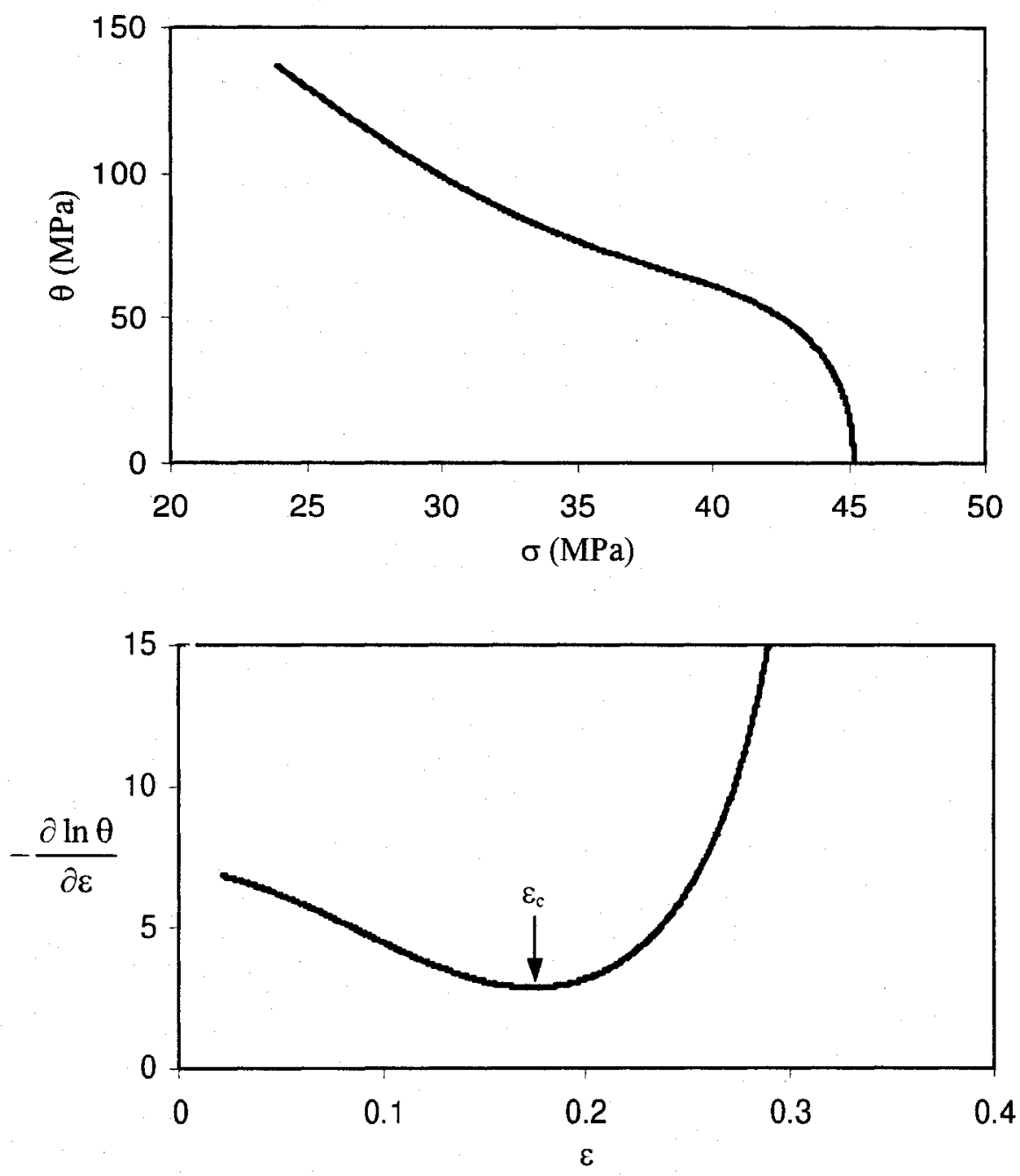

Figure 6.19. Determination of the critical strain in the specimen fractured at $1100^{\circ} \mathrm{C}$, Figure $5.7(\mathrm{~b})$. 


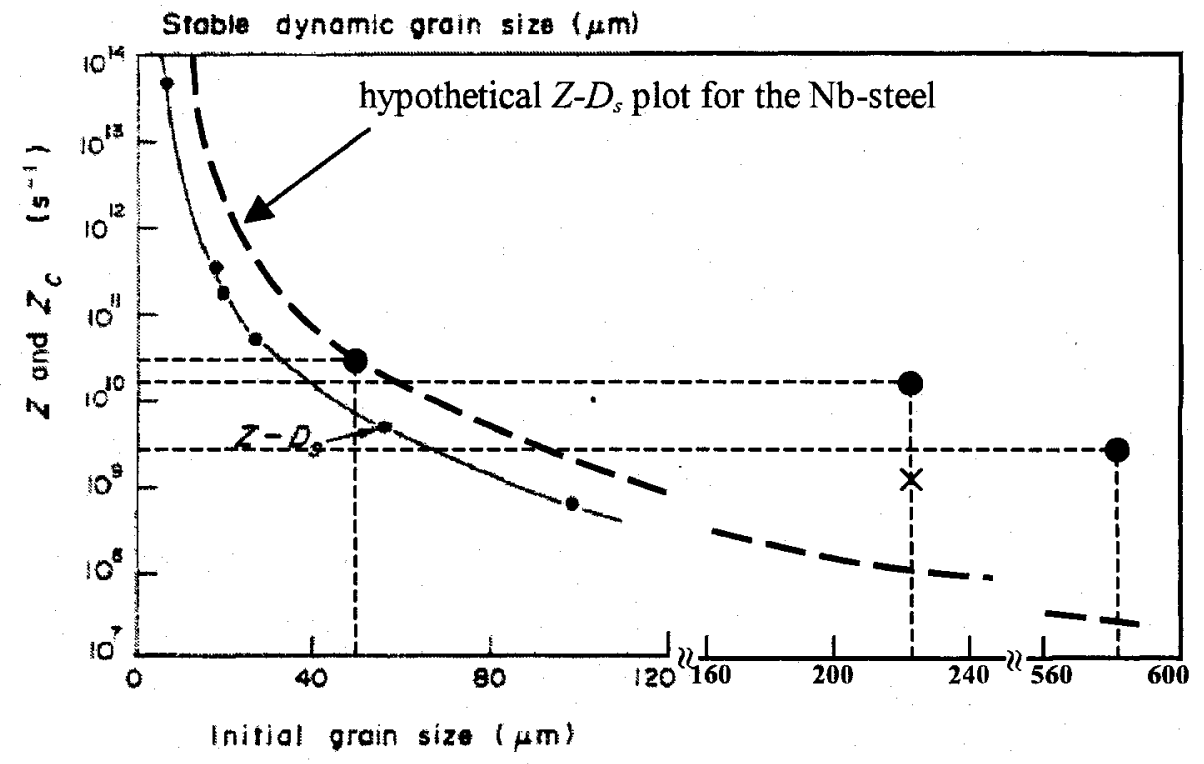

Figure 6.20. $Z-D_{s}$ plot anticipated for the $\mathrm{Nb}$-steel. 


\section{CONCLUSIONS}

The strength transition during the $\delta \rightarrow \gamma$ transformation in a CCC experiment is a strain rate dependent phenomenon. The higher the strain rate, the lower the transition rate.

Grain boundary sliding is the embrittling mechanism in all three steels studied in this work. The reason for this is the resistance of the austenite lattice to plastic flow and, hence, grain boundary sliding is accommodated by the nucleation of cavities at grain boundaries. Such resistance can be attributed to the retardation of dislocation movement mainly by $\mathrm{Nb}$ in the form of precipitates and solutes as well as flow saturation. The former seemed more significant in the Nb-steel and the latter in the B-steel.

The thermal history undergone by a steel before the straightening operation has a major effect on the hot ductility. Comparing the results of this work with previous ones, it appears that the thermal schedule employed in this work for the Nb-steel has a deleterious effect on the hot ductility. (With regard to the cooling rate and temperature oscillation, for instance.)

The addition of boron to the Nb-containing steel improves the hot ductility significantly. This is attributed to either the higher strength ratio of grain 
boundary/grain interior in the B-steel than in the $\mathrm{Nb}$-steel, or easier plastic flow in the grain interior in the B-steel, or both of these. In any case, austenite grains are much more deformed plastically in the B-steel than in the Nb-steel. This beneficial effect of $\mathrm{B}$ in a $\mathrm{Nb}$-containing steel can be considered from two points of view. (i) Enhancement of the nucleation and growth of precipitates that leads to the depletion of carbonitride precipitants in the lattice, and (ii) the depletion of strengthening elements, especially $\mathrm{Nb}$, in the lattice owing to the non-equilibrium co-segregation of $\mathrm{B}$ and $\mathrm{Nb}$ to the grain boundaries. The strengthening effect of segregated $\mathrm{B}$ to grain boundaries is also a factor in both of these scenarios.

In both the $\mathrm{Nb}$-steel and the $\mathrm{B}$-steel, dynamic recrystallization counteracts grain boundary sliding and leads to hot ductility enhancement. However, there is a temperature specific to each grade above which the hot ductility decreases rapidly due to grain boundary melting. Such a deterioration in the hot ductility was observed in specimens subjected to the thermal schedule, in contrast to the conventional hot ductility experiments, i.e. cooling specimens to the test temperature at $1^{\circ} \mathrm{C} / \mathrm{s}$ after melting, which showed continuous improvement in the hot ductility as the temperature increased.

Incorporation of any deformation during the solidification of steel seriously deteriorates the hot ductility. Although both compression and tension have similar effects, tension is more detrimental. This is attributed to an alteration of the segregation patterns and the weakening of the grain boundaries. The deterioration increases with both the amount of deformation and the deformation start temperature.

Melting in situ has a very significant effect on the hot ductility. In the Nb-steel heated up to $1400{ }^{\circ} \mathrm{C}$ and then subjected to the thermal schedule, the hot ductility was found to be $100 \% \mathrm{RA}$, versus $15 \% \mathrm{RA}$ in the in situ melted specimen. Deformation did not influence the hot ductility of the former.

Since deformation during solidification affects the hot ductility and it is occurring in the mill, any attempt to simulate the straightening operation in the laboratory should 
consider not only in situ melting and the thermal schedule, but also deformation. In this way, the experimental conditions would be closer to those of the industrial process and the results would be more directly applicable to the mill.

$>\quad$ The effect of deformation in the $\delta$-ferrite region on the hot ductility is moderately pronounced and it can be deleterious or beneficial. If deformation fractures the freshly solidified region at the grain boundaries, the hot ductility is slightly deteriorated. If there is no crack at the grain boundaries, the closure of solidification shrinkages under compression can lead to slight improvements in the hot ductility.

Deformation incorporated with the $\delta \rightarrow \gamma$ transformation improves the hot ductility through accelerating the transformation. This leads to smaller grains at the straightening stage.

Deformation after the completion of transformation has a beneficial effect on the hot ductility. This is attributed to dynamic and possibly metadynamic recrystallization in the austenite.

The highest hot ductility can be achieved when deformation during the $\delta \rightarrow \gamma$ transformation is followed by deformation of the austenite. In this way, the beneficial effects of deformations during and after completion of the $\delta \rightarrow \gamma$ transformation are synergized and the hot ductility is significantly improved.

Considering the amount of deformation required to activate mechanisms by which the hot ductility is improved as well as the experimental limitations due to bulging and buckling of the specimen, there is an optimum condition that leads to the highest improvement in the hot ductility. There is also an optimum deformation rate.

Applying cyclic deformation over the last stage of the thermal schedule to a specimen that has already undergone a deformation in the proximity of the $\delta \rightarrow \gamma$ transformation region did not influence the hot ductility. This corresponds with $10 \%$ 
tension or compression during each half-cycle. Nevertheless, the application of higher amounts of deformation is expected to improve the hot ductility.

$>$ A suggested approach to achieve the highest possible hot ductility in the $\mathrm{Nb}$-steel at the straightening stage involves a compression in the vicinity of the $\delta \rightarrow \gamma$ transformation followed by another compression in the vicinity of $1100{ }^{\circ} \mathrm{C}$ over the last stage of the thermal schedule.

$>\quad$ Neither the $\mathrm{Nb}$-steel nor the B-steel revealed a peak stress, which would have been indicative of dynamic recrystallization. This can be attributed to the presence of $\mathrm{Nb}$ that prevents the drop in flow stress.

The occurrence of dynamic recrystallization in the $\mathrm{Nb}$-steel was confirmed by using the concept of the thermodynamics of irreversible processes, the 'one-parameter approach', in tension. This was also supported by observing the recrystallized microstructure. However, this approach should be used with caution in the vicinity of flow localization and in materials in which grain boundary decohesion is the mechanism of fracture. These phenomena can affect the strain hardening behavior. In this respect, it is suggested that for $\varepsilon_{d} \varepsilon_{p}>0.6$ dynamic recrystallization is less likely to be taking place. 


\section{RECOMMENDATIONS FOR FUTURE WORK}

Even though the hot ductility of steel, with relevance to the continuous casting process, has been studied for more than three decades, the results of this work highlight some new issues.

Deformation during the $\delta \rightarrow \gamma$ transformation appeared to influence the transformation kinetics and, consequently, the hot ductility. Since dynamic recovery in $\delta$-ferrite is the dominant mechanism of softening and it is very fast at high temperatures, it can be argued that the dislocation density would not increase that much to encourage a deformation-induced transformation. However, the grain refinement suggests accelerated transformation. Therefore, the mechanism of transformation under deformation needs to be clarified.

It was noticed that a fibrous structure formed at grain boundaries during cooling after melting. This was observed in both the Nb-steel and the B-steel. Such a structure may affect the grain boundary strength and fracture characteristics. The mechanism of the formation of these fibers at grain boundaries has yet to be defined.

It has been shown that segregation patterns do not change during the $\delta \rightarrow \gamma$ transformation. However, according to the findings in this work, it is reasonable to consider that faster kinetics of the transformation due to the deformation may affect segregation patterns, especially at grain boundaries. In order to study this, specimens must be quenched after completion of the transformation in two cases; (i) transformation incorporated with deformation, and (ii) transformation without deformation. Then, segregations at grain boundaries, especially for $\mathrm{Nb}$ and $\mathrm{Ti}$, should be studied using Auger electron microscopy, for instance.

Some speculations were proposed regarding the beneficial effect of boron on the hot ductility of the Nb-containing steel. These speculations need to be verified. The LEAP technique is suggested for this purpose. 
All studies regarding recrystallization have been performed on re-heated structures. The results of this work clearly show how the mechanical characteristics of the as cast structure differ from those of the reheated structure. Accordingly, the recrystallization parameters can be affected. The 'one-parameter approach' was employed for the first time in tension for the as cast structure and the results agreed with the microstructure. Nevertheless, the grain size calculated using the models based on the re-heated structure do not fully comply with the results of the as cast structures. Therefore, recrystallization parameters are required to be studied in as cast structure as well. The most important area may be the effect of deformation during the $\delta \rightarrow \gamma$ transformation on the metallurgical characteristics, i.e. the recrystallization and precipitation kinetics, at and after the straightening stage. This is very significant since the mechanical characteristics after the straightening stage are influenced by the straightening deformation and, in turn, these characteristics at the straightening stage are affected by the deformation during the $\delta \rightarrow \gamma$ transformation. Hence, there is a successive development of the properties and these properties can be designed at the beginning of the continuous casting of steel. This will be even more important once hot charging is replaced by direct rolling.

The grain refining mechanisms in the vicinity of the $\delta \rightarrow \gamma$ transformation need to be studied in more detail. This is important since, for instance, the resultant austenite grain size determines the strain rate required to refine the grain size after the transformation.

Because of the specimen dimensions and shape, it was very difficult to study medium and large amounts of deformation since bulging and buckling of specimen can lead to unreliable results, as far as the deformation curve is concerned. In order to overcome this constraint and provide a condition to study larger amounts of deformation, shorter and thicker specimens should be prepared. Accordingly, the induction heating coil needs to be modified in order to be able to control a larger amount of liquid by levitation. 


\section{STATEMENT OF ORIGINALITY AND CONTRIBUTIONS TO KNOWLEDGE}

1. For the first time, an experimental apparatus was developed in order to hold melted steel with levitation on the deformation machine, here at McGill.

2. The solidus temperature was approximated for the first time using continuous cooling compression experiments.

3. The hot ductility trough was compared in the $\mathrm{Nb}$-microalloyed steels containing boron and without boron for the first time in in situ melted specimens subjected to the thermal schedule.

4. The effect of deformation during solidification on the hot ductility was studied and physically modeled for the first time.

5. The effect of deformation in the $\delta$-ferrite region on the hot ductility was studied for the first time.

6. The effect of deformation rate on the flow stress transition during the $\delta \rightarrow \gamma$ transformation in steel was studied for the first time.

7. The effect of deformation during the $\delta \rightarrow \gamma$ transformation on the hot ductility was studied for the first time.

8. The mechanisms by which boron improves the hot ductility in $\mathrm{Nb}$-microalloyed steel at high temperatures, i.e. single phase austenite, were proposed for the first time.

9. Using the Field Emission Scanning Electron Microscope in examining fracture surfaces in $\mathrm{Nb}$-containing steels, it was recognized that some grain surfaces have a fibrous structure and some others contain $\mathrm{Al}_{2} \mathrm{O}_{3}$ particles. 
10. The Local Electrode Atom Probe technique was employed for the first time in the $\mathrm{Nb}$ microalloyed steel in order to track the atomic distributions.

11. Using the 'one-parameter approach', the initiation of dynamic recrystallization, in the absence of a peak stress, was determined for the first time in tensile experiments and as cast structures. As well, a criterion was proposed to distinguish if an inflection point in the $\theta-\sigma$ curve is likely to be ascribed to dynamic recrystallization or to flow localization.

12. For the first time, a thermomechanical processing schedule was developed in order to improve the hot ductility of $\mathrm{Nb}$-microalloyed steels. 


\section{APPLICATION TO THE INDUSTRY TO RESOLVE THE PROBLEM}

As has been discussed throughout this thesis, the continuous casting process of steel has been tackling the problem of surface defects after the straightening operation by considering the mechanism to be hot ductility loss. Most solutions to the problem have focused on changing the steel chemistry and cooling rate, which are not always feasible in industry. Therefore, this work has attempted to find a solution, without changing the steel chemistry and the thermal history, by incorporating very high temperature deformation.

Deformation during solidification leads to hot ductility deterioration at the straightening stage and, hence, such deformation should be avoided during solidification. Unfortunately, internal stresses are present during steel solidification, mostly in order to prevent the solidified shell from sticking to the mould, and the hot ductility may well be deteriorated because of this. Nevertheless, it seems that the actual effect in the mould is less intense than what was indicated in this work, possibly because there is less deformation being applied (or maybe the shell is mainly solidified as soon as the liquid hits the mould wall). There are ongoing investigations trying to find ways, other than mould oscillation, to prevent the adhesion of steel to the mould. Essentially, the model proposed in this work will lead to a better understanding of the mechanisms of hot ductility loss due to deformation during steel solidification and help generate an effective solution to alleviate its detrimental effects.

However, even in the absence of any deformation during solidification, the hot ductility at the straightening stage can still be low, if the steel grade is inherently susceptible. To improve the situation, deformation at very high temperatures just below the solidus is promising.

The transformation of $\delta$-ferrite $\rightarrow \gamma$ takes place in the solidified shell while the billet is still inside the continuous casting mould. Hence, any deformation applied in this stage may 
also generate strain in the liquid+solid two phase region. However, assuming that a horizontal compression can be applied to the lateral sides of the solidified shell, section $\mathbf{A}$ in Figure I, then accelerated transformation is stimulated in the top and bottom sections of the shell, section B, leading to refined austenite grains. During application of such a deformation, it is necessary that bulging on the top and bottom sections of the shell be prevented. Otherwise, the detrimental effect of deformation during solidification is encouraged. It is desirable to refine grains in both the horizontal and vertical sections since transverse cracks are also found in the corners of billets. To deal with this, the billet section can be compressed in both the horizontal and vertical sections simultaneously and compression in one section would prevent bulging in the perpendicular section. The optimum conditions found for such compression is $\varepsilon \geq 0.1$ and $\dot{\varepsilon}=9 \times 10^{-3} \mathrm{~s}^{-1}$. In this way, the grain size at the straightening stage is decreased and dynamic recrystallization could take place, leading to hot ductility improvement.

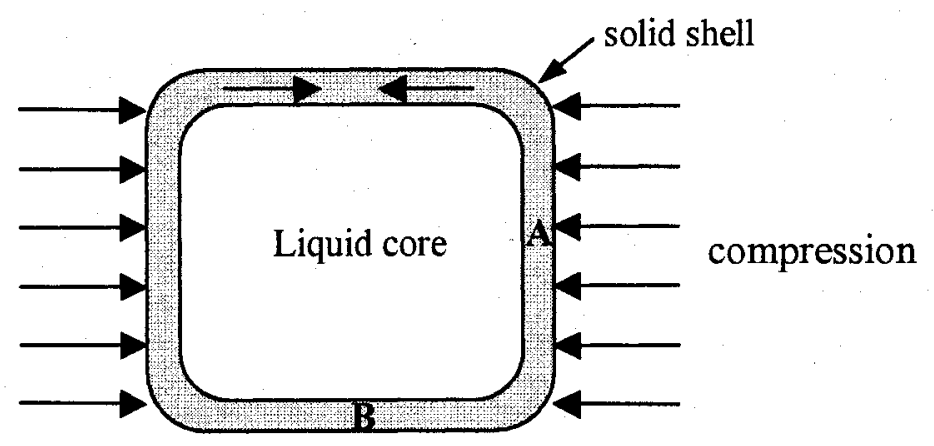

Figure I. Cross section of the billet in the mould.

There is a second scenario if the first one, mentioned above, is practically difficult to be applied. At the exit of steel from the mould, the surface temperature is in the vicinity of $1000{ }^{\circ} \mathrm{C}$, depending on the mould cooling conditions and casting speed. At this stage, the accelerating effect of deformation on the $\delta \rightarrow \gamma$ transformation cannot be utilized since the transformation has already finished. Consequently, compression in the proximity of $1200^{\circ} \mathrm{C}$, the beginning of the last stage of the thermal schedule, should be considered. It was found that dynamic recrystallization in the as cast structure, i.e. after the thermal schedule alone, began at $1100^{\circ} \mathrm{C}$ at the straightening stage (Figure 5.26(e)). Hence, the 
corresponding value of $Z$, i.e. $4.14 \times 10^{9} \mathrm{~s}^{-1}$, is taken as a minimum value for grain refinement at this temperature. Similarly, assuming that the difference between the as cast grain size at the beginning and end of the thermal schedule last segment is negligible, the minimum strain rate required to refine the austenite grain size, through dynamic recrystallization, at $1200^{\circ} \mathrm{C}$ is determined to be $\dot{\varepsilon}=0.032 \mathrm{~s}^{-1}$. This deformation is designated as $\mathbf{A}$ in Figure II. In order to achieve the finest possible grain size, the compression should continue to the steady state strain of recrystallization. Figure 5.26(e), suggests that the resultant grain size would be smaller than $\sim 80 \mu \mathrm{m}$. Note that the microstructure shown in Figure 5.26(e) corresponds with a strain smaller than the steady state strain, i.e. the fracture strain preceded the steady state strain. This implies. that $\varepsilon \approx 0.3$ can easily lead to grain sizes of $\sim 80 \mu \mathrm{m}$.

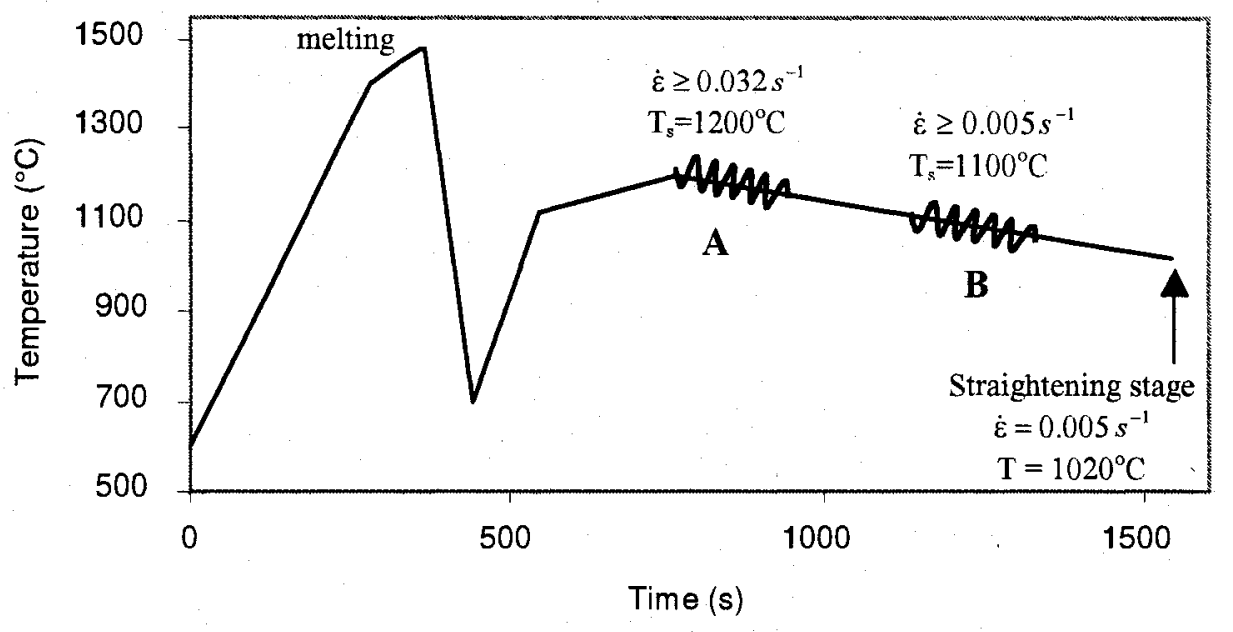

Figure II. Illustrations of compression schedules to be applied to the billet during continuous casting.

Following this deformation, more grain refinement can be ascertained by a second compression starting at $1100^{\circ} \mathrm{C}$ provided $Z$ is not smaller than $4.14 \times 10^{9} \mathrm{~s}^{-1}$. This can be inferred from the general $Z-d_{0}$ profile. It should be indicated that $Z=4.14 \times 10^{9} \mathrm{~s}^{-1}$ would result in the same grain size as that resulting from the first compression at its steady state. Accordingly, the strain rate for the second compression needs to be larger than $5 \times 10^{-3} \mathrm{~s}^{-1}$. 
This is also illustrated in Figure II. Essentially, the critical strain for dynamic recrystallization at the straightening stage, $1020^{\circ} \mathrm{C}$, is decreased and the problem of hot ductility is alleviated. Such compressive deformation schedules can easily be applied on the billet surface using two rolls.

Moreover, if the first scenario is practical in industry, it can be followed by the second one in order to achieve more refined grains at the straightening stage. In this case, similar values for the aforementioned strain rates can still be used. However, the amounts of required deformation will be less since the initial grain size is smaller and dynamic recrystallization starts earlier. With such deformation processes, there is also an opportunity to control downstream metallurgical phenomena, while the steel is going through the continuous casting machine. This could be of great interest in direct rolling or hot charging scenarios. 
1. H. G. Suzuki, S. Nishimura, and S. Yamaguchi, "Characteristics of Hot Ductility in Steels Subjected to the Melting and Solidification", Transaction ISIJ, Vol.22, 1982, pp.[48]-[56].

2. W. T. Nachtrab and Y. T. Chou, "High Temperature Ductility Loss in CarbonManganese and Niobium-Treated Steels', Metallurgical Transactions A, Vol.17A, No.11, 1986, pp.1995-2006.

3. B. Mintz, S. Yue, and J. J. Jonas, "Hot Ductility of Steels and Its Relationship to the Problem of Transverse Cracking During Continuous Casting', International Materials Reviews, Vol.36, No.5, 1991, pp.187-217.

4. B. Mintz, A. Cowley, R. Abushosha, and D. N. Crowther, "Hot Ductility Curve of an Austenitic Stainless Steel and Importance of Dynamic Recrystallization in Determining Ductility Recovery at High Temperatures“, Materials Science and Technology, Vol.15, No.10, 1999, pp.1179-1185.

5. C. Ouchi and K. Matsumoto, "Hot Ductility in Nb-Bearing High-Strength Low-Alloy Steels", Transaction of Iron and Steel Institute, Japan, Vol.22, No.3, 1982, pp.181189.

6. O. Cominelei, R. Abushosha, and B. Mintz, "Influence of Titanium and Nitrogen on Hot Ductility of C-Mn-Nb-Al Steels", Materials Science and Technology, Vol.15, No.9, 1999, pp.1058-1068.

7. E. Hurtado-Delgado and R. D. Morales, "Hot Ductility and Fracture Mechanisms of a C-Mn-Nb-Al Steel", Metallurgical and Materials Transactions B, Vol.32B, No.10, 2001, pp.919-927.

8. R. Priestner and C. Zhou, "Simulation of Microstructural Evolution in Nb-Ti microalloyed Steel During Hot Direct Rolling", Ironmaking and Steelmaking, Vol.22, No.4, 1995, pp.326-332.

9. B. Mintz, "The Influence of Composition on the Hot Ductility of Steels and to the Problem of Transverse Cracking," ISIJ International, Vol.39, No.9, 1999, pp.833855.

10. C. Zhou and R. Priestner, "The Evolution of Precipitates in Nb-Ti Microalloyed Steels During Solidification and Post-Solidification Cooling," ISIJ International, Vol.36, No.11, 1996, pp.1397-1405.

11. A. M. Elwazri, "Effect of Thermal History on Hot Ductility of Steel," Master's Thesis, Department of Metallurgical Engineering, McGill University, June 1998. 
12. S. Akhlaghi, "Effect of Deformation on Hot Ductility," Ph.D. Thesis, Department of Metallurgical Engineering, McGill University, October 2000.

13. T. Revaux, P. Deprez, J. Bricout, and J. Oudin, "In Situ solidified Hot Tensile Test and Hot Ductility of Some Plain Carbon Steels and Microalloyed Steels," ISIJ International, Vol.34, No.6, 1994, pp.528-535.

14. J. K. Brimacombe and E. Takeuchi, "Mechanism of the Positive Segregation and the Initiation of the Transverse Cracks along the Oscillation Marks," Transaction ISIJ, Vol.25, 1985, p.B-338.

15. S. Itoyama, H. Tozawa, T. Mochida, K. Kurokawa, T. Matsukawa, and K. Sorimachi, "Control of Early Solidification in Continuous Casting by Horizontal Oscillation in Synchronization with Vertical Oscillation of the Mold," ISIJ International, Vol.38, No.5, 1998, pp.461-468.

16. S. Harada, S. Tanaka, H. Misumi, S. Mizoguchi, and H. Horiguchi, "A Formation Mechanism of ransverse Cracks on CC Slab Surface," ISIJ International, Vol.30, No.4, 1990, pp.310-316.

17. S. S. Hansen, J. B. Vander Sande, and M. Cohen, "Niobium Carbonitride Precipitation and Austenite Recrystallization in Hot-Rolled Microalloyed Steels", Metallurgical Transactions A, Vol.11A, No.3, 1980, pp.387-402.

18. E. Takeuchi and J.K. Brimacombe, "The Formation of Oscillation Marks in the Continuous Casting of Steel Slabs", Metallurgical Transaction B, Vol.15B, No.9, 1984, pp.493-509.

19. J. K. Brimacombe and K. Sorimachi, "Crack Formation in the Continuous Casting of Steel", Metallurgical Transactions B, Vol. 8B, No. 9, 1977, pp.489-505.

20. W. T. Lankford, "Some Considerations of Strength and Ductility in the ContinuousCasting Process", Metallurgical Transactions, Vol.3, No.6, 1972, pp.1331-1357.

21. W. R. Irving, "Continuous Casting of Steel”, London, Institute of Materials, ISBN: $0901716537,1993$.

22. S. Harada, S. Tanaka, H. Misumi, S. Mizoguchi, and H. Horiguchi, "A Formation of Transverse Cracks on CC Slab Surface", ISIJ International, Vol.30, No.4, 1990, pp.310-316.

23. R. Abushosha, S. Ayyad, and B. Mintz, "Influence of Cooling Rate on Hot Ductility of C-Mn-Al and C-Mn-Nb-Al Steels", Materials Science and Technology, Vol.14, No.4, 1998, pp.346-351.

24. B. Mintz and R. Abushosha, "The Hot Ductility of $\mathrm{V}, \mathrm{Nb} / \mathrm{V}$ and $\mathrm{Nb}$ containing Steels", Materials Science Forum, Vols.284-286, 1998, pp.461-468. 
25. S. Yue and S. Akhlaghi, "The Effect of Deformation on the Hot Ductility of Steel," Proceeding of COM 2000, Thermomechanical Processing of Steel, edited by S. Yue and E.Es-sadiqi, Ottawa, August 20-23, 2000, pp.657-667.

26. O. J. Ilegbusi and J. Szekely, "Effect of Magnetic Field on Flow, Temperature and Inclusion Removal in Shallow Tundishes", ISIJ international, Vol.29, No.12, 1989, pp.1031-1039.

27. I. Miyoshino, E. Takeuchi, H. Yano, J. Sakane, T. Saeki, and H. Kajioka, "Influence of Electromagnetic Pressure on the Early Solidification in a Continuous Casting Mold", ISIJ international, Vol.29, No.12, 1989, pp.1040-1047.

28. J. W. Evans, B.Q. Li, and D.P. Cook, "2D and 3D Mathematical Models and a Physical Model of Electromagnetic Casters", ISIJ international, Vol.29, No.12, 1989, pp.1048-1055.

29. N. Genma, T. Soejoima, T. Saito, M. Kimura, Y. Kaihara, H. Fukumoto, and K. Ayata, "The Linear-Motor Type In-Mold Electromagnetic Stirring Technoque for the Slab Continuous Caster", ISIJ international, Vol.29, No.12, 1989, pp.10561062 .

30. D. Hardwick and W. J. McG Tegart, "Structural Changes During the Deformation of Copper, Aluminium and Nickel at High Temperatures and High Strain Rates", Journal of the Institute of Metals, Vol.90, 1962, pp.17-21.

31. J. J. Jonas, C. M. Sellars, and W. J. McG. Tegart, "Strength and Structure Under Hot Working Conditions", Metallurgy Review, Vol.14, 1969, pp.1-24.

32. F. Garofalo, "Ductility in Creep", 'DUCTILITY', American Society for Metals, Metals Park, Ohio, 1967, pp.87-132.

33. W. J. McG. Tegart, "The Role of Ductility in Hot Working", 'DUCTILITY', American Society for Metals, Metals Park, Ohio, 1967, pp.133-178.

34. W. A. Backofen, F. J. Azzarto, G. S. Murty, and S. W. Zehr, "Superplasticity", 'DUCTILITY', American Society for Metals, Metals Park, Ohio, 1967, pp.279-310.

35. J. O. Stiegler and J. R. Weir Jr., "Effects of Irradiation on Ductility", 'DUCTILITY', American Society for Metals, Metals Park, Ohio, 1967, pp.311-342.

36. J. R. Wilcox and R. W. K. Honeycombe, "Effect of Precipitation on Hot Ductility of Niobium and Aluminium Microalloyed Steels", Materials Science and Technology, Vol.3, No.10, 1987, pp. 849-854.

37. J. R. Wilcox and R. W. K. Honeycombe, "Hot Ductility of Niobium and Aluminium Microalloyed Steels Following High-Temperature Solution Treatment", Metals Technology, Vol.11, No.6, 1984, pp. 217-225. 
38. J. R. Wilcox and R. W. K. Honeycombe, "Influence of Prior Precipitation on Hot Ductility of C--Mn--Nb--Al Steels", Hot Working and Forming Processes Conference, Sheffield, England, July 1979, 1980, pp. 108-112.

39. D. N. Crowther and B. Mintz, "Influence of Carbon on Hot Ductility of Steels", Materials Science and Technology, Vol.2, No.7, 1986, pp. 671-676.

40. G. I. S. L. Cardoso and S. Yue, "Hot Ductility of Three Low Carbon Steels in Continuously Cast Slabs", Mechanical Working and Steel Processing Conference, 1989 , pp.585-593.

41. B. Mintz, R. Abushosha, and M. Shaker, "Influence of Deformation Induced Ferrite, Grain Boundary Sliding, and Dynamic Recrystallization on Hot Ductility of 0.1-0.75\%C Steels", Materials Science and Technology, Vol.9, No.10, 1993, pp. 907-914.

42. B. Mintz and J. J. Jonas, "Influence of Strain Rate on Production of Deformation Induced Ferrite and Hot Ductility of Steels", Materials Science and Technology, Vol.10, No.8, 1994, pp. 721-727.

43. B. Mintz, J. Lewis, and J. J. Jonas, "Importance of Deformation Induced Ferrite and Factors which Control its Formation", Materials Science and Technology, Vol.13, No.5, 1997, pp. 379-388.

44. C. Cowley, R. Abushosha, and B. Mintz, "Influence of $\mathrm{Ar}_{3}$ and $\mathrm{Ae}_{3}$ Temperatures on Hot Ductility of Steels", Materials Science and Technology, Vol. 14, No.11, 1998, pp. 1145-1153.

45. J. Lewis, J. J. Jonas, and B. Mintz, "The Formation of Deformation Induced Ferrite During Mechanical Testing", ISIJ International, Vol.38, No.3, 1998, pp. 300-309.

46. E. Essadiqi and J. J. Jonas, "Effect of Deformation on the Austenite-to-Ferrite Transformation in a Plain Carbon and Two Microalloyed Steels", Metallurgical Transactions A, Vol.19A, No.3, 1988, pp. 417-426.

47. C.M. Chimani and K. Morwald, "Micromechanical Investigation of the Hot Ductility Behavior of Steel," ISIJ International, Vol.39, No.11, 1999, pp.1194-1197.

48. P. J.Wray, "Plastic Flow and Failure of Plain Carbon Steels in Ferrite + Austenite Region", Metals Technology, Vol.8, No.12, 1981, pp.466-471.

49. B. Mintz, J. R. Wilcox, and D. N. Crowther, "Hot Ductility of Directly Cast C-MnNb-Al Steel”, Materials Science and Technology, Vol.2, No.6, 1986, pp.589-594.

50. Y. Maehara and Y. Ohmori, "The Precipitation of AIN and $\mathrm{NbC}$ and the hot ductility of low carbon steels," Materials Science and Engineering, Vol. 62, No. 1, 1984, pp. 109-119. 
51. H. G. Suzuki, S. Nishimura, J. Imamura, and Y. Nakamura, "Embrittlement of Steels Occurring in the Temperature Range from 1000 to $600^{\circ} \mathrm{C}$ ", Transaction ISIJ, Vol.24, 1984, pp.169-177.

52. R. E. Reed-Hill and R. Abbaschian, "Physical Metallurgy Principles", $3^{\text {rd }}$ edition, Boston PWS publication, 1996.

53. D.N. Crowther and B. Mintz, "Influence of Grain Size and Precipitation on Hot Ductility of Microalloyed Steels," Materials Science and Technology, Vol.2, No.11, 1986, pp. 1099-1105.

54. P.J. Wray, "Tensile Failure of Austenitic Iron at Intermediate Strain Rates," Metallurgical Transactions A, Vol.6A, No.7, 1975, pp.1379-1391.

55. M. J. Luton and C. M. Sellars, "Dynamic Recrystallization in Nickel and NickelIron Alloys During High Temperature Deformation", Acta Metallurgica, Vol.17, No.8, 1969, pp.1033-1043.

56. D. N. Crowther, Z. Mohamed, and B. Mintz, "Influence of Micro-alloying Additions on the Hot Ductility of Steels Heated Directly to the Test Temperature", Transactions ISIJ, Vol.27, No.5, 1987, pp.366-375.

57. D. N. Crowther, Z. Mohamed, and B. Mintz, "The Relative Influence of Dynamic and Static Precipitation on the Hot Ductility of Microalloyed Steels", Metallurgical Transactions A, Vol.18A, No.11, 1987, pp.1929-1939.

58. P. J. Wray, "Tensile Failure Behavior of Plain Carbon Steel at Elevated Temperatures", Metallurgical Transaction A, Vol.15A, No.11, 1984, pp.2059-2073.

59. K. A. Bywater and T. Gladman, "Influence of composition and microstructure on hot workability of austenitic stainless steels", Metals Technology, Vol.3, No.8, 1976, pp.358-365.

60. H. E. Evans, "The Mechanism of Void Growth and Factors Affecting the Onset of Intergranular Failure During Creep of a Magnesium-0.8 percent Aluminium Alloy", Metal Science Journal, Vol.3, Jan.-Feb.1969, pp.33-38.

61. J. H. Reynold and T. Gladman, "Hot Cracking of Low-Alloy Steels", Hot Working and Forming Processes Conference, Sheffield, England, July 1979, 1980, pp.171175.

62. V. Kutumba Rao, D. M. R. Taplin, and P. Rama Rao, "The Grain Size Dependence of Flow and Fracture in a Cr-Mn-N Austenitic Steel From 300 to 1300 K", Metallurgical Transactions A, Vol. 6A, No.1, 1975, pp.77-86.

63. B. Mintz, A. Cowley, and R. Abushusha, "Importance of Columnar Grains in Dictating Hot Ductility of Steels", Materials Science and Engineering, Vol.16, No.1, 2000, pp.1-5. 
64. V. Kutumba Rao, D. M. R. Taplin, and P. Rama Rao, "The Grain Size Dependence of Flow and Fracture in a Cr-Mn-N Austenitic Steel From 300 to 1300 K", Metallurgical Transactions A, Vol. 6A, No.1, 1975, pp.77-86.

65. D. N. Crowther and B. Mintz, "Influence of Grain Size on Hot Ductility of Plain C-Mn Steels", Materials Science and Technology, Vol.2, No.9, 1986, pp.951-955.

66. Y. Maehara, K. Yasumoto, Y. Sugitani, and K. Gunji, "Effect of Carbon on Hot Ductility of As-cast Low Alloy Steels", Transactions ISIJ, Vol.25, No.10, 1985, pp.1045-1052.

67. M. G. Akben, I. Weiss, and J. J. Jonas, "Dynamic Precipitation and Solute Hardening in a Vanadium Microalloyed Steel and Two Niobium Steels Containing High Levels of Manganese", Acta Metallurgica, Vol.29, No.1, 1981, pp.111-121.

68. I. Weiss and J. J. Jonas, "Dynamic Precipitation and Coarsening of Niobium Carbonitrides During the Hot Compression of HSLA Steels", Metallurgical Transactions A, Vol.11A, No.3, 1980, pp.403-410.

69. A. Kothe, J. Kunze, G. Backmann, and C. Mickel, "Precipitation of TiN and $(\mathrm{Ti}, \mathrm{Nb})(\mathrm{C}, \mathrm{N})$ during Solidification, Cooling, and Hot Direct Deformation", Materials Science Forum, Vols.284-286, 1998, pp.493-500.

70. P. Sricharoenchai, C. Nagasaki, and J. Kihara, "Hot Ductility of High Purity Steels Containing Niobium", ISIJ International, Vol.32, No.10, 1992, pp.11021109.

71. W J. Liu, "A New Theory and Kinetic Modeling of Strain-Induced Precipitation of $\mathrm{Nb}(\mathrm{CN})$ in Microalloyed Austenite", Metallurgical Transactions A, Vol.26A, No.7, 1995, pp.1641-1657.

72. C. M. Sellars: "Modeling Strain Induced Precipitation of Niobium Carbonitride during Hot Rolling of Microalloyed Steel", Materials Science Forum, Vols.284286, 1998, pp.73-82.

73. M. J. Luton, R. Dorvel, and R. A. Petkovic, "Interaction Between Deformation, Recrystallization and Precipitation in Niobium Steels", Metallurgical Transactions A, Vol.11A, No.3, 1980, pp.411-420.

74. I Weiss and J. J. Jonas, "Interaction Between Recrystallization and Precipitation During the High Temperature Deformation of HSLA Steels", Metallurgical Transactions A, Vol.10A, No.7, 1979, pp.831-840.

75. T. Nozaki, J. Matsuno, K. Murata, H. Ooi, and M. Kodama, "A Secondary Cooling Pattern for Preventing Surface Cracks of Continuous Casting Slab", Transactions of Iron Steel Institute of Japan, Vol.18, No.6, 1978, pp.330-338. 
76. T. H. Coleman and J. R. Wilcox, "Transverse cracking in continuously cast HSLA slabs-influence of composition", Materials Science and Technology, Vol.1, No.1, 1985, pp.80-83.

77. B. G. Thomas, J. K. Brimacombe, and I. V. Samarasekera, "The formation of panel cracks in steel ingots: A state-of-the-art review" Iron and Steel Society Transaction, Vol.7, 1986, pp.7-20.

78. B. Mintz and J. M. Arrowsmith, "Hot-Ductility Behaviour of C--Mn--Nb--Al Steels and Its Relationship to Crack Propagation During the Straightening of Continuously Cast Strand", Metals Technology, Vol.6, No.1, 1979, pp.24-32.

79. R. Abushosha, O. Cominelei, and B. Mintz, "Influence of Ti on Hot Ductility of CMn-Al Steels", Materials Science and Technology, Vol.15, No.3, 1999, pp.278-286.

80. B. Mintz and R. Abushosha, "Effectiveness of hot tensile test in simulating straightening in continuous casting", Materials Science and Technology, Vol.8, No.2, 1992, pp.171-177.

81. R. Abushosha, R. Vipond, and B. Mintz, "Influence of Titanium on Hot Ductility of As Cast Steels", Materials Science and Technology, Vol.7, No.7, 1991, pp.613-621.

82. R. Abushosha, R. Vipond, and B. Mintz, "Influence of Sulphur and Niobium on Hot Ductility of As Cast Steels", Materials Science and Technology, Vol.7, No.127, 1991, pp.1101-1107.

83. G. I. S. L. Cardoso; B. Mintz, and S. Yue, "Hot ductility of aluminium and titanium containing steels with and without cyclic temperature oscillations" Ironmaking and Steelmaking (UK), Vol.22, No.5, 1995, pp.365-377.

84. B. Mintz, J. M. Stewart, and D. N. Growther, "The Influence of Cyclic Temperature Oscillations on Precipitation and Hot Ductility of a C-Mn-Nb-Al Steel", Transactions ISIJ, Vol.27, No.12, 1987, pp.959-964.

85. A. M. El-wazri, F. Hassani, S. Yue, E. Es-sadiqi, L. E. Collins, and K. Iqbal, "Effects of Reheat Conditions on the Hot Ductility of $\mathrm{Nb}-\mathrm{Ti}$ and Ti-B Microalloyed Steels", Canadian Metallurgical Quarterly, Vol.39, No.1, 2000, pp.55-63.

86. D. A. Melford, "Influence of Residual and Trace Elements on Hot Shortness and High Temperature Embrittlement", Residuals, Additives and Materials Properties, London May 1978, Proceeding, 1980, pp.89-103.

87. G. L. Fisher, "The Effect of Nickel on the High-Temperature Oxidation Characteristics of Copper-Bearing Steels", Journal of Iron and Steel Institute, No.7, 1969, pp.1010-1016. 
88. N. E. Hannerz, "Critical Hot Plasticity and Transverse Cracking in Continuous Slab Casting With Particular Reference to Composition", Transactions of Iron and Steel Institute of Japan, Vol.25, No.2, 1985, pp.149-158.

89. M. H. Burden, G. D. Funnell, A. G. Whitaker and J. M. Young, "Origins of Defects in Continuously Cast Blooms Produced on a Curved Mould Machine", Solidification and Casting of Metals Conference, Sheffield, England, July 1977, 1979, pp. 279-286.

90. E. Anelli, A. Mollo, and A. Oulhadj, "Surface Cracking and Hot Ductility of Lowalloy Steel Blooms", 34th Mechanical Working and Steel Processing Conference, Montreal, Quebec, Canada, 25-28 October 1992, 1992, pp.399-407.

91. M. M. Wolf, "Effects of Tramp Elements in Continuous Casting", Ironmaking Steelmaking, Vol.12, No.6, 1985, pp.299-301.

92. B. Mintz, R. Abushosha, and D. N. Crowther, "Influence of Small Additions of Copper and Nickel on Hot Ductility of Steels", Materials Science and Technology (UK), Vol.11, No.5, 1995, pp.474-481.

93. J. C. Herman and V. Leroy, "Influence of residual elements on steel processing and mechanical properties", Iron and Steelmaker (USA), Vol.23, No.12, 1996, pp.3543.

94. Y. Yashima, M Fujii, C. Matsumoto, and T. Moriya, "Effects of Solidification Structures and Manganese/Sulphur Ratios on Hot Ductility of Fe--42\% Ni alloys", Nisshin Steel Tech. Rep, No.55, Dec. 1986, pp.10-17.

95. G. A. Osinkolu, M. Tacikowski, and A. Kobylanski, "Combined Effect of AlN and Sulphur on Hot Ductility of High-Purity Iron-Base Alloys", Materials Science and Technology, Vol 1, No.7, 1985, pp.520-525.

96. K. Yasumoto, Y. Maehara, S. Ura, and Y. Ohmori, "Effects of Sulphur on Hot Ductility of Low-Carbon Steel Austenite", Materials Science and Technology, Vol.1, No.2, 1985, pp.111-116.

97. G. A. Osinkolu, M. Tacikowski, and A. Kobylanski, "AIN and Sulphur Embrittlement of Austenite Grain Boundaries in High Purity Iron Alloys", Transactions of Japan Institute of Metals, Vol.27, Suppl., 1986, pp.797-804.

98. R. P. Messmer and C. L. Briant, "The Role of Chemical Bonding in Grain Boundary Embrittlement", Acta Metallurgica, Vol.30, No.2, 1982, pp.457-467.

99. R. J. Gray, A. Perkins, and B. Walker, "Quality of Continuously Cast Slabs", International Conference of Solidification and Casting, Metals Society, London, 2, 1977, p.27. 
100. G. Bernard, J. P. Brait, B. Conseil, and J. C. Humbert, "Study of the Susceptibility to Cracking of Continuously Cast Steels Using Hot-Ductility Tests", Rev. Metall., Vol.75, No.7, 1978, pp.467-480.

101. K. Yamanaka, F. Terasaki, H. Ohtani, M. Oda, and M. Yoshihara, "Relation Between Hot Ductility and Grain Boundary Embrittlement of Low-Carbon Killed Steels", Transactions of Iron and Steel Institute of Japan, Vol.20, No.12, 1980, pp.810-816.

102. B. Mintz and Z. Mohamed, "Intergranular Failure in Micro-Alloyed Steels and Its Relationship to Carbon Content", International Conference on Fracture 7, Advances in Fracture Research, Vol.4, Houston, Texas, USA, 20-24 Mar. 1989, Pergamon Press plc, 1989, pp. 2545-2553.

103. G. D. Funnell and R. J. Davies, "Effect of AlN Particles on Hot Ductility of Steel", Metal Technology, Vol.5, No.5, 1978, pp.150-153.

104. O. N. Dogan, G. M. Michal, and H. W. Kwon, "Pinning of Austenite Grain Boundaries by AIN Precipitates and Abnormal Grain Growth", Metallurgical Transactions A, Vol.23A, No.8, 1992, pp.2121-2129.

105. R. H. Edwards, F. J. Barbaro, and K. W. Gunn, "Stress Relief Cracking in Cr-MoV Steels", Metals Forum, Vol.5, No.2, 1982, pp.119-129.

106. F. Vodopivec, M. Torkar, and M. Debelak, "Influence of Aluminum on Solidification Structure and Initial Deformability of Continuously Cast C--Mn--Si-N Steel", Materials Science and Technology, Vol.4, No.10, 1988, pp.917-925.

107. M. Suehiro, Z. K Liu, and J. Agren, "Effect of Niobium on Massive Transformation in Ultra Low Carbon Steels: A Solute Drag Treatment", Acta Materialia, Vol.44, No.10, 1996, pp.4241-4251.

108. B. E. Lindblom and N. J. Grant, "Hot Plasticity of a Nb-treated C-steel at High Strain Rates", Jernkontorets Ann, Vol. 155, No.9, 1971, pp.595-600.

109. P. R. Rios, "A Theory for Grain Boundary Pinning by Particles", Acta Metallurgica, Vol.35, No.12, 1987, pp.2805-814.

110. B. Mintz and R. Abushosha, "Influence of vanadium on hot ductility of steel", Ironmaking and Steelmaking (UK), Vol.20, No.6, 1993, pp.445-452.

111. M G. Akben, B. Bacroix, and J. J. Jonas, "Effect of Vanadium and Molybdenum Addition on High-Temperature Recovery, Recrystallization and Precipitation Behavior of Niobium-Based Microalloyed Steels", Acta Metallurgica, Vol.31, No.1, 1983, pp.161-174. 
112. S. K. Kim, J. S. Kim, and N. J. Kim, "Effect of Boron on the Hot Ductility of Nbcontaining Steel (Communications)", Metallurgical and Materials Transactions A, Vol.33A, No.3, 2002, pp.701-704.

113. K. I. Suzuki, S. Miyagawa, Y. Saito, and K. Shoitani, "Effect of Microalloyed Nitride Forming Elements on Precipitation of Carbonitride and High Temperature Ductility of Continuously Cast Low Carbon Nb Containing Steel Slab", ISIJ International, Vol.35, No.1, 1995, pp.34-41.

114. S. Kojima, T. Matsukawa, and M. Kodama, "Condition of Internal Cracks in Continuous Casting of Steel Slabs", Process Technology Conference Proceedings, Vol.3, 1982, pp.255-262.

115. J. Glownia and J. Banas, "Effect of Modification and Segregation on the DeltaFerrite Morphology and Corrosion Resistance of Cast Duplex Steel," Metallurgy and Foundry Engineering, Vol.23, No.2, 1997, pp.261-268.

116. P. J. Wray, "Plastic Deformation of Delta-Ferrite Iron at Intermediate Strain Rates," Metallurgical Transactions A, Vol.7A, No.11, 1976, pp.1621-1627.

117. D. J. Seol, Y. M. Won, T. J. Yeo, K. H. Oh, J. K. Park, and C. H. Yim, "High Temperature Deformation Behavior of Carbon Steel in the Austenite and $\delta$-Ferrite Regions," ISIJ International, Vol.39, No.1, 1999, pp.91-98.

118. H. Yin, T. Emi, and H. Shibata, "Determination of free energy of Deltaferrite/gamma-austenite interphase boundary of low carbon steels by in-situ observation," ISIJ International (Japan), Vol.38, No.8, 1998, pp. 794-801.

119. E. V. Konopleva and H. J. McQueen, "Effects of Hot Deformation on $\delta$-Ferrite in Austenitic Stainless Steels," Processes \& Materials: Innovation Stainless Steel, Vol. 3, Florence, Italy, 11-14 October 1993, pp.3.291-3.296.

120. F. Hassani, "Mechanical Behaviour of Steel Near the Incipient Melting Temperature," Master's Thesis, Department of Metallurgical Engineering. McGill University, July 1993.

121. A. Zarei-Hanzaki, R. Pandi, P.D. Hodgson and S. Yue, "Continuous Cooling Compression Testing of Steels," Metall. Trans., 24A, 1993, pp. 2657-2665.

122. M. K. Miller, P. J. Pareige, and Kaye F. Russell, "Seeing and Catching Atoms", Oak Ridge National Laboratory".

123. T. Kelly et al., "High Mass Resolution Local-Electrode Atom Probe", US Patent $5440124,1995$.

124. WWW.imago.com. 
125. T. Sakai, M. G. Akben, J. J. Jonas, "The Role of Dynamic Recrystallization in Producing Grain Refinement and Grain Coarsening in Microalloyed Steels",Thermomechanical Processing of Microalloyed Austenite, Pittsburgh, Pa., 17-19 Aug. 1981, 1982, pp. 237-252.

126. T. Sakai and J. J. Jonas, "Dynamic Recrystallization: Mechanical and Microstructural Considerations", Acta Metallurgica, Vol.32, No.2, 1984, pp.189209.

127. H. J. Frost and M. F. Ashby, "Deformation-Mechanism Maps," Pergamon Press, 1982.

128. Y. Zhang, J. Ma, X. Li, and C. Cao, "A preliminary study on superplasticity of Ti-14Al-21Nb alloy," International Conference on Superplasticity in Advanced Materials (ICSAM-94), Moscow, Russia, 24-26 May. 1994, Trans Tech Publications Ltd, Materials Science Forum (Switzerland), 1994, pp. 495-500.

129. B.P. Kashyap, A. Arieli, and A.K. Mukherjee, "Microstructural Aspects of Superplasticity," Journal of Materials Science, Vol.20, No.8, 1985, pp. 26612686.

130. R.B. Vastava and T.G. Langdon, "An Investigation of Intercrystalline and Interphase Boundary Sliding in the Superplastic Pb--62\% Sn Eutectic, "Acta Metall., Vol.27, No.2, 1979, pp. 251-257.

131. T.G. Langdon and R.B. Vastava, "An Evaluation of Deformation Models for Grain Boundary Sliding," Mechanical Testing for Deformation Models Development, Florida, 12-13 Nov, 1980, American Society for Testing and Materials, 1980, pp. 435-451.

132. B.P. Kashyan, A. Arieli, A.K. Mukherjee, "Microstructural Aspects of Superplasticity", Journal of Materials Science, Vol.20, 1985, pp2661-2686.

133. A.D. Sheikh-Ali, "On the Accommodation of Grain Boundary Sliding by Crystallographic Slip", Defect and Diffusion Forum, Vols.188-190, 2001, pp.137-142.

134. R.S. Gates, "The Role of Grain Boundary Dislocations in Grain Boundary Sliding," Acta Metallurgica, Vol.21, No.7, 1973, pp.855-865.

135. G.E. Dieter, “Mechanical Metallurgy," McGraw Hill, 1988, pp.432-470.

136. B.F. Dyson, "Continuous Cavity Nucleation and Creep Fracture," Scripta Met., Vol.17, No.1, 1983, pp.31-37.

137. E. Smith and J.T. Barnby, "Crack Nucleation in Crystalline Solids," Metal Science Journal, Vol.1, 1967, pp.56-64. 
138. N. Fujita, T. Narushima, Y. Iguchi, and C. Ouchi, "Grain Refinement of As Cast Austenite by Dynamic Recrystallization in HSLA Steels", ISIJ International, Vol.43, No.7, 2003, pp.1063-1072.

139. S.F. Medina and C.A. Hernandez, "The Influence of Chemical Composition on Peak Strain of Deformed Austenite in Low Alloy and Microalloyed Steels", Acta Materialia, Vol.44, No.1, 1996, pp.149-154.

140. S.H. Cho, K.B. Kang, and J.J. Jonas, "Mathematical Modeling of the Recrystallization Kinetics of Nb Microalloyed Steels", ISIJ International, Vol.41, No.7, 2001, pp.766-773.

141. S.V. Subramanian et al., "Effect of $\mathrm{Nb}$ on the Transformation Behaviour of $\mathrm{Nb}$ Ti Microalloyed Steels", International Sypmosium on Low-Carbon Steels for the 90's, The Minerals, Metals, and Materials Society, 1993, pp.313-322.

142. D.N. Crowther, Z. Mohamed, and B. Mintz, "The Relative Influence of Dynamic and Static Precipitation on the Hot Ductility of Microalloyed Steels", Metallurgical Transactions A, Vol.18, No.11, 1987, pp.1929-1939.

143. B. Mintz, Z. Mohamed, and R. Abushosha," Influence of Calcium on Hot Ductility of Steels," Materials Science and Technology, Vol. 5, No. 7, 1989, pp.682-688.

144. "Nickel Aluminides: Breaking into the Marketplace", An Oak Ridge National Laboratory report by Carolyn Krause. January 1997.

145. "Seeing and Catching Atoms", An Oak Ridge National Laboratory report by M. K. Miller, P. J. Pareige, and K. F. Russell. April 2001.

146. M. Militzer, W.P. Sun, and J.J. Jonas, "Modeling the Effect of DeformationInduced Vacancies on Segregation and Precipitation," Acta Metallurgia et Materialia, Vol. 24, No. 1, 1994, pp.133-141.

147. M. Cohen, "Self-Diffusion During Plastic Deformation," Transaction of Japan Institute of Metals, May 1970, 11, pp.145-151.

148. M. Djahazi, Ph.D. Thesis, McGill University, Canada, 1990.

149. X.L. He, M. Djahazi, J.J. Jonas, and J. Jackman, "The Non-Equilibrium Segregation of Boron During the Recrystallization of Nb-Treated HSLA Steels," Acta Metallurgia et Materialia, Vol. 39, No. 10, 1991, pp. 2295-2308.

150. X.L. He, Y. Y. Chu, and J.J. Jonas, "Grain Boundary Segregation of Boron During Continuous Cooling," Acta Metallurgia et Materialia, Vol. 37, No. 1, 1989 , pp. 147-161. 
151. X.L. He, Y. Y. Chu, and J.J. Jonas, "The Grain Boundary Segregation of Boron During Isothermal Holding," Acta Metallurgia et Materialia, Vol. 37, No. 11, 1989, pp. 2905-2916.

152. L.T. Mavropoulos and J.J. Jonas, "Retardation of Austenite Recrystallization by the Strain Induced Segregation of Boron," Canadian Metallurgical Quarterly, Vol. 28, No. 2, 1989, pp. 159-169.

153. T.M. Williams, A.M. Stoneham, and D.R. Harries, "Segregation of B to Grain Boundaries in Solution-Treated Type 316 Austenitic Stainless Steel," Met. Science, Vol. 10, No. 1, 1976, pp.14-19.

154. M.A.V. Chapman and R.G. Faulkner, "Computer Modeling of Grain Boundary Segregation," Acta Metallurgica, Vol. 31, No. 5, 1983, pp. 677-689.

155. L. Karlsson, "Non-Equilibrium Grain Boundary Segregation of Boron in Austenitic Stainless Steel. III. Computer Simulations," Acta Metallurgica, Vol. 36, No. 1, 1988, pp. 25-34.

156. L. Karlsson and H. Norden, "Non-Equilibrium Grain Boundary Segregation of Boron in Austenitic Stainless Steel. II. Fine Scale Segregation Behaviour," Acta Metallurgica, Vol. 36, No. 1, 1988, pp.13-24.

157. M. Hillert and B. Sundman, "Treatment of the Solute Drag on Moving Grain Boundaries and Phase Interfaces in Binary Alloys," Acta Metallurgica, Vol.24, No.8, 1976, pp.731-743.

158. M. Lagerquist and R. Lagneborg, "The Influence of Boron on the Creep Properties of Austenitic Stainless Steels", Soviet-Swedish Symposium on Clean Steel Sandviken Sweden, 1971, pp.38-53.

159. H.J. Grabke, "Grain Boundary Segregation of Impurities in ron and Steels and Effects on Steel Properties", Impurities in Engineering Materials, edited by Clyde L. Briant, Marcel Dekker Inc. publication, 1999, pp.143-192.

160. S. Suzuki, M. Tanino, and Y. Waseda, "Phosphorus and Boron Segregation at Prior Austenite Grain Boundaries in Low-alloyed Steel", ISJ International, Vol.42, No.6, 2002, pp.676-678.

161. M. Paju and H.J. Grabke, "Segregation of Phosphorus and Boron in Austenite in Fe-10\%Mn-P-B alloys", Materials Technology, Vol.60, No.1, 1989, pp.41-48.

162. C.M. Flemings, "Solidification Processing," McGraw-Hill, 1974.

163. E.T. Turkdogan, "Fundamentals of Steelmaking," The University Press, Cambridge, 1996. 
164. Z. Chen, M.H. Loretto, and R.C. Cochrane, "Nature of Large Precipitates in Titanium-Containing HSLA Steels," Materials Science and Technology, Vol.3, No.10, 1987, p.836-844.

165. Metallography, Structures and Phase Diagrams, ASM Metals Handbook, Vol. 8, $8^{\text {th }}$ Edition, P.306.

166. D. Salvadori, M. Bobadilla, G. Lesoult, D. Benoit, and B. Debiesme, "Modelling Segregation during Equiaxed Dendritic Growth: Application to the Solidification of Steel," Rev. Metall., Cah. Inf. Tech. (France), Vol.90, No.2, 1993, pp.211218.

167. George F. VanderVoort, "Private Communications", August 2003.

168. ASM Failure Analysis and Testing Discussion Group, "Private Communications", August 2003.

169. B. Barber and A. Perkins, "Strand Deformation in Continuous Casting," Ironmaking and Steelmaking, Vol.16, No.6, 1989, pp.406-411.

170. Z. Han, K. Cai, and B. Liu, "Prediction and Analysis on Formation of Internal Cracks in Continuously Cast Slabs by Mathematical Models," ISIJ International, Vol.41, No.12, 2001, pp.1473-1480.

171. D.Q. Bai, S. Yue, J.J. Jonas, "Metadynamic Recrystallization of Low Carbon Steels Containing Nb", COM 2001, Ottawa, Canada. J.J. Jonas Symposium, Thermomechanical Processing of Steel, edited by S. Yue and E. Es-sadiqi, 2001, pp.669-683.

172. E.I. Poliak and J.J. Jonas, "A One-Parameter Approach to Determining the Critical Conditions for the Initiation of Dynamic Recrystallization", Acta Materialia, Vol.44, No.1, 1996, pp.127-136.

173. N.D. Ryan and H.J. McQueen, "Dynamic Softening Mechanisms in 304 Austenitic Stainless Steel", Canadian Metallurgical Quarterly, Vol.29, No.2, 1990, pp. 147-162.

174. G. Gottstein, M. Frommert, M. Goerdeler, and M. Zeng, "Prediction of the Critical Conditions for Dynamic Recrystallization in Metals", Z. Metallkd., Vol.94, No.5, 2003, pp.628-635.

175. S.H. Cho, K.B. Kang, and J.J. Jonas, "The Dynamic, Static and Metadynamic Recrystallization of a Nb-Microalloyed Steel", ISIJ International, Vol.41, No.1, 2001, pp.63-69.

176. E.I. Poliak and J.J. Jonas, "Initiation of Dynamic Recrystallization in Constant Strain Rate Hot Deformation", ISIJ international, Vol.43, No.5, 2003, pp.684691. 
177. J.J. Jonas and E.I Poliak, "The Critical Strain for Dynamic Recrystallization in Rolling Mills", Materials Science Forum, Vols.426-432, 2003, pp.57-66.

178. E.I. Poliak and J.J. Jonas, "Critical Strain for Dynamic Recrystallization in Variable Strain Rate Hot Deformation", ISIJ international, Vol.43, No.5, 2003, pp.692-700.

179. S.V. Subramanian and H. Zou, "Quantitative Modelling of Solidification, Precipitation and Recrystallization Behaviour of Microalloyed Plates", International Conference on Processing, Microstructure and Properties of Microalloyed and Other Modern High Strength Low Alloy Steels, Pittsburgh, Pennsylvania, USA, 3-6 June 1991, Iron and Steel Society, 1992, pp. 23-31.

180. D. Badiola, R. Bartolome, and I. Gutierrez, "Effect of the Strain Reversal in Both the Recrystallization and the Strain Induced Precipitation in a Nb-Microalloyed Steel", Thermomechanical Processing: Mechanics, Microstructure \& Control, June 23-26, 2002, The University of Sheffield, England, 2003, pp.63-68. 